\title{
Feasibility Study for Remedial Action for the Groundwater Operable Units at the Chemical Plant Area and the Ordnance Works Area at the Weldon Spring Site, Weldon Spring, Missouri
}

December 1998

prepared by

Environmental Assessment Division, Argonne National Laboratory

prepared for

U.S. Department of Energy, Weldon Spring Site Remedial Action Project, Weldon Spring, Missouri, under Contract W-31-109-Eng-38

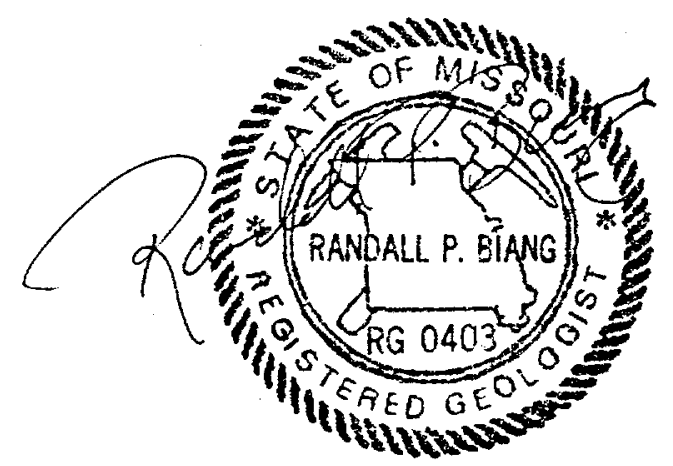




\section{DISCLAIMER}

This report was prepared as an account of work sponsored by an agency of the United States Government. Neither the United States Government nor any agency thereof, nor any of their employees, make any warranty, express or implied, or assumes any legal liability or responsibility for the accuracy, completeness, or usefulness of any information, apparatus, product, or process disclosed, or represents that its use would not infringe privately owned rights. Reference herein to any specific commercial product, process, or service by trade name, trademark, manufacturer, or otherwise does not necessarily constitute or imply its endorsement, recommendation, or favoring by the United States Government or any agency thereof. The views and opinions of authors expressed herein do not necessarily state or reflect those of the United States Government or any agency thereof. 


\section{DISCLAIMER}

Portions of this document may be illegible in electronic image products. Images are produced from the best available original document. 


\section{CONTENTS}

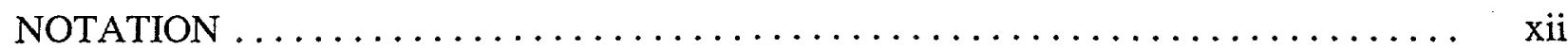

ENGLISH/METRIC AND METRIC/ENGLISH EQUIVALENTS $\ldots \ldots \ldots \ldots \ldots \ldots$

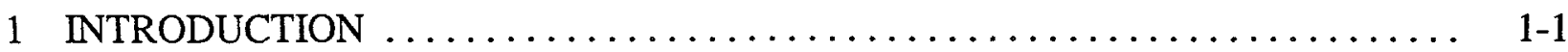

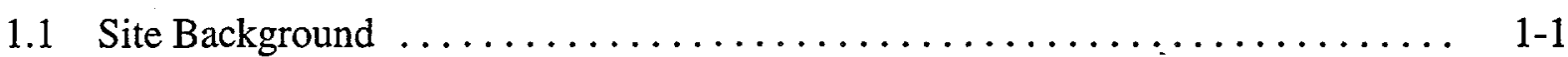

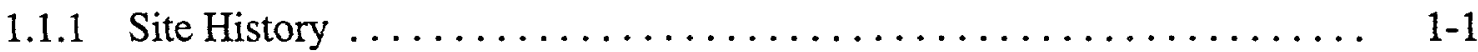

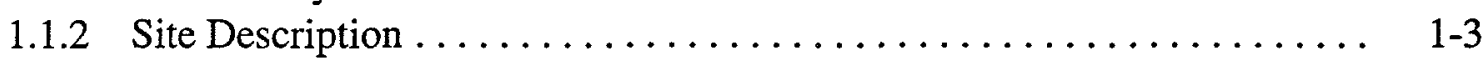

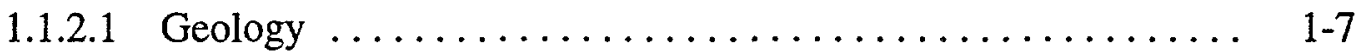

1.1.2.2 Surface Water ....................... 1-10

1.1.2.3 Hydrogeology ......................... 1-12

1.1.2.4 Biotic Resources ....................... 1-14

1.1.2.5 Land and Groundwater Use .................. 1-15

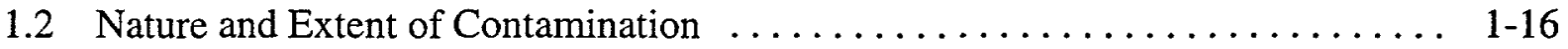

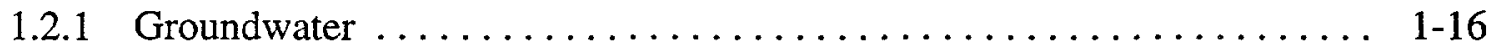

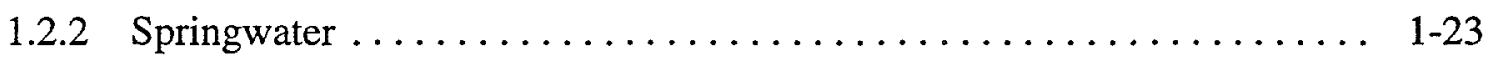

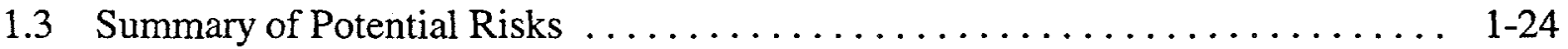

1.3.1 Human Health Assessment . . . . . . . . . . . . . . . . . . . 1-24

1.3.1.1 Identification of Contaminants of Potential Concern . . . . . 1-24

1.3.1.2 Exposure Assessment . . . . . . . . . . . . . . . . . . 1-25

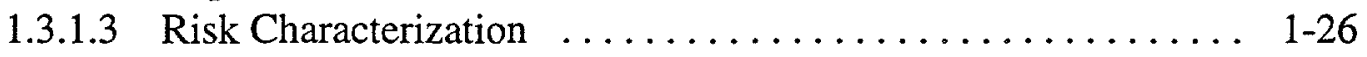

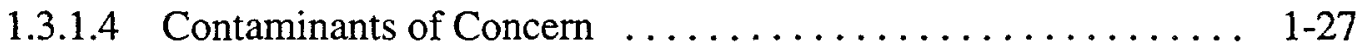

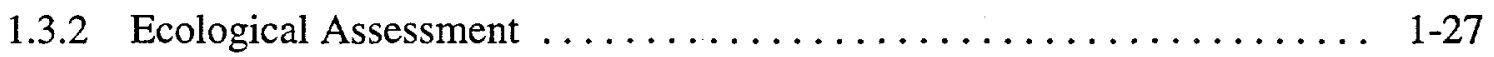

1.3.2.1 Methodology ........................ 1-27

1.3.2.2 Results and Conclusions .................... 1-28

1.4 Objective of the Feasibility Study . . . . . . . . . . . . . . . . . . 1-29

1.5 Determination of Preliminary Remediation Goals for Groundwater

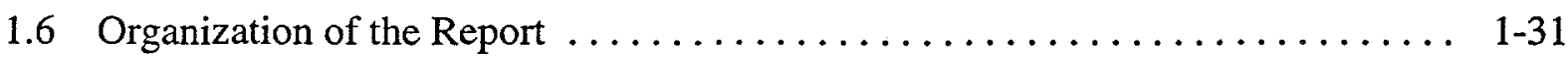

2 IDENTIFICATION AND SCREENING OF TECHNOLOGIES $\ldots \ldots \ldots \ldots \ldots \ldots$

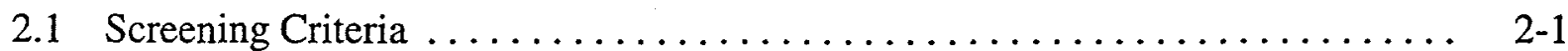

2.2 Technology Identification and Screening $\ldots \ldots \ldots \ldots \ldots \ldots \ldots \ldots \ldots \ldots \ldots$

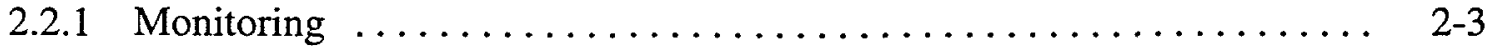

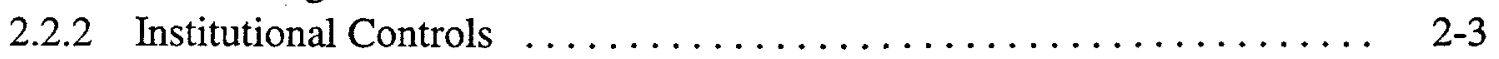

2.2.3 Natural Processes ............................. 2-4

2.2 .4 In-Situ Containment $\ldots \ldots \ldots \ldots \ldots \ldots \ldots \ldots \ldots \ldots \ldots \ldots \ldots \ldots \ldots$

2.2.4.1 Barrier Walls ........................ 2-7

2.2.4.2 Hydraulic Containment ................. 2-9 


\section{CONTENTS (Cont.)}

2.2.4.3 Immobilization $\ldots \ldots \ldots \ldots \ldots \ldots \ldots \ldots \ldots \ldots \ldots \ldots, 2-10$

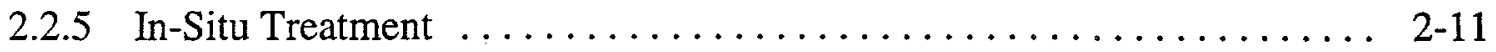

2.2.5:1 Bioremediation ............................ 2-11

2.2.5.2 Electrokinetics .......................... 2-12

2.2.5.3 Reactive Walls ........................... 2-13

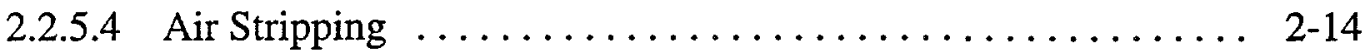

2.2.5.5 Fenton-Like Reagents $\ldots \ldots \ldots \ldots \ldots \ldots \ldots \ldots \ldots \ldots . \ldots \ldots \ldots$

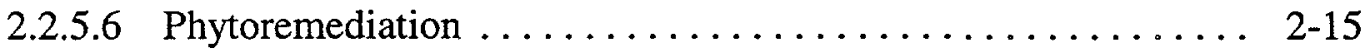

2.2.6 Removal of Groundwater from the Aquifer $\ldots \ldots \ldots \ldots \ldots \ldots \ldots . \ldots \ldots$

2.2.6.1 Vertical Wells ............................ 2-17

2.2.6.2 Horizontal Wells $\ldots \ldots \ldots \ldots \ldots \ldots \ldots \ldots \ldots \ldots \ldots . \ldots \ldots . \ldots \ldots$

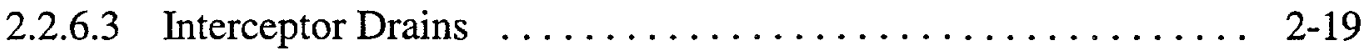

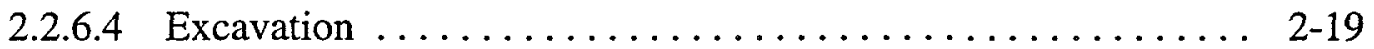

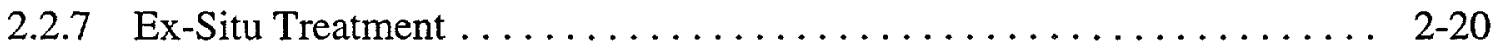

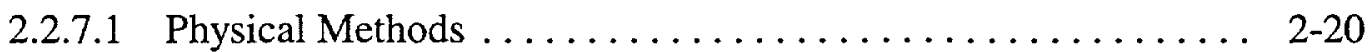

2.2.7.2 Chemical Methods ....................... 2-21

2.2.7.3 Biological Methods ...................... 2-25

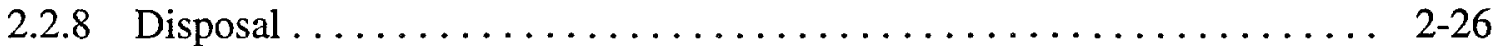

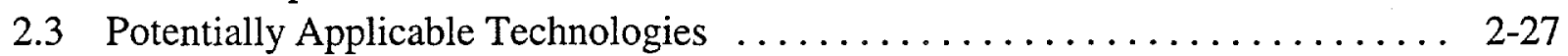

3 DEVELOPMENT AND SCREENING OF PRELIMINARY ALTERNATIVES .... 3-1

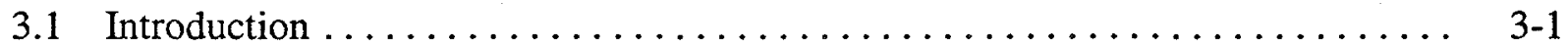

3.2 Criteria for Developing Alternatives $\ldots \ldots \ldots \ldots \ldots \ldots \ldots \ldots \ldots \ldots \ldots \ldots \ldots \ldots \ldots, 3-2$

3.3 Identification of Preliminary Alternatives $\ldots \ldots \ldots \ldots \ldots \ldots \ldots \ldots . . \ldots \ldots . . .2$

3.3.1 Factors Common to All Preliminary Action Alternatives .......... 3-4

3.3.2 Factors Specific to Each Preliminary Alternative $\ldots \ldots \ldots \ldots \ldots \ldots$. $3-5$

3.3.2.1 Alternative 1: No Action .................... 3-5

3.3.2.2 Alternative 2: Long-Term Monitoring ............ 3-5

3.3.2.3 Alternative 3: Natural Attenuation............... 3-7

3.3.2.4 Alternative 4: Groundwater Removal and On-Site

Treatment Using Granular Activated Carbon .......... 3-12

3.3.2.5 Alternative 5: Groundwater Removal and On-Site

Treatment Using Ultraviolet Oxidation ............. 3-18

3.3.2.6 Alternative 6: Groundwater Removal and On-Site

Treatment Using Phytoremediation ............... 3-21

3.3.2.7 Alternative 7: Removal and On-Site Treatment of TCE-Contaminated Groundwater .............. 3-24

3.3.2.8 Alternative 8: In-Situ Treatment of TCE Using In-Well Vapor Stripping 


\section{CONTENTS (Cont.)}

\subsubsection{Alternative 9: In-Situ Chemical Oxidation of TCE}

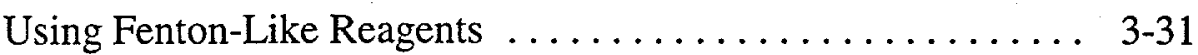

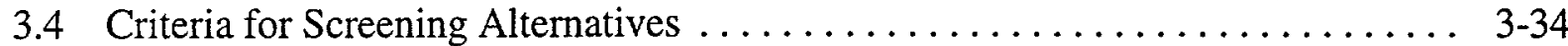

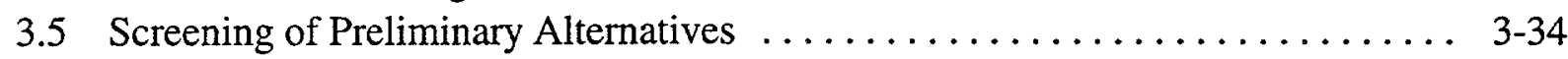

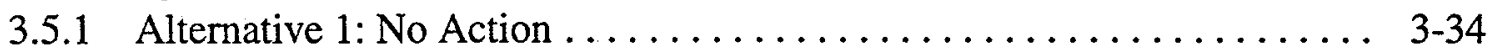

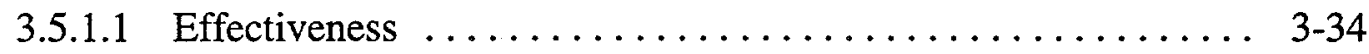

3.5.1.2 Implementability $\ldots \ldots \ldots \ldots \ldots \ldots \ldots \ldots \ldots \ldots \ldots \ldots \ldots \ldots \ldots, 3-35$

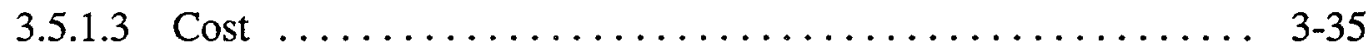

3.5.2 Alternative 2: Long-Term Monitoring $\ldots \ldots \ldots \ldots \ldots \ldots \ldots \ldots \ldots \ldots \ldots \ldots \ldots \ldots \ldots$

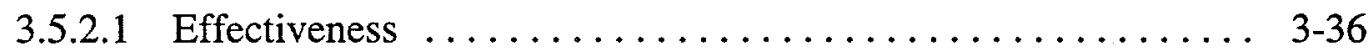

3.5.2.2 Implementability $\ldots \ldots \ldots \ldots \ldots \ldots \ldots \ldots \ldots \ldots \ldots, 3-36$

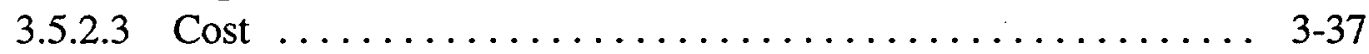

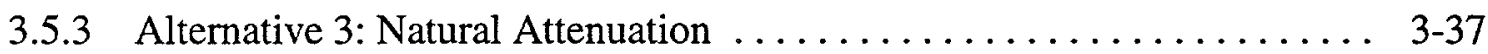

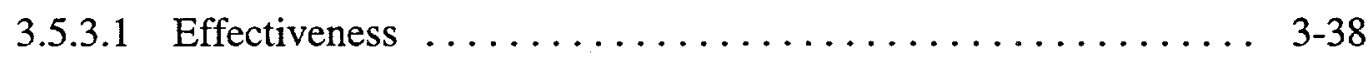

3.5.3.2 Implementability $\ldots \ldots \ldots \ldots \ldots \ldots \ldots \ldots \ldots \ldots \ldots, 3-38$

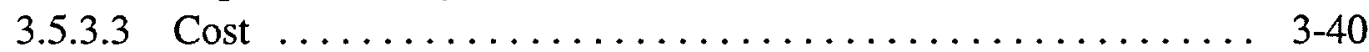

3.5.4 Alternative 4: Groundwater Removal and On-Site Treatment

Using Granular Activated Carbon . . . . . . . . . . . . . . . . . $3-40$

3.5.4.1 Effectiveness ........................... $3-40$

3.5.4.2 Implementability $\ldots \ldots \ldots \ldots \ldots \ldots \ldots \ldots \ldots \ldots \ldots, 3-41$

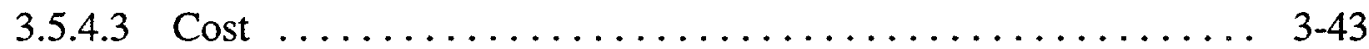

3.5.5 Alternative 5: Groundwater Removal and On-Site Treatment

Using Ultraviolet Oxidation $\ldots \ldots \ldots \ldots \ldots \ldots \ldots \ldots \ldots \ldots \ldots \ldots \ldots, 34$

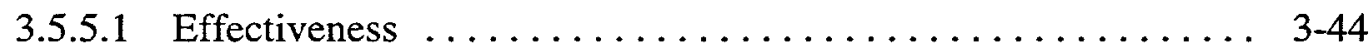

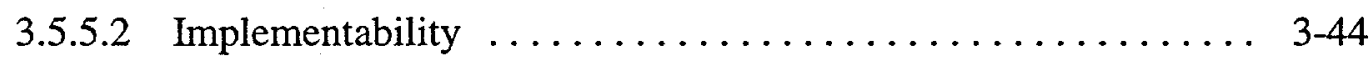

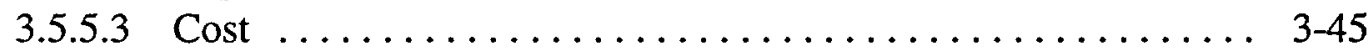

3.5.6 Alternative 6: Groundwater Removal and On-Site Treatment

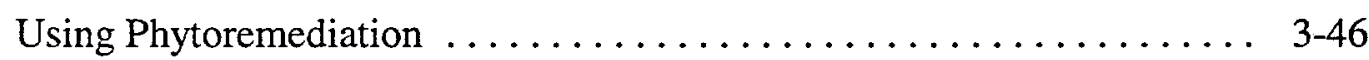

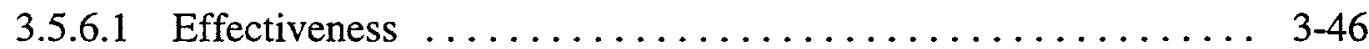

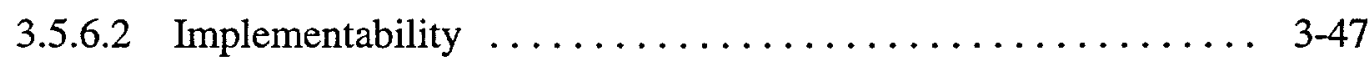

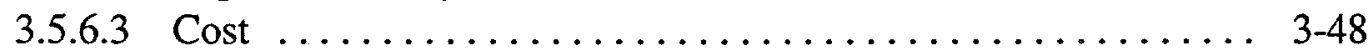

3.5.7 Alternative 7: Removal and On-Site Treatment of

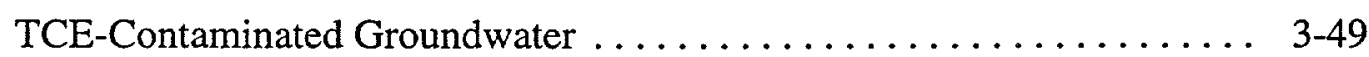

3.5.7.1 Effectiveness ............................. 3-49

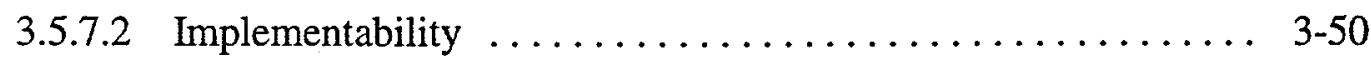

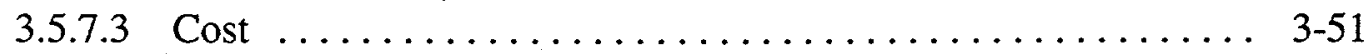

3.5.8 Alternative 8: In-Situ Treatment of TCE Using

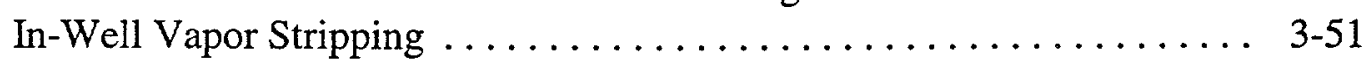

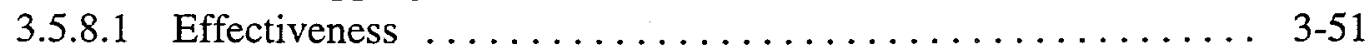

3.5.8.2 Implementability $\ldots \ldots \ldots \ldots \ldots \ldots \ldots \ldots \ldots \ldots \ldots \ldots \ldots \ldots, 3-52$

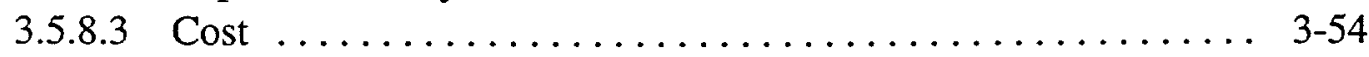




\section{CONTENTS (Cont.)}

3.5.9 Alternative 9: In-Situ Chemical Oxidation Using

Fenton-Like Reagents ........................... 3-54

3.5.9.1 Effectiveness ............................ 3-54

3.5.9.2 Implementability $\ldots \ldots \ldots \ldots \ldots \ldots \ldots \ldots \ldots \ldots, 3-55$

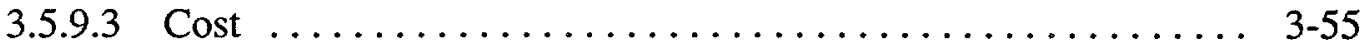

3.6 Screening Summary and Identification of Final Alternatives ........... 3-56

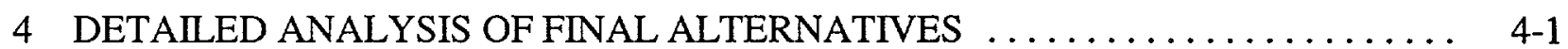

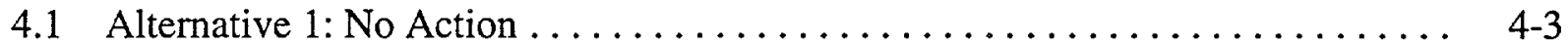

4.1.1 Overall Protection of Human Health and the Environment ........ 4-3

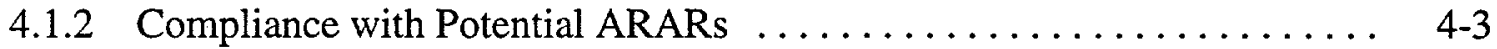

4.1.3 Long-Term Effectiveness and Permanence ............... 4-3

4.1.4 Reduction of Toxicity, Mobility, or Volume through Treatment ....... 4-4

4.1.5 Short-Term Effectiveness $\ldots \ldots \ldots \ldots \ldots \ldots \ldots \ldots \ldots \ldots \ldots .4 .4$

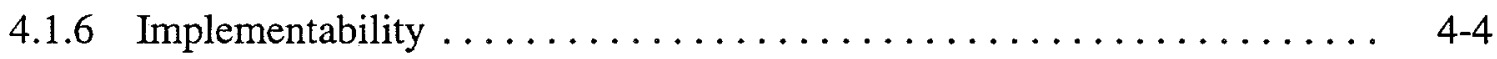

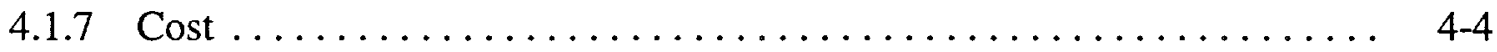

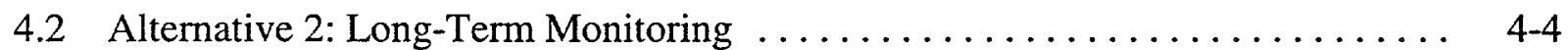

4.2.1 Overall Protection of Human Health and the Environment $\ldots \ldots \ldots \ldots$ 4.6

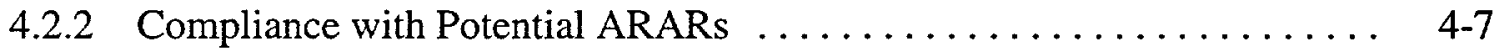

4.2.3 Long-Term Effectiveness and Permanence ............... 4-7

4.2.4 Reduction of Toxicity, Mobility, or Volume through Treatment ...... 4-7

4.2.5 Short-Term Effectiveness . . . . . . . . . . . . . . . . . . . . . . .

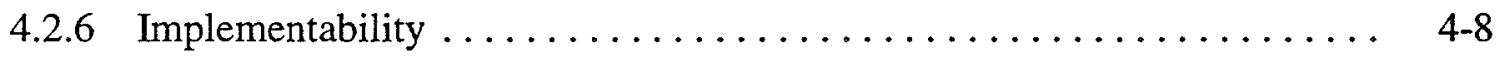

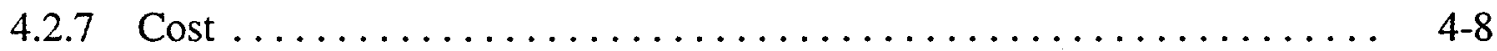

4.3 Alternative 4: Groundwater Removal and On-Site Treatment

Using Granular Activated Carbon $\ldots \ldots \ldots \ldots \ldots \ldots \ldots \ldots \ldots \ldots .4 .6 \ldots \ldots$

4.3.1 Overall Protection of Human Health and the Environment ......... 4-11

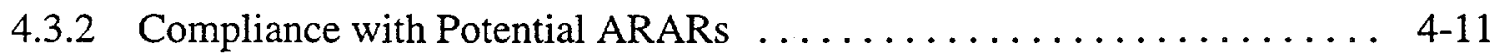

4.3.3 Long-Term Effectiveness and Permanence ................ 4-11

4.3.4 Reduction of Toxicity, Mobility, or Volume through Treatment ....... 4-11

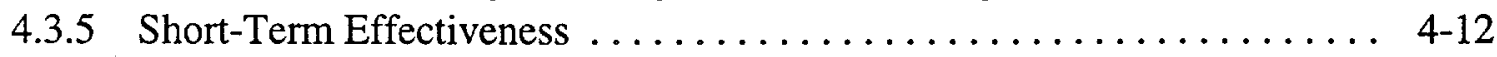

4.3 .6 Implementability . . . . . . . . . . . . . . . . . . . . . . .

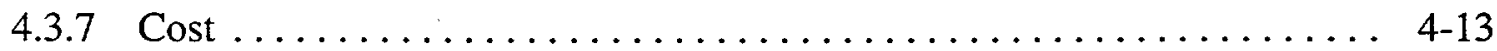

4.4 Alternative 7: Removal and On-Site Treatment

of TCE-Contaminated Groundwater . . . . . . . . . . . .

4.4.1 Overall Protection of Human Health and the Environment ......... 4-15

4.4.2 Compliance with Potential ARARs ..................... 4-16

4.4.3 Long-Term Effectiveness and Permanence ................ 4-16

4.4.4 Reduction of Toxicity, Mobility, or Volume through Treatment ....... 4-16

4.4.5 Short-Term Effectiveness . . . . . . . . . . . . . . . . . . . . . . 4-16 


\section{CONTENTS (Cont.)}

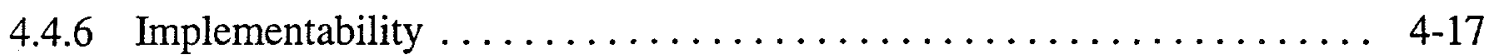

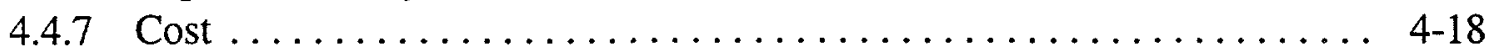

4.5 Alternative 8: In-Situ Treatment of TCE Using In-Well Vapor Stripping . . . . . . 4-19 4-19

4.5.1 Overall Protection of Human Health and the Environment ......... 4-20

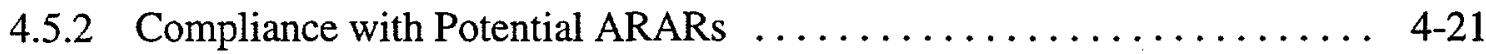

4.5.3 Long-Term Effectiveness and Permanence ................ 4-21

4.5.4 Reduction of Toxicity, Mobility, or Volume through Treatment ...... 4-21

4.5.5 Short-Term Effectiveness . . . . . . . . . . . . . . . . . . . . . .

4.5.6 Implementability . . . . . . . . . .

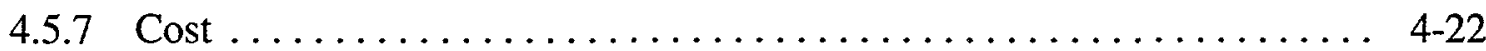

4.6 Alternative 9: In-Situ Chemical Oxidation of TCE

Using Fenton-Like Reagents . . . . . . . . . . . . . .

4.6.1 Overall Protection of Human Health and the Environment ......... 4-24

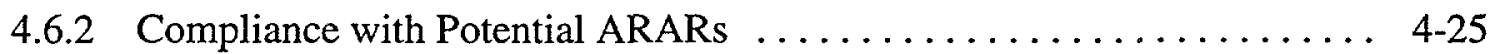

4.6.3 Long-Term Effectiveness and Permanence ............... 4-25

4.6.4 Reduction of Toxicity, Mobility, or Volume through Treatment ...... 4-25

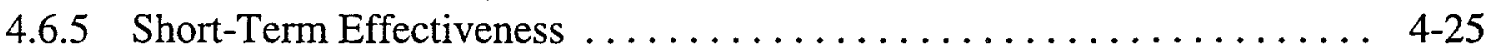

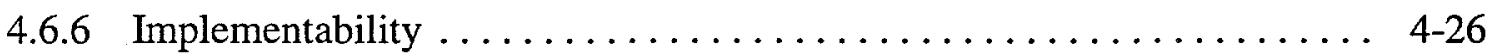

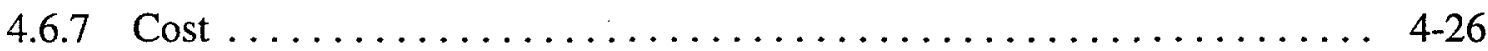

5 COMPARATIVE ANALYSIS OF ALTERNATIVES $\ldots \ldots \ldots \ldots \ldots \ldots \ldots \ldots \ldots$

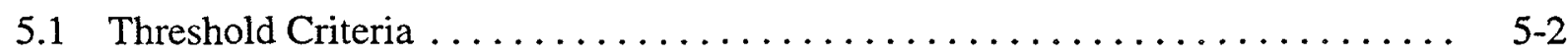

5.1.1 Overall Protection of Human Health and the Environment $\ldots \ldots \ldots \ldots$ 5-2

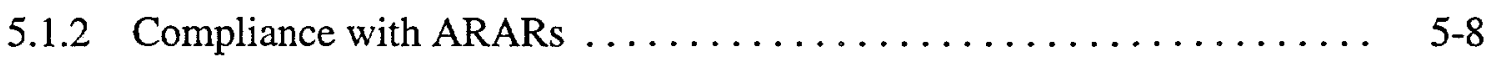

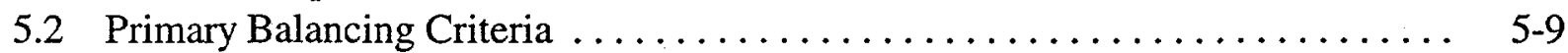

5.2.1 Long-Term Effectiveness and Permanence ................ 5-9

5.2.2 Reduction of Toxicity, Mobility, or Volume through Treatment ...... 5-10

5.2 .3 Short-Term Effectiveness .......................... 5-10

5.2 .4 Implementability $\ldots \ldots \ldots \ldots \ldots \ldots \ldots \ldots \ldots \ldots \ldots \ldots \ldots \ldots \ldots \ldots \ldots \ldots, 11$

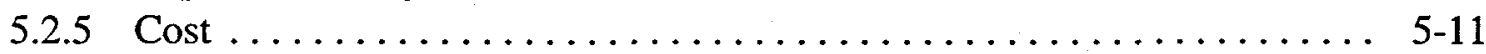

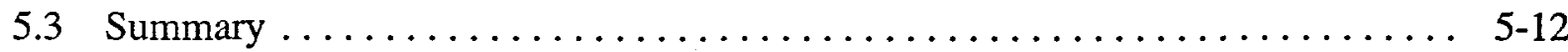

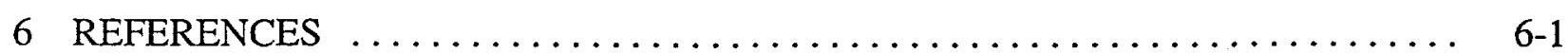

APPENDIX A: Regulatory Requirements Potentially Applicable or Relevant and Appropriate to the Remedial Action $\ldots \ldots \ldots \ldots \ldots \ldots \ldots \ldots$ A-1

APPENDIX B: Derivation of Risk-Based Preliminary Remediation Goals for Groundwater at the WSCP and the WSOW $\ldots \ldots \ldots \ldots \ldots \ldots$ B-1 


\section{CONTENTS (Cont.)}

APPENDIX C: Methodology and Assumptions Used to Calculate the Potential

Number of Extraction Wells for the WSCP and the WSOW ........ C-1

APPENDIX D: Methodology and Assumptions Used to Determine the Costs

of the Various Alternatives in This Feasibility Study ........... D-1

\section{FIGURES}

1.1 Locations of the Weldon Spring Chemical Plant and the Weldon Spring

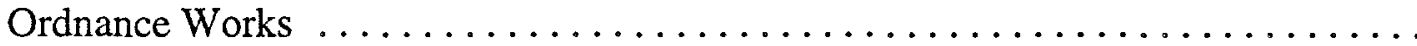

1.2 Map of the WSCP and the WSOW and Immediate Vicinity $\ldots \ldots \ldots \ldots \ldots \ldots$

1.3 Locations of Waste Disposal Operations at the WSOW $\ldots \ldots \ldots \ldots \ldots \ldots \ldots$

1.4 Original Layout of the WSCP $\ldots \ldots \ldots \ldots \ldots \ldots \ldots \ldots \ldots \ldots \ldots \ldots \ldots \ldots \ldots \ldots$

1.5 Gaining and Losing Stream Segments and Associated Springs

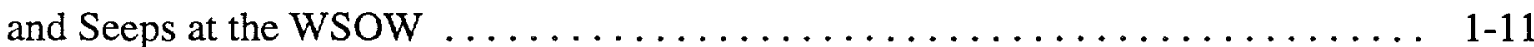

1.6 Hydraulic Head Distribution in the Shallow Groundwater — July $1995 \ldots \ldots \ldots$ 1-13

1.7 Distribution of TCE and 1,2-DCE at the WSCP and the WSOW $\ldots \ldots \ldots \ldots \ldots$ 1-17

1.8 Distribution of Nitrate at the WSCP and the WSOW $\ldots \ldots \ldots \ldots \ldots \ldots \ldots \ldots$

1.9 Distribution of 2,4-DNT at the WSCP and the WSOW $\ldots \ldots \ldots \ldots \ldots \ldots \ldots$ 1-19

1.10 Distribution of $2,4,6-\mathrm{TNT}$ at the WSCP and the WSOW $\ldots \ldots \ldots \ldots \ldots \ldots .1-20$

1.11 Distribution of $1,3-\mathrm{DNB}$ at the WSCP and the WSOW $\ldots \ldots \ldots \ldots \ldots \ldots \ldots, 1-21$

1.12 Distribution of Uranium at the WSCP and the WSOW $\ldots \ldots \ldots \ldots \ldots \ldots \ldots .1-22$

1.13 Locations of Wells at the WSCP Containing TCE Exceeding Proposed PRGs

1.14 Locations of Wells at the WSCP Containing Nitrate Exceeding Proposed PRGs 


\section{FIGURES (Cont.)}

1.15 Locations of Wells at the WSCP Containing 2,4-DNT Exceeding Proposed PRGs

1.16 Locations of Wells at the WSOW Containing 2,4-DNT Exceeding Proposed PRGs

2.1 Potential Technologies for Groundwater Remediation

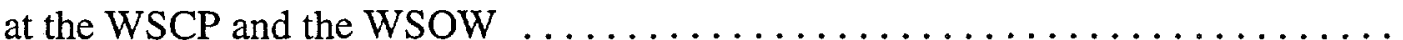

3.1 Process Flow Diagram for Proposed Groundwater Treatment under Alternative 4

3.2 Typical Fixed-Bed GAC Adsorption System $\ldots . \ldots \ldots \ldots \ldots \ldots \ldots \ldots \ldots . . \ldots \ldots$

3.3 Ultraviolet Oxidation Treatment System $\ldots \ldots \ldots \ldots \ldots \ldots \ldots \ldots \ldots \ldots \ldots \ldots$

3.4 Process Flow Diagram for Proposed Groundwater Treatment under Alternative 5

3.5 Typical Root Zone Bed

3.6 Area That Would Be Remediated under Alternative 7

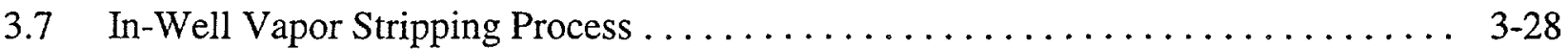

3.8 Application of Fenton-Like Reagents for In-Situ TCE Remediation . . . . . . . . . 3-33 


\section{TABLES}

1.1 Generalized Stratigraphy and Hydrostratigraphy for the WSCP

and the WSOW

1.2 Summary of ARARs, Risk-Based Values, and Preliminary

Remediation Goals for Groundwater Contaminants of Concern ........... 1-32

1.3 Wells with Contaminant Concentrations Exceeding PRGs $\ldots \ldots \ldots \ldots \ldots \ldots$ 1-33

2.1 Summary of Screening Analysis for Institutional Controls $\ldots \ldots \ldots \ldots \ldots \ldots$

2.2 Summary of Screening Analysis for In-Situ Containment

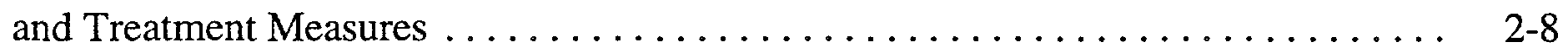

2.3 Summary of Screening Analysis for Groundwater Removal $\ldots \ldots \ldots \ldots \ldots \ldots$ 2-18

2.4 Summary of Screening Analysis for Ex-Situ Treatment Measures $\ldots \ldots \ldots \ldots \ldots$ 2-22

2.5 Screening of Potentially Applicable Technologies for Groundwater

Remediation at the WSCP and the WSOW $\ldots \ldots \ldots \ldots \ldots \ldots \ldots \ldots \ldots \ldots \ldots \ldots \ldots .2-28$

3.1 Analytical Parameters that Provide Information on Natural

Attenuation of Chlorinated Aliphatic Hydrocarbons

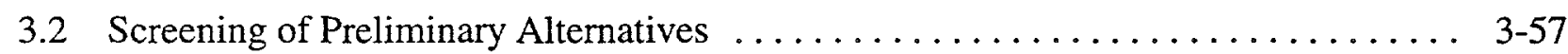

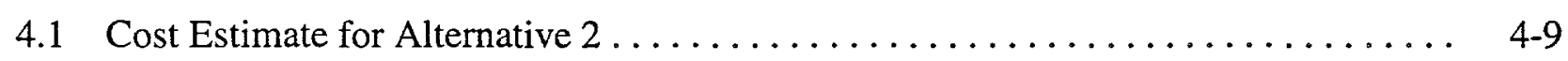

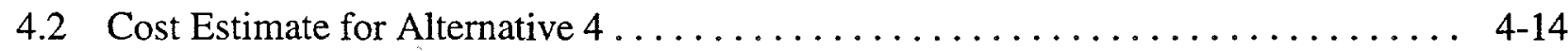

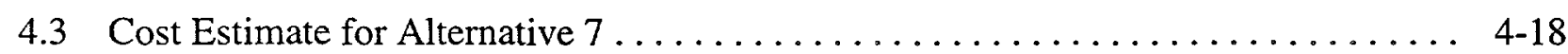

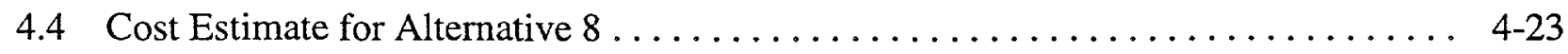

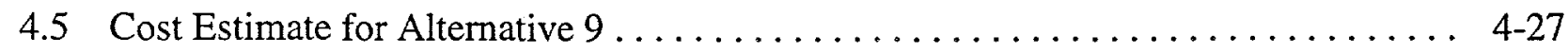

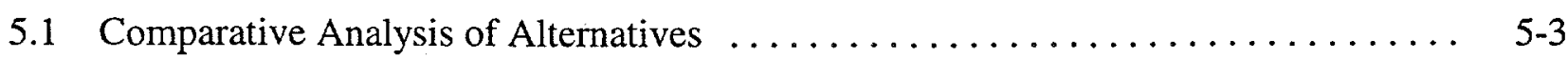

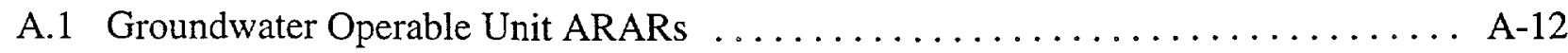

B.1 Exposure Scenario Assumptions and Intake Parameters $\ldots \ldots \ldots \ldots \ldots \ldots$ B-4 


\section{TABLES (Cont.)}

B.2 Water Concentrations of COCs Associated with the Acceptable Risk Range and Hazard Index . . . . . . . . . . . . . . . . .

C.1 Input Parameters and Calculated Number of Extraction Wells for Each of the Contaminated Areas at the WSCP and the WSOW

C.2 Wells Associated with Contaminated Zones at the WSCP $\ldots \ldots \ldots \ldots \ldots \ldots$ C-10

C.3 Wells Associated with Contaminated Zones at the WSOW .............. C-11

C.4 Summary of Parameters and Their Uncertainties Used to Calculate the Number of Extraction Wells under Local Conditions . . . . . . . . . . . . C-13

C.5 Number of Extraction Wells Required for Implementing a Pump-and-Treat Design at the WSCP and the WSOW

D.1 WSCP-Specific Indirect Cost Relationships Applied in This FS ........... D-5

D.2 WSOW-Specific Indirect Cost Relationships Applied in This FS $\ldots \ldots \ldots \ldots$ D-6

D.3 Estimated Direct Costs for Alternative $2 \ldots \ldots \ldots \ldots \ldots \ldots \ldots \ldots \ldots \ldots \ldots \ldots \ldots$

D.4 Present-Worth Cost Calculation for Alternative $2 \ldots \ldots \ldots \ldots \ldots \ldots \ldots$ D-11 


\section{NOTATION}

The following is a list of the acronyms, initialisms, and abbreviations (including units of measure) used in this document. Some acronyms used in tables or equations only are defined in the respective tables or equations.

\section{ACRONYMS, INITIALISMS, AND ABBREVIATIONS}

\section{General}

$\begin{array}{ll}\text { ACL } & \text { alternate concentration limit } \\ \text { AEC } & \text { U.S. Atomic Energy Commission } \\ \text { ARAR } & \text { applicable or relevant and appropriate requirement } \\ \text { BRA } & \text { baseline risk assessment } \\ \text { CERCLA } & \text { Comprehensive Environmental Response, Compensation, and Liability Act } \\ \text { CFR } & \text { Code of Federal Regulations } \\ \text { COC } & \text { contaminant of concern } \\ \text { COPC } & \text { contaminant of potential concern } \\ \text { CSR } & \text { Code of State Regulations } \\ \text { DA } & \text { U.S. Department of Army } \\ \text { D\&D } & \text { decontamination and decommissioning } \\ \text { DOD } & \text { U.S. Department of Defense } \\ \text { DOE } & \text { U.S. Department of Energy } \\ \text { EPA } & \text { U.S. Environmental Protection Agency } \\ \text { FR } & \text { Federal Register } \\ \text { FS } & \text { feasibility study (this document) } \\ \text { GAC } & \text { granular activated carbon } \\ \text { GWOU } & \text { groundwater operable unit } \\ \text { HGMS } & \text { high-gradient magnetic separation } \\ \text { IT } & \text { International Technology (Corporation) } \\ \text { MCL } & \text { maximum contaminant level } \\ \text { MCLG } & \text { maximum contaminant level goal } \\ \text { NCP } & \text { National Oil and Hazardous Substances Contingency Plan } \\ \text { NPDES } & \text { National Pollutant Discharge Elimination System } \\ \text { NPL } & \text { National Priorities List } \\ \text { O\&M } & \text { operation and maintenance } \\ \text { OU } & \text { operable unit } \\ \text { PCB } & \text { polychlorinated biphenyl } \\ \text { PRG } & \text { preliminary remediation goal } \\ \text { PVC } & \text { polyvinyl chloride } \\ \text { QWTP } & \text { Quarry Water Treatment Plant } \\ & \end{array}$




\section{General (Cont.)}

$\begin{array}{ll}\text { RA } & \text { remedial action } \\ \text { RACER } & \text { Remedial Action Cost Estimating and Requirements System } \\ \text { RD } & \text { remedial design } \\ \text { RfD } & \text { reference dose } \\ \text { RH } & \text { relative humidity } \\ \text { RI } & \text { remedial investigation } \\ \text { ROD } & \text { Record of Decision } \\ \text { SDWA } & \text { Safe Drinking Water Act } \\ \text { SWTP } & \text { Site Water Treatment Plant } \\ \text { TBC } & \text { to-be-considered (requirement) } \\ \text { UCL } & \text { upper confidence level } \\ \text { UV } & \text { ultraviolet } \\ \text { VOC } & \text { volatile organic compound } \\ \text { WSCP } & \text { Weldon Spring Chemical Plant } \\ \text { WSOW } & \text { Weldon Spring Ordnance Works } \\ \text { WSSRAP } & \text { Weldon Spring Site Remedial Action Project } \\ \text { WSTA } & \text { Weldon Spring Training Area }\end{array}$

\section{Chemicals}

$\mathrm{Ca}^{2+}$

$\mathrm{Cl}^{-}$

$\mathrm{CO}_{2}$

1,2-DCE

1,3-DNB

DNT

2-amino-4,6-DNT

4-amino-2,6-DNT

2,4-DNT

2,6-DNT

$\mathrm{Fe}^{2+}$

$\mathrm{Fe}_{2} \mathrm{SO}_{4}$

$\mathrm{H}_{2} \mathrm{O}_{2}$

$\mathrm{Na}^{+}$

$\mathrm{O}_{3}$

$\mathrm{OH} \bullet$

$\mathrm{O}_{2}$

TCE

1,3,5-TNB

TNT

2,4,6-TNT calcium ion

chloride ions

carbon dioxide

1,2-dichloroethylene

1,3-dinitrobenzene

dinitrotoluene

2-amino-4,6-dinitrotoluene

4-amino-2,6-dinitrotoluene

2,4-dinitrotoluene

2,6-dinitrotoluene

ferrous ion

ferrous sulfate

hydrogen peroxide

sodium ion

ozone

hydroxyl radical

oxygen

trichloroethylene

1,3,5-trinitrobenzene

trinitrotoluene

2,4,6-trinitrotoluene 
$\mathrm{UO}_{2}$

$\mathrm{UO}_{2}{ }^{2+}$ uranium dioxide

uranium dioxide ion

\section{UNITS OF MEASURE}

$\begin{array}{ll}{ }^{\circ} \mathrm{C} & \text { degree(s) Celsius } \\ \mathrm{cm} & \text { centimeter(s) } \\ \mathrm{cm}^{2} & \text { square centimeter(s) } \\ \mathrm{cm}^{3} & \text { cubic centimeter(s) } \\ \mathrm{d} & \text { day(s) } \\ { }^{\circ} \mathrm{F} & \text { degree(s) Fahrenheit } \\ \mathrm{ft} & \text { foot (feet) } \\ \mathrm{ft}^{2} & \text { square foot (feet) } \\ \mathrm{g} & \text { gram(s) } \\ \mathrm{gal} & \text { gallon(s) } \\ \mathrm{gpm} & \text { gallon(s) per minute } \\ \mathrm{h} & \text { hour(s) } \\ \mathrm{ha} & \text { hectare(s) } \\ \text { in. } & \text { inch(es) } \\ \mathrm{kg} & \text { kilogram(s) } \\ \mathrm{km} & \text { kilometer(s) } \\ \mathrm{L} & \text { liter(s) } \\ \mathrm{lb} & \text { pound(s) }\end{array}$

$\begin{array}{ll}\mathrm{oz} & \text { ounce(s) } \\ \mu \mathrm{Ci} & \text { microcurie(s) } \\ \mu \mathrm{g} & \text { microgram(s) } \\ \mu \mathrm{m} & \text { micrometer(s) } \\ \mathrm{m} & \text { meter(s) } \\ \mathrm{m}^{2} & \text { square meter(s) } \\ \mathrm{m}^{3} & \text { cubic meter(s) } \\ \mathrm{mg} & \text { milligram(s) } \\ \mathrm{mi} & \text { mile(s) } \\ \mathrm{min} & \text { minute(s) } \\ \mathrm{mL} & \text { milliliter(s) } \\ \mathrm{mrem} & \text { millirem(s) } \\ \mathrm{mSv} & \text { millisievert(s) } \\ \mathrm{pCi} & \text { picocurie(s) } \\ \mathrm{ppm} & \text { parts per million } \\ \mathrm{s} & \text { second(s) } \\ \mathrm{yd} & \text { cubic yard(s) } \\ \mathrm{yr} & \text { year(s) }\end{array}$




\section{ENGLISH/METRIC AND METRIC/ENGLISH EQUIVALENTS}

The following table lists the appropriate equivalents for English and metric units.

\begin{tabular}{|c|c|c|}
\hline Multiply & By & To Obtain \\
\hline \multicolumn{3}{|l|}{ English/Metric Equivalents } \\
\hline acres & 0.4047 & hectares (ha) \\
\hline cubic feet $\left(\mathrm{ft}^{3}\right)$ & 0.02832 & cubic meters $\left(\mathrm{m}^{3}\right)$ \\
\hline cubic yards $\left(\mathrm{yd}^{3}\right)$ & 0.7646 & cubic meters $\left(\mathrm{m}^{3}\right)$ \\
\hline degrees Fahrenheit $\left({ }^{\circ} \mathrm{F}\right)-32$ & 0.5555 & degrees Celsius $\left({ }^{\circ} \mathrm{C}\right)$ \\
\hline feet $(\mathrm{ft})$ & 0.3048 & meters $(\mathrm{m})$ \\
\hline gallons (gal) & 3.785 & liters $(L)$ \\
\hline gallons (gal) & 0.003785 & cubic meters $\left(\mathrm{m}^{3}\right)$ \\
\hline inches (in.) & 2.540 & centimeters $(\mathrm{cm})$ \\
\hline miles (mi) & 1.609 & kilometers $(\mathrm{km})$ \\
\hline pounds (lb) & 0.4536 & kilograms (kg) \\
\hline short tons (tons) & 907.2 & kilograms (kg) \\
\hline short tons (tons) & 0.9072 & metric tons $(\mathrm{t})$ \\
\hline square feet $\left(\mathrm{ft}^{2}\right)$ & 0.09290 & square meters $\left(\mathrm{m}^{2}\right)$ \\
\hline square yards $\left(\mathrm{yd}^{2}\right)$ & 0.8361 & square meters $\left(\mathrm{m}^{2}\right)$ \\
\hline square miles $\left(\mathrm{mi}^{2}\right)$ & 2.590 & square kilometers $\left(\mathrm{km}^{2}\right)$ \\
\hline yards $(y d)$ & 0.9144 & meters $(\mathrm{m})$ \\
\hline \multicolumn{3}{|l|}{ Metric/English Equivalents } \\
\hline centimeters $(\mathrm{cm})$ & 0.3937 & inches (in.) \\
\hline cubic meters $\left(\mathrm{m}^{3}\right)$ & 35.31 & cubic feet $\left(\mathrm{ft}^{3}\right)$ \\
\hline cubic meters $\left(\mathrm{m}^{3}\right)$ & 1.308 & cubic yards $\left(\mathrm{yd}^{3}\right)$ \\
\hline cubic meters $\left(\mathrm{m}^{3}\right)$ & 264.2 & gallons (gal) \\
\hline degrees Celsius $\left({ }^{\circ} \mathrm{C}\right)+17.78$ & 1.8 & degrees Fahrenheit $\left({ }^{\circ} \mathrm{F}\right)$ \\
\hline hectares (ha) & 2.471 & acres \\
\hline kilograms (kg) & 2.205 & pounds (lb) \\
\hline kilograms (kg) & 0.001102 & short tons (tons) \\
\hline kilometers $(\mathrm{km})$ & 0.6214 & miles (mi) \\
\hline liters (L) & 0.2642 & gallons (gal) \\
\hline meters (m) & 3.281 & feet $(\mathrm{ft})$ \\
\hline meters (m) & 1.094 & yards $(\mathrm{yd})$ \\
\hline metric tons $(\mathrm{t})$ & 1.102 & short tons (tons) \\
\hline square kilometers $\left(\mathrm{km}^{2}\right)$ & 0.3861 & square miles $\left(\mathrm{mi}^{2}\right)$ \\
\hline square meters $\left(\mathrm{m}^{2}\right)$ & 10.76 & square feet $\left(\mathrm{ft}^{2}\right)$ \\
\hline square meters $\left(\mathrm{m}^{2}\right)$ & 1.196 & square yards $\left(\mathrm{yd}^{2}\right)$ \\
\hline
\end{tabular}


$x v i$ 


\section{INTRODUCTION}

The U.S. Department of Energy (DOE) and the U.S. Department of Army (DA) are conducting an evaluation to identify the appropriate response action to address groundwater contamination at the Weldon Spring Chemical Plant (WSCP) and the Weldon Spring Ordnance Works (WSOW), respectively. The two areas are located in St. Charles County, about $48 \mathrm{~km}$ (30 mi) west of St. Louis (Figure 1.1). The groundwater operable unit (GWOU) at the WSCP is one of four operable units being evaluated by DOE as part of the Weldon Spring Site Remedial Action Project (WSSRAP). The groundwater operable unit at the WSOW is being evaluated by the DA as Operable Unit 2 (OU2); soil and pipeline contamination are being managed under Operable Unit 1 (OU1).

Remedial activities at the WSCP and the WSOW are being conducted in accordance with the Comprehensive Environmental Response, Compensation, and Liability Act (CERCLA). Consistent with DOE policy, National Environmental Policy Act (NEPA) values have been incorporated into the CERCLA process. A remedial investigation/feasibility study (RI/FS) work plan summarizing initial site conditions and providing site hydrogeological and exposure models was published in August of 1995 (DOE 1995). The remedial investigation (RI) and baseline risk assessment (BRA) have also recently been completed. The RI (DOE and DA 1998b) discusses in detail the nature, extent, fate, and transport of groundwater and springwater contamination. The BRA (DOE and DA 1998a) is a combined baseline assessment of potential human health and ecological impacts and provides the estimated potential health risks and ecological impacts associated with groundwater and springwater contamination if no remedial action were taken.

This feasibility study (FS) has been prepared to evaluate potential options for addressing groundwater contamination at the WSCP and the WSOW. A brief description of the history and environmental setting of the sites is presented in Section 1.1, key information relative to the nature and extent of contamination is presented in Section 1.2, and the results of the BRA are summarized in Section 1.3. The objective of this FS is discussed in Section 1.4, and preliminary remediation goals are identified in Section 1.5. The organization of the remaining chapters of this FS is outlined in Section 1.6.

\subsection{SITE BACKGROUND}

\subsubsection{Site History}

The DA obtained the land for the WSOW by direct purchase and condemnation in the late 1930s from farmers and residents in St. Charles County. Following construction of the ordnance works, the Atlas Powder Company operated the facility from 1941 to 1945 to produce trinitrotoluene 


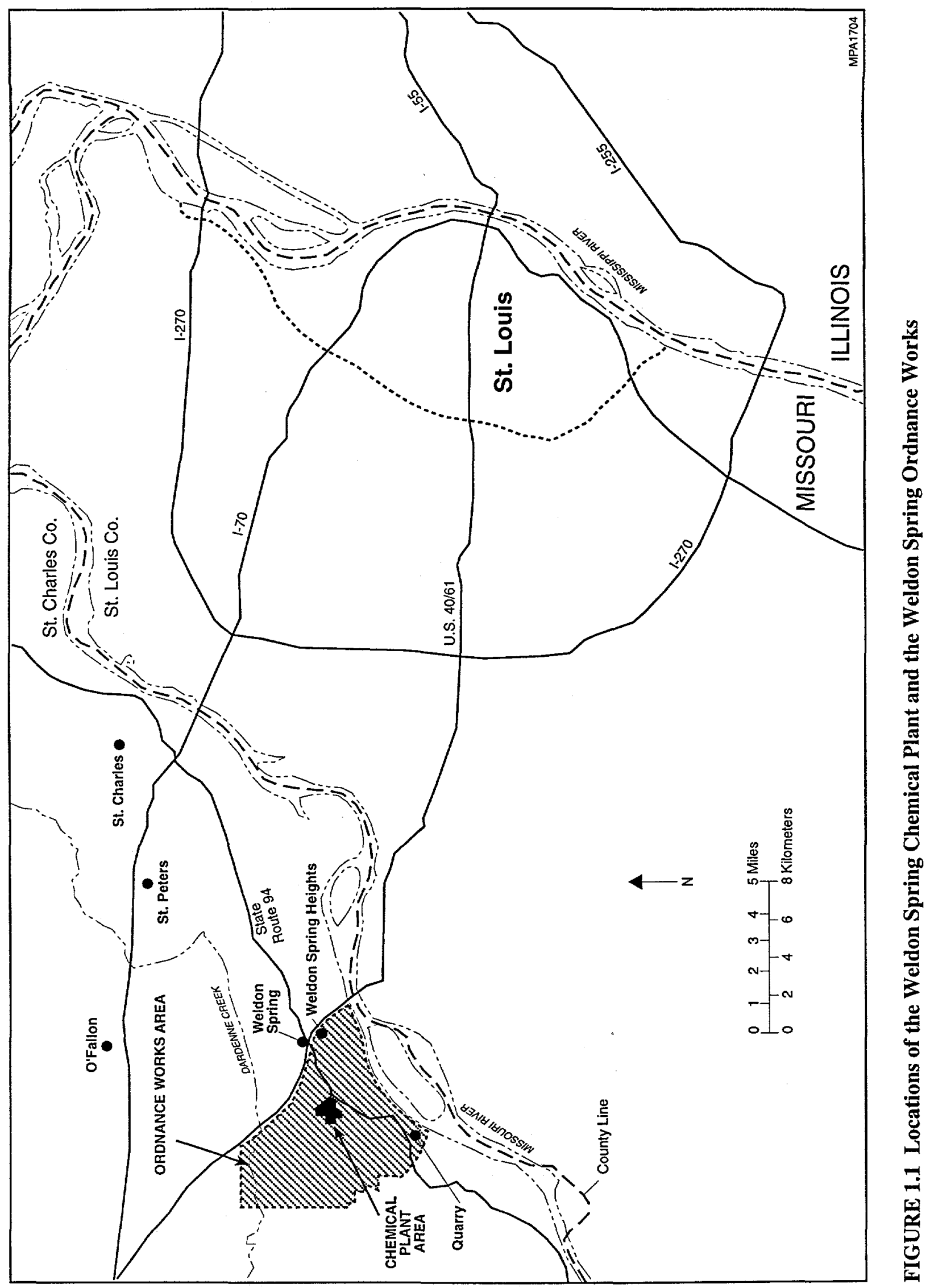


(TNT) and dinitrotoluene (DNT) explosives for use during World War II. In 1946, the facility was declared surplus property, and, by 1949 , all but about 810 ha $(2,000$ acres) of the property (WSCP and Weldon Spring Training Area [WSTA]) had been transferred to the State of Missouri and the University of Missouri (International Technology [IT] Corporation 1993a).

The WSOW was listed on the National Priorities List (NPL) of the U.S. Environmental Protection Agency (EPA) in February 1990 (EPA 1990b). The DA is responsible for remediation of this site, as stipulated in the Federal Facilities Agreement (FFA) among the EPA, the DA, and the Missouri Department of Natural Resources.

In 1955, a total of 83 ha (205 acres) of the WSOW was transferred to the U.S. Atomic Energy Commission ([AEC]; a predecessor of DOE) for construction and operation of the Weldon Spring Uranium Feed Materials Plant, now referred to as the chemical plant (WSCP); an additional 6 ha (15 acres) was later transferred for storage of waste. The chemical plant was operated for the AEC by the Uranium Division of Mallinckrodt Chemical Works from 1957 to 1966 to process uranium and a limited amount of thorium ore concentrates. Waste slurries were piped to four raffinate pits, where the solids settled to the bottom; the supernatant liquids were decanted to the plant process sewer. This sewer drained off-site to the Missouri River via a 2.4-km (1.5-mi) natural drainage channel referred to as the Southeast Drainage.

In 1985, DOE assumed custody and designated the control and decontamination of the WSCP as a Major Project; it was redesignated as a Major System Acquisition in May 1988. In March 1989, the EPA listed the WSCP on the NPL (EPA 1989a).

\subsubsection{Site Description}

The original property of the WSOW encompassed a total area of 6,974 ha (17,232 acres). This property has since been divided into several contiguous areas with different ownership including the WSCP and quarry, WSTA, August A. Busch Memorial Conservation Area, Weldon Spring Conservation Area, Francis Howell High School and Francis Howell Administration Annex, community of Weldon Spring Heights, University of Missouri Research Park, St. Charles County well field, and Missouri Highway Department maintenance facility (Figure 1.2). The Army currently retains ownership of the 670-ha (1,655-acre) WSTA, which contains the majority of the former production facilities. Public access to the training area is restricted.

The potential source areas of groundwater contamination at the WSOW include the TNT and DNT production lines, three wastewater treatment plants, in-line settling tanks, burning grounds, sellite/acid plants, laboratory buildings, Mechanical City (facility maintenance area), regraining areas, underground toluene and wooden wastewater transport pipelines, and wastewater lagoons (Figure 1.3). Currently, the WSOW has relatively few of the 1,038 structures that constituted the 


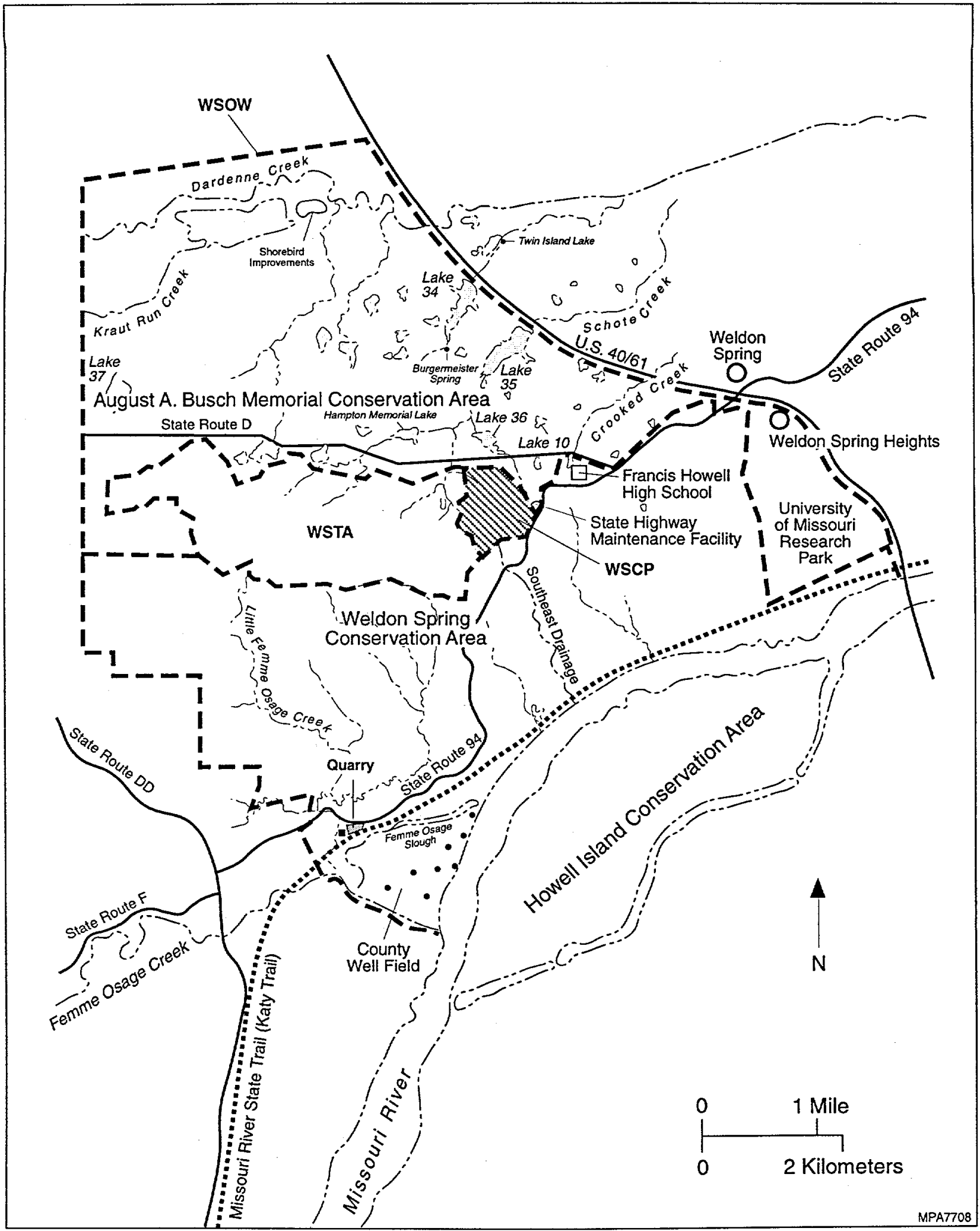

FIGURE 1.2 Map of the WSCP and the WSOW and Immediate Vicinity 


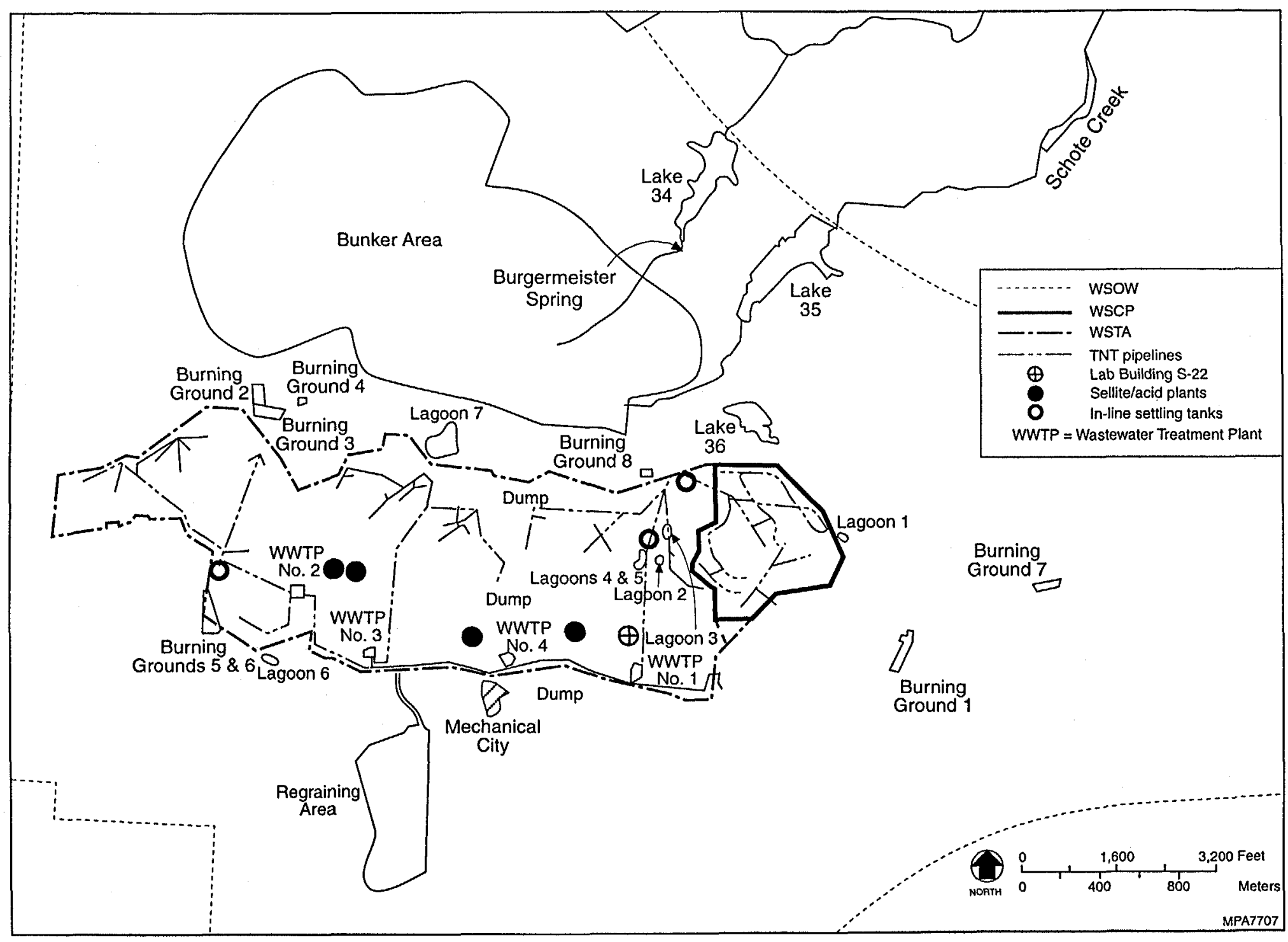

FIGURE 1.3 Locations of Waste Disposal Operations at the WSOW 


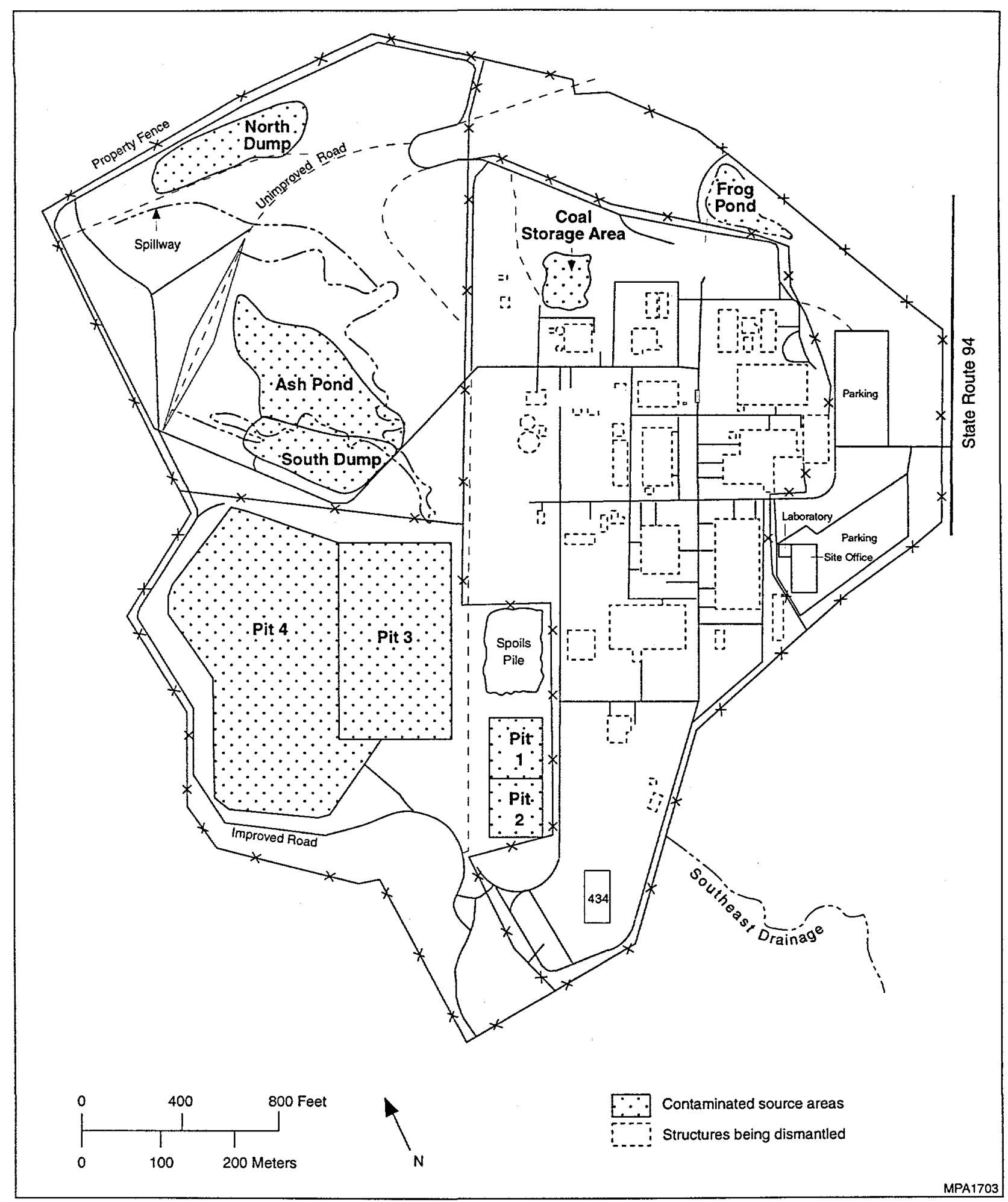

FIGURE 1.4 Original Layout of the WSCP 
explosives production facility. Most of the buildings were either burned or demolished during initial decontamination activities and subsequent cleanup efforts. Except for a few buildings on the WSTA, 100 storage bunkers, the residences in Weldon Spring Heights, and a few storage buildings at Francis Howell High School, only concrete foundations remain of the former WSOW. In addition, approximately $25,400 \mathrm{~m}(83,300 \mathrm{ft})$ of buried wooden pipeline is believed to remain in the WSTA.

The 88-ha (217-acre) WSCP lies within the boundaries of the WSOW. The original layout of the WSCP consisted of about 40 buildings, four waste retention ponds referred to as raffinate pits, two ponds (Ash Pond and Frog Pond), and two former dumps (north and south) (Figure 1.4). Remediation of the buildings, Frog Pond, and the north dump has been completed. The remaining source areas are in the process of being remediated or are scheduled for cleanup within the next year. The area was contaminated by TNT and DNT production as well as by subsequent processing of uranium and thorium ores. The area is currently fenced to restrict public access. Burgermeister Spring, included in this operable unit, is located in the August A. Busch Memorial Conservation Area, directly south of Lake 34.

\subsubsection{Geology}

As part of site characterization, a number of investigations have been conducted at the WSCP and the WSOW to describe geological conditions (DOE 1992; Rueff 1992; IT Corporation 1992a, 1993b; DOE and DA 1998b). Locally, the subsurface consists of unconsolidated deposits that unconformably overlie bedrock. Specific investigations at the WSTA and the WSCP have indicated that the unconsolidated overburden consists mainly of modified loess, glacial drift, preglacial deposits, and residuum (Rueff 1992; DOE 1992; DOE and DA 1998b). The thickness of the overburden deposits generally ranges from 0 to $21 \mathrm{~m}(0$ to $70 \mathrm{ft}$ ) across the WSCP and the WSOW (Mugel 1997). The variable thickness of the overburden deposits is controlled by both surface erosion and bedrock topography (DOE 1992). Additional information on the overburden deposits can be found in the RI reports for various operable units at the WSCP and the WSOW (IT Corporation 1992a, 1993b; DOE 1992; DOE and DA 1998b).

Beneath the unconsolidated Quaternary overburden deposits, the subsurface consists primarily of fractured and silicified carbonate units from the Mississippian, Devonian, and Ordovician Periods. Some sandstones and shales are also present (Table 1.1).

The uppermost bedrock unit and the primary focus of these GWOUs is the BurlingtonKeokuk Limestone. On the basis of weathering characteristics, the formation has been divided into two zones. The upper zone, which is more weathered than the lower portion of the limestone, is referred to as the weathered limestone. The lower zone, which is less weathered, is identified as the unweathered limestone. The stratigraphic boundary between the two units is gradational. 
TABLE 1.1 Generalized Stratigraphy and Hydrostratigraphy for the WSCP and the WSOW

\begin{tabular}{|c|c|c|c|c|c|}
\hline System & Series & Stratigraphic Unit & Thickness (ft) & Physical Characteristics & Hydrostratigraphic Unit ${ }^{a}$ \\
\hline \multirow[t]{5}{*}{ Quaternary } & Holocene & Alluvium & $0-120$ & Silt, sand, gravel & Alluvial aquifer \\
\hline & Pleistocene & Loess and glacial drift & $0-11$ & Silty clay to silt & Not classified ${ }^{b}$ \\
\hline & & Ferrelview Formation & $0-22$ & Clay to silty clay & Glacial drift confining unit ${ }^{\mathrm{c}}$ \\
\hline & & Glacial till unit & $0-47$ & $\begin{array}{l}\text { Sandy and silty clay to clayey silt, with scattered rock } \\
\text { fragments }\end{array}$ & Shallow aquifer \\
\hline & & Basal till unit & $0-10$ & Sandy, clayey, silty gravel or gravelly silt & \\
\hline \multirow[t]{5}{*}{ Mississippian } & Osagean & Residuum unit $^{d}$ & $0-38$ & Clay, chert, silt; locally contains limestone fragments & \\
\hline & & Burlington-Keokuk Limestone & $0-185$ & $\begin{array}{l}\text { Limestone; silty, argillaceous, thickly bedded, cherty, } \\
\text { fractured }\end{array}$ & Shallow aquifer \\
\hline & & Fern Glen Formation & $0-67$ & $\begin{array}{l}\text { Limestone; fine-grained, medium to thickly bedded, } \\
\text { cherty }\end{array}$ & \\
\hline & Kinderhookian & Chouteau Group & $0-45(+)$ & $\begin{array}{l}\text { Dolomitic limestone; fine-grained, thinly to medium } \\
\text { bedded }\end{array}$ & Upper confining \\
\hline & & Bachelor Formation & $0-2$ & Sandstone; calcareous cement & \\
\hline \multirow[t]{3}{*}{ Devonian } & Upper & Sulphur Springs Group & & & \\
\hline & & Bushberg Sandstone & $0-20$ & Quartz sandstone; fine to medium-grained, friable & \\
\hline & & Glen Park Limestone & $0-25$ & $\begin{array}{l}\text { Calcareous siltstone, sandstone, uletic limestone, and } \\
\text { hard carbonaceous shale }\end{array}$ & \\
\hline \multirow[t]{3}{*}{ Ordovician } & Cincinnatian & Maquoketa Shale $^{\mathrm{e}}$ & $0-11$ & $\begin{array}{l}\text { Calcareous or dolomitic shale; typically thinly } \\
\text { laminated, silty with shaley limestone lenses }\end{array}$ & \\
\hline & Champlainian & Kimmswick Limestone & $41-104$ & $\begin{array}{l}\text { Limestone; coarsely crystalline, medium to thick } \\
\text { bedded, cherty near base }\end{array}$ & Middle aquifer \\
\hline & & Decorah Group & $25-36$ & $\begin{array}{l}\text { Shale with thin interbeds of very finely crystalline } \\
\text { limestone }\end{array}$ & Confining unit \\
\hline
\end{tabular}


TABLE 1.1 (Cont.)

\begin{tabular}{|c|c|c|c|c|c|}
\hline System & Series & Stratigraphic Unit & Thickness (ft) & Physical Characteristics & Hydrostratigraphic Unit ${ }^{a}$ \\
\hline \multirow[t]{8}{*}{$\begin{array}{l}\text { Ordovician } \\
\text { (Cont.) }\end{array}$} & $\begin{array}{l}\text { Champlainian } \\
\text { (Cont.) }\end{array}$ & Plattin Limestone & $70-125$ & Limestone; finely crystalline, thinly bedded & Lower confining unit \\
\hline & & Joachim Dolomite & $80-105$ & $\begin{array}{l}\text { Dolostone; thin to thickly bedded, grades into } \\
\text { siltstone, shales common }\end{array}$ & \\
\hline & & St. Peter Sandstone & $120-150$ & $\begin{array}{l}\text { Quartz sandstone; fine- to medium-grained, } \\
\text { massively bedded }\end{array}$ & Deep aquifer \\
\hline & Canadian & Powell Dolomite & $50-60$ & $\begin{array}{l}\text { Dolostone; fine to medium crystalline, minor chert } \\
\text { and shale }\end{array}$ & \\
\hline & & Cotter Dolomite & $200-250$ & $\begin{array}{l}\text { Argillaceous, cherty dolomite; fine to medium } \\
\text { crystalline; interbedded with shale }\end{array}$ & \\
\hline & & Jefferson City Dolomite & $160-180$ & Dolomite; fine to medium crystalline & \\
\hline & & Roubidoux Formation & $150-170$ & Dolomitic sandstone & \\
\hline & & Gasconade Dolomite & - & Cherty dolomite & \\
\hline \multirow[t]{2}{*}{ Cambrian } & Upper & Eminence Dolomite & $-\mathbf{f}$ & $\begin{array}{l}\text { Dolomite; medium to coarsely crystalline, medium- } \\
\text { bedded to massive }\end{array}$ & \\
\hline & & Potosi Dolomite & $-\mathbf{f}$ & $\begin{array}{l}\text { Dolomite; fine to medium crystalline, thick bedded to } \\
\text { massive; drusy quartz common }\end{array}$ & \\
\hline
\end{tabular}

a When no hydrostratigraphic unit is listed, the unit is the same as for the preceding entry.

b These units are saturated in some places at the WSCP and the WSOW.

c A confining unit only where the base of the unit is below the potentiometric of the shallow aquifer, mainly in the August A. Busch Memorial Conservation Area.

d Residuum consists of the residual material from weathering of the uppermost bedrock formation and possibly younger rocks. The uppermost bedrock formation in most places is the Burlington-Keokuk Limestone.

e Identified in monitoring well MWGS-2.

f Insufficient data to estimate thickness.

Sources: Data from Whitfield et al. (1989); DOE (1992); Kleeschulte and Imes (1994); and Mugel (1997). 
On the basis of the estimated stratigraphic contact from rock cores and boring logs, the weathered limestone typically ranges in thickness from 0 to $34 \mathrm{~m}$ (0 to $113 \mathrm{ft}$ ) (Mugel 1997). The weathered unit is an argillaceous limestone, commonly containing as much as $60 \%$ chert as nodules, breccia fragments, and interbeds. The unit is moderately to highly fractured and slightly to severely weathered. Abundant iron oxide staining and manganese oxide occur in the rock matrix and along fractures.

At the WSCP, core sampling from the angled boreholes indicates that fracturing in the Burlington-Keokuk is predominantly horizontal and typically occurs along shaley interbeds, bedding planes, or chert interbeds. Solution features are common in the weathered portion of the BurlingtonKeokuk Limestone, ranging from pinpoint vugs to small zones of core loss, typically less than $2 \mathrm{~m}$ $(5 \mathrm{ft})$. The larger zones in many cases appear to be at least partially filled with clay or clay mixture (DOE 1992).

In most cases, the unweathered unit underlies the weathered zone of the Burlington-Keokuk Limestone and is thinly to massively bedded and finely to coarsely crystalline and cherty. Both horizontal and vertical fracture densities are significantly lower in the unweathered unit than in the weathered unit (MK-Ferguson Company and Jacobs Engineering Group, Inc. 1990b). On the basis of subsurface data obtained at the WSCP and WSOW, this unit ranges in thickness from 0 to $34 \mathrm{~m}$ (0 to $113 \mathrm{ft}$ ) (Mugel 1994). Field data from borehole packer testing of the saturated bedrock also indicate a decrease in hydraulic conductivity with depth, which is attributed to decreased weathering and related solution activity.

\subsubsection{Surface Water}

The WSOW and the WSCP are located on an east-west drainage divide between the Missouri and Mississippi watersheds (Missouri Department of Natural Resources 1991; IT Corporation 1992b) (Figure 1.5). At the western part of the WSOW, surface drainage to the south of the divide flows to Little Femme Osage Creek and its tributaries, which ultimately discharge into the Missouri River. At the eastern part of the WSOW, surface drainage to the south of the divide flows toward and discharges to the Missouri River. Surface drainage to the north of the divide flows toward Dardenne Creek and its tributaries. Schote Creek, the largest of the tributaries, drains a major portion of the training area and the WSCP. Dardenne Creek flows easterly and ultimately into the Mississippi River (IT Corporation 1992a; DOE 1992). Because of the presence of the surface drainage divide, surface water from the WSCP flows to the adjacent WSOW. 


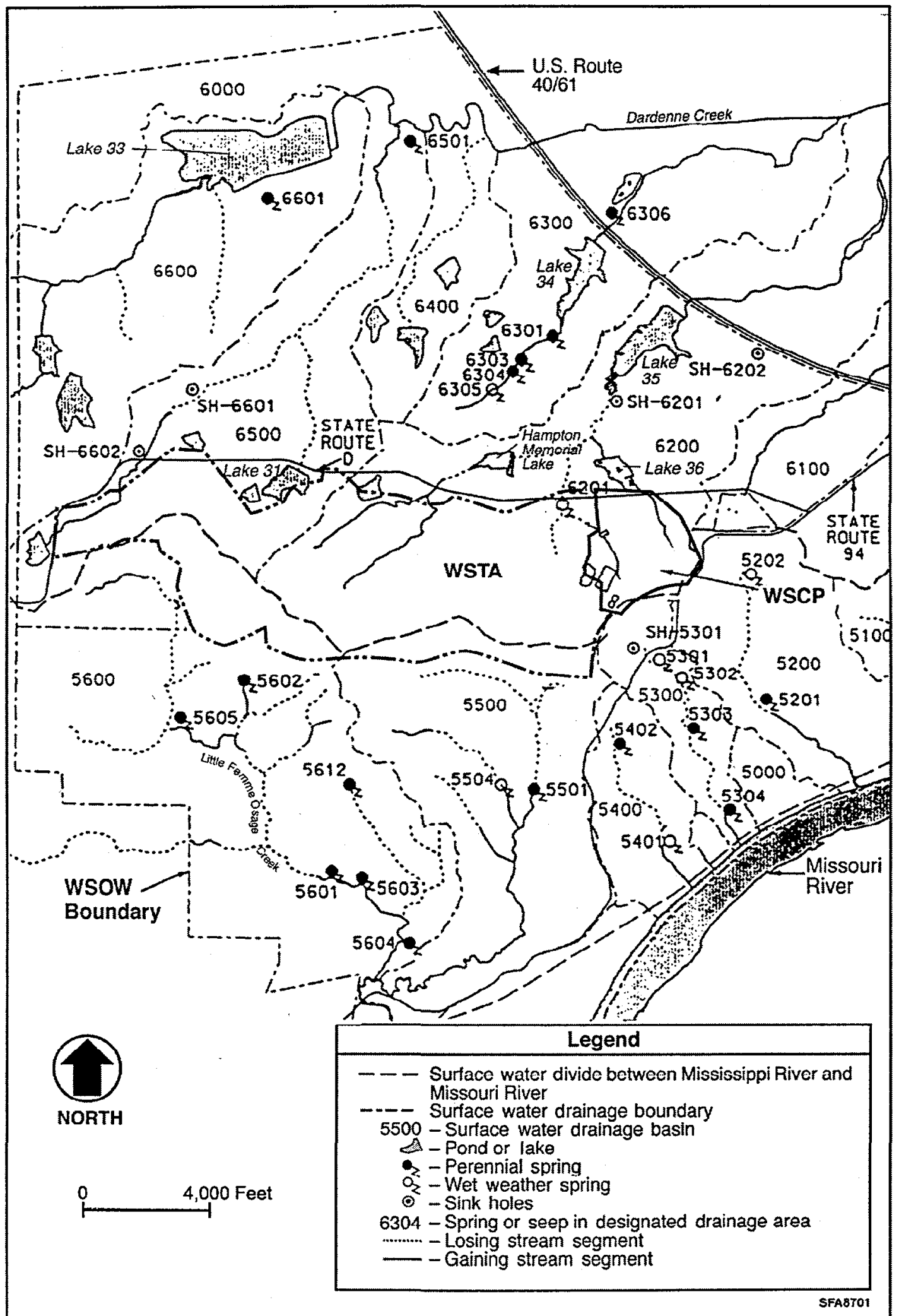

FIGURE 1.5 Gaining and Losing Stream Segments and Associated Springs and Seeps at the WSOW 


\subsubsection{Hydrogeology}

The three regional bedrock aquifer systems present in the Weldon Spring area include a shallow unconfined aquifer (although it may be confined in some local areas), a confined middle aquifer, and a deep confined aquifer (Table 1.1). These systems are separated by confining units made up of limestone, dolomite, sandstone, and shale formations (Kleeschulte and Imes 1994). Regionally, the shallow bedrock aquifer primarily consists of saturated rocks of the BurlingtonKeokuk Limestone and Fern Glen Formation; the middle aquifer is composed of the Kimmswick Limestone. The deep bedrock aquifer system consists of Ordovician and Upper Cambrian saturated rocks, which include formations from the top of the St. Peter Sandstone down through the bottom of the Potosi Dolomite (Kleeschulte and Emmett 1987). Groundwater that is used as a drinking water supply in the area is primarily taken from the deep aquifer and from an alluvial aquifer near the Missouri River; however, in St. Charles County, the shallow and middle aquifers are also used, primarily for rural domestic water supply (Kleeschulte 1991).

The groundwater system of primary interest in the Weldon Spring area is the shallow bedrock aquifer, which consists of a series of hydraulically connected limestones and, in some locations, the overlying saturated residuum or glacial drift. The shallow aquifer includes the Burlington-Keokuk Limestone, which is the uppermost bedrock formation beneath the WSCP and most of the WSOW. The principal recharge to this shallow groundwater system is through infiltration of precipitation from the overburden or from losing streams. The shallow groundwater system is the focus of these operable units because of impacts from previous activities.

The shallow aquifer is primarily unconfined, although it may be confined in a few local areas where the groundwater extends into the overlying glacial drift. The water table elevation fluctuates seasonally and with precipitation, but remains within the upper bedrock, residuum, or glacial drift. An east-west trending groundwater divide, which coincides with the topographic high, has been identified that results in two distinct drainage systems (Missouri Department of Natural Resources 1991; DOE 1992; IT Corporation 1992a; Kleeschulte and Imes 1994).

At the WSOW, shallow groundwater north of the divide flows to the north, and shallow groundwater south of the divide flows to the south following natural gradients (DOE and DA 1998b; Figure 1.6). In the northeastern portion of the WSTA and northwest of the WSCP, a subsurface conduit system transports water rapidly to Burgermeister Spring. The presence of the conduit system (a subsurface pathway in which water flows at a high velocity and does not obey Darcy's law [White 1988]) is inferred by a groundwater trough in the contoured water table surface south of Burgermeister Spring, which extends into the northern portion of the chemical plant and the northeastern portion of the ordnance works area. Water-tracing tests provide additional evidence for the presence of a conduit system in this area (Missouri Department of Natural Resources 1991; Price 1991; DOE and DA 1998b). These features are located north and south of the WSTA. 


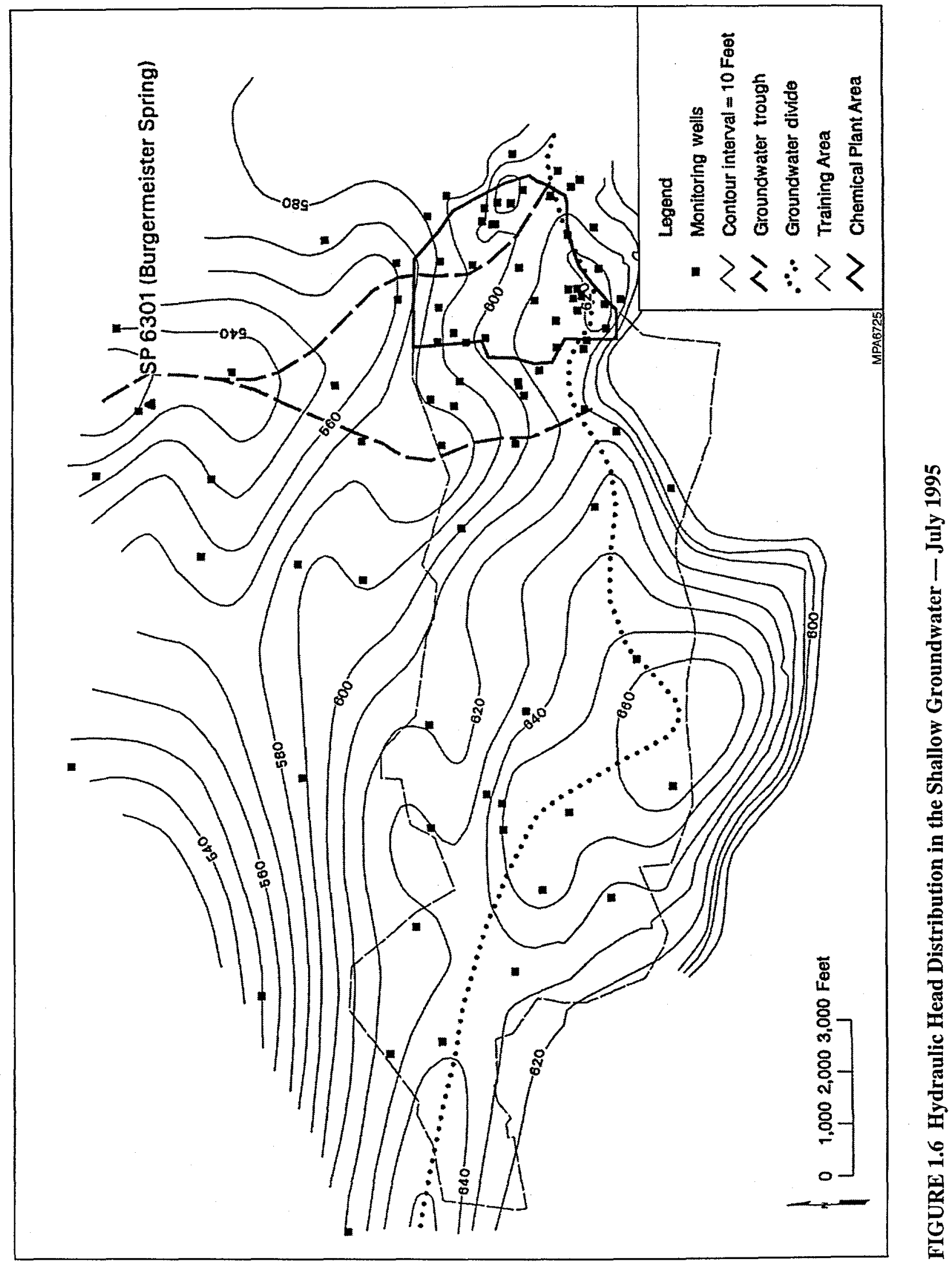


The Burgermeister Spring area appears to be a major groundwater discharge area for drainage from the eastern and central portions of the WSTA and the northern and western portion of the WSCP. Groundwater in the northwestern portion of the WSTA flows to two western valleys (i.e., the 6500 drainage and a small drainage to the west of the 6500 drainage) (IT Corporation 1993b). Groundwater flow in the southern portion of the WSOW is contained within its surface drainage (i.e., does not cross into other drainages) and discharges at numerous small springs (Figure 1.5).

At the WSCP, groundwater to the north of the divide flows north and west toward Burgermeister Spring and eventually toward Dardenne Creek, a tributary of the Mississippi River. At the chemical plant, groundwater to the south of the divide flows south to southeast toward the Missouri River, primarily through the 5300 drainage. Because the Southeast Drainage is a losing stream in portions of its upper reaches, mixing between groundwater and surface water runoff can occur.

\subsubsection{Biotic Resources}

The principal surface water feature of relevance to these operable units is Burgermeister Spring. This spring is located in the former WSOW north of the WSCP in upland forest with a relatively dense understory. Tree species present in this area include red oak, persimmon, Kentucky coffee tree, and cottonwood. Ground cover immediately around the spring is dominated by periwinkle, whereas the shrubby understory is predominantly honeysuckle. At Burgermeister Spring, groundwater discharges into a square concrete enclosure about $1.5 \mathrm{~m}(4.9 \mathrm{ft})$ on each side and about $0.5 \mathrm{~m}(1.6 \mathrm{ft})$ high. Springwater within the enclosure flows through a crack in the concrete wall into a small natural stream channel (about $1 \mathrm{~m}$ [3.2 ft] wide). A small concrete weir is located about $15 \mathrm{~m}$ $(50 \mathrm{ft}$ ) downstream of the spring and creates a small pool with a sand/silt bottom (about $2 \mathrm{~m} \times 3 \mathrm{~m}$ $[7 \mathrm{ft} \times 9 \mathrm{ft}]$ and about $0.3 \mathrm{~m}[1 \mathrm{ft}]$ deep). Below the weir, the stream flows over a sand, gravel, and

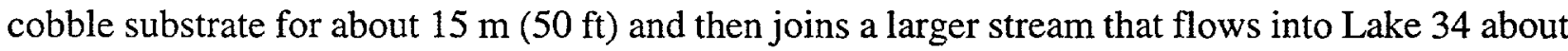
$1 \mathrm{~km}(0.6 \mathrm{mi})$ downstream of the spring.

No fish occur above the weir, which effectively serves as a barrier to the upstream passage of fish. The fish community of Burgermeister Spring below the weir is typical of Midwestern headwater streams; reported species include the orange throat darter, green sunfish, brook silverside, and redfin shiner. The larger stream that receives inflow from the spring and discharges to Lake 34 supports a more diverse fish fauna, including species common to Lake 34 that may use the stream as spawning and nursery habitat. Fish using the stream may include the black and white crappie, green sunfish, bluegill, largemouth bass, carp, and black bullhead. 


\subsubsection{Land and Groundwater Use}

The 700-ha (1,655-acre) WSTA is adjacent to the WSCP. Both areas are fenced, and access by the general public is restricted. One employee performs general oversight and maintenance activities on a full-time basis at the WSOW. Portions of the training area that are not contaminated are currently used for field training and outdoor maneuvers by the U.S. Army Reserve, the Missouri Army National Guard, and other military and police units. An estimated 3,300 local Army reservists and 3,400 other reserve troops use the training area each year. The Army intends to continue and even expand use of the WSTA area for training activities in the future. In 1998, approximately 40 contractor personnel affiliated with OU1 cleanup are also on-site at the WSOW.

A large portion of the WSOW has been converted into conservation areas (Figure 1.2). The 2,828-ha (6,987-acre) August A. Busch Memorial Conservation Area and the 2,977-ha (7,356-acre) Weldon Spring Conservation Area are managed by about 40 staff members of the Missouri Department of Conservation and are open throughout the year for recreational use. These areas receive an estimated 1,200,000 visitors each year (Crigler 1992).

A state highway maintenance facility is located just east of the WSCP. The facility employs nine full-time staff. The former staff housing complex for the former WSOW, located southeast of the intersection of State Route 94 and U.S. Route 40/61, is currently a private housing development known as Weldon Spring Heights, which has a population of about 95. Francis Howell High School is located about $1 \mathrm{~km}(0.6 \mathrm{mi})$ east of the WSCP. The school employs about 180 faculty and staff (including employees at the Francis Howell Administration Annex) and is attended by about 1,850 students (MK-Ferguson Company and Jacobs Engineering Group, Inc. 1998).

The current source of water for residents in the area is municipal water. County zoning requirements for future housing developments in the area around the WSCP and the WSOW indicate that municipal water would continue to be the source of drinking water even for potential future residents in the area. Housing developments or subdivisions are generally platted for home lots of no more than 0.4 ha $(1$ acre) in size that must be provided with municipal water. During the last two years, only one building permit was issued in the City of Weldon Spring for a private residence with an individual well. During the past 10 years, no building permits have been issued in the City of O'Fallon for residences with private wells for water supply. Also, for the period between 1993

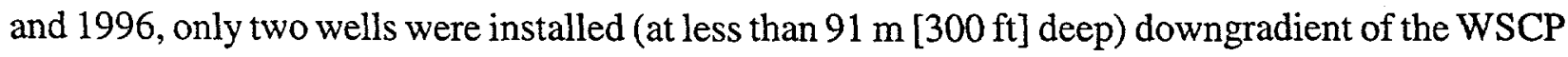
and the WSOW sites, out of approximately 2,200 new homes started (Tunnicliff 1997). These housing trends suggest little use of groundwater for residential purposes. 


\subsection{NATURE AND EXTENT OF CONTAMINATION}

The nature and extent of contamination within the groundwater system for the WSCP and the WSOW were evaluated on the basis of groundwater and spring data collected under DOE and DA environmental monitoring programs from 1987 through 1995 and a joint sampling effort conducted in 1995. Data for groundwater at the WSCP and the WSOW were combined and evaluated together because the groundwater system is continuous beneath both areas.

\subsubsection{Groundwater}

To facilitate the interpretation of data regarding the vertical distribution of contaminants in groundwater, data were grouped into four stratigraphic units: the overburden, weathered Burlington-Keokuk, unweathered Burlington-Keokuk, and deeper units. The results of the data evaluation indicated that contaminants determined to be at greater than background levels include nitrate, uranium, chloride, sulfate, lithium, and molybdenum. Organic compounds that include trichloroethylene (TCE), 1,2-dichloroethylene (1,2-DCE), and nitroaromatic compounds have also been detected. This discussion will focus on the set of contaminants that are considered to be primary contributors to potential site risk. These contaminants have been determined to be TCE, nitrate, and nitroaromatic compounds. A discussion regarding uranium levels in groundwater has been included because of possible transport to the springs. Historically, higher uranium concentrations have been detected in Burgermeister Spring samples than in groundwater samples (DOE and DA 1998b).

The horizontal and vertical distribution of contamination for selected contaminants (i.e., TCE and 1,2-DCE, nitrate, 2,4-DNT, 2,4,6-TNT, 1,3-dinitrobenzene [DNB], and uranium) is illustrated in Figures 1.7 through 1.12. The 95\% upper confidence limit (UCL) of the arithmetic average values for each well are shown in the figures for different stratigraphic groupings (i.e., overburden and weathered Burlington-Keokuk Limestone grouping; and unweathered Burlington-Keokuk and deeper units grouping). For naturally occurring constituents (i.e., uranium and nitrate), only those wells that exceed the statistically derived background are shown. For uranium and nitrate, the UCL values for each well are calculated on the basis of more recent data only (1995-1997), because these data are believed to be a more accurate representation of current contamination levels. Wells that are considered to be affected by uranium processing activities are designated in the distribution maps; these wells were determined on the basis of data evaluation, existing or previous source areas, and groundwater flow. The distribution maps for nitroaromatic compounds, TCE, and 1,2-DCE show all the locations where these compounds were detected. The UCL values for nitroaromatic compounds were calculated on the basis of all data collected since 1987. The UCL values for TCE and 1,2-DCE were calculated on the basis of data collected since 1996. Distribution maps for the other site contaminants are presented in the RI (DOE and DA 1998b). 


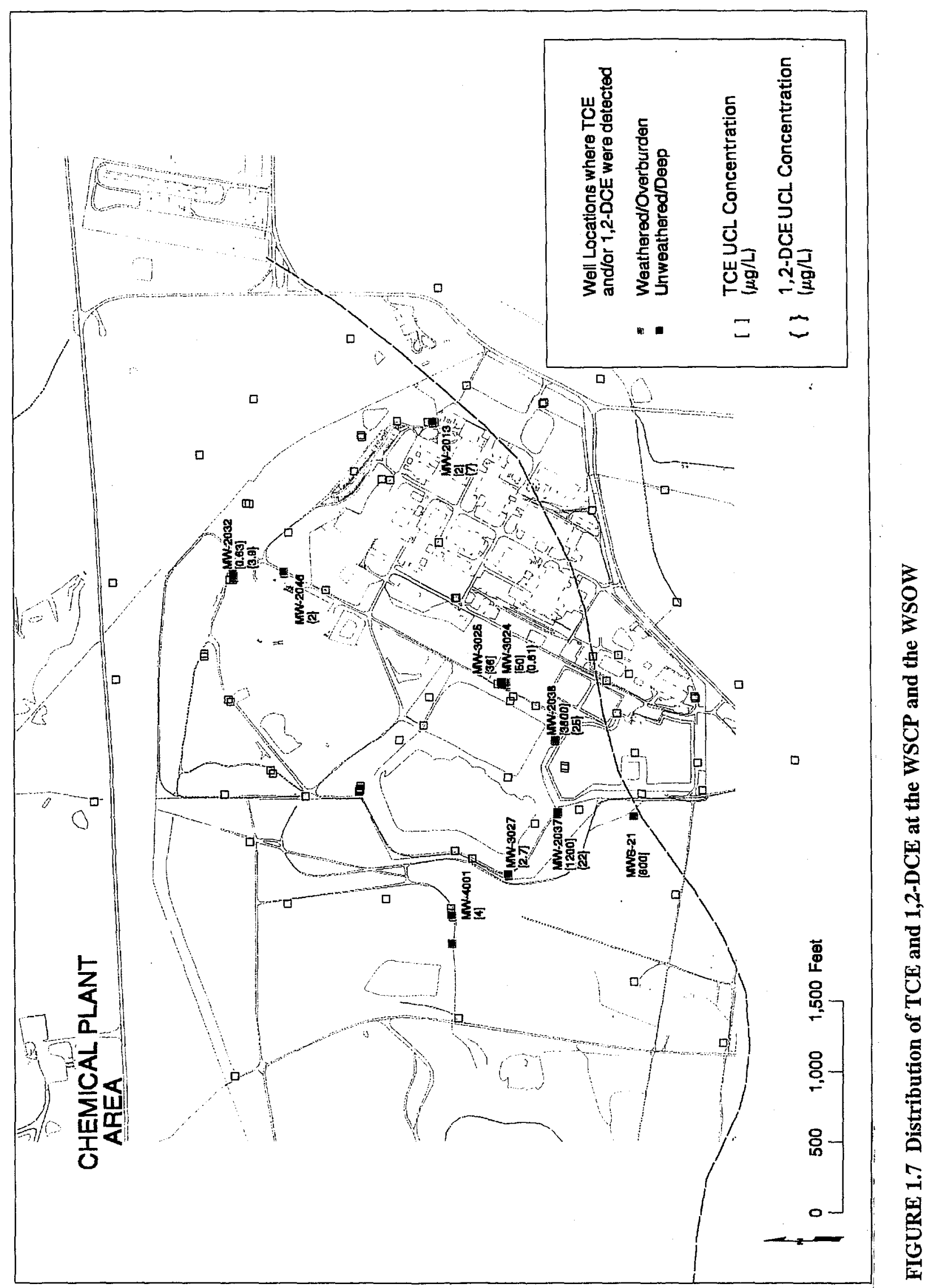




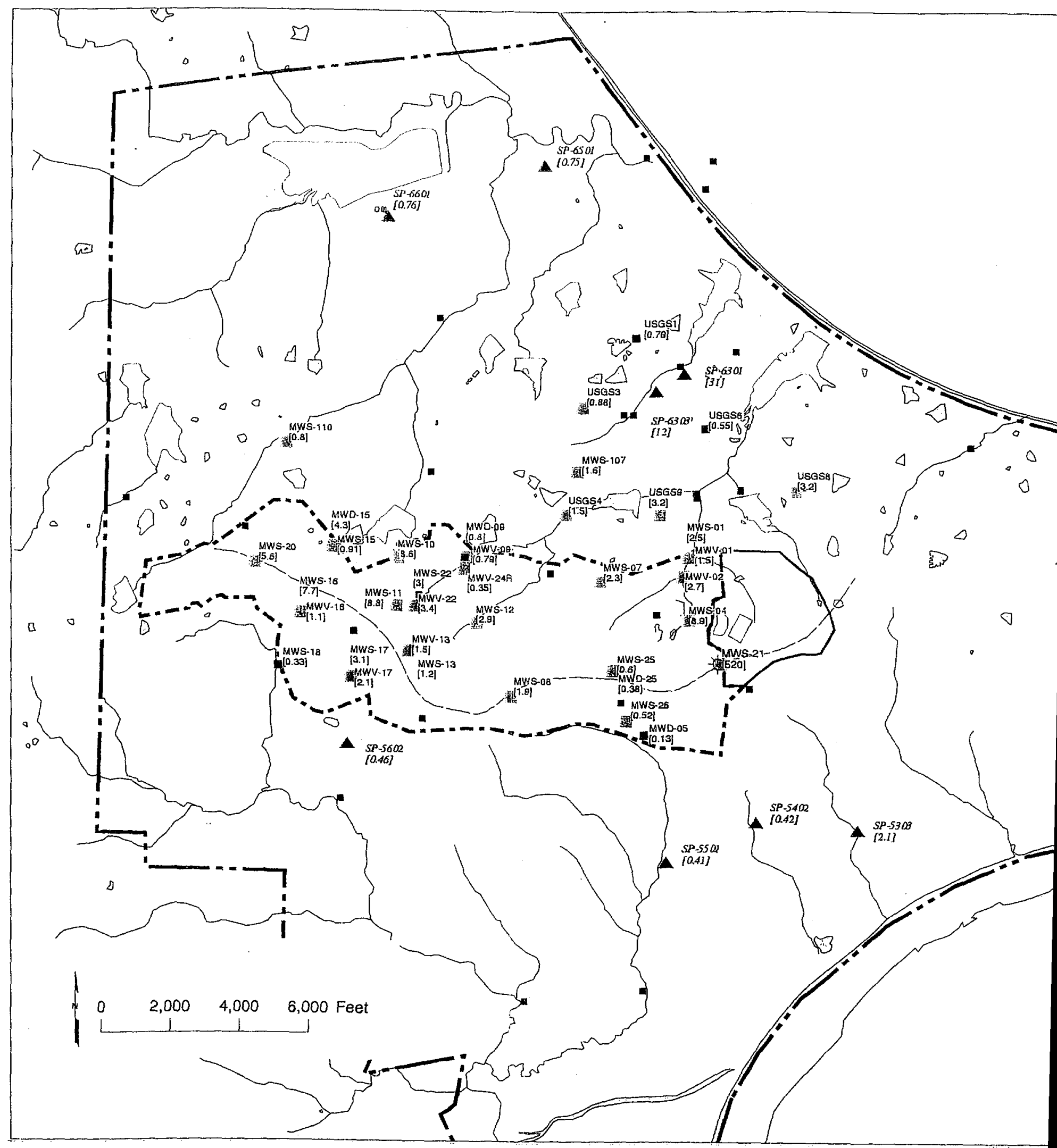

FIGURE 1.8 Distribution of Nitrate at the WSCP and the WSOW 


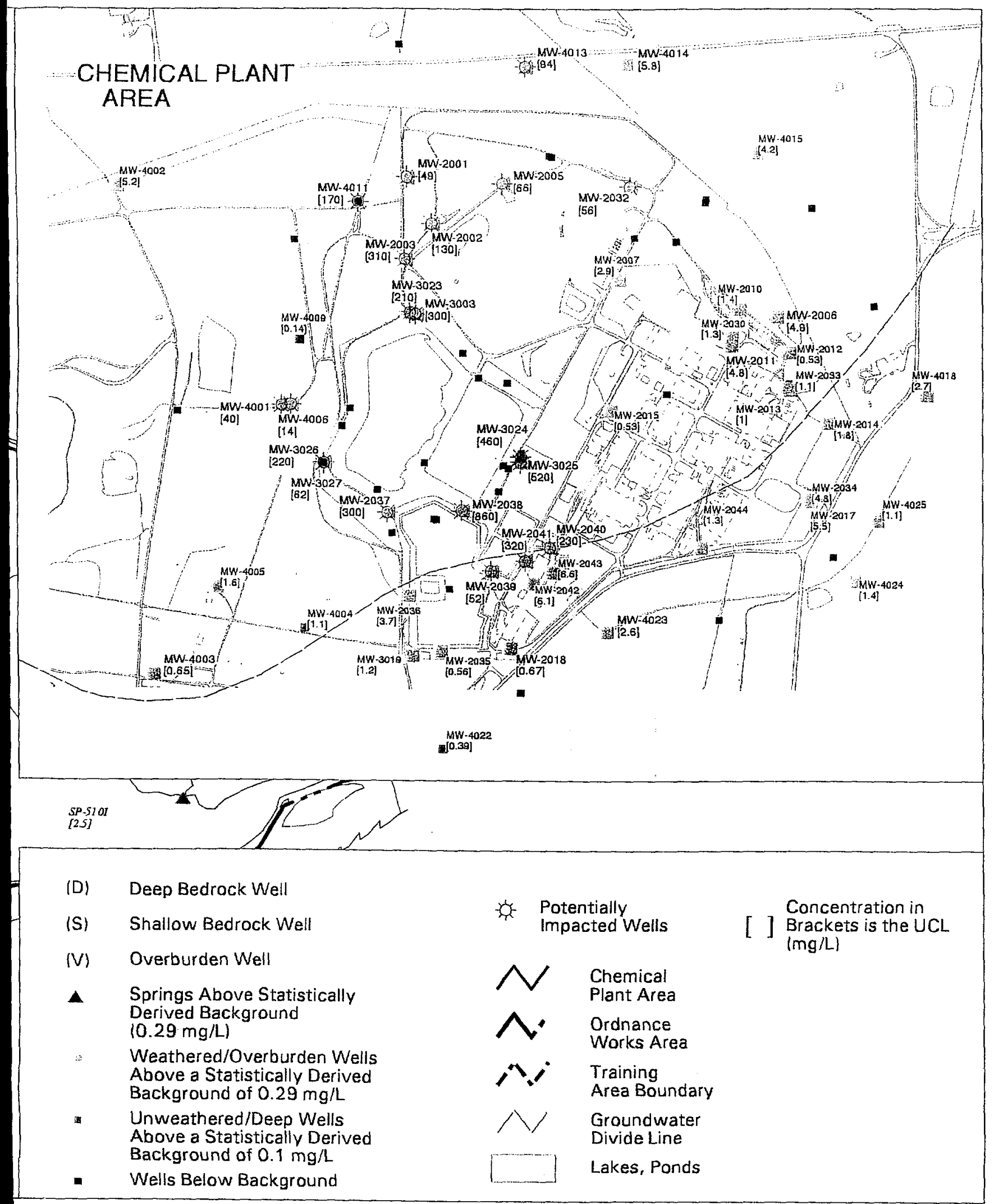




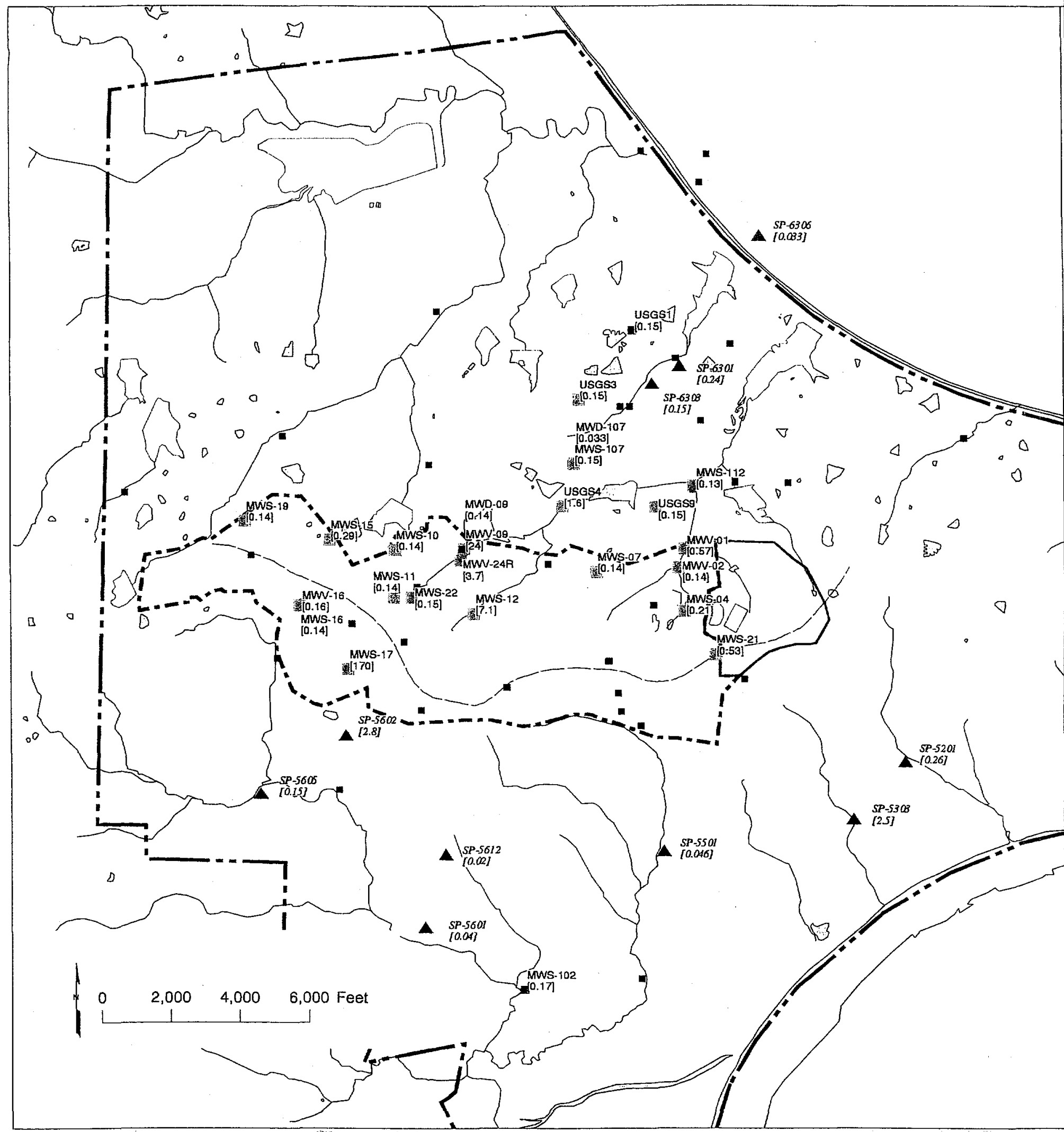

FIGURE 1.9 Distribution of 2,4-DNT at the WSCP and the WSOW 


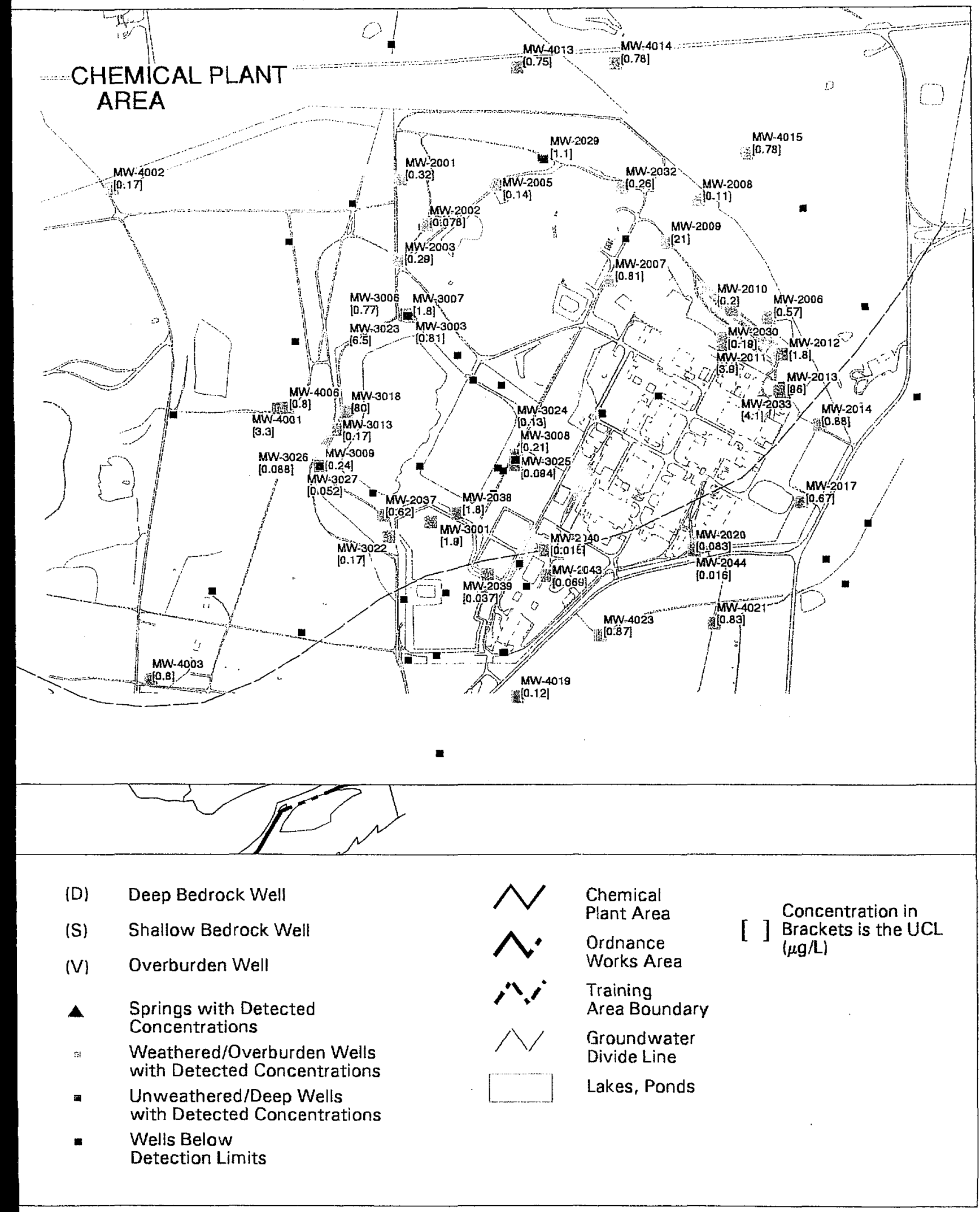




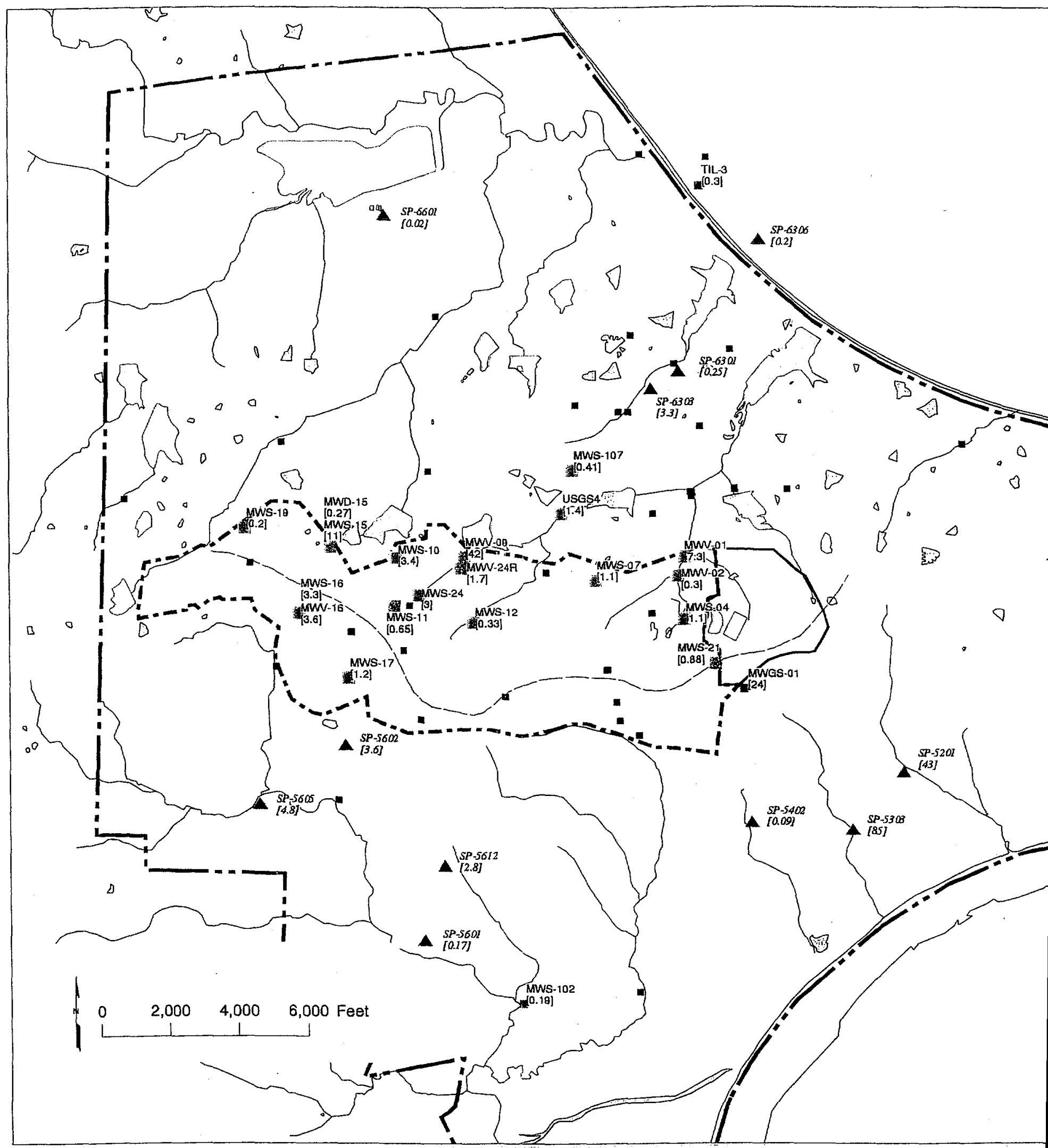

FIGURE 1.10 Distribution of 2,4,6-TNT at the WSCP and the WSOW 


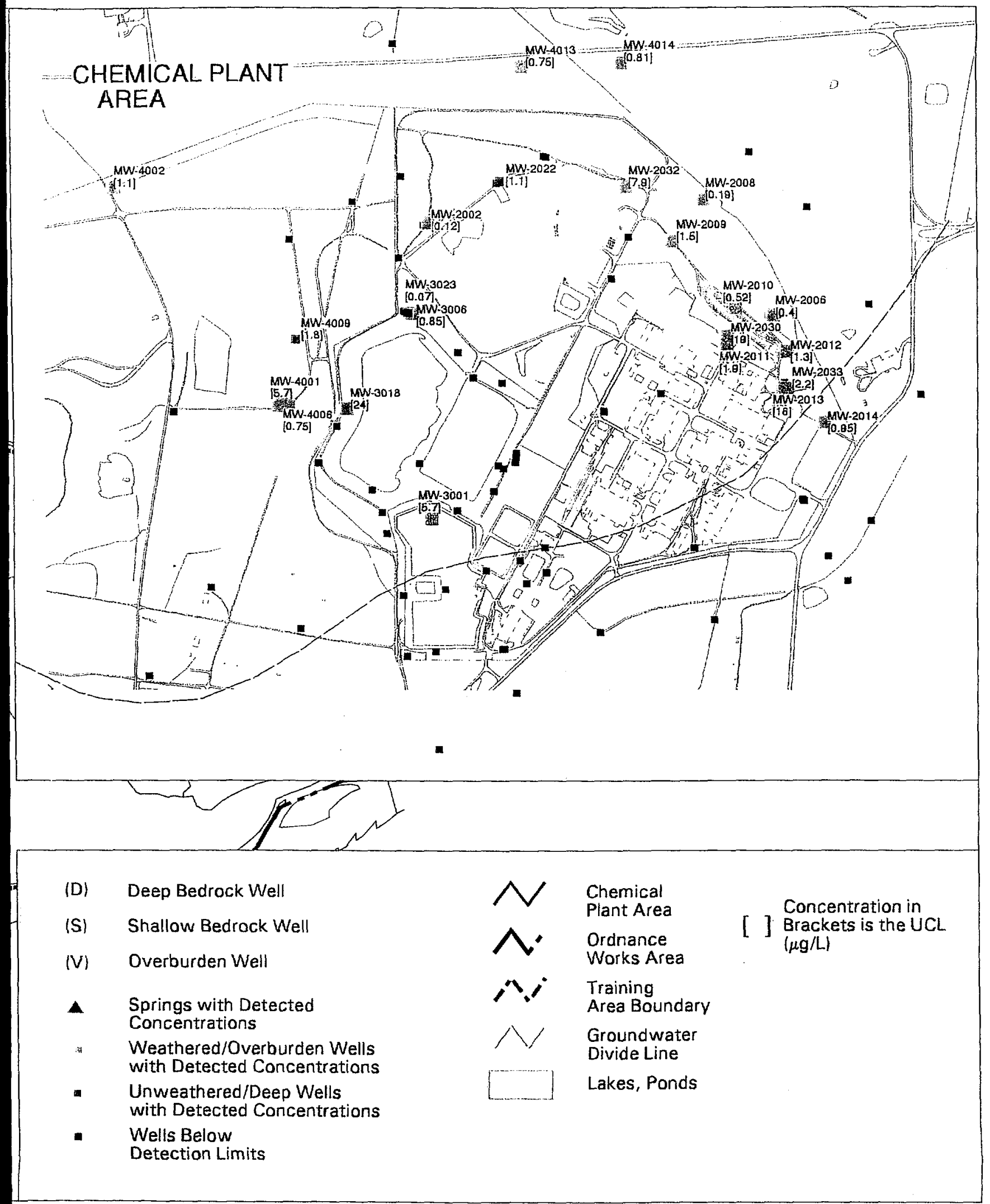




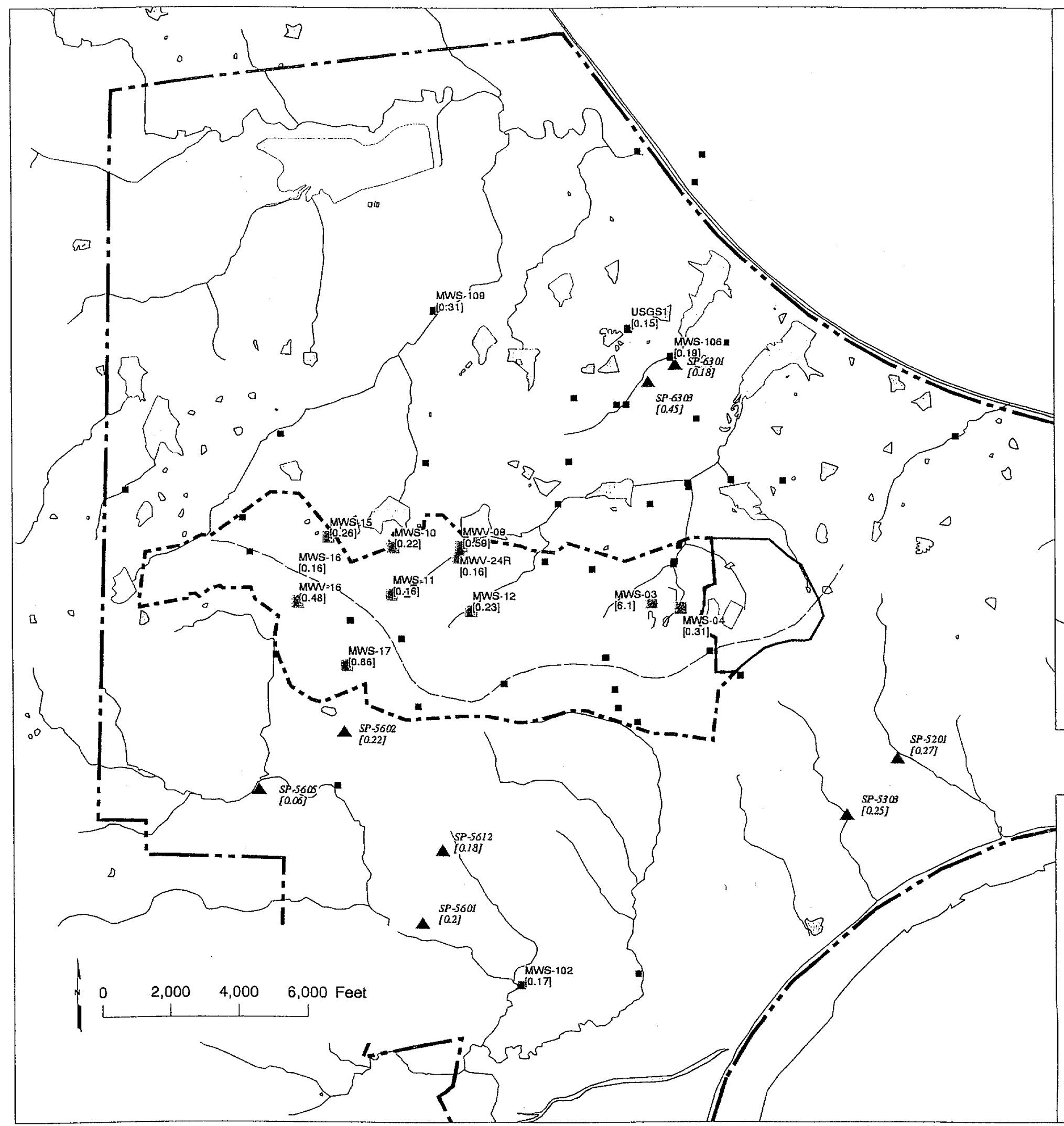

FIGURE 1.11 Distribution of 1,3-DNB at the WSCP and the WSOW 


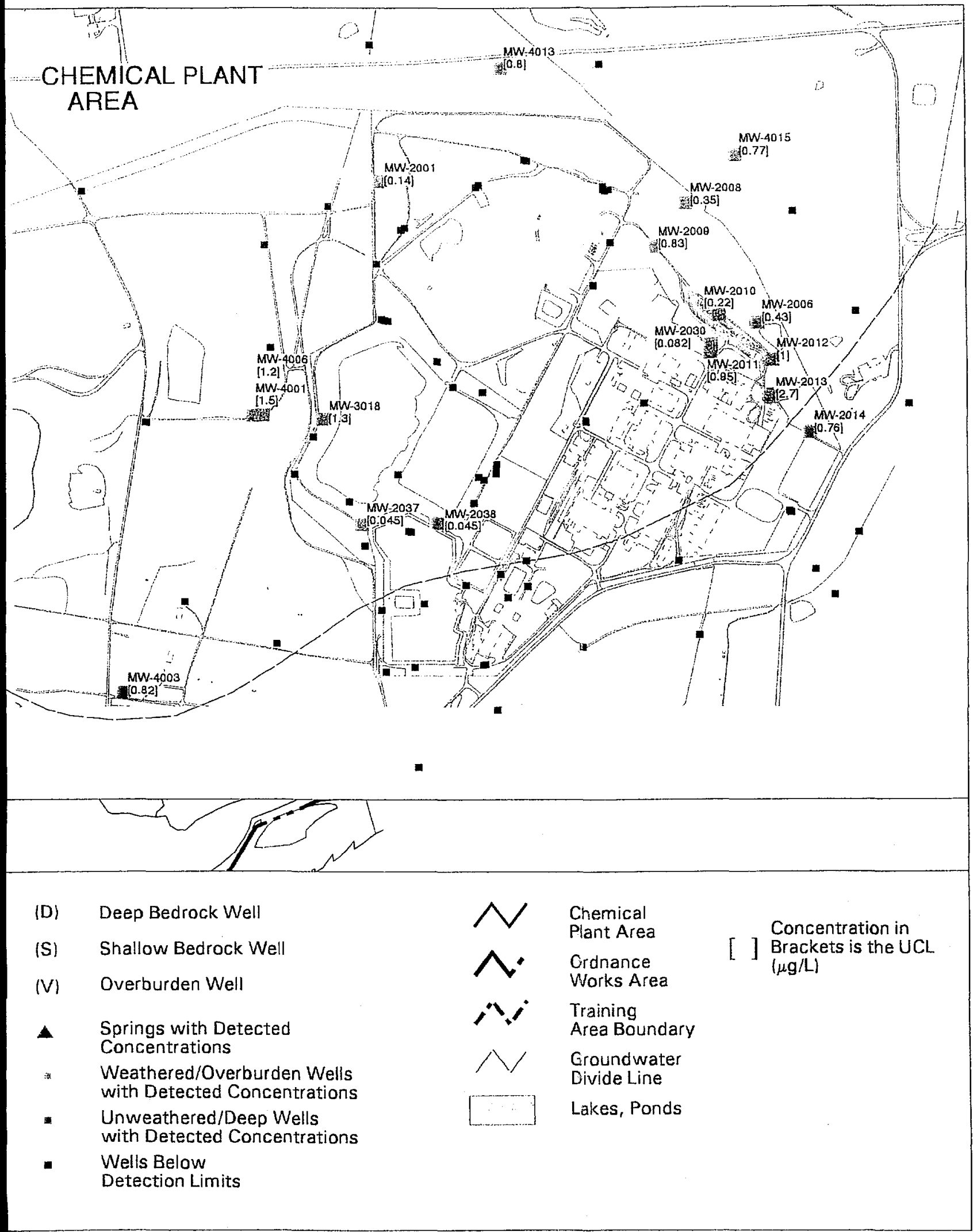




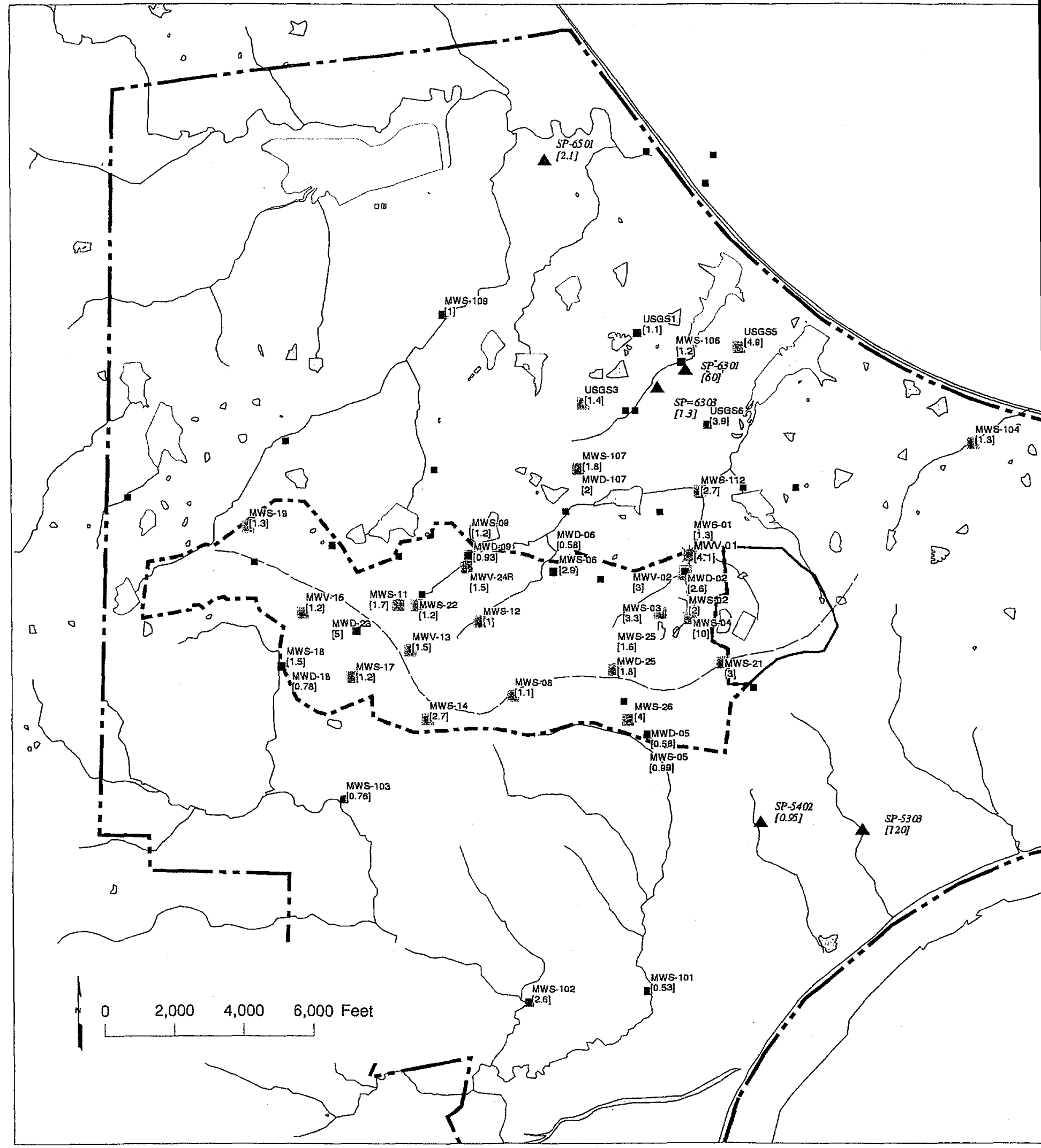

FIGURE 1.12 Distribution of Uranium at the WSCP and the WSOW 
Uranium and nitrate contamination in groundwater is primarily limited to the WSCP and nearby vicinity. Highest observed concentrations have typically been measured near the raffinate pits, predominantly in the overburden and weathered units of the aquifer. Data from the joint sampling effort conducted in 1995 indicated concentrations as high as $900 \mathrm{mg} / \mathrm{L}$ for nitrate and $60 \mathrm{pCi} / \mathrm{L}$ for uranium. The maximum concentration observed for uranium was reported for a well located in the southeastern portion of the chemical plant (see Figure 1.12). Well MW-4024 was installed just before the $60 \mathrm{pCi} / \mathrm{L}$ concentration was observed. It is suspected that bentonite grout used for well installation contributed to the high concentrations of uranium (DOE and DA 1998b). A more recent data point reported for this well (July 1997) was $6.7 \mathrm{pCi} / \mathrm{L}$. Elevated levels of uranium were also detected in shallow groundwater in the Southeast Drainage; in-situ samples ranged in concentration from 2.1 to $160 \mathrm{pCi} / \mathrm{L}$. However, sampling of a new well installed in the Southeast Drainage area in May 1997 has shown no detected concentrations of uranium (i.e., below the $0.68 \mathrm{pCi} / \mathrm{L}$ detection limit).

Nitroaromatic compounds occur sporadically at low levels across the groundwater system; higher levels have generally been detected in the overburden and weathered units of the aquifer. The primary nitroaromatic compounds detected include 2,4-dinitrotoluene (2,4-DNT), 2,6-dinitrotoluene (2,6-DNT), 1,3,5-trinitrobenzene (1,3,5-TNB), 2,4,6-trinitrotoluene (2,4,6-TNT), and the amino-DNT compounds (2-amino-4,6-dinitrotoluene [2-amino-4,6-DNT] and 4-amino-2,6-dinitrotoluene (4-amino-2,6-DNT]). The 1995 joint sampling data indicated maximum concentrations ranging from 8 to $100 \mu \mathrm{g} / \mathrm{L}$ for these compounds.

Groundwater contamination of TCE and 1,2-DCE is localized at the WSCP, primarily in the vicinity of the raffinate pits. The areal extent of contamination extends from east of raffinate pit 3 to the south and southeast of raffinate pit 4, just beyond the adjacent boundary with the WSTA. Most of the contamination occurs in the weathered portion of the aquifer. TCE has been detected in one unweathered well (MW-3025); however, after this well was retrofitted to fix a leaking seal, no TCE was detected. Concentrations in groundwater have ranged from 1 to $9,000 \mu \mathrm{g} / \mathrm{L}$ for TCE and from 1 to $39 \mu \mathrm{g} / \mathrm{L}$ for 1,2-DCE. The most recent data collected (as of December 1997) indicate TCE concentrations ranging from 1 to $1,300 \mu \mathrm{g} / \mathrm{L}$ and $1,2-\mathrm{DCE}$ concentrations ranging from 1 to $29 \mu \mathrm{g} / \mathrm{L}$.

\subsubsection{Springwater}

The primary contaminants detected in springwater include uranium, nitrate, sulfate, and nitroaromatic compounds. Elevated levels of uranium and nitrate have been routinely detected at Burgermeister Spring (6300 drainage). Nitrate concentrations at this location have historically ranged from 0.5 to $10,000 \mathrm{mg} / \mathrm{L}$; data collected since 1995 indicated a range of 3.8 to $47 \mathrm{mg} / \mathrm{L}$. The 1995 joint sampling indicated a maximum concentration of $91 \mathrm{pCi} / \mathrm{L}$. Elevated uranium levels have also been routinely detected in the Southeast Drainage (5300 drainage). Elevated sulfate levels, ranging from 3.2 to $86 \mathrm{mg} / \mathrm{L}$, were found in springs in the $5100,5200,5300$, and 6300 drainages. 
Nitroaromatic compounds have been detected in springs at low levels from most of the drainages in the former WSOW, except for the 5100 drainage. The highest levels of 2,4,6-TNT occurred in Spring 5201 (downstream of Burning Ground 1) and in the Southeast Drainage, with concentrations of 120 and $280 \mu \mathrm{g} / \mathrm{L}$, respectively. Concentrations of other nitroaromatic compounds detected throughout the area have ranged from 0.02 to $24 \mu \mathrm{g} / \mathrm{L}$.

Other naturally occurring constituents detected at above background levels include chloride, antimony, cadmium, lithium, manganese, mercury, molybdenum, and silver. Four springs were also sampled for volatile organic compounds (VOCs), beginning in August 1996. The springs included Burgermeister Spring, Spring-6303, and two springs in the Southeast Drainage. No VOCs were detected in the Southeast Drainage. Low levels of TCE were detected in the 6300 drainage (i.e., less than $1.72 \mu \mathrm{g} / \mathrm{L})$.

\subsection{SUMMARY OF POTENTIAL RISKS}

A baseline risk assessment (DOE and DA 1998a) was conducted for the WSCP and the WSOW as part of the RI (DOE and DA 1998b) to estimate human health and environmental impacts that could occur if no cleanup action were taken. Current and likely future land uses were incorporated into assumptions for these risk estimates.

\subsubsection{Human Health Assessment}

Potential carcinogenic risks for both radiological and chemical exposures were assessed in terms of the increased probability that an individual would develop cancer over a lifetime. The EPA has indicated that the acceptable exposure levels for members of the general public are generally concentrations of between $1 \times 10^{-6}$ and $1 \times 10^{-4}$ (EPA 1989b). This range is used as a point of reference for discussing the results of the carcinogenic risk assessment for the GWOUs at the WSCP and the WSOW.

Potential health effects other than cancer from exposure to chemical contaminants were also assessed. The quantitative measure of noncarcinogenic health effects is the hazard index. The EPA has defined a hazard index of greater than 1 as the level of concern for noncarcinogenic health effects.

\subsubsection{Identification of Contaminants of Potential Concern}

Contaminants determined in the RI (DOE and DA 1998b) as site-related contaminants were identified as contaminants of potential concern (COPCs) and were included in the risk calculations. 
Site-related contaminants were identified on the basis of the understanding of the processes that occurred at the sites and on evaluation of approximately 10 years of data. For naturally occurring contaminants (i.e., metals and inorganic anions), the site data were also compared with background values in the determination of COPCs.

\subsubsection{Exposure Assessment}

Current Land Use. The most likely receptor under current land use was assumed to be a recreational visitor who might be exposed to contaminated discharge water at one of the springs. On the basis of current land use information, the analysis also assumed that there would be no current access and use of the groundwater (see Section 1.1.2.5).

Army reservists and a full-time site caretaker of the WSOW were also considered as potential receptors; however, these scenarios were not evaluated. There are no potential pathways of exposure for the reservist because no active springs occur in the WSTA, and municipal water is available at the tap. Similarly, the potential for the site caretaker to come in contact with the contaminated groundwater and springs is unlikely because of the availability of municipal water. The potential risk to a reservist who might venture outside the fenced training area and drink springwater would be represented by the calculations performed for the recreational visitor. It was considered reasonable for reservists to train at the WSTA two to three weekends (about six days) per year. If these same reservists also spent their yearly retreat training of two weeks at the WSTA, the frequency of exposure would extend to about 20 days, which is the same as the exposure frequency assumed in the risk calculations for a recreational visitor.

The potential risk from exposure to contaminated groundwater and springwater to DOE and contractor employees currently present at the WSCP was also considered. However, these personnel have no access to nor do they use the contaminated water (a municipal water supply is used) except for purposes of sampling and analysis.

Future Land Use. Under future land use, the most likely receptor would also be a recreational visitor. It is unlikely that the shallow aquifer beneath the WSCP and the WSOW would be used by a future resident on the basis of current and foreseeable future land use. The Army intends to continue using the WSTA for training activities in the future. The WSCP is currently being remediated; all site waste will ultimately be disposed of in an engineered disposal cell constructed on-site. The size of the cell is estimated to encompass approximately one-third of the WSCP.

In addition, a large portion of the former WSOW has been converted into conservation areas. The August A. Busch Memorial Conservation Area and the Weldon Spring Conservation Area 
are managed by the Missouri Department of Conservation and are open throughout the year for recreational use. These areas are extensively used, as indicated by the estimated 1,200,000 visitors each year (Crigler 1992).

Because of the low transmissivity and low yield of the upper part of the shallow aquifer, a future resident would likely screen a private well in the deeper, more productive aquifers. Also, the well would be open to a larger portion of the shallow aquifer (rather than only the upper weathered unit of the Burlington-Keokuk) because of the $24-\mathrm{m}(80-\mathrm{ft})$ casing requirement.

Nevertheless, as a means of providing information representing the upper-bound risk to human health from groundwater contamination, risk calculations were performed for the hypothetical future resident. Separate calculations to estimate risk for recreational use of the groundwater were not performed because access to the contaminated groundwater is not available to a recreational visitor. Further, if necessary, one can infer potential risk to a recreational user from the calculations for the residential scenario. By using the standard exposure parameter assumptions recommended by the EPA for a recreational visitor (i.e., assuming the recreational visitor could somehow access the groundwater 20 times per year for 30 years and ingest approximately $400 \mathrm{~mL}$ each visit), the potential risk and hazard index would be approximately one-hundredth of those for a resident.

\subsubsection{Risk Characterization}

On the basis of results presented in the BRA (DOE and DA 1998a), neither carcinogenic risk nor systemic toxicity is indicated for the recreational visitor ingesting springwater at the 15 springs evaluated. These results are expected to be representative of all springs located in the area covered by the GWOUs. The radiological risk estimates range from $4 \times 10^{-9}$ to $2 \times 10^{-6}$. These values are low and well within the acceptable risk range of $1 \times 10^{-6}$ to $1 \times 10^{-4}$ recommended by the EPA (1989b). The chemical risk estimates are similarly low and range from $3 \times 10^{-10}$ to $6 \times 10^{-7}$. The hazard indices estimated for the recreational visitor at the springs range from 0.001 to 0.4 .

Calculations performed for each well for the hypothetical future resident scenario indicate that of the 155 wells evaluated, chemical risks would be greater than $1 \times 10^{-4}$ for seven wells. The chemical risk estimates for the 155 wells range from $1 \times 10^{-7}$ to $3 \times 10^{-3}$. The upper end of this range is attributable to TCE detected at well MW-2038, which is located north of the groundwater divide. The chemical risk estimates and primary risk contributors for the other six wells are as follows: $2 \times 10^{-4}$ at MWV-09 and MWS-12 due to nitroaromatic compounds; $1 \times 10^{-4}$ at MWS-17 due to nitroaromatic compounds; $1 \times 10^{-4}$ at MW-2030 due to nitroaromatic compounds; $4 \times 10^{-4}$ at MW-2037 due to TCE; and $3 \times 10^{-4}$ at MWS-21 due to TCE. The TCE-contaminated wells are near the raffinate pits and are completed in the weathered portion of the shallow aquifer. The radiological risk estimates for the hypothetical future resident scenario range from $7 \times 10^{-8}$ to $7 \times 10^{-5}$, all within the EPA's acceptable risk range. 
The hazard indices estimated for the 155 wells on the basis of the residential scenario range from $<0.01$ to 40 . The hazard indices for 42 of the 155 wells evaluated are greater than 1 . Of the 42 , hazard indices for 27 wells are attributable to nitroaromatic compounds. The remaining 15 hazard indices that are greater than 1 are attributable to nitrate concentrations in wells located near the raffinate pits at the WSCP.

\subsubsection{Contaminants of Concern}

In summary, the following contaminants can be identified as contaminants of concern (COCs) on the basis of their contributions to carcinogenic estimates: TCE and the nitroaromatic compounds 2,4,6-TNT, 2,4-DNT, and 2,6-DNT. In addition, nitrate and nitroaromatic compounds (primarily 1,3,5-TNB, 2-amino-4,6-DNT, and 4-amino-2,6-DNT) are considered COCs relative to their contributions to the hazard indices. Uranium is considered a COC only with regard to its possible transport to the springs. Higher uranium concentrations have been detected in Burgermeister Spring samples than in groundwater samples. Groundwater concentrations of uranium have been determined to result in potential radiological risk within the acceptable risk range.

\subsubsection{Ecological Assessment}

\subsubsection{Methodology}

The ecological risk assessment for the GWOUs employed a number of approaches for evaluating risks to ecological resources using springs at the WSCP and the WSOW. Risks to aquatic biota were evaluated with biotic surveys, tissue analyses of fish and macroinvertebrates, media toxicity testing, and comparison of media concentrations to ecological benchmark ("safe") media concentrations. Risks to terrestrial biota were evaluated by modeling contaminant uptake and comparing the predicted doses to species-specific benchmark doses. Contaminant data used in the assessment included the same surface water data used in the human health risk assessment, as well as sediment data collected specifically for the ecological risk assessment at Burgermeister Spring and selected downstream locations.

Biotic surveys for aquatic invertebrates, fish, and amphibians were conducted at Burgermeister Spring and its downstream drainage to determine the status of the biotic communities currently exposed to contaminants in surface water and sediment at the spring. Tissues were also analyzed to evaluate contaminant bioconcentration by aquatic biota. Toxicity testing of surface water

and sediment from the spring and downstream locations included acute and chronic toxicity testing of aquatic invertebrates, fish, and amphibians. These tests determined whether current contaminant concentrations in the surface water and sediment are toxic to aquatic biota. Contaminant uptake from 
the ingestion of surface water was modeled for two terrestrial receptor species, the white-tailed deer and the American robin. The uptake modeling employed species-specific exposure factors; the exposure point concentrations were the maximum reported contaminant concentrations in surface water from springs at the WSCP and the WSOW.

\subsubsection{Results and Conclusions}

The results of surveys of macroinvertebrates, fish, and amphibians that inhabit the Burgermeister Spring drainage indicated no evidence of adverse effects to these aquatic biota. The spring was determined to contain generally good aquatic habitat, and the species present are typical of those found in similar habitats throughout the Midwest. Although the fish community was limited in diversity and the macroinvertebrate community was categorized as slightly impaired, the communities are likely affected by the physical nature of the spring and its drainage rather than contaminant levels. Flow in the uppermost portion of Burgermeister Spring is maintained by groundwater discharge at the spring. Under low-flow conditions, as commonly occur in the summer, the stream drainage below the spring becomes intermittent and portions of the habitat become dry. Surveys of amphibians found a community typical of similar habitats in the Midwest.

The results of toxicity testing indicate the potential for some toxicity to fish and invertebrates from surface water and sediment in Burgermeister Spring proper, although the magnitude of the toxicity is low to moderate. Surface water and sediment toxicities were also measured at some locations downstream of the spring, but no clear toxicity gradient was evident extending downstream from the spring. However, the presence of apparently unaffected macroinvertebrate, fish, and amphibian communities in the drainage at locations where media toxicity was detected suggests that local populations are tolerant of (or have adapted to) the contaminant levels present in surface water and sediment in the Burgermeister Spring drainage. Tissue analyses revealed relatively low levels of contaminant bioconcentration; all analysis results were below levels of concern.

Modeling of contaminant uptake by the white-tailed deer and American robin drinking from Burgermeister Spring (but using maximum contaminant concentrations reported from all springs) predicted very low levels of contaminant uptake by these species. Risk estimates for terrestrial biota based on the modeled contaminant doses indicate no risks to terrestrial biota drinking from Burgermeister Spring or other springs in the area.

Risk estimates for aquatic biota based on media concentrations indicate that surface water concentrations of iron, manganese, mercury, uranium, 1,3,5-TNB, and 2,4,6-TNT, and sediment concentrations of arsenic, lead, and silver might pose low to moderate risks to aquatic biota. However, the aquatic community in Burgermeister Spring is typical of similar habitats elsewhere in the Midwest and does not appear to be adversely affected by contaminant concentrations at this time. 
Few of the other springs in the area provide suitable habitat and, at best, naturally support only very limited aquatic communities.

On the basis of the results of biotic surveys, media toxicity testing, tissue analyses, mediabased risk calculations, and contaminant uptake modeling, current contaminant levels in surface water and sediment in area springs are considered to pose little or no risk to aquatic or terrestrial biota of the Weldon Spring area. Screening-level risk calculations indicated a potential for low to moderate risks to aquatic biota from some contaminants in springs, and surface water and sediment toxicities were detected for Burgermeister Spring. However, follow-up biotic surveys of Burgermeister Spring and downstream habitats found no evidence that aquatic biota inhabiting this spring are being adversely affected; few other springs naturally provide sufficient permanent habitat to support more than only very limited aquatic communities. Uptake modeling indicates no risks to terrestrial wildlife using the area springs for drinking water.

\subsection{OBJECTIVE OF THE FEASIBILITY STUDY}

The objective of this FS is to evaluate potential options for addressing groundwater contamination at the WSCP and the WSOW. Because it is expected that source removals planned and/or currently ongoing at both the WSCP and the WSOW would lead to a decrease in groundwater contaminant concentrations, options that allow for verification of decreasing concentrations were evaluated. The analysis for this FS also focused on the evaluation of applicable engineering options for removing or reducing groundwater contaminant concentrations to provide as possible, additional overall protection of human health and the environment.

This FS provides sufficient information to support decisions in accordance with the integrated environmental compliance processes for the WSSRAP and for the remedial action project at the WSOW, which includes the WSTA.

Water at surface springs located at the WSCP and the WSOW was also evaluated as part of the BRA and RI (DOE and DA 1998a,b). Contaminant concentrations are estimated to result in human health risk within or lower than the acceptable risk range recommended by the EPA (i.e., $1 \times 10^{-6}$ to $1 \times 10^{-4}$ ). The results of the ecological assessment also did not indicate the need for remediation at the springs. The likely future land use is considered to be similar to the current recreational land use, in which exposure to the contaminated groundwater does not occur because there is no direct access to and use of the contaminated groundwater. Risk estimates provided for additional information and based on the hypothetical assumption of residential land use do indicate that exposure to contaminated groundwater at a few wells would result in a potential risk of greater than $1 \times 10^{-4}$ and a hazard index of greater than 1 . 


\subsection{DETERMINATION OF PRELIMINARY REMEDIATION GOALS FOR GROUNDWATER AT THE WSCP AND THE WSOW}

On the basis of the results of evaluations presented in the BRA and RI (DOE and DA 1998a,b), the primary COCs in groundwater are TCE, nitrate, nitroaromatic compounds, and uranium. Nitrate and TCE contamination are primarily of concern at the raffinate pits area at the WSCP. Nitroaromatic compounds have been identified as COCs in a few wells at both the WSCP and the WSOW. Although uranium concentrations in groundwater at the WSCP and at the WSOW are elevated over background, concentrations are generally low. Uranium is included as a COC only with regard to its possible transport to the springs (see Section 1.3.1.4).

Preliminary remediation goals (PRGs) for TCE, nitrate, nitroaromatic compounds (i.e., 2,4,6-TNT, 2,4-DNT, 2,6-DNT, 2-amino-4,6-DNT, 4-amino-2,6-DNT, nitrotoluenes, 1,3,5-TNB, 1,3-DNB, and nitrobenzene) and uranium are identified in this FS as a basis for evaluating the effectiveness of the various technologies and alternatives being considered. In accordance with the National Oil and Hazardous Substances Contingency Plan ([NCP]; EPA 1990a), the PRGs are concentrations of contaminants for each exposure route that are believed to provide adequate protection of human health and the environment on the basis of preliminary site information. They are based on applicable or relevant and appropriate requirements (ARARs) such as maximum contaminant levels (MCLs). When ARARs are not available or are not sufficiently protective, the EPA selects remedies resulting in a risk range of $1 \times 10^{-4}$ to $1 \times 10^{-6}$ for carcinogens and at or below a hazard index of 1 for noncarcinogens. A detailed discussion and compilation of ARARs and to-be-considered (TBC) requirements is presented in Appendix A.

MCLs for TCE and nitrate as nitrogen (nitrate-N) have been identified at $5 \mu \mathrm{g} / \mathrm{L}$ and $10 \mathrm{mg} / \mathrm{L}$, respectively. Missouri water quality standards, which are considered ARARs, have been identified for three nitroaromatic compounds: nitrobenzene, 2,4-DNT, and 1,3-DNB (10 Code of State Regulations [CSR] 20-7.031(5)). The ARARs for these compounds are 17,0.11, and $1.0 \mu \mathrm{g} / \mathrm{L}$, respectively.

No federal or state MCL or maximum contaminant level goal (MCLG) exists for uranium. On July 18,1991 , the EPA published a proposed rule that set an MCL of $20 \mu \mathrm{g} / \mathrm{L}$ for uranium (EPA 1991). The proposed MCL, which is considered a TBC (see Appendix A), corresponds to $14 \mathrm{pCi} / \mathrm{L}$ for the activity concentration ratio of uranium isotopes found in groundwater at the WSCP.

Because no ARARs have been identified for the remaining nitroaromatic compounds and uranium, PRGs were determined from risk-based values for the recreational visitor scenario. Likely future land uses for the WSCP and the WSOW are expected to be similar to current land uses. Current land uses for both areas are considered recreational. Assumptions and methodologies used in calculating the risk-based values were similar to those used for risk estimates in the BRA 
(DOE and DA 1998a) and are further discussed in Appendix B of this FS. Table 1.2 presents a tabulation of the ARARs, risk-based values, and proposed PRGs.

Table 1.3 lists the wells at which PRGs are exceeded for COCs considered for WSCP and WSOW groundwater. Figures 1.13, 1.14, and 1.15 illustrate locations where TCE, nitrate and 2,4-DNT PRGs are exceeded at the WSCP. Figure 1.16 illustrates locations where 2,4-DNT PRGs are exceeded at the WSOW.

\subsection{ORGANIZATION OF THE REPORT}

The remainder of this FS is organized as follows:

- Chapter 2 presents the identification and evaluation of potential response technologies;

- Chapter 3 presents the development and screening of preliminary alternatives;

- Chapter 4 gives a detailed description and evaluation of the final alternatives;

- Chapter 5 is a comparative analysis of the final alternatives; and

- Chapter 6 lists the references cited in the report.

- Appendix A discusses and lists the regulatory requirements potentially applicable or relevant and appropriate to the remedial action.

- Appendix B presents details of the calculations for PRGs.

- Appendices $\mathrm{C}$ and $\mathrm{D}$ provide discussions of the methodologies used to analyze certain alternatives considered in the FS:

- Appendix C, Methodology and Assumptions Used to Calculate the Potential Number of Extraction Wells for the WSCP and the WSOW;

- Appendix D, Methodology and Assumptions Used to Determine the Costs of the Various Alternatives in this Feasibility Study. 
TABLE 1.2 Summary of ARARs, Risk-Based Values, and Preliminary Remediation Goals for Groundwater Contaminants of Concern

\begin{tabular}{|c|c|c|c|c|c|c|c|}
\hline \multirow[b]{3}{*}{$\begin{array}{l}\text { Contaminant } \\
\text { of Concern }\end{array}$} & \multirow[b]{3}{*}{ Unit } & \multirow[b]{3}{*}{ ARARs $^{2}$} & \multicolumn{4}{|c|}{ Risk-Based Values ${ }^{\mathrm{b}}$} & \multirow[b]{3}{*}{$\begin{array}{l}\text { Proposed } \\
\text { PRGs for } \\
\text { the GWOUs }\end{array}$} \\
\hline & & & \multicolumn{2}{|c|}{ Residential Scenario } & \multicolumn{2}{|c|}{ Recreational Scenario } & \\
\hline & & & $\begin{array}{l}10^{-6} \text { to } 10^{-4} \\
\text { Carcinogenic } \\
\text { Risk Range }\end{array}$ & $\begin{array}{l}\text { Hazard } \\
\text { Index } \\
\text { of } 1\end{array}$ & $\begin{array}{l}10^{-6} \text { to } 10^{-4} \\
\text { Carcinogenic } \\
\text { Risk Range }\end{array}$ & $\begin{array}{c}\text { Hazard } \\
\text { Index } \\
\text { of } 1\end{array}$ & \\
\hline 2-Amino-4,6-DNT & $\mu \mathrm{g} / \mathrm{L}$ &.$h$ & $\mathrm{NA}^{\mathrm{i}}$ & 2.2 & NA & 190 & 190 \\
\hline 4-Amino-2,6-DNT & $\mu \mathrm{g} / \mathrm{L}$ & - & $\mathrm{NA}$ & 2.2 & NA & 190 & 190 \\
\hline $1,3-\mathrm{DNB}$ & $\mu \mathrm{g} / \mathrm{L}$ & $1.0^{\mathrm{j}}$ & NA & 3.7 & NA & 320 & 1.0 \\
\hline 2,4-DNT & $\mu \mathrm{g} / \mathrm{L}$ & $0.11^{j}$ & $0.13-13$ & 73 & $11-1,100$ & 6,400 & 0.11 \\
\hline 2,6-DNT & $\mu \mathrm{g} / \mathrm{L}$ & - & $0.13-13$ & 37 & $11-1,100$ & 3,200 & 11 \\
\hline Nitrobenzene & $\mu \mathrm{g} / \mathrm{L}$ & $17^{j}$ & NA & 18 & NA & 1,600 & 17 \\
\hline Nitrate-N & $\mathrm{mg} / \mathrm{L}$ & 10 & NA & $58^{\mathrm{k}}$ & NA & 5,100 & 10 \\
\hline m-Nitrotoluene & $\mu \mathrm{g} / \mathrm{L}$ & - & NA & 37 & NA & 3,200 & 3,200 \\
\hline o-Nitrotoluene & $\mu \mathrm{g} / \mathrm{L}$ & - & NA & 37 & NA & 3,200 & 3,200 \\
\hline p-Nitrotoluene & $\mu \mathrm{g} / \mathrm{L}$ & - & NA & 37 & NA & 3,200 & 3,200 \\
\hline TCE & $\mu g / L$ & 5 & $7.7-770$ & NA & $680-68,000$ & NA & 5 \\
\hline $1,3,5-\mathrm{TNB}$ & $\mu \mathrm{g} / \mathrm{L}$ & - & NA & 1.8 & $\mathrm{NA}$ & 160 & 160 \\
\hline $2,4,6-\mathrm{TNT}$ & $\mu g / L$ & - & $2.8-280$ & 18 & $250-25,000$ & 1,600 & 250 \\
\hline Uranium & $\mathrm{pCi} / \mathrm{L}$ & - & $0.90-90^{1}$ & $110 \mu \mathrm{g} / \mathrm{L}^{\mathrm{m}}$ & $78-7,800^{1}$ & $9,600 \mu \mathrm{g} / \mathrm{L}^{\mathrm{m}}$ & 78 \\
\hline
\end{tabular}

a The values in this column include MCLs and Missouri water quality standards. A detailed tabulation of ARARs is presented in Appendix A.

b

Risk-based values were estimated for the recreational and residential scenarios following the risk methodology and equations used for risk calculations as presented in the BRA (DOE and DA 1998a) and in Appendix B. The forseeable future land use at the WSCP and the WSOW is likely to be recreational, which is the same as current land use.

c Values in this column represent concentrations for each contaminant that would be within the acceptable risk range for the residential scenario.

d Values in this column represent the highest concentration for each contaminant that would be acceptable or within the hazard index of 1 for the residential scenario.

e Values in this column represent concentrations for each contaminant that would be within the acceptable risk range for the recreational scenario.

f Values in this column represent the highest concentration for each contaminant that would be acceptable or within the hazard index of 1 for the recreational scenario.

g The proposed PRGs for TCE, nitrate-N, 2,4-DNT, 1,3-DNB, and nitrobenzene were based on ARARs. PRGs for carcinogenic nitroaromatic compounds (i.e., 2,4,6-TNT, 2,6-DNT) and uranium were based on concentrations equivalent to the 1 in 1 million risk for the recreational scenario. PRGs for noncarcinogenic nitroaromatic compounds (i.e., 2-amino-4,6-DNT, 4-amino-2,6-DNT, m-nitrotoluene, o-nitrotoluene, and p-nitrotoluene) were based on concentrations equivalent to a hazard index of 1 for each compound for the recreational scenario.

$\mathrm{h}$ A hyphen (-) indicates that no ARARs are available.

i NA = not applicable.

j Missouri water quality standard that is an ARAR.

$\mathrm{k}$ Value based on an adult residential receptor; the value for infants would be less because nitrate- $\mathrm{N}$ would be more toxic to infants than adults.

1 Based on the radiological risk for uranium.

$m$ Based on the chemical toxicity of uranium. 
TABLE 1.3 Wells with Contaminant Concentrations Exceeding PRGs ${ }^{\mathrm{a}}$

\begin{tabular}{|c|c|c|c|c|c|c|c|c|c|c|c|c|c|c|}
\hline Well & $\begin{array}{c}\text { TCE } \\
(\mu \mathrm{g} / \mathrm{L})\end{array}$ & $\begin{array}{l}\text { Nitrate } \\
(\mathrm{mg} / \mathrm{L})\end{array}$ & $\begin{array}{c}1,3,5-\mathrm{TNB} \\
(\mu \mathrm{g} / \mathrm{L})\end{array}$ & $\begin{array}{c}2,4,6-\mathrm{TNT} \\
(\mu \mathrm{g} / \mathrm{L})\end{array}$ & $\begin{array}{c}2,4-\mathrm{DNT} \\
(\mu \mathrm{g} / \mathrm{L})\end{array}$ & $\begin{array}{c}2,6-\mathrm{DNT} \\
(\mu \mathrm{g} / \mathrm{L})\end{array}$ & $\begin{array}{c}\text { 2-Amino- } \\
\text { 4,6-DNT } \\
(\mu \mathrm{g} / \mathrm{L})\end{array}$ & $\begin{array}{c}\text { 4-Amino } \\
\text { 2,6-DNT } \\
(\mu \mathrm{g} / \mathrm{L})\end{array}$ & $\begin{array}{l}\text { 2-Nitro- } \\
\text { toluene } \\
(\mu \mathrm{g} / \mathrm{L})\end{array}$ & $\begin{array}{l}\text { 3-Nitro- } \\
\text { toluene } \\
(\mu \mathrm{g} / \mathrm{L})\end{array}$ & $\begin{array}{l}\text { 4-Nitro- } \\
\text { tolucne } \\
(\mu \mathrm{g} / \mathrm{L})\end{array}$ & $\begin{array}{c}\text { Nitro- } \\
\text { benzene } \\
(\mu \mathrm{g} / \mathrm{L})\end{array}$ & $\begin{array}{c}\text { 1,3-DNB } \\
(\mu \mathrm{g} / \mathrm{L})\end{array}$ & $\begin{array}{l}\text { Uranium } \\
\text { (pCi/L) }\end{array}$ \\
\hline IPRG & 5 & 10 & 160 & 250 & 0.11 & 11 & 190 & 190 & 3,200 & 3,200 & 3,200 & 17 & 1.0 & 78 \\
\hline \multicolumn{15}{|c|}{ WSCP: Weathered } \\
\hline MW-2002 & - & 130 & - & - & - & - & - & - & - & - & - & - & - & - \\
\hline MW-2003 & - & 310 & - & - & 0.15 & - & - & - & - & - & - & - & - & - \\
\hline MW-2005 & . & 66 & - & - & - & - & . & - & - & - & - & - & - & - \\
\hline MW-2006 & - & - & - & - & 0.14 & - & - & - & - & - & - & - & - & - \\
\hline $\mathrm{MW}-2010$ & - & - & - & - & - & - & - & - & - & - & - & - & - & - \\
\hline MW-2011 & - & - & - & - & .0 .20 & - & - & - & - & - & - & - & - & - \\
\hline MW-2012 & - & - & - & - & - & - & - & - & - & - & - & - & - & - \\
\hline MW-2013 & - & - & - & - & 0.36 & - & - & - & - & - & - & - & - & - \\
\hline MW-2014 & - & - & - & - & 0.16 & - & - & - & - & - & - & - & - & - \\
\hline MW-2030 & - & - & - & - & 0.25 & 11 & - & - & - & $\therefore$ & - & - &. & - \\
\hline$M W-2032$ & - & 56 & - & - & - & - & - & - & - & - & - & - & - & - \\
\hline$M W-2033$ & - & - & - & - & 0.55 & - & - & - & - & - & - & - & - & - \\
\hline MW-2037 & 1,300 & 290 & - & - & 0.56 & - & - & - & - & - & - & - & - & - \\
\hline MW-2038 & 9,000 & 900 & - & - & 1.7 & - & - & - & - & - & - & - & - & - \\
\hline MW-2039 & - & 52 & - & - & - & - & - & - & - & - & - & - & - & - \\
\hline MW-2040 & - & 230 & - & - & - & - & - & - & - & - & - & - & - & - \\
\hline$M W-2041$ & - & 300 & - & - & - & - & - & - & - & - & - & - & . & - \\
\hline MW-3003 & - & 440 & - & - & - & - & - & - & - & - & - & - & - & - \\
\hline MW-3023 & - & 210 & - & - & 5.0 & - & - & - & - & - & - & - & - & - \\
\hline MW-3025 & 40 & 520 & - & - & - & - & - & - & - & - & - & - & - & - \\
\hline MW-3027 & - & 62 & - & - & - & - & - & - & - & - & - & - & - & - \\
\hline MW-4001 & - & 40 & - & - & 1.3 & - & - & - & - & - & - & - & - & - \\
\hline MW-4002 & - & - & - & - & 0.14 & - & - & - & - & - & - & - & - & - \\
\hline MW4006 & - & 14 & - & - & 0.16 & - & - & - & - & - & - & - & - & - \\
\hline MW-4013 & - & 94 & - & - & - & - & - & - & - & - & - & - & - & - \\
\hline MW-4015 & - & - & - & - & 0.19 & - & - & - & - & - & - & - & - & - \\
\hline \multicolumn{15}{|c|}{ WSCP: Unweathered } \\
\hline MW-3024 & 60 & 370 & - & - & 0.13 & - & - & - & - & - & - & - & - & - \\
\hline MW-3026 & - & 220 & - & - & - & - & - & - & - & - & - & - & - & - \\
\hline MW-4011 & - & 170 & - & - & . & - & - & - & - & - & - & - & - & - \\
\hline
\end{tabular}


TABLE 1.3 (Cont.)

\begin{tabular}{|c|c|c|c|c|c|c|c|c|c|c|c|c|c|c|}
\hline Well & $\begin{array}{c}\text { TCE } \\
(\mu \mathrm{g} / \mathrm{L})\end{array}$ & $\begin{array}{l}\text { Nitrate } \\
(\mathrm{mg} / \mathrm{L})\end{array}$ & $\begin{array}{c}1,3,5-\mathrm{TNB} \\
(\mu \mathrm{g} / \mathrm{L})\end{array}$ & $\begin{array}{c}2,4,6-\mathrm{TNT} \\
(\mu \mathrm{g} / \mathrm{L})\end{array}$ & $\begin{array}{c}2,4-\mathrm{DNT} \\
(\mu \mathrm{g} / \mathrm{L})\end{array}$ & $\begin{array}{c}2,6-\mathrm{DNT} \\
(\mu \mathrm{g} / \mathrm{L})\end{array}$ & $\begin{array}{c}\text { 2-Amino- } \\
4,6-\mathrm{DNT} \\
(\mu \mathrm{g} / \mathrm{L})\end{array}$ & $\begin{array}{c}\text { 4-Amino } \\
\text { 2,6-DNT } \\
(\mu \mathrm{g} / \mathrm{L})\end{array}$ & $\begin{array}{l}2-\text { Nitro- } \\
\text { toluene } \\
(\mu \mathrm{g} / \mathrm{L})\end{array}$ & $\begin{array}{l}\text { 3-Nitro- } \\
\text { toluene } \\
(\mu \mathrm{g} / \mathrm{L})\end{array}$ & $\begin{array}{l}\text { 4-Nitro- } \\
\text { toluene } \\
(\mu \mathrm{g} / \mathrm{L})\end{array}$ & $\begin{array}{c}\text { Nitro- } \\
\text { benzene } \\
(\mu \mathrm{g} / \mathrm{L})\end{array}$ & $\begin{array}{c}\text { 1,3-DNB } \\
(\mu \mathrm{g} / \mathrm{L})\end{array}$ & $\begin{array}{l}\text { Uranium } \\
(\mathrm{pCi} / \mathrm{L})\end{array}$ \\
\hline PRG $^{b}$ & 5 & 10 & 160 & 250 & 0.11 & 11 & 190 & 190 & 3,200 & 3,200 & 3,200 & 17 & 1.0 & 78 \\
\hline \multicolumn{15}{|c|}{ WSOW: Weathered } \\
\hline MWS-12 & - & - & - & - & 8.8 & 15 & - & - & - & - & - & - & - & - \\
\hline MWS-17 & $\cdot$ & - & - & - & 1.1 & 13 & . & - & - & - & - & - & - & - \\
\hline MWS-21 & 800 & 520 & - & - & 0.94 & - & - & - & - & - & - & - & - & - \\
\hline \multicolumn{15}{|c|}{ WSOW: Overburden } \\
\hline MWV-9 & - & - & - & - & 20 & - & - & - & - & - & - & - & - & - \\
\hline$M W V-24$ & - & - & - & - & 0.13 & - & - & - & - & - & - & - & - & - \\
\hline USGS-4 & - & - & $\cdots$ & - & 1.5 & - & - & - & - & - & - & - & - & - \\
\hline
\end{tabular}

a Concentrations are maximum concentrations detected during the 1995 joint DOE and DA sampling.

b PRGs are risk-based values for the recreational scenario, except for TCE, uranium, 2,4-DNT, 1,3-DNB, and nitrobenzene.

c A hyphen (-) indicates that the maximum contaminant concentration detected is below the proposed PRG. 


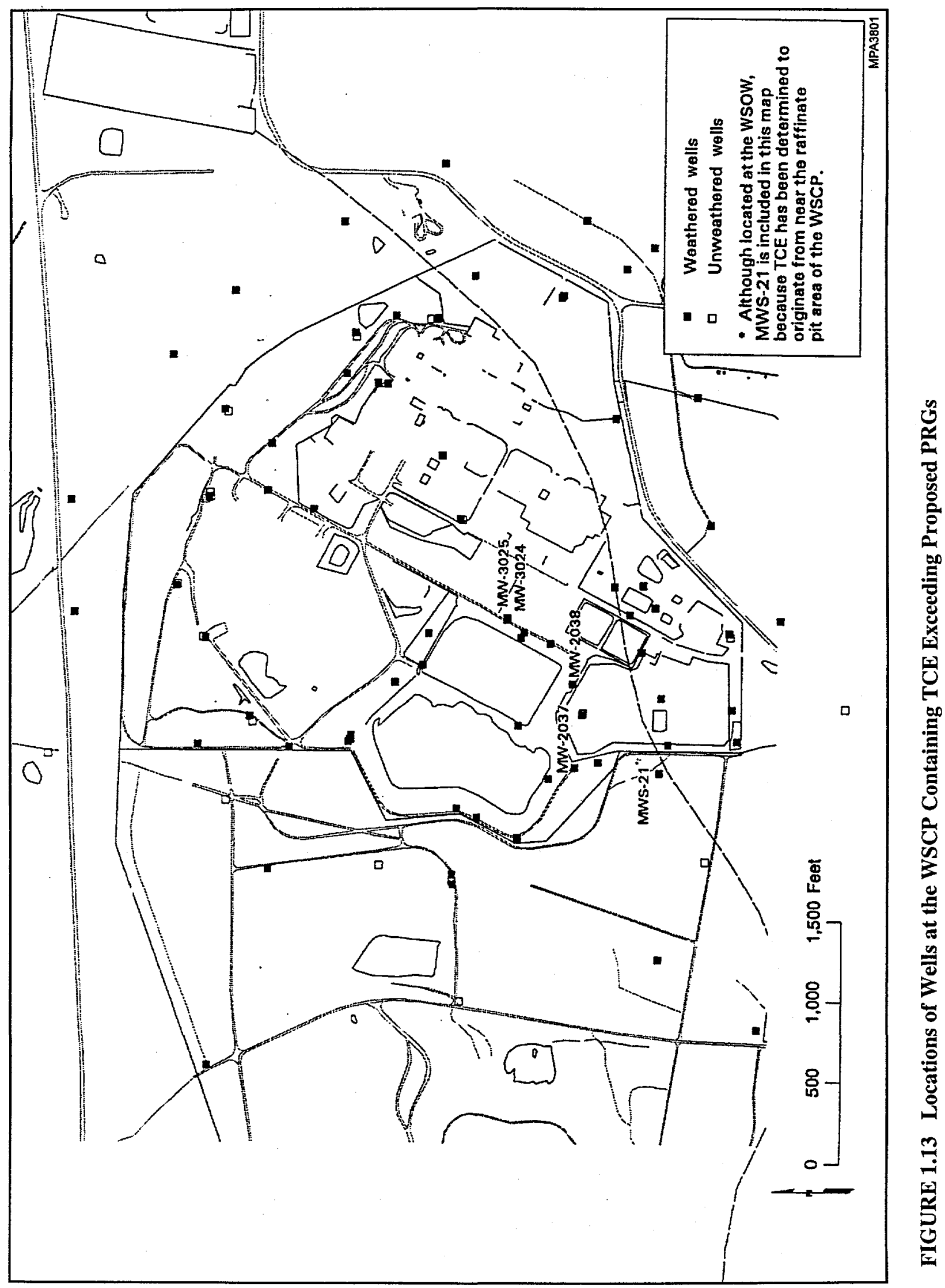




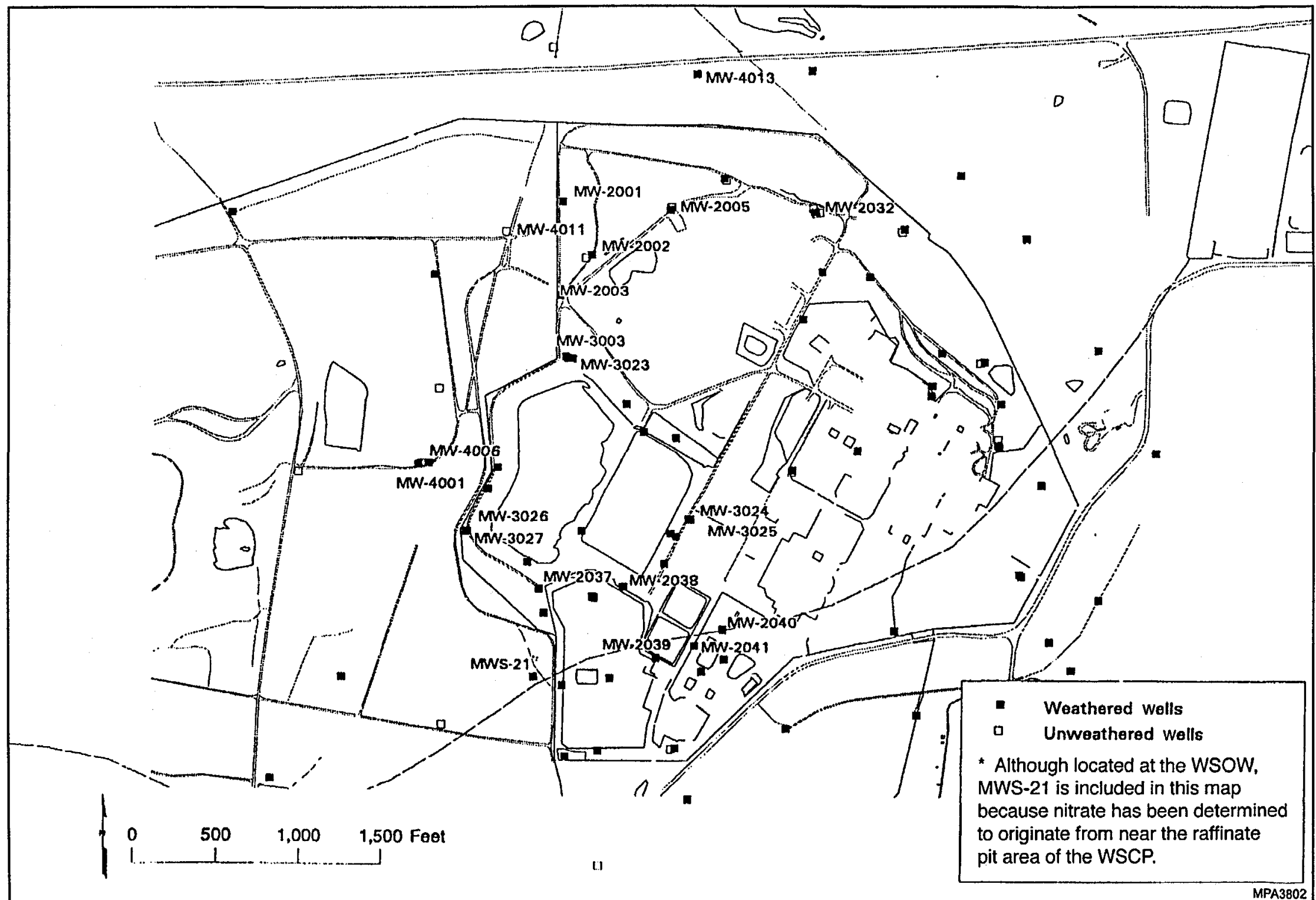




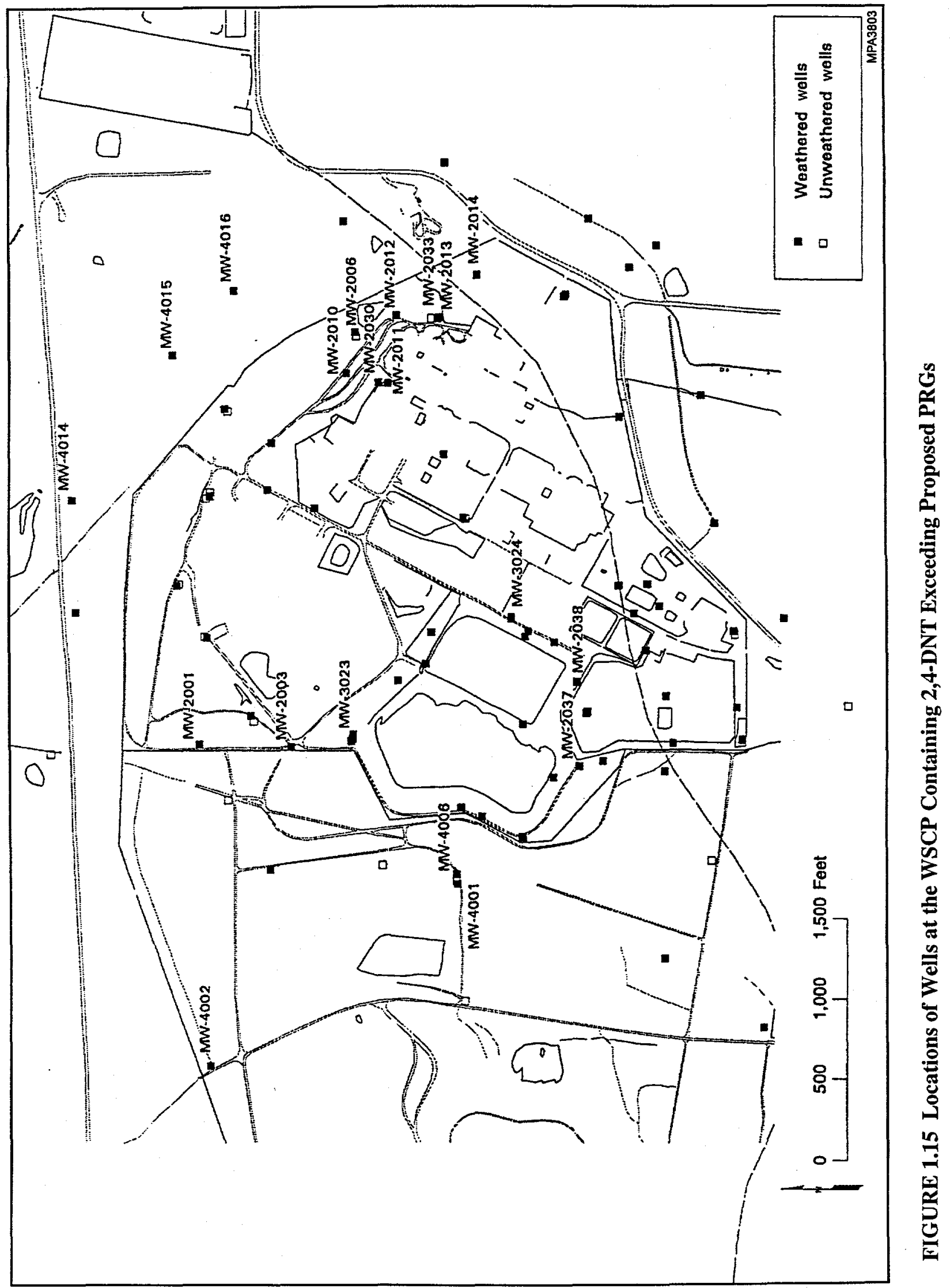




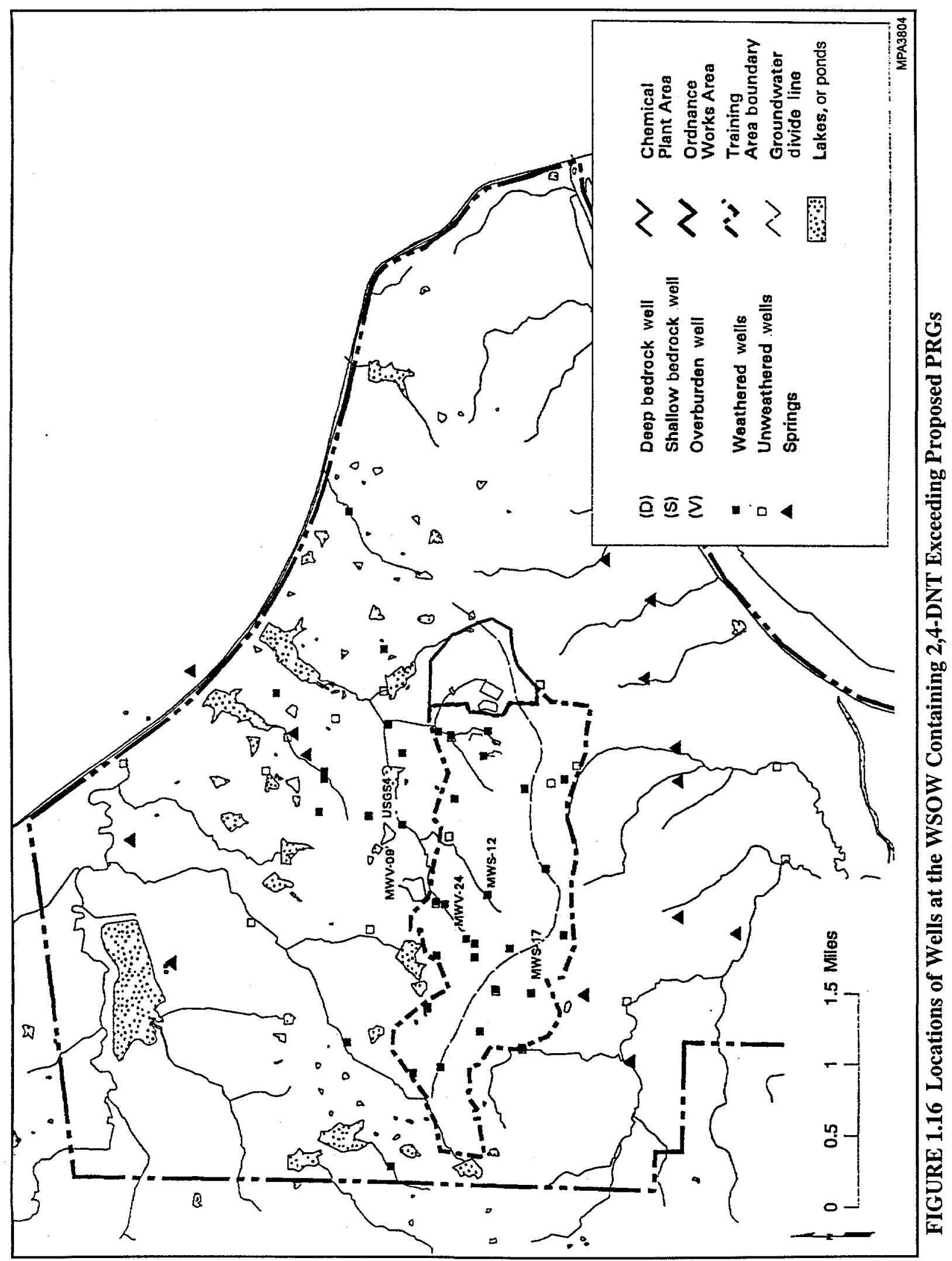




\section{IDENTIFICATION AND SCREENING OF TECHNOLOGIES}

\subsection{SCREENING CRITERIA}

The criteria for identifying potentially applicable technologies are provided in EPA guidance (EPA 1988a) and in the NCP (EPA 1994). The primary requirements for a final remedy are that it be both protective of human health and the environment and cost effective. Hence, technology screening focuses on these two factors. Additional selection criteria include the following:

- Preferred remedies are those in which the principal element is treatment to permanently or significantly reduce the toxicity, mobility, or volume of hazardous substances, pollutants, or contaminants;

- Where practical treatment technologies are available, off-site transport and disposal without treatment is the least preferred alternative; and

- Permanent solutions and alternative treatment technologies or recycle/resource recovery technologies should be assessed and used to the maximum extent practicable.

These criteria have been considered in identifying and screening technologies to determine the appropriate components of remedial action alternatives for the contaminated groundwater at the WSCP and the WSOW.

On the basis of current knowledge of the nature and extent of groundwater contamination at the WSCP and the WSOW, the following are the general response actions that could be implemented to help reduce exposure to the contaminants or to reduce or remove elevated contaminant concentrations: (1) monitoring; (2) institutional controls; (3) natural processes; (4) in-situ containment; (5) in-situ treatment; or (6) removal, storage, ex-situ treatment, and disposal. Technology types and process options that could be used to implement each general response action (4 through 6) are presented schematically in Figure 2.1. Specific application of these technology types and process options to conditions at the WSCP and the WSOW was evaluated in Section 2.2 to determine which would be the most appropriate for groundwater remediation. 


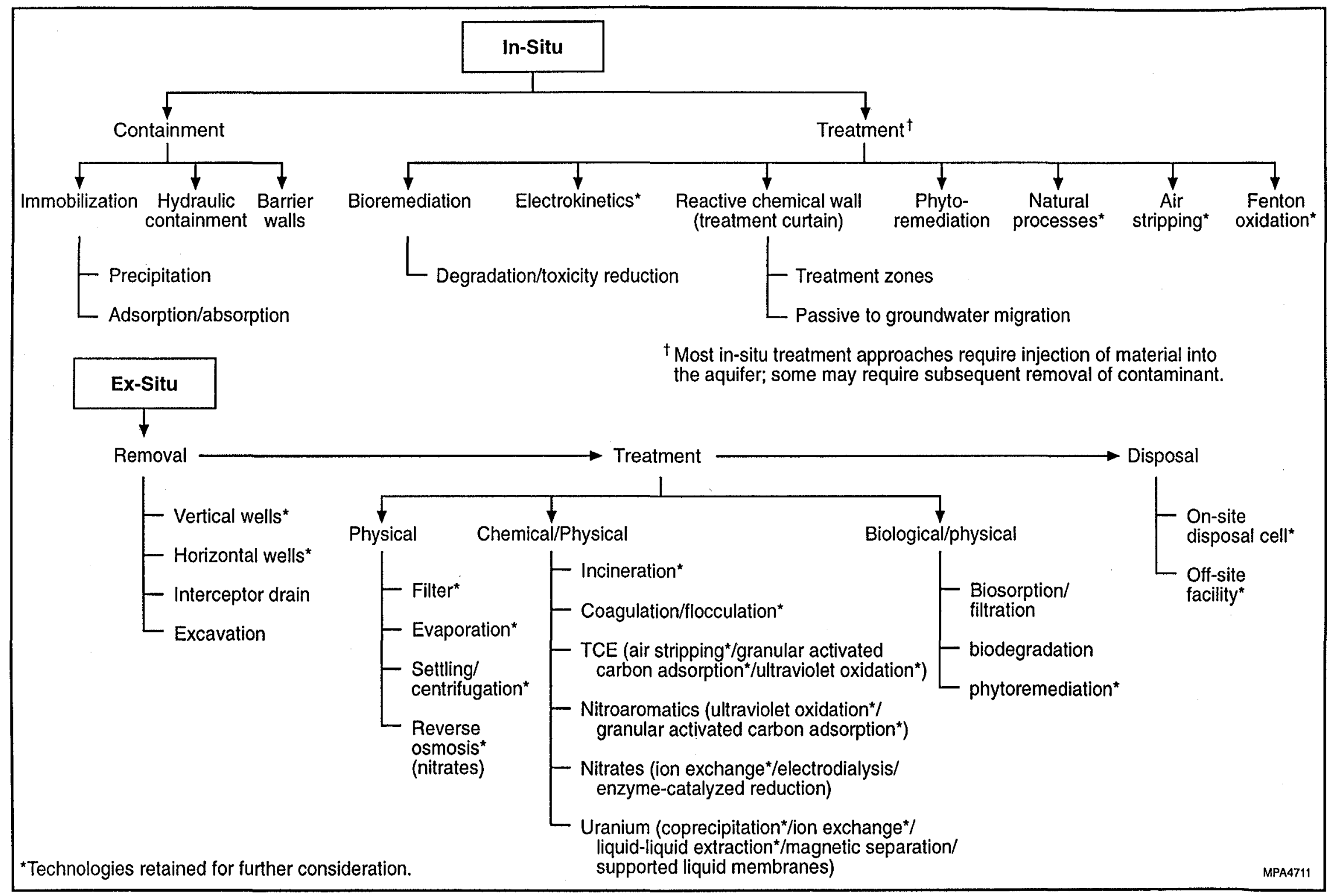


These technologies were screened on the basis of effectiveness, implementability, and cost, defined as follows:

- Effectiveness - in terms of protecting human health and the environment in both the short and long term; minimizing toxicity, mobility, or volume; complying with ARARs; and achieving protection in a reasonable time frame.

- Implementability - in terms of technical feasibility, resource availability, and administrative feasibility.

- Cost - in terms of comparing costs (i.e., low, moderate, or high) in both the short term (capital) and long term (operation and maintenance [O\&M]) for technologies of similar performance and/or implementability.

\subsection{TECHNOLOGY IDENTIFICATION AND SCREENING}

\subsubsection{Monitoring}

Monitoring is a measure that provides data regarding contaminant concentrations. These data would also provide the necessary information to indicate the need for maintaining or implementing institutional controls during and after remedial actions.

\subsubsection{Institutional Controls}

Institutional controls are measures that preclude or minimize public exposure by limiting access to or use of contaminated groundwater. Institutional controls include measures to restrict access, such as security guards, ownership, and use or deed restrictions. These measures do not reduce contaminant toxicity, mobility, or volume, but they can reduce the potential for human exposure to the contaminated groundwater. Institutional controls that apply solely to groundwater, such as groundwater restrictions, may be used to prohibit or limit the drilling of wells for the purpose of groundwater consumption.

The screening analysis for institutional controls is summarized in Table 2.1. On the basis of effectiveness, implementability, and cost, all of these measures were retained for further consideration. 
TABLE 2.1 Summary of Screening Analysis for Institutional Controls

\begin{tabular}{lll}
\hline $\begin{array}{l}\text { Institutional Control } \\
\text { Measure }\end{array}$ & \multicolumn{1}{c}{ Effectiveness } & \multicolumn{1}{c}{ Implementability } \\
\hline $\begin{array}{l}\text { Groundwater access } \\
\text { restrictions }\end{array}$ & $\begin{array}{l}\text { The area where groundwater contamination } \\
\text { is highest could be restricted by imposing } \\
\text { barriers, such as well caps, which could } \\
\text { control exposure to contaminated } \\
\text { groundwater. }\end{array}$ & $\begin{array}{l}\text { Access restriction measures would be } \\
\text { easy to implement, and resources would } \\
\text { be readily available. }\end{array}$ \\
\hline Use restrictions & $\begin{array}{l}\text { The DOE and DA have accountability for } \\
\text { as long as contamination is present. This } \\
\text { measure would allow the control of public } \\
\text { exposure to on-site contamination by } \\
\text { restricting access and use. }\end{array}$ & $\begin{array}{l}\text { Lse restrictions are technically easy to } \\
\text { implement. However, agreements with } \\
\text { appropriate landowners (i.e., Missouri } \\
\text { Department of Conservation) would } \\
\text { have to be obtained before DOE and the } \\
\text { DA could implement use restrictions on } \\
\text { land that is not federally owned. }\end{array}$ \\
\hline
\end{tabular}

\subsubsection{Natural Processes}

Naturally occurring processes can contribute to cleaning up groundwater and soil contaminated with various toxic and hazardous materials. With time, these processes gradually reduce the hazards of contamination. Two types of natural processes can be considered: (1) physical/chemical processes whereby the contaminant concentration would be reduced through chemical or physical means, and (2) biological processes whereby the contaminant is broken down or absorbed by microbes or plants.

The first classification includes a number of processes such as dilution, absorption, adsorption, and chemical reactions. Biological processes, the second classification, includes two broad categories: accumulation and degradation by microbes and accumulation and degradation by plants.

Extensive, ongoing remedial actions at both the WSCP and the WSOW are expected to remove contaminated structures and soil to achieve site-derived cleanup levels. The remaining contamination in groundwater is expected to decrease over time because infiltration of rainwater and runoff will provide a clean source of water to dilute the contaminant concentrations in the aquifer.

The sorption process could also play a role in determining the fate of the contaminants in groundwater. Sorption of a contaminant refers to the tendency of contaminant molecules to be bound to the surface (adsorption) of and to internal sites (absorption) in the bulk solid phase of the aquifer. This process occurs primarily in the soil layers above the bedrock because the soil has more sorption sites. 
Two parameters are important in describing this interaction between the contaminant and the solid phase (soil). The total sorption capacity is proportional to the total number of available sorption sites. When all of the sorption sites are occupied, the sorption capacity is exhausted, and contaminant concentrations are no longer attenuated as the groundwater passes through the solid phase. A second parameter of importance is the strength of the binding between the contaminant and the sites in or on the solid phase. This strength is related to the value of a distribution coefficient, $\mathrm{K}_{\mathrm{d}}$. $\mathrm{K}_{\mathrm{d}}$ values are specific to a given contaminant in relation to a particular type of soil. Understanding the movement of a given contaminant through an aquifer depends in part on knowing the $K_{d}$ values for each soil type and the groundwater flow conditions.

The $\mathrm{K}_{\mathrm{d}}$ values for TCE, nitroaromatic compounds, and nitrate in soil at the WSCP and the WSOW are expected to be low (DOE and DA 1998b), which means that minimal sorption is expected to be taking place. On the other hand, the $\mathrm{K}_{\mathrm{d}}$ value for uranium is higher, which suggests that uranium is more likely to be sorbed than the other contaminants. Less sorption would be expected for all contaminants in the bedrock portion of the aquifer because of fewer accessible sorption sites. Adsorption of nitroaromatic compounds is prevented in the presence of highly hydrated cations such as $\mathrm{Ca}^{2+}$ (Haderlein et al. 1996); therefore, little, if any, adsorption of nitroaromatic compounds is expected to be occurring in the limestone bedrock. In any areas of high organic content in the aquifer (e.g., from decaying plants), there is a much higher probability of sorption (and reaction) of the organic contaminants and of uranium.

Chemical reactions occur when ions or compounds react with other species to form new ions or compounds. These reactions generally involve electron exchange or oxidation-reduction (redox), which results in the oxidation of one species (electron loss) and the reduction of the other (electron gain). One such example is the precipitation of uranium from solution as uranium dioxide $\left(\mathrm{UO}_{2}\right)$ following the reduction of the soluble $\mathrm{UO}_{2}{ }^{2+}$ ion. Thus, one controlling factor is the relative affinity of species for electrons. Another major controlling factor in chemical reactions involves the concentrations of the different species in solution and their equilibria with any solid phases. In a groundwater aquifer such as that at the WSCP and the WSOW, most of the chemical reactions taking place involve dissolved inorganic species. The majority of organic contaminants in the aquifer are more likely to be involved in biological degradation reactions.

Biological processes are important for the natural degradation of organic compounds in the environment. The degradation of TCE by various microbe populations has been extensively studied (Lu et al. 1989; Hopkins et al. 1993; Krumme et al. 1993; Enzien et al. 1994; Leahy et al. 1996). Intrinsic bioremediation of TCE has been shown to occur. At some sites, biological activity is being supported under anaerobic conditions by other organic contaminants such as acetone, methanol, or BTEX compounds (benzene, toluene, ethylbenzene, and xylenes), and the degradation of TCE is the result of cometabolism (Lee et al. 1995; Major et al. 1995; Wiedemeier et al. 1997). Cometabolism may also have played a role in degradation of TCE at other sites (Guest et al. 1995). The intrinsic anaerobic biodegradation of TCE has been observed in the absence of anthropogenic cometabolites 
such as acetone and methanol (Martin and Imbrigiotta 1994; Cox et al. 1995; Ellis et al. 1997; Weaver et al. 1997). Under such conditions, the microorganisms responsible for the degradation may be using naturally occurring organic carbon concentrations as a substrate (Wiedemeier et al. 1997). However, the vinyl chloride degradation product may also be degraded by iron (III) reduction or aerobic respiration (Weidemeier et al. 1997).

A number of investigators have examined the efficacy of microbial degradation as a mechanism for breaking up the nitroaromatic contaminants. Most of these studies have used preselected microbial communities rather than the natural indigenous community of microbes. The particular microbial communities studied have included sewage (Hallas and Alexander 1983), bioslurry (Funk et al. 1993), composting (Kaplan and Kaplan 1982), particular strains of bacteria (Spanggora et al. 1991; Boopathy et al. 1993, 1997), and particular fungi (Fernando et al. 1990; Valli et al. 1992). Only one study, which was carried out at a munitions-contaminated site (Bradley et al. 1994), used the indigenous microbial community present at the site.

Degradation of nitroaromatic compounds has been shown to occur under both aerobic and anaerobic conditions (Spain 1996). A number of studies have shown that microbial denitrification occurs in nitrate-contaminated groundwater (Smith and Duff 1988; Bottcher et al. 1990; Smith et al. 1996); however, because the process is electron-donor-limited (Smith et al. 1991), a carbon substrate such as ethanol must be added to stimulate activity. Accumulation or precipitation of uranium by microbes is also possible (Lovely et al. 1993; Barton et al. 1996; Uhrie et al. 1996).

Although TCE can be degraded by certain microbial populations, many factors appear to be important in determining the rate of degradation. The addition of a carbon substrate (e.g., toluene, benzene, or phenol) to supply energy to the microbes greatly enhances the degradation process; the microbes apparently are unable to derive much energy directly from the TCE. Therefore, any natural biological degradation of TCE at the WSCP might be expected to occur at a slow rate. Biological degradation of the nitroaromatic compounds could be occurring at the WSCP and the WSOW. Concentrations of nitroaromatic compounds in groundwater at the WSCP and the WSOW (DOE and DA 1998b) are not expected to be high enough to cause toxic shock (EPA 1993) for most microorganisms capable of degrading nitroaromatic compounds (Kaplan 1992). Nitrate might also be expected to be degraded in the aquifer because anaerobic conditions favor nitrate decomposition.

Plant (vegetation) activity can also accumulate or degrade TCE, nitroaromatic compounds, nitrate, and uranium in the environment (see Section 2.2.4.6). However, most of this activity occurs within a zone from the surface down to about $3 \mathrm{~m}(10 \mathrm{ft})$. Therefore, the natural vegetative activity at the WSCP and the WSOW is not expected to be a major factor in attenuating the contaminant concentrations at greater depths. 
The screening analysis for natural processes is summarized in Table 2.2. On the basis of this evaluation, natural processes have been retained as potentially applicable to attenuating contaminant concentrations in groundwater.

\subsubsection{In-Situ Containment}

In-situ (in-place) containment consists of technologies that confine contaminated groundwater at its current location. In-situ containment technologies include the erection of barrier walls, hydraulic containment, or immobilization of the contaminant species at its current location. These technologies reduce contaminant mobility and the associated potential for exposure, but, except for one variation of hydraulic containment, they do not reduce contaminant toxicity or volume.

Current groundwater discharges to surface water outside the WSCP and the WSOW do not contain contaminants at concentrations high enough to warrant remedial action, even though the groundwater travel times from the contaminated areas to outside surface waters may, in some instances, be on the order of a few hours. Therefore, the use of in-situ containment may not provide any benefit.

\subsubsection{Barrier Walls}

The use of a physical barrier to stop migration of contaminants through groundwater is not feasible at the WSCP and the WSOW because the contamination is too widespread and too deep in some areas, and a barrier would not be effective in controlling groundwater flow. Contamination in this region is spread out over several square miles (DOE and DA 1998b); a groundwater divide runs the length of the region. Therefore, two barrier walls would have to be erected, one on each side of the divide and each approximately $5 \mathrm{~km}(3 \mathrm{mi})$ long. The high cost of installing such long walls would not be reasonable because of the relatively low concentrations of contaminants in most affected areas within the region. Even if barriers were to be considered in localized areas, contamination has been found at depths greater than $15 \mathrm{~m}(50 \mathrm{ft})$ in bedrock in some areas. Implementing a barrier wall technology would therefore be difficult because conventional trenching equipment cannot be used at such depths or in bedrock formations. In addition, channeling of the groundwater flow through natural conduits in the shallow aquifer within the Burlington-Keokuk Limestone could not be effectively controlled (because of high hydraulic pressures in localized areas).

The screening analysis for in-situ containment is summarized in Table 2.2. The use of a physical barrier as potentially applicable to a groundwater remedial action was rejected on the basis of effectiveness, implementability, and cost. 
TABLE 2.2 Summary of Screening Analysis for In-Situ Containment and Treatment Measures

$\begin{array}{lll}\text { In-Situ Measure } \quad \text { Effectiveness } & \text { Implementability }\end{array}$

Natural processes

Immobilization

Bioremediation

Electrokinetics
Contaminant concentrations would decrease over time because of source removal and dilution. The primary water source is infiltration from rainwater and runoff, which provides a clean source of water to dilute the contaminant concentrations in the aquifer. Microbial degradation of TCE, nitroaromatic compounds, and nitrate might be occurring. Sorption of nitroaromatic compounds and uranium could be limiting groundwater concentrations of these contaminants.

A physical barrier - such as a slurry wall or plastic sheeting - could effectively reduce lateral migration. The barrier would act to confine contamination to the currently affected areas but would not lower the contaminant concentrations. However, local areas of high hydraulic pressure exerted by natural conduits underground would likely cause the barrier to fail.

Immobilization of the TCE, nitroaromatic compounds, nitrate, and uranium through either precipitation or adsorption/absorption would effectively remove the contaminants from the groundwater.

Microorganisms could be used in-situ to break down TCE, nitroaromatic compounds, and nitrate into less toxic materials. Such an approach cannot be used with uranium.

Underground electrodes cause preferential migration of chemical species in the aquifer to treatment zones at or around the electrodes. Shown to be effective for TCE in an unsaturated soil field test. The effectiveness of TCE in saturated bedrock is uncertain. The effectiveness of full-scale groundwater remediation for nitroaromatic compounds, nitrate, and uranium is not well established.
Occur naturally, but showing their effectiveness in reducing or affecting concentrations of nitroaromatic compounds and nitrate might be difficult. However, standard analytical procedures for determining effects of natural processes on TCE are available.

Could not be implemented by conventional methods and equipment because of the depth of contamination in bedrock.

Could not be implemented because of the low permeability of the aquifer.

Could not be implemented because the low permeability of the aquifer would preclude injection of the microorganisms and their feed.

Could be implemented by conventional methods and equipment.
Moderate

Moderate to high 
TABLE 2.2 (Cont.)

\begin{tabular}{|c|c|c|c|}
\hline In-Situ Measure & Effectiveness & Implementability & Cost \\
\hline Reactive wall & $\begin{array}{l}\text { A permeable barrier is placed across the } \\
\text { contaminated groundwater flow path. The } \\
\text { barrier contains species that either react } \\
\text { with the contaminant to remove it from } \\
\text { solution or catalyze the breakdown of the } \\
\text { contaminant. A number of materials have } \\
\text { been identified that are capable of removing } \\
\text { TCE, nitroaromatic compounds, nitrate, and } \\
\text { uranium from groundwater. }\end{array}$ & $\begin{array}{l}\text { Could not be implemented by conven- } \\
\text { tional methods and equipment because } \\
\text { of contamination in the bedrock and } \\
\text { the existence of natural underground } \\
\text { conduits. }\end{array}$ & High \\
\hline Air stripping & $\begin{array}{l}\text { Air is passed through the water in a well to } \\
\text { extract dissolved TCE, thereby generating a } \\
\text { recirculation pattern in the aquifer } \\
\text { surrounding the well. This technology is } \\
\text { known to be effective primarily for volatile } \\
\text { organic compounds like TCE. }\end{array}$ & $\begin{array}{l}\text { May be implementable in certain areas } \\
\text { of the WSCP. }\end{array}$ & Moderate \\
\hline Fenton oxidation & $\begin{array}{l}\text { Hydrogen peroxide }\left(\mathrm{H}_{2} \mathrm{O}_{2}\right) \text { and ferrous } \\
\text { sulfate }\left(\mathrm{FeSO} \mathrm{S}_{4}\right) \text { are injected into an aquifer } \\
\text { to produce hydroxyl radicals under acidic } \\
\text { conditions, which degrade (oxidize) most } \\
\text { organic contaminants, including TCE. }\end{array}$ & $\begin{array}{l}\text { Low and variable permeability make } \\
\text { implementation uncertain. }\end{array}$ & $\begin{array}{l}\text { Low to } \\
\text { moderate }\end{array}$ \\
\hline Phytoremediation & $\begin{array}{l}\text { Vegetation is used to preferentially absorb } \\
\text { contaminants from soil and groundwater } \\
\text { and either break down the contaminants or } \\
\text { retain them in the biomass of the vegetation. } \\
\text { Initial studies have shown that the measure } \\
\text { is effective with the contaminants of } \\
\text { interest, but only in near-surface layers. }\end{array}$ & $\begin{array}{l}\text { Implementation to a depth of } \\
\text { approximately } 15 \mathrm{~m}(50 \mathrm{ft}) \text { would take } \\
\text { a long time. }\end{array}$ & Low \\
\hline
\end{tabular}

\subsubsection{Hydraulic Containment}

Hydraulic containment of contaminants in an aquifer can be achieved through the use of pumping wells, injection wells, or a combination of the two (EPA 1996b). Hydraulic containment is also the primary objective of pump-and-treat systems. Further discussion of groundwater removal in pump-and-treat systems can be found in Section 2.2.5.

The hydraulic control exerted by a vertical pumping well relies on the creation of a capture zone where water is drawn toward the well. A line of wells with overlapping capture zones can be situated downgradient of the contamination to form a barrier to further migration. A different type of barrier to migration, a pressure ridge, can also be formed by injecting uncontaminated water through a series of injection wells. The resulting increase in hydraulic pressure prevents groundwater from flowing along its original path. Pressure ridges are often used in conjunction with 
pump-and-treat systems in which the treated water extracted from within the contaminated area is used for injection (EPA 1996b).

Implementation of hydraulic containment, other than pump-and-treat in specific localized areas (as discussed in Section 2.2.5), is not feasible. Creating a proper capture zone in this area may be problematic because of the low permeability (Cohen et al. 1994) found over most of the WSCP and the WSOW. Hydraulic conductivities in the WSCP range from $10^{-6}$ to $10^{-2} \mathrm{~cm} / \mathrm{s}$; the range in the WSOW is even lower at $10^{-8}$ to $10^{-5} \mathrm{~cm} / \mathrm{s}$ (DOE and DA 1998b). In the regions in the WSCP where the aquifer permeability is highest, such as the TCE-contaminated area south of the raffinate pits, hydraulic control by means of a downgradient capture zone would not be very effective compared to a pump-and-treat approach because of low groundwater flow rates. Because low levels of contamination are widespread, any attempt at confining higher contaminant concentrations in areas of higher permeability by means of pressure ridges would also result in the acceleration of contaminants away from the area on the other side of the pressure ridges.

The karst formations in the aquifer would also compromise the effectiveness of capture zones and pressure ridges in the areas of the WSCP and the WSOW. Identifying and containing all preferential flows in even a localized area would be impractical. For pressure ridges, it would be difficult to maintain the proper water pressures in these formations, or inordinately large amounts of water would have to be used in the attempt to maintain a uniform pressure ridge.

The screening analysis for in-situ containment is summarized in Table 2.2. The technology of hydraulic containment as potentially applicable to groundwater remedial action was rejected on the basis of effectiveness and implementability because of low permeability in most areas, widespread low levels of contamination, and the existence of preferential flow conduits.

\subsubsection{Immobilization}

Immobilization of the contaminant species in-situ relies on either precipitation of the dissolved contaminant out of solution through an induced chemical reaction, or binding (adsorption or absorption) of the contaminant by an immobile solid-phase material within the groundwater aquifer. Immobilization of TCE and nitroaromatic compounds through precipitation could not be implemented because chemical reaction changes the nature of the contaminant and generally leads to degradation in groundwater systems (see Sections 2.2.4 and 2.2.6 for discussion of degradation in in-situ and ex-situ treatment). Precipitation is also not feasible for nitrate because of the need to inject metals. Precipitation, including the use of microorganisms, could be used to immobilize uranium (Lovely et al. 1993; Barton et al. 1996; Uhrie et al. 1996), but the uranium concentrations in groundwater are only slightly above background levels. 
Either immobilization process, precipitation or binding, would require the injection of material into the aquifer. However, the low permeability of the aquifer at the WSOW (hydraulic conductivity ranges from $10^{-8}$ to $10^{-5} \mathrm{~cm} / \mathrm{s}$ ) and the WSCP (hydraulic conductivity ranges from $10^{-6}$ to $10^{-2} \mathrm{~cm} / \mathrm{s}$ ) makes injection impractical because large amounts of material would be required to bind the nitroaromatic compounds, especially in the case of clay-based sorption materials. Injection into the aquifer in the areas of higher permeability in the WSCP (hydraulic conductivity $\leq 10^{-2} \mathrm{~cm} / \mathrm{s}$ ) may still be problematic because of potential clogging of the injection wells and nonuniform delivery, which results from the bulky nature of the materials required to immobilize the organic contaminants by sorption - organic materials for TCE or nitroaromatic compounds or clays for nitroaromatic compounds.

The screening analysis for in-situ containment is summarized in Table 2.2. Because of the inability to inject the required types of materials into the aquifer, in-situ immobilization was eliminated from further consideration for groundwater remediation on the basis of implementability.

\subsubsection{In-Situ Treatment}

In-situ treatment consists of the use of technologies that treat the groundwater in place and generally remove or break down the contaminant in some form. The main advantage of in-situ treatment is that the groundwater can be treated without being brought to the surface, which could result in large cost savings. The main disadvantages of in-situ technologies are usually a longer treatment period and difficulty in verifying how well the process is working, especially in heterogenous aquifers. The in-situ treatment technologies considered for this analysis include bioremediation, electrokinetics, reactive walls, air stripping, Fenton-like reagents, and phytoremediation.

\subsubsection{Bioremediation}

In-situ bioremediation involves the use of microorganisms to degrade hazardous chemicals or compounds such as organics and nitrate into less complex, generally less toxic forms. Such an approach is not applicable to uranium in groundwater, although biosorption can be used to remove uranium from groundwater in an ex-situ process (see Section 2.2.6). Traditional in-situ groundwater bioremediation systems generally involve a series of injection wells or trenches to introduce oxygenated, nutrient-rich water to the contaminated aquifer; water is recovered by another series of wells downgradient of the contamination. The recovered water must also be treated and then discharged, either back into the aquifer (if local regulations permit), to surface water, or to a local sanitary wastewater treatment plant. 
The biodegradation of TCE is a well-known phenomenon and has been shown to occur under anaerobic conditions in both the laboratory and the field and under aerobic conditions in the laboratory (see Section 2.2.2). This process could also occur under aerobic conditions in the field (McCarty 1994). Biodegradation of nitroaromatic compounds has been extensively studied (Section 2.2.2); however, in-situ treatment is not recommended because of the potential mobility of intermediates and other difficulties such as problems with delivery of nutrient sources (EPA 1993). For biodegradation of nitrate, the anaerobic nature of most aquifers favors denitrification because oxygen competes with nitrate as an electron acceptor in the metabolism of microorganisms (Hiscock et al. 1991). However, for TCE and nitroaromatic compounds, the potential for biodegradation of nitrate is enhanced by the availability of oxidizable carbon to sustain the microorganisms.

Bioremediation of groundwater could be implemented only in limited areas at the WSCP because the low permeability of the aquifer (Section 2.2.3) would make injecting material (microorganisms and their feed) into the aquifer difficult. In addition, the heterogeneous nature of the aquifer in these areas precludes the uniform delivery of this material, thus making implementability highly questionable.

The screening analysis for in-situ treatment is summarized in Table 2.2. Because of the inability to inject materials into the aquifer, bioremediation was rejected from further consideration at the WSCP and the WSOW on the basis of implementability.

\subsubsection{Electrokinetics}

Technologies involving electrokinetics rely on the transport phenomena associated with the application of a voltage between implanted electrodes in porous media. These phenomena include electrophoresis (movement of a charged particle or colloid in an electric field), electromigration (movement of solute ions in an electric field), and electroosmosis (movement of water in response to an electric field). Once the contaminants reach an electrode, they can be extracted to a recovery system (ex-situ treatment), treated in a reaction zone surrounding the electrode, or deposited (precipitated, adsorbed, or electroplated) at the electrode. Electrokinetics is potentially applicable for treating TCE, nitrate, and uranium (Acar et al. 1993; Trombly 1994; EPA 1995b; Van Cauwenberghe 1997) found at the WSCP and the WSOW.

The feasibility of using electrokinetics at the WSCP and the WSOW is uncertain because of the relative newness of the technology, the depth of contamination, and the presence of contamination in both overburden and bedrock. The application of electrokinetics to full-scale remediation of nitrate- or uranium-contaminated sites is not established. For TCE, a limited field test has been conducted successfully in unsaturated soil (Shannon 1995). However, the effectiveness of electrokinetics to treat the TCE-contaminated area in the saturated zone near raffinate pits 3 and 4 
is highly uncertain. Contamination is present in both the overburden and the bedrock at depths exceeding $15 \mathrm{~m}(50 \mathrm{ft})$. Also, extensive research and development would be required before electrokinetics could be applied to the TCE-contaminated area in order to optimize the removal process, because of the technology's dependence on several compositional (chemical makeup) and environmental (e.g., water content, soil homogeneity) variables. Currently, no full-scale remediation of TCE, nitroaromatic compounds, nitrate, or uranium using electrokinetics has been reported for any sites in the United States.

The screening analysis for in-situ treatment is summarized in Table 2.2. Electrokinetics has been rejected as potentially applicable to remediating the TCE contamination at the WSCP because its effectiveness and implementability in groundwater have not yet been demonstrated.

\subsubsection{Reactive Walls}

A technology involving the construction of a physical barrier to halt contaminated groundwater migration (Section 2.2.3.1) is the use of a reactive chemical wall. Barrier walls could be erected that would funnel the flowing groundwater into treatment zones where the contaminant(s) would be extracted. Another variation of the reactive wall concept would be construction of a wall filled with material that has an affinity for sorption or reaction (precipitation or degradation) with the contaminant. With this method, the contaminant is preferentially removed from the groundwater as the groundwater passes through this more passive chemical wall (permeable treatment wall) during natural migration through the aquifer.

The use of a reactive wall with treatment zones to extract contaminants in groundwater at the WSCP and WSOW is not warranted, because these zones would have to be maintained indefinitely to treat small amounts of groundwater with low levels of contamination until the contaminant concentrations decreased below levels of concern. However, a variation of this technology - a passive, permeable chemical wall - could be constructed, left to filter the groundwater, and monitored periodically. Like the reactive wall, some maintenance is also required. The wall material would need to be excavated, disposed of, and replaced with fresh material once it was saturated with the contaminants. Field tests or commercial applications of permeable walls have already been employed to treat groundwater for TCE, nitrate, and uranium (Vidic and Pohland 1996). Also, some natural clays have been shown to have good adsorption properties for nitroaromatic compounds such as TNT (Haderlein et al. 1996; Weissmahr et al. 1997). Implementing this approach would require further characterization of the chemical systems operating in the aquifer, and, like the physical barrier discussed in Section 2.2 .3 , the reactive wall would need to be maintained indefinitely.

Placing long reactive walls to treat the contamination found over the entire WSOW and WSCP areas is impractical. For localized applications, the major obstacles to the use of a reactive 
wall at the WSCP and WSOW are the same as those for a barrier wall: depth of contamination in the aquifer, installation in bedrock, and presence of natural groundwater conduits. Therefore, reactive walls were not considered further as an in-situ treatment technology, as summarized in Table 2.2.

\subsubsection{Air Stripping}

In-situ air stripping (also known as in-well vapor stripping or in-situ vapor stripping) is a potential technology for the removal of TCE from the groundwater at the southwest corner of the WSCP. A typical setup (Miller and Roote 1997) involves a well that has screens in both the upper and lower intervals. Air is injected from the surface into a region near the lower screen inside the well, resulting in an upward flow within the well because of the decreased density of the groundwater. As the air bubbles rise, VOCs such as TCE transfer from the dissolved to the vapor phase. The upper screen is situated just below or above the top of the contaminated aquifer where the less-contaminated groundwater exits the well back into the aquifer. The contaminated air discharged at the top of the well is vacuum-extracted for VOC vapor treatment. This arrangement results in a recirculating pattern of groundwater around each well; water enters at the bottom and exits at the top. One commercial application of this technology is the NoVOCs ${ }^{\mathrm{TM}}$ process (Miller and Roote 1997). Air injection also has the added potential to enhance aerobic biological degradation processes in an aquifer.

The TCE plume near the raffinate pits at the WSCP might be amenable to remediation with in-situ air stripping because of the permeability of the groundwater aquifer. The plume is located near one of the regions of highest permeability in the area; the hydraulic conductivity is in the $10^{-3}$ to $10^{-2} \mathrm{~cm} / \mathrm{s}$ range (MK-Ferguson Company and Jacobs Engineering Group, Inc. 1990a). However, some of the TCE lies within the Burlington-Keokuk Limestone formation, which is highly fractured in the upper weathered portion; the horizontal fractures along the bedding planes outnumber the vertical fractures by a ratio of about 20:1 (DOE and DA 1998b). These conditions might prevent establishment of a recirculation pattern around an air stripping well; the water discharged at the top of the well would actually push contaminated water away from the well through the horizontal fractures because the groundwater's travel in the vertical direction is more limited.

Because of the potential effectiveness of air-stripping in removing the TCE, this technology has been retained for further consideration, as summarized in Table 2.2. However, a field test of this technology would be required before full-scale implementation, because of the uncertainties related to the aquifer's permeability and the horizontal-to-vertical flow ratio. 


\subsubsection{Fenton-Like Reagents}

Another potential technology for remediating TCE contamination at the WSCP is a Fentonlike process. The general process involves the introduction of Fenton like reagents (e.g., hydrogen peroxide $\left[\mathrm{H}_{2} \mathrm{O}_{2}\right]$ and a ferrous ion $\left[\mathrm{Fe}^{2+}\right]$ such as ferrous sulfate $\left.\left[\mathrm{FeSO}_{4}\right]\right)$ into an aquifer with organic contamination. Reaction of $\mathrm{H}_{2} \mathrm{O}_{2}$ with $\mathrm{FeSO}_{4}$ produces hydroxyl radicals, which are strong oxidants. The hydroxyl radicals in turn react with most organic contaminants at rates close to the theoretical limit, which is controlled by the diffusion rate in water. The advantages of such a technology include the potential full mineralization of TCE to form oxygen, carbon dioxide, and chloride ions $\left(\mathrm{O}_{2}, \mathrm{CO}_{2}\right.$, and $\mathrm{Cl}^{-}$); the potential application to remediating the nitroaromatic compound contamination; and the ability of the $\mathrm{H}_{2} \mathrm{O}_{2}$ to follow the TCE in the aquifer because both are heavier than water.

The use of Fenton's reagent for groundwater remediation of organic compounds is relatively new. Application to TNT and 2,4-DNT groundwater remediation has been limited to lab-scale testing (Mohanty and Wei 1993; Li et al. 1997). Laboratory studies (Gates and Siegrist 1995), in-situ field tests for degradation of TCE contamination in groundwater (Andrews et al. 1997; Pucik et al. 1997), and site remediation (Vigneri 1996) have shown promising results.

However, a number of potential problems are related to the application of Fenton's reagent technology to the TCE-contaminated aquifer (or other areas with nitroaromatic contamination) at the WSCP and the WSOW. Thorough mixing of the Fenton's reagent with the contaminated groundwater (uniform delivery) is necessary for effective remediation (Venkatadri and Peters 1993). Uniform delivery may be difficult because of the karst conditions of the aquifer and the variability in the hydraulic conductivity, which is approximately $10^{-5} \mathrm{~cm} / \mathrm{s}$ or less over most of the WSCP and WSOW area. The hydraulic conductivity is as high as approximately $10^{-2} \mathrm{~cm} / \mathrm{s}$ in the TCEcontaminated portion of the aquifer. However, the variability of the permeability in this area (down to a hydraulic conductivity of approximately $10^{-6} \mathrm{~cm} / \mathrm{s}$ near monitoring well MWS-21) and the karst conditions would again cause problems with uniform delivery.

The screening analysis for in-situ treatment is summarized in Table 2.2. The use of Fentonlike reagents was retained as potentially applicable to remediation of the TCE-contaminated groundwater at the WSCP.

\subsubsection{Phytoremediation}

Phytoremediation is a recently recognized technology that uses vegetation (plants) to remove contaminant concentrations from soil and groundwater in-situ. The process can be applied to metals contamination through extraction or stabilization. Organic compounds are remediated through degradation or extraction. Application of phytoremediation is dependent upon the depth of 
contamination and the selection of plant species appropriate to the type and amount of contamination, cleanup standard, and climate.

One aspect of phytoremediation is exploitation of the enhanced microbial populations that coexist with a plant's root system (the rhizosphere). Within the rhizosphere, plants contribute the carbonaceous substrate and oxygen transfer for in-situ biodegradation. Rhizodeposition is partially the result of the decay of dead roots and root hairs. Also important to the process are root exudations, such as leakage from epidermic cells, secretions resulting from metabolic activity, mucilage from root tips, and lysates from sloughed cells. This resultant carbonaceous material stimulates overall bacterial activity and provides substrate for cometabolic degradation of xenobiotic hydrocarbons.

The dominant active mechanism for phytoremediation of metals such as uranium is phytoextraction into the tissue of the plant (Cornish et al. 1995; Cooney 1996). Plant enzymes are responsible for the degradation of TNT (Schnoor et al. 1995), which may be degraded either in the rhizosphere or after uptake by the plant (Hughes et al. 1997). For some organics such as TCE, some of the organic contaminants may be transpired to the atmosphere before complete degradation in the plant following phytoextraction (Gordon et al. 1996). The mechanism for metal accumulation includes chelation, precipitation, compartmentalization, and translocation. To successfully apply this technology to a site contaminated with metals, the $\mathrm{pH}$, organic complexes, and interfering elements must be assessed, and the plant species used must have the appropriate metal selectivity. In some instances, it may be necessary to apply soil amendments to enhance the process.

Application of phytoremediation for removing TCE, nitroaromatic compounds, nitrate, and uranium is promising. However, a depth limitation of approximately $3 \mathrm{~m} \mathrm{(10} \mathrm{ft)} \mathrm{(Miller} \mathrm{1996a)}$ precludes its use for remediation of the groundwater at the WSCP and the WSOW because contamination has been detected at depths of $15 \mathrm{~m}$ (50 ft) or more at some locations. Other issues also need resolution, such as the relatively long times necessary to reach remediation goals, subsequent handling and disposition of accumulated biomass, securing plants from other bioaccumulators (wild fauna), and introduction of nonnative plants for phytoremediation (Negri and Hinchman 1996).

The screening analysis for in-situ treatment is summarized in Table 2.2. Phytoremediation was rejected as a remediation technology on the basis of implementability (the technology is limited to an effective depth of about $3 \mathrm{~m}[10 \mathrm{ft}]$ ).

\subsubsection{Removal of Groundwater from the Aquifer}

Remediation of groundwater with ex-situ treatment requires that the contaminated groundwater first be extracted from the aquifer. The groundwater removal technologies investigated for the WSCP and the WSOW included the use of vertical wells, horizontal wells, interceptor drains, and excavation. 


\subsubsection{Vertical Wells}

The use of vertical wells is most common in pump-and-treat technologies for groundwater remediation. However, the low permeability of the aquifer at the WSOW and a large portion of the WSCP with hydraulic conductivities on the order of $10^{-5} \mathrm{~cm} / \mathrm{s}$ or less preclude the use of such wells. Well yields are typically about $1 \mathrm{~L} / \mathrm{min}(0.3 \mathrm{gpm})$ or less at the WSCP (MK-Ferguson Company and Jacobs Engineering Group, Inc. 1990a). A significant increase in pumping capacity, as much as a factor of 100 , has been observed at other remediation sites where fracturing of the surrounding consolidated aquifer material was carried out (Miller 1996b). Such an approach applies hydro-, pneumatic-, or blast-fracturing methods to bedrock material. Most materials other than bedrock only deform under such treatment, and pumping capacity is not improved.

The use of vertical wells for groundwater extraction at the WSCP may be feasible without fracturing because of the higher permeability of the groundwater aquifer in the vicinity of the raffinate pits and well MW-2009, where the hydraulic conductivity is on the order of $10^{-3}$ to $10^{-2} \mathrm{~cm} / \mathrm{s}$. Fracturing methods in the TCE-contaminated area near the raffinate pits should be used with caution because any vertical fractures might allow TCE to penetrate deeper into the bedrock. Because the TCE contamination does not exist as a dense, nonaqueous phase liquid (DNAPL) at the site, its migration downward into any induced fractures will be slow, because it is dissolved in the groundwater and is expected to be captured at the start of pumping operations. Confining the fracturing operations to the contaminated layers will also reduce the risk of contaminating underlying layers. However, there is concern that fracturing operations would be detrimental to the integrity of the nearby disposal cell that is already under construction at the WSCP.

Also of concern is the potential effectiveness of using vertical wells to capture any contaminant, because of the karst nature of the contaminated aquifer at the WSOW and the WSCP (Mugel 1997). Accounting for and containing all preferential flow conduits is impractical. Small, unknown flow channels can severely compromise the effectiveness of a single vertical well, which in turn limits the effectiveness of the entire pump-and-treat network.

The screening analysis for removal of groundwater from the aquifer is summarized in Table 2.3. Vertical wells have been retained as potentially applicable to removing groundwater in limited areas at the WSCP where the permeability of the aquifer is highest.

\subsubsection{Horizontal Wells}

The use of horizontal wells is a more advanced technology than the use of vertical wells. Horizontal wells could be drilled through the aquifer in an effort to increase the area available for pumping the groundwater. Two methods commonly used to position the wells are directional drilling and trenching. Excavating a trench and partially backfilling it with porous material over a horizontal 
TABLE 2.3 Summary of Screening Analysis for Groundwater Removal

\begin{tabular}{|c|c|c|c|}
\hline Removal Measure & Effectiveness & Implementability & Cost \\
\hline Vertical wells & $\begin{array}{l}\text { Standard method for removing ground- } \\
\text { water from an underground aquifer. }\end{array}$ & $\begin{array}{l}\text { Very difficult to implement. The low } \\
\text { permeability of the aquifer precludes } \\
\text { reasonable pump rates, except for } \\
\text { limited locations at the WSCP. Pump } \\
\text { rates might be increased by fracturing of } \\
\text { the bedrock. }\end{array}$ & $\begin{array}{l}\text { Low to } \\
\text { moderate }\end{array}$ \\
\hline Horizontal wells & $\begin{array}{l}\text { Larger surface area available for } \\
\text { collecting groundwater than a conven- } \\
\text { tional vertical well; which results in } \\
\text { higher pump rates. }\end{array}$ & $\begin{array}{l}\text { Very difficult to implement. The low } \\
\text { permeability of the aquifer precludes } \\
\text { reasonable pump rates except for limited } \\
\text { locations at the WSCP. Pump rates } \\
\text { might be increased by fracturing of the } \\
\text { bedrock. }\end{array}$ & Moderate \\
\hline Interceptor drain & $\begin{array}{l}\text { A trench placed downgradient of the } \\
\text { contamination on both sides of the } \\
\text { groundwater divide could intercept all } \\
\text { contaminated groundwater leaving the } \\
\text { area. The groundwater that collected in } \\
\text { the trench could then be pumped out } \\
\text { for treatment. }\end{array}$ & $\begin{array}{l}\text { Could not be implemented with conven- } \\
\text { tional methods and equipment in a } \\
\text { bedrock aquifer. }\end{array}$ & Moderate \\
\hline $\begin{array}{l}\text { Excavation/dredging } \\
\text { and pumping }\end{array}$ & $\begin{array}{l}\text { Could effectively remove contaminated } \\
\text { material in the aquifer. The original } \\
\text { sources of groundwater contamination } \\
\text { have been removed or are in the } \\
\text { process of being removed. The } \\
\text { contaminant concentrations in the } \\
\text { aquifer material are expected to be low. }\end{array}$ & $\begin{array}{l}\text { Could not be implemented with conven- } \\
\text { tional equipment and procedures in a } \\
\text { bedrock aquifer. }\end{array}$ & High \\
\hline
\end{tabular}

well pipe can increase the pumping capacity of a well and is similar in concept to fracturing of the aquifer around the well intake. However, excavating trenches for this application is not feasible because certain locations at the WSCP and the WSOW often contain contamination down to an

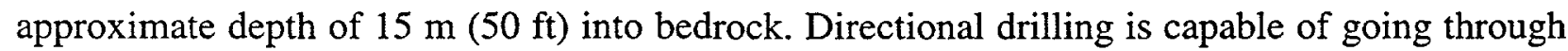
bedrock and might be feasible for installing horizontal wells at the WSCP and the WSOW.

The screening analysis for removal of groundwater from the aquifer is summarized in Table 2.3. Horizontal wells have been retained as potentially applicable to removing groundwater in regions of higher permeability at the WSCP. 


\subsubsection{Interceptor Drains}

An interceptor trench drain could be installed to further increase groundwater recovery. A trench placed perpendicular to the groundwater flow would intercept the contaminated groundwater. The trench could be backfilled with porous material so that the entire side of the trench would act as a sink for the groundwater, which would be pumped to a treatment facility. The advantages of a trench are its simplicity and effectiveness; when properly positioned, it can ensure that any contaminated water is intercepted. Implementation of a remediation strategy using an interceptor trench has similar problems to those discussed for barrier walls (Section 2.2.3.1) and reactive walls (Section 2.2.4.3) for a broad or local implementation. It would be impractical to construct two

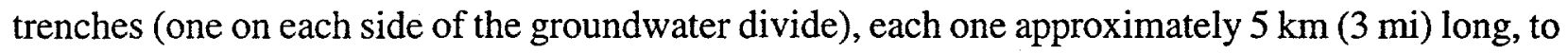
capture all of the contamination, which is widely scattered and at relatively low levels in most locations. Implementation of an interceptor drain on a smaller scale for containing areas of higher contamination is not feasible because contaminants have been detected at depths to at least $15 \mathrm{~m}$ $(50 \mathrm{ft})$ in bedrock at both the WSCP and the WSOW. Thus, the interceptor drain technology for groundwater removal was rejected, as shown in Table 2.3.

\subsubsection{Excavation}

Because of the low permeability of the aquifer at the WSOW and a large portion of the WSCP (hydraulic conductivity $\leq 10^{-5} \mathrm{~cm} / \mathrm{s}$ ), an alternative to pumping or draining the contaminated groundwater from the aquifer would be to excavate the aquifer material for treatment and disposal. Conventional earthmoving equipment (e.g., bulldozers, backhoes, and front-end loaders) would be used in conjunction with hydraulic dredges and pumps. Any uncontaminated overlying soil could be stripped off and replaced after removal of the underlying contaminated aquifer material. However, because the contamination is so widespread and the contaminant concentrations are relatively low, little would be gained by excavating the aquifer material. Also, the contaminant sources have been or are in the process of being removed. It would be impractical to excavate such large volumes of aquifer materials and any of the bedrock that contains contaminated groundwater.

The screening analysis for removal of groundwater is summarized in Table 2.3. Excavation was rejected from further consideration on the basis of the low contaminant concentrations in the aquifer material and implementability (i.e., the large volume of material and difficulty in removing bedrock). 


\subsubsection{Ex-Situ Treatment}

Ex-situ treatment consists of technologies that treat the groundwater and any contaminated soil or sludge after removal from the aquifer. The many methods available for treating contaminated groundwater rely on the physical, chemical, or biological properties of the contaminants.

\subsubsection{Physical Methods}

Settling or Centrifuge. Settling (sedimentation) tanks for removal of suspended solids constitute one of the first stages of many water treatment plants. Settling tanks allow these nondissolved solids (approximately $10 \mu \mathrm{m}$ in diameter or larger) to settle to the bottom of the tank under the influence of gravity. After an appropriate time period, the clarified water may then be drawn off and sent on to the next phase of treatment. Centrifuges may also be used to remove suspended particles from solution. In addition, settling tanks may be used in conjunction with chemical precipitation treatments.

Filtration. Filtration is another process found in many water treatment plants. Like settling, filtration is used for removing suspended solids. Filters may consist of a single thin membrane (typically a polycarbonate) or a granular medium (typically sand in a filter bed). The driving force is either gravity or a pressure differential such as applied pressure or an induced vacuum. Filtration processes are relatively simple to operate and maintain, and like settling, filtration is an old and proven technology. Filtration is often used in conjunction with chemical precipitation processes.

Evaporation. Evaporation is used primarily for reducing the volume of contaminated water or sludge wastes and for concentrating nonvolatile contaminants such as nitroaromatic compounds, nitrate, and uranium. Any volatile contaminants (such as TCE) must be removed prior to this treatment process. Evaporation of water leaves behind all nondissolved and dissolved solids. The treated waste must then be mechanically removed for further treatment or disposal. Evaporation ponds are often used as retention areas for treated wastewater in between treatment steps. Evaporation is a well-established treatment process.

Reverse Osmosis. Reverse osmosis is commonly used to remove dissolved species from solution. Osmosis is the tendency of a solvent such as water to pass through a semipermeable membrane from the side with a lower solute (dissolved species) concentration to the side with a higher solute concentration in an attempt to equalize concentrations on both sides of the membrane. The membrane is semipermeable in that it permits migration of water but not the dissolved species. 
This process may be reversed (reverse osmosis) by applying pressure to the side with a high solute concentration. The dissolved species thus become more concentrated, thereby reducing the volume of contaminated water. Reverse osmosis is very effective at removing almost all dissolved species. This process is an established method often used for treating water contaminated with nitrate (Canter 1997; Kapoor and Viraraghavan 1997) or uranium (EPA 1993).

Summary. The screening analysis for ex-situ treatment of groundwater is summarized in Table 2.4. All physical treatment technologies were retained for possible use in conjunction with groundwater extraction.

\subsubsection{Chemical Methods}

Coagulation/Flocculation. Coagulation is a chemical treatment process in which chemicals are added to promote particle growth under flocculation, a physical process that increases particle collisions through slow mixing with large blades or paddles. Coagulation/flocculation is often used in conjunction with precipitation processes or as a component in a settling or filtration treatment stage.

Precipitation. Precipitation of inorganic contaminants in water is induced by a chemical reaction that converts a soluble contaminant species to an insoluble form. The precipitate is then removed through sedimentation or filtration. One advantage of precipitation treatments is the relatively low waste volumes produced. Because of the diverse chemical species found in groundwater, selection of the proper chemicals for use generally requires bench and field studies that often include $\mathrm{pH}$ adjustment for optimum results. Precipitation is an effective and well-established treatment for many contaminants and has been a primary treatment for metals in industrial waste waters for years (DOD 1994). Lime softening is one precipitation process that has an efficiency of approximately 85 to $99 \%$ for removal of dissolved uranium (EPA 1993).

Ion Exchange. Ion exchange is a process in which ions of interest are exchanged for other ions held on an insoluble exchange material. The exchange material is generally a synthetic organic resin that is stable under a wide range of temperature and $\mathrm{pH}$ conditions. These materials can be tailored to be highly specific toward a given ion. Once a resin becomes saturated with the target ion, the resin can be regenerated using a highly concentrated solution of the relatively harmless, originally bound ion. This solution shifts the equilibrium back to the original state of the resin and leaves a solution concentrated in the target (contaminant) ion. Ion exchange is a well-established treatment 
TABLE 2.4 Summary of Screening Analysis for Ex-Situ Treatment Measures

\begin{tabular}{|c|c|c|c|}
\hline Ex-Situ Measure & Effectiveness & Implementability & Cost \\
\hline $\begin{array}{l}\text { Settling/centrifugation } \\
\text { (clarification) }\end{array}$ & $\begin{array}{l}\text { Preliminary step to separate suspended solids } \\
\text { from the extracted groundwater. }\end{array}$ & Easy to implement. & Low \\
\hline Filter & $\begin{array}{l}\text { Preliminary step to separate suspended solids } \\
\text { from the extracted groundwater. }\end{array}$ & $\begin{array}{l}\text { Easy to implement with existing } \\
\text { water treatment technology. }\end{array}$ & Low \\
\hline Evaporation & $\begin{array}{l}\text { Consolidates suspended and dissolved solids } \\
\text { by driving off the water. The resulting } \\
\text { contaminated solid can be sent for disposal. }\end{array}$ & Easy to implement. & Low \\
\hline $\begin{array}{l}\text { Coagulation/ } \\
\text { flocculation }\end{array}$ & $\begin{array}{l}\text { Used to enhance filtration and settling } \\
\text { processes. }\end{array}$ & Easy to implement. & Low \\
\hline Reverse osmosis & $\begin{array}{l}\text { Potential preliminary step for treatment. } \\
\text { Effective at concentrating dissolved } \\
\text { contaminants in solution. }\end{array}$ & $\begin{array}{l}\text { Could be implemented with } \\
\text { existing technology. }\end{array}$ & Moderate \\
\hline Precipitation & $\begin{array}{l}\text { Conventional method for extracting uranium } \\
\text { from solution. Dependent on dissolved } \\
\text { species. }\end{array}$ & $\begin{array}{l}\text { Could be implemented with } \\
\text { existing technology. }\end{array}$ & Moderate \\
\hline Ion exchange & $\begin{array}{l}\text { Conventional method for extracting uranium } \\
\text { and nitrate from solution. Dependent on } \\
\text { dissolved species. }\end{array}$ & $\begin{array}{l}\text { Could be implemented with } \\
\text { existing technology. }\end{array}$ & Moderate \\
\hline $\begin{array}{l}\text { Liquid-liquid } \\
\text { extraction }\end{array}$ & $\begin{array}{l}\text { Conventional method for extracting uranium } \\
\text { from solution. Dependent on dissolved } \\
\text { species. }\end{array}$ & $\begin{array}{l}\text { Could be implemented with } \\
\text { existing technology. }\end{array}$ & Moderate \\
\hline Magnetic separation & $\begin{array}{l}\text { Newer technology for extracting dissolved } \\
\text { metals; being investigated for remediation } \\
\text { programs. }\end{array}$ & Implementation questionable. & High \\
\hline $\begin{array}{l}\text { Supported liquid } \\
\text { membranes }\end{array}$ & $\begin{array}{l}\text { Newer technology for extracting dissolved } \\
\text { metals; being investigated for remediation } \\
\text { programs. }\end{array}$ & Implementation questionable. & High \\
\hline Ultraviolet oxidation & $\begin{array}{l}\text { Conventional method for degradation of } \\
\text { nitroaromatic compounds and TCE. }\end{array}$ & $\begin{array}{l}\text { Could be implemented with } \\
\text { existing technology. }\end{array}$ & Moderate \\
\hline $\begin{array}{l}\text { Granular activated } \\
\text { carbon }\end{array}$ & $\begin{array}{l}\text { Conventional method for extracting TCE from } \\
\text { vapor and for extracting TCE and nitro- } \\
\text { aromatic compounds from solution. }\end{array}$ & $\begin{array}{l}\text { Could be implemented with } \\
\text { existing technology. }\end{array}$ & Moderate \\
\hline Incineration & $\begin{array}{l}\text { Supporting measure. Conventional method for } \\
\text { destruction of organic compounds and waste } \\
\text { volume reduction. }\end{array}$ & $\begin{array}{l}\text { Could be implemented with } \\
\text { existing technology. }\end{array}$ & Moderate \\
\hline Electrodialysis & $\begin{array}{l}\text { Effective at extracting nitrate from drinking } \\
\text { water. }\end{array}$ & $\begin{array}{l}\text { Could be implemented with } \\
\text { existing technology. }\end{array}$ & High \\
\hline
\end{tabular}


TABLE 2.4 (Cont.)

\begin{tabular}{llll}
\hline \multicolumn{1}{c}{ Ex-Situ Measure } & \multicolumn{1}{c}{ Effectiveness } & Implementability & Cost \\
\hline $\begin{array}{l}\text { Enzyme-catalyzed } \\
\text { reduction }\end{array}$ & $\begin{array}{l}\text { Newer technology under development for } \\
\text { extracting nitrate from drinking water. }\end{array}$ & Implementation questionable. & High \\
Biodegradation & $\begin{array}{l}\text { Newer technology under development for } \\
\text { degradation of TCE, nitroaromatic } \\
\text { compounds, and nitrate by microorganisms; } \\
\text { being investigated for remediation programs. }\end{array}$ & Implementation questionable. & High \\
& $\begin{array}{l}\text { Newer technology under development for } \\
\text { extracting dissolved metals; being investigated } \\
\text { for remediation programs. }\end{array}$ & Implementation questionable. \\
Biosorption & $\begin{array}{l}\text { Constructed wetlands could remove/degrade } \\
\text { TCE, nitroaromatic compounds, nitrate, and } \\
\text { uranium from extracted groundwater. }\end{array}$ & $\begin{array}{l}\text { Could be implemented with } \\
\text { existing technology. }\end{array}$ \\
\hline
\end{tabular}

for many contaminants and is widely used for the treatment of nitrate (Canter 1997) and uranium (DOE 1991).

Liquid-Liquid Extraction. Liquid-liquid extraction involves the complexation of an inorganic species such as a dissolved uranium ion with an organic compound. The contaminated aqueous solution is then mixed with an organic solvent that is not soluble in water. The complexed species is designed to be more soluble in the organic solvent than water, and therefore is preferentially extracted into the organic liquid phase, which is subsequently drawn off from the aqueous phase. This method can be highly selective toward a single contaminant in a complex solution. Liquid-liquid extraction has been used extensively in the nuclear industry for processing spent nuclear fuel to separate uranium and plutonium (Ivanovich and Harmon 1992). However, the involvement of an organic liquid phase, often a hazardous chemical itself, relegates this method to operations where other methods have proven ineffective.

Magnetic Separation. Two different types of magnetic separation processes have recently been investigated for the remediation of contaminated groundwater - the Mag*Sep ${ }^{\mathrm{SM}}$ and highgradient magnetic separation (HGMS).

In the Mag*Sep ${ }^{\mathrm{SM}}$ process, engineered particles are injected into a liquid waste stream. The particles range in size from 25 to $300 \mu \mathrm{m}$, have a magnetic core, and are coated with a functionalized resin. The resin acts in a manner similar to ion-exchange resins; that is, it adsorbs selective target ions. After the particles have been in the contaminated water for an appropriate period of time, they 
are magnetically removed from solution (DOE 1996). Proponents claim the process is more selective than ion exchange and, therefore, produces less waste product. No full-scale commercial applications of this process for remediation of uranium in groundwater have been completed.

In the HGMS process, the contaminated fluid passes through a highly magnetized volume containing a magnetic matrix material such as steel wool. A slightly magnetic contaminant species such as uranium becomes attached to the matrix material and is then removed from solution. The process results in very small waste volumes. Application of this technology to water treatment is still in the research phase at Los Alamos National Laboratory.

Supported Liquid Membranes. A liquid membrane containing a complexing agent for a specific contaminant such as uranium is supported on a hollow-fiber membrane through which a liquid waste stream is passed. The complexing agent attaches to its target ion when the ion contacts the liquid membrane. The contaminant ion complex is then selectively passed through the membrane, where it comes into contact with a stripping solution. Supported liquid membranes have been studied for over 20 years for a variety of applications and more recently for the removal of uranium, chromium, and technetium from contaminated groundwaters (DOE 1995). The interest in the process is related to its high target specificity, which results in reduced waste volumes. Also, the recovered contaminant, such as uranium, would be in a reasonably pure form for potential reuse. However, no field tests have been reported.

Ultraviolet Oxidation. Ultraviolet (UV) oxidation is a treatment process for organic compounds that is also effective in the treatment of nitroaromatic compounds (DOD 1994). Its primary advantage over other methods, such as carbon adsorption, is its destruction of the contaminant compounds; it is capable of completely reducing the compounds to $\mathrm{CO}_{2}$, water, and salts through mineralization. The process involves exposing the contaminated water to strong UV light in the presence of strong chemical oxidizers such as ozone and/or $\mathrm{H}_{2} \mathrm{O}_{2}$. UV oxidation is an established treatment process and is readily available from commercial vendors.

Granular Activated Carbon. Carbon adsorption is very effective in treating wastewater contaminated with organics. Granular activated carbon (GAC) has a large surface area and has been used extensively in treating process waters at munitions plants (EPA 1993). This process involves the adsorption of organic contaminants on carbon surfaces as the wastewater is passed through a GAC filter. The contaminants are not destroyed, and the GAC in the filter must be further treated or disposed of. The materials for carbon adsorption are readily available from commercial vendors because it is a well-established technology for treating municipal, industrial, and hazardous wastes. 
Incineration. Incineration is not directly applicable to groundwater treatment but can be used to treat secondary waste products. The incineration of hazardous wastes is an effective technology for destruction of organic contaminants and can also be used for volume reduction of combustible wastes contaminated with inorganic contaminants. Furnace temperatures typically range from 870 to $1,200^{\circ} \mathrm{C}\left(1,400\right.$ to $\left.2,200^{\circ} \mathrm{F}\right)$. Incineration has been used for the destruction of nitroaromatic compounds in contaminated soils (EPA 1993). The equipment for this technology is readily available from commercial vendors.

Electrodialysis. Electrodialysis uses a direct electric current to transport ions through semipermeable membranes from solutions of low to high concentrations (Canter 1997; Kapoor and Viraraghavan 1997). Pretreatment of the water (e.g., filtration) is generally necessary to avoid fouling the membranes. The efficiency for the removal of nitrate from solution is comparable to that for reverse osmosis.

Enzyme-Catalyzed Reduction. The reduction of nitrate to nitrogen by enzymes has the advantage of destroying the contaminant rather than concentrating it (as in other physical/chemical processes such as ion exchange, reverse osmosis, or electrodialysis). While biodegradation of nitrate also destroys the nitrate, enzyme-catalyzed reduction does not involve the problem of maintaining cultures of microorganisms.

Summary. The screening analysis for ex-situ treatment of groundwater is summarized in Table 2.4. All chemical treatment technologies, except the supported liquid membrane and magnetic separation technologies for uranium, were retained for possible use in conjunction with groundwater extraction. The appropriate technologies would be selected on the basis of the chemical characteristics of the groundwater at the time of extraction. Enzyme-catalyzed reduction and electrodialysis were not retained for consideration for nitrate removal. Enzyme-catalyzed reduction is still a developmental technology, and electrodialysis is useful only for treating soft water and has high operating costs (Kapoor and Viraraghavan 1997). Ion exchange was retained for nitrate removal because it is an established process and is used at the quarry water treatment plant.

\subsubsection{Biological Methods}

Biodegradation. Biological treatment technologies involving microbial degradation are available for TCE, nitroaromatic compounds, and nitrate. The organic contaminants and nitrate can be broken down into less hazardous constituents by certain microorganisms (see Section 2.2.2). These remedial technologies are still in various stages of development, except for biological 
denitrification, which has been developed over the years to treat domestic wastewater (Canter 1997; Kapoor and Viraraghavan 1997). However, domestic wastewater generally has a high organic content that provides nutrients for the microorganisms, whereas most groundwater aquifers (such as that at the WSCP and the WSOW) have low organic content. Development of an appropriate bioreactor to treat nitrate in groundwater at the WSCP and the WSOW would be required.

Biosorption/Biotransformation. Biosorption of uranium by microorganisms is currently being studied for use in treating contaminated water. Microorganisms can be fixed in media in a filter bed or injected into solution, thus absorbing the uranium as the water is passed through the filter. Filtration or centrifugation of the biomass would be necessary for processes where the microorganisms were not fixed in a filter medium.

Biotransformation involves the oxidation or reduction of metals by microorganisms, which may result in conversion to an insoluble form. The precipitated form may then be removed through filtration or centrifugation. Both biosorption and biotransformation processes are still in the research stage for cleaning contaminated water.

Phytoremediation. Phytoremediation is a biological technology that can be used as an ex-situ treatment method (see Section 2.2.4.6). Irrigation of a constructed wetlands can be used to remove the contaminants by filtering the extracted groundwater. Advantages over other methods include lower cost, destruction of the contaminant (except for uranium), and lower final waste volumes.

Summary. No biological methods involving microbial degradation or biosorption were retained for ex-situ groundwater treatment, as summarized in Table 2.4, because of their developmental nature and the lack of clear advantages over physical and chemical methods. Phytoremediation was retained for future consideration as an ex-situ treatment technology.

\subsubsection{Disposal}

The disposal option supports other groundwater response actions. This option is limited to disposal of the by-products of other response actions. All solid contaminated waste resulting from

groundwater remediation would be sent to an off-site facility. Uncontaminated solid process waste could be disposed of off-site at a commercial facility, as appropriate. The treated groundwater could be discharged to the Missouri River or used for landscape irrigation. 


\subsection{POTENTIALLY APPLICABLE TECHNOLOGIES}

Potentially applicable technologies for groundwater remediation are summarized in Table 2.5. This summary is based on the screening analysis presented in Section 2.2. The technologies that have been retained through this analysis were used to develop preliminary remedial action alternatives for the site. These alternatives are identified in Chapter 3. 


\section{TABLE 2.5 Screening of Potentially Applicable Technologies for Groundwater Remediation at the WSCP and the WSOW}

\begin{tabular}{|c|c|c|c|}
\hline $\begin{array}{l}\text { General Response } \\
\text { Action }\end{array}$ & Technology Type & $\begin{array}{l}\text { Evaluation } \\
\text { Result }\end{array}$ & Comments \\
\hline \multirow[t]{2}{*}{$\begin{array}{l}\text { Institutional } \\
\text { controls }\end{array}$} & $\begin{array}{l}\text { Groundwater access } \\
\text { restrictions }\end{array}$ & Retained & $\begin{array}{l}\text { Could effectively limit access to areas with contaminated } \\
\text { groundwater. Could be used to support other response actions. }\end{array}$ \\
\hline & $\begin{array}{l}\text { Ownership and land } \\
\text { use or deed restrictions }\end{array}$ & Retained & $\begin{array}{l}\text { Could minimize exposures to site contaminants by limiting use } \\
\text { of contaminated groundwater areas. Could be used to support } \\
\text { other response actions. }\end{array}$ \\
\hline Monitoring & Vertical wells & Retained & $\begin{array}{l}\text { Could provide data useful for minimizing exposures. Could be } \\
\text { used to support other response actions. }\end{array}$ \\
\hline \multirow[t]{3}{*}{$\begin{array}{l}\text { In-situ } \\
\text { containment }\end{array}$} & Physical barrier & Rejected & $\begin{array}{l}\text { Difficult to install barrier walls in bedrock and difficult to } \\
\text { control groundwater flow that can occur in natural conduits. }\end{array}$ \\
\hline & Hydraulic containment & Rejected & $\begin{array}{l}\text { Low permeability and preferential flow conduits in the aquifer } \\
\text { would limit effectiveness. }\end{array}$ \\
\hline & Immobilization & Rejected & $\begin{array}{l}\text { Could not inject required material into the aquifer because of } \\
\text { the aquifer's low permeability. }\end{array}$ \\
\hline \multirow[t]{7}{*}{ In-situ treatment } & Natural processes & Retained & $\begin{array}{l}\text { Could reduce contaminant concentrations given sufficient time. } \\
\text { Could be used to support other response actions. }\end{array}$ \\
\hline & Bioremediation & Rejected & $\begin{array}{l}\text { Could not inject required material into the aquifer because of } \\
\text { the aquifer's low permeability. }\end{array}$ \\
\hline & Electrokinetics & Rejected & $\begin{array}{l}\text { Application to full-scale remediation for the contaminants of } \\
\text { concern has not yet been demonstrated. }\end{array}$ \\
\hline & Reactive walls & Rejected & $\begin{array}{l}\text { Difficult to install long barrier walls in bedrock and difficult to } \\
\text { control groundwater flow that can occur in natural conduits. }\end{array}$ \\
\hline & Air stripping & Retained & For limited use at the WSCP to treat the TCE contamination. \\
\hline & Fenton-like reagent & Retained & $\begin{array}{l}\text { Low and nonuniform permeability of the aquifer may limit its } \\
\text { effectiveness in remediating organic contaminants. }\end{array}$ \\
\hline & Phytoremediation & Rejected & $\begin{array}{l}\text { Ineffective at remediating contamination that is more than about } \\
3 \mathrm{~m}(10 \mathrm{ft}) \text { deep. }\end{array}$ \\
\hline \multirow[t]{4}{*}{ Removal } & Vertical wells & Retained & $\begin{array}{l}\text { For limited use at the WSCP where the aquifer's permeability } \\
\text { might be high enough for reasonable pump rates. }\end{array}$ \\
\hline & Horizontal wells & Retained & $\begin{array}{l}\text { For limited use at the WSCP where the aquifer's permeability } \\
\text { might be high enough for reasonable pump rates. }\end{array}$ \\
\hline & Interceptor drains & Rejected & $\begin{array}{l}\text { Difficult to install trenches in bedrock and difficult to control } \\
\text { groundwater flow that can occur in natural conduits. }\end{array}$ \\
\hline & $\begin{array}{l}\text { Excavating/dredging } \\
\text { and pumping }\end{array}$ & Rejected & $\begin{array}{l}\text { Sources of contamination have already been removed or are in } \\
\text { the process of being removed. Concentrations of remaining } \\
\text { contaminants in the aquifer material are expected to be } \\
\text { relatively low. Removal of bedrock would be difficult. }\end{array}$ \\
\hline
\end{tabular}


TABLE 2.5 (Cont.)

\begin{tabular}{|c|c|c|c|}
\hline $\begin{array}{l}\text { General Response } \\
\text { Action }\end{array}$ & Technology Type & $\begin{array}{l}\text { Evaluation } \\
\text { Result }\end{array}$ & Comments \\
\hline \multirow[t]{18}{*}{ Ex-situ treatment } & Filtration & Retained & $\begin{array}{l}\text { Effective in removing suspended solids from solutions. Could } \\
\text { be used to support other response actions. }\end{array}$ \\
\hline & Evaporation & Retained & $\begin{array}{l}\text { Effective in removing suspended and dissolved solids from } \\
\text { solution. Could be used to support other response actions. }\end{array}$ \\
\hline & Reverse osmosis & Retained & $\begin{array}{l}\text { Effective in concentrating contaminants in solution. Could be } \\
\text { used to support other response actions. }\end{array}$ \\
\hline & $\begin{array}{l}\text { Coagulation/ } \\
\text { flocculation }\end{array}$ & Retained & Effective in enhancing filtration and settling processes. \\
\hline & Precipitation & Retained & $\begin{array}{l}\text { Effective conventional method for removing uranium from } \\
\text { solution. }\end{array}$ \\
\hline & Ion exchange & Retained & $\begin{array}{l}\text { Effective conventional method for removing uranium and } \\
\text { nitrate from solution. }\end{array}$ \\
\hline & $\begin{array}{l}\text { Settling/centrifugation } \\
\text { (clarification) }\end{array}$ & Retained & $\begin{array}{l}\text { Effective in removing suspended solids from solution. Could be } \\
\text { used to support other response actions. }\end{array}$ \\
\hline & $\begin{array}{l}\text { Liquid-liquid } \\
\text { extraction }\end{array}$ & Retained & $\begin{array}{l}\text { Effective conventional method for removing uranium from } \\
\text { solution. }\end{array}$ \\
\hline & Magnetic separation & Rejected & Method under development for removing metals from solution. \\
\hline & $\begin{array}{l}\text { Supported liquid } \\
\text { membranes }\end{array}$ & Rejected & Method under development for removing metals from solution. \\
\hline & Ultraviolet oxidation & Retained & $\begin{array}{l}\text { Effective conventional method for degrading nitroaromatic } \\
\text { compounds from solution. }\end{array}$ \\
\hline & $\begin{array}{l}\text { Granular activated } \\
\text { carbon }\end{array}$ & Retained & $\begin{array}{l}\text { Effective conventional method for removing TCE from vapor } \\
\text { and TCE and nitroaromatic compounds from solution. }\end{array}$ \\
\hline & Incineration & Retained & $\begin{array}{l}\text { Effective conventional method for degrading organic } \\
\text { compounds and reducing waste volumes. Could be used to } \\
\text { support other response actions. }\end{array}$ \\
\hline & Electrodialysis & Rejected & $\begin{array}{l}\text { Suitable only for treating soft water and has relatively high } \\
\text { costs. }\end{array}$ \\
\hline & $\begin{array}{l}\text { Enzyme-catalyzed } \\
\text { reduction }\end{array}$ & Rejected & Method under development for removing nitrate from solution. \\
\hline & Biodegradation & Rejected & $\begin{array}{l}\text { Method under development for degrading organic compounds } \\
\text { in solution. }\end{array}$ \\
\hline & Biosorption & Rejected & Method under development for removing metals from solution. \\
\hline & Phytoremediation & Retained & $\begin{array}{l}\text { Effective emerging technology for degrading/removing TCE, } \\
\text { nitroaromatic compounds, nitrate, and uranium. }\end{array}$ \\
\hline Disposal & Off-site facility & Retained & $\begin{array}{l}\text { Required for disposition of contaminated solid waste from other } \\
\text { remedial options. }\end{array}$ \\
\hline
\end{tabular}


2-30 


\section{DEVELOPMENT AND SCREENING OF PRELIMINARY ALTERNATIVES}

\subsection{INTRODUCTION}

The purpose of an FS and the overall remedy selection process is to develop, evaluate, and select appropriate remedial action alternatives that eliminate, reduce, or control risks to human health and the environment. On the basis of the screening and evaluation procedures described in Chapter 2 , nine preliminary alternatives were developed for the GWOUs from combinations of appropriate technologies and associated process options. The development of these preliminary alternatives is discussed in Sections 3.2 and 3.3, and the screening process to determine the final alternatives is described in Sections 3.4 and 3.5. The final alternatives retained for subsequent analysis in this FS are identified in Section 3.6.

The alternatives discussed in this chapter were developed on the basis of the assumption that activities related to source removal and control response actions have been implemented at the WSCP and the WSOW. These activities are stipulated in the Records of Decision (RODs) addressing soil and structural contamination at the WSCP (DOE 1993) and soil and pipeline contamination at the WSOW (DA 1996). Therefore, the preliminary alternatives discussed in this FS should be considered as follow-on activities that could be implemented after sources of contamination have been remediated.

As stipulated in the chemical plant ROD (DOE 1993), remedial activities are being conducted to provide source control at the WSCP, including remediation of contaminated soil and subsurface materials surrounding building foundations; removal of the foundations of contaminated structures; construction of berms around the raffinate pits to eliminate surface runoff; and dewatering, removal, and treatment of contents of the raffinate pits. Drums and rubble disposed of in the raffinate pits during earlier decontamination activities at the WSCP will be removed. These source-control activities are expected to remove or reduce further migration of contaminants from source materials to the groundwater.

Remedial action for OU1 at the WSOW, as stipulated in the ROD (DA 1996), include excavation of soil containing TNT, DNT, lead, polychlorinated biphenyls (PCBs), and polycyclic aromatic hydrocarbons (PAHs). This soil is located primarily along the TNT production lines, in two wastewater lagoons, and at seven burning grounds. In addition to the contaminated soil, approximately 85,000 linear feet of wooden pipeline that transported TNT wastewater will be removed. Most of the excavated material contaminated with TNT is expected to undergo treatment by incineration; however, any material containing more than $500 \mathrm{ppm}$ lead will be sent for disposal in the engineered disposal facility at the WSCP. 


\subsection{CRITERIA FOR DEVELOPING ALTERNATIVES}

EPA guidance (EPA 1988a) and the NCP (EPA 1990a) provide criteria for developing alternatives that protect human health and the environment by controlling risks posed through each exposure pathway at a site. The numbers and types of alternatives to be analyzed are site specific and take into account the scope, characteristics, and complexity of the problem that is being addressed. The following types of alternatives were developed for the GWOUs consistent with EPA guidance:

- Alternatives that involve treatment as a principal component to reduce the toxicity, mobility, or volume of contaminants in groundwater. The range of treatment alternatives includes an alternative that removes or destroys the contaminants to the maximum extent feasible, thereby eliminating or minimizing (to the degree possible) the need for long-term management.

- Containment alternatives that involve little or no treatment but provide protection to human health and the environment by preventing or controlling exposure to the contaminants. These alternatives include engineering controls and, as necessary, institutional controls to protect human health and the environment and to ensure continued effectiveness of the response action.

- A no action alternative - that is, no further action after source removal activities have been implemented and completed at the WSCP and the WSOW - is included as a baseline for comparison with other alternatives. Actions taken to reduce the potential for exposure (e.g., institutional controls such as deed restrictions) are not included as a component in the no action alternative.

The general response actions for groundwater identified in Chapter 2 are (1) no action, (2) institutional controls, (3) monitoring, (4) containment, and (5) extraction and treatment. Institutional controls include access and legal restrictions. Groundwater monitoring includes the existing monitoring well network as well as any additional wells to be constructed as part of an alternative action. Containment actions include interception of groundwater, horizontal and vertical barriers, and containment by pumping. Treatment actions typically include physicochemical treatment, biological treatment, thermal treatment, and electrical treatment (e.g., electrokinetic remediation).

\subsection{IDENTIFICATION OF PRELIMINARY ALTERNATIVES}

Preliminary alternatives were assembled from combinations of technologies and associated management strategies that were retained following the screening and evaluation process described in Chapter 2. Potential action alternatives were screened to eliminate those alternatives determined 
to be too difficult to implement on the basis of unproven technologies, those determined to be insufficient to remediate groundwater at the WSCP and the WSOW within a reasonable time period, or those determined to have limited application for the specific contaminant or site conditions (EPA 1988a). The technologies and management strategies that were not eliminated were incorporated into the following preliminary alternatives:

- Alternative 1: No Action;

- Alternative 2: Long-Term Monitoring;

- Alternative 3: Natural Attenuation;

- Alternative 4: Groundwater Removal and On-Site Treatment Using Granular Activated Carbon (GAC);

- Alternative 5: Groundwater Removal and On-Site Treatment Using Ultraviolet Oxidation;

- Alternative 6: Groundwater Removal and On-Site Treatment Using Phytoremediation;

- Alternative 7: Removal and On-Site Treatment of TCE-Contaminated Groundwater;

- Alternative 8: In-Situ Treatment of TCE Using In-Well Vapor Stripping; and

- Alternative 9: In-Situ Chemical Oxidation of TCE Using Fenton-Like Reagents.

These nine alternatives incorporate the five general response actions for groundwater listed in Section 3.2. The alternatives range from no action, for which no further action would be taken at the site, to ex-situ and in-situ treatment of the groundwater, which would prevent or reduce any future migration of the contamination toward any off-site receptors. The preliminary alternatives developed in this FS represent a range of remediation options. Some alternatives address all groundwater contaminants in the entire affected aquifer, whereas others focus on more localized treatment of TCE only. Alternatives 2, 3,4,5, and 6 were developed and evaluated to determine their feasibility in addressing all contaminants in the affected aquifer at the WSCP and the WSOW. Alternatives 7,8, and 9 were evaluated for their feasibility in addressing the TCE-contaminated groundwater primarily at the WSCP. 
Factors considered in the selection of the TCE-contaminated area as the focus of a more limited active remediation effort included the following:

1. The TCE contamination has been observed to be confined to one defined plume in the upper portion of the weathered Burlington-Keokuk Limestone, primarily at the WSCP. Nitrate, nitroaromatic compound, and uranium contaminants are distributed in small, noncontiguous areas throughout the WSCP. Nitroaromatic compounds are also distributed in small noncontiguous areas throughout the WSOW.

2. On the basis of the risk calculations presented in the BRA (DOE and DA 1998a), TCE has been indicated to be the primary contributor to the estimated potential human health risk for a hypothetical resident scenario.

\subsubsection{Factors Common to All Preliminary Action Alternatives}

The approaches for implementing these nine preliminary action alternatives contain a number of similar activities. For example, it was assumed that groundwater monitoring would occur under each action alternative for the cleanup period. Monitoring would be needed to evaluate whether the groundwater action was achieving, or would achieve, the intended response objectives. Monitoring would be continued, as needed, for those alternatives not involving active removal of contaminants from the groundwater.

In addition, each action alternative requires various support operations prior to implementation. These activities could include procurement of appropriate equipment and development of contingency plans and operational controls to minimize contaminant migration during implementation. Some action alternatives may involve destruction or storage of removed contaminants in an appropriately permitted facility.

In the analyses performed for this FS, it was assumed that remedial action activities stipulated in RODs addressing source removal and controls at the WSCP and the WSOW have been implemented. 


\subsubsection{Factors Specific to Each Preliminary Alternative}

\subsubsection{Alternative 1: No Action}

The no action alternative (Alternative 1) is intended to provide a baseline for comparison with the other alternatives evaluated. Under this alternative, no action other than those stipulated in previous RODs for the WSCP and the WSOW would be taken to remediate groundwater, and any currently ongoing maintenance or monitoring would be discontinued. Alternative 1 would not provide for any active or passive institutional controls to reduce any potential for exposure to contaminants currently in the groundwater. By definition, this alternative is a zero-cost alternative that provides no added protection to any receptor in the form of engineering or institutional controls.

\subsubsection{Alternative 2: Long-Term Monitoring}

Alternative 2 would not involve any form of active remediation such as groundwater extraction, in-situ or ex-situ treatment, or containment actions. It would rely upon the groundwater's natural ability to lower contaminant concentrations through physical, chemical, and biological processes until PRGs were met. These processes include adsorption to soil particles (for uranium), biodegradation (for nitroaromatic compounds and TCE), and dilution and dispersion in groundwater (for all contaminants).

Activities associated with Alternative 2 would include the following:

- Monitoring of groundwater to verify that future contaminant concentrations would not result in unacceptable risks to human health;

- Institutional controls to ensure that contaminated groundwater was not used before PRGs were attained; and

- Contingency measures in the event that PRGs are not attained through natural processes.

Source-control measures for the WSCP and the WSOW are listed in Section 3.1. These actions would prevent or minimize further migration of contaminants from source materials to groundwater. The concentrations of contaminants in the WSCP and the WSOW would be expected to continue to decrease with time because of removal of the source of contamination; dilution through infiltration from rainwater and runoff; and natural processes such as biodegradation, adsorption, and chemical reactions with subsurface materials. 
Several natural underground conduits exist across the WSCP and the WSOW where the groundwater travel time to surface springs is on the order of hours. However, monitoring of the water from these springs has indicated low contaminant concentrations that do not result in unacceptable human health exposures at these groundwater discharge points. Natural processes occurring in groundwater, combined with dilution or dispersion, would likely contribute to contaminant concentrations below PRGs at these springs. Although the exact mechanisms that are naturally occurring cannot be identified, these observations suggest that active remediation of groundwater might not be necessary.

Alternative 2 would also involve continued monitoring of groundwater. Groundwater would be routinely sampled and analyzed to track contaminant migration and degradation (e.g., TCE and nitroaromatic compounds) and to verify that potential drinking water supplies would remain protected. The direction and rate of movement of the contaminated groundwater would be tracked as a function of time. Groundwater monitoring under Alternative 2 would continue for a reasonable period of time (i.e., greater than 10 years) or until remedial objectives were met.

Groundwater would be monitored using the existing well network, as appropriate. Additional monitoring wells might be installed and sampled to evaluate the protectiveness of this alternative. Alternative 2 was conservatively assumed to involve the construction and operation of 15 additional monitoring wells (approximately $10 \%$ of the number of existing wells). The exact monitoring network and details regarding frequency of sampling and parameters analyzed would be identified in the ROD or subsequent remedial design/remedial action (RD/RA) reports, as appropriate. In general, monitoring of the additional wells would take into account the groundwater migration patterns and any seasonal influences.

Institutional controls that might be applied for the WSCP and the WSOW groundwater include land use restrictions and continued federal ownership. Land use restrictions could include St. Charles County zoning regulations and deed restrictions by the Missouri Department of Conservation on land not currently under federal ownership (e.g., August A. Busch Memorial Conservation Area). Zoning of properties other than the WSCP and the WSTA at the WSOW might become relevant at some future period. Deed restrictions would involve specific limitations on future land use that are incorporated in the deed of ownership to the property. Such restrictions would prevent activities that could cause direct exposure or releases of groundwater contaminants. Deed restrictions accompany the deed to the property in a manner that is generally binding and must be transferred to all subsequent owners of the property. Examples of deed restrictions include those prohibiting residential or agricultural use. Drilling for mineral, water, or other purposes would also be prohibited.

Continued federal ownership of the WSTA by the DA and of the area containing the on-site disposal cell at the WSCP by the DOE is certain. The federal government will continue to control these areas, with the intention of restricting site development activities through the rights of 
ownership. On-property development activities, such as agricultural or residential use, could be restricted or prohibited by the federal government which, as the property owner, would retain all rights to preclude these activities.

Because contaminants would remain on-site at concentrations above those that would allow for unlimited use and unrestricted exposure under Alternative 2, reviews would be conducted at least every five years, consistent with CERCLA requirements. However, to optimize interpretation of future monitoring results, it would be worthwhile to allow an adequate amount of time to elapse so that beneficial impacts from source removals could occur (e.g., after three years or more). The sampling frequency would depend on the location of the monitoring wells and the groundwater flow velocity. The number of monitoring wells and sampling frequency would be determined in collaboration with the regulators. (Response measures might be considered if data indicated that future migration of contamination would result in unacceptable off-site exposure. Contingency measures to prevent exposure to contaminated groundwater could include developing an alternate water supply for the public [which could be provided by a wide range of actions, such as well relocation, selective use of wells, or connection to an existing system or surface water source], well head treatment, and use restrictions.)

\subsubsection{Alternative 3: Natural Attenuation}

Natural attenuation is defined in the NCP (EPA 1990a) as "biodegradation, dispersion, dilution, and adsorption" of contaminants in groundwater. The NCP preamble states that natural attenuation is generally recommended when active restoration is not practicable, cost effective, or warranted on the basis of site-specific conditions (e.g., where groundwater is not a likely source of drinking water) or when natural attenuation could achieve remedial goals in a reasonable time frame. Natural attenuation may be a useful remedial approach if site-specific data indicate that these processes would effectively reduce contaminants in the groundwater to concentrations protective of human health and the environment in a time frame comparable to that which could be achieved through active remediation (EPA 1988b).

Natural attenuation relies on natural subsurface processes to reduce contaminant concentrations to acceptable levels. Such processes include dilution, volatilization, biodegradation, adsorption, chemical reactions with subsurface materials, and radioactive decay. Further information on natural attenuation is provided in Section 2.2.2. Natural attenuation has been found to have many advantages over conventional engineering remediation alternatives (Goffredi 1997), including the following:

- Contaminants are ultimately transformed into innocuous by-products (such as $\mathrm{CO}_{2}$, ethylene, ethane, $\mathrm{Cl}^{-}$, and water for TCE) and are not just transferred to another phase or location in the environment; 
- Attenuation allows use of the existing infrastructure at a site during remediation;

- Contaminants are generally not transferred to the atmosphere, which prevents increased risk to nearby populations and the environment.

- Attenuation is less expensive than currently available remediation technologies such as conventional extraction and ex-situ treatment ("pump and treat");

- No equipment downtime or maintenance is involved; and

- The most mobile and toxic organic compounds are usually the most susceptible to biodegradation.

Hydrogeologic constraints can limit the effectiveness of active restoration when plumes migrate into formations from which they cannot easily be removed; in these special situations, natural attenuation with monitoring and institutional controls has been identified as potentially the only feasible remedy (EPA 1988b). Such situations include sites where contaminants have migrated into formations with a high degree of secondary permeability, such as fractured bedrock or karst aquifers. For comparative purposes, the shallow bedrock aquifer system, which contains the majority of the groundwater contamination, has been conceptualized to be a diffuse flow system where the bedrock is thinly bedded or fractured sufficiently to serve as a uniform porous medium; superimposed conduit flow occurs in large isolated fractures. These conditions indicate that a karst hydrologic system is in operation in the bedrock beneath and around the site; therefore, it may not be practicable or feasible to fully restore groundwater by active remediation.

The conditions potentially favoring the use of natural attenuation are as follows (EPA 1988a): groundwater naturally unsuitable for consumption, low-mobility contaminants, low concentrations of contaminants, low potential for exposure, and low projected demand for future use of the groundwater. These conditions may be compared with the prevailing conditions at the WSCP and the WSOW, as follows:

- Groundwater Naturally Unsuitable for Consumption: Groundwater that is naturally unsuitable for consumption includes groundwater that is saline (total dissolved solids levels over $10,000 \mathrm{mg} / \mathrm{L}$ ) or groundwater that is not available in sufficient quantity at any depth to meet the needs of an average household. Existing data suggest that long-term sustainable pumping rates are very low, about $1.2 \mathrm{~L} / \mathrm{min}(0.3 \mathrm{gpm})$, from wells installed in the shallow bedrock aquifer where the majority of the contamination is located (MK-Ferguson and Jacobs Engineering Group, Inc. 1990a). 
- Low-Mobility Contaminants: Information on contaminant mobility (see Section 2.2.2) indicates that precipitation of uranium from solution as insoluble $\mathrm{UO}_{2}$ may be occurring within the shallow aquifer. Nitroaromatic compounds found in the soil overburden exhibit relatively low water solubility and, therefore, low leachability and mobility. Also, none of the nitroaromatic compound contaminants are highly volatile (DA 1993).

- Low Concentrations of Contaminants: Nitroaromatic contamination within the shallow aquifer system is widespread and occurs at low concentrations throughout the aquifer (DOE and DA 1998b). However, the uranium, TCE, and nitrate contaminants are more localized (i.e., in the vicinity of the raffinate pits at the WSCP).

- Low Potential for Exposure: The likelihood that groundwater from the shallow aquifer system would be used for residential purposes is low. Access to the WSCP and the WSTA by the general public is restricted, and groundwater from the shallow aquifer is unlikely to be used by the public in the future (DOE 1995). The DA expects to retain ownership of the WSTA and to continue using this property for training activities. At the WSCP, a disposal cell is being built on-site that will occupy approximately one-third of the total area.

- Low Projected Demand for Future Use of the Groundwater: Groundwater occurs in three principal bedrock aquifer systems: (1) the shallow aquifer that is contaminated; (2) a middle confined aquifer composed of the Kimmswick Limestone; and (3) a deep confined aquifer. Groundwater that is used as a drinking water supply in the area is primarily taken from the deep productive aquifer of the Ordovician/Cambrian bedrock system and from an alluvial aquifer near the Missouri River. The projected demand for the groundwater within the shallow aquifer system is expected to be low on the basis of foreseeable land use and low pumping yields (about $1.2 \mathrm{~L} / \mathrm{min}[0.3 \mathrm{gpm}]$ for a single well [MK-Ferguson and Jacobs Engineering Group, Inc. 1990a]) measured in the area of highest conductivity at the WSCP (i.e., the groundwater trough north of the divide and along the western edge of the WSCP).

This comparison indicates that conditions at the WSCP and the WSOW potentially favor the use of natural attenuation. 
Guidance on the use of natural attenuation is evolving. A protocol has been developed for determining the feasibility and effectiveness of using natural attenuation in remediating groundwater contaminated with chlorinated aliphatic hydrocarbons (such as TCE) at DA and DOE sites; this protocol is summarized in Wiedemeier et al. (1996). Consideration of natural attenuation as a potential option requires modeling and evaluation of contaminant degradation rates and pathways. The primary objective of such modeling would be to demonstrate that natural processes of contaminant degradation would reduce contaminant concentrations below regulatory standards or cleanup goals before potential exposure pathways would be encountered. This groundwater modeling would require a thorough understanding of how site geology, hydrology, geochemistry, and microbiology can affect the behavior of contaminants. The following data are required (Wiedemeier et al. 1996):

- Extent and type of soil and groundwater contamination;

- Location and extent of contaminant source areas;

- Information on whether the source will continue to release contaminants;

- Aquifer geochemical characteristics;

- Regional hydrogeologic information; and

- Local and site-specific hydrogeologic data, including information on drinking water aquifers, locations of wells and surface water bodies, patterns of aquifer use (current and future), lithology, site stratigraphy, grain-size distribution, aquifer hydraulic conductivity, groundwater hydraulic gradient, porosity, dispersivity, preferential flow paths, and areas of local groundwater recharge and discharge.

Extensive soil and groundwater contaminant data are available for both the WSCP and the WSOW. However, to document the occurrence of natural attenuation, groundwater data would be needed regarding decay products and geochemical parameters to determine the three-dimensional contaminant distribution.

Additional data would be needed to determine other model input parameters under aquifer conditions (e.g., biodegradation rate constants and distribution coefficients $\left[K_{d}\right]$ for each contaminant). Table 3.1 lists the analytical parameters used to provide information on whether natural attenuation of chlorinated aliphatic hydrocarbons such as TCE is occurring. (Currently, no natural attenuation sampling protocols are available for nitroaromatics, nitrate, and uranium.) Sampling and sample analysis would be conducted throughout the operational duration of Alternative 3 to confirm that natural attenuation was proceeding at rates consistent with meeting cleanup objectives. 
TABLE 3.1 Analytical Parameters that Provide Information on Natural Attenuation of Chlorinated Aliphatic Hydrocarbons

\begin{tabular}{ll}
\hline Alkalinity & Oxidation-reduction potential \\
\hline Chloride concentration & Oxygen (dissolved) \\
Conductivity & $\mathrm{pH}$ \\
Hydrogen (dissolved) & Sulfate concentration \\
Iron (II) & Temperature \\
Methane, ethane, and ethylene concentrations & Total organic carbon \\
Nitrate concentration & Volatile organic compounds \\
\hline
\end{tabular}

Source: Wiedemeier et al. (1996).

Like Alternative 2, Alternative 3 would involve continued groundwater monitoring. A more elaborate sampling and analytical scheme would be required to verify that natural attenuation was occurring at rates that would ensure no off-site migration of contaminant concentrations above health-based levels. Groundwater sampling would be conducted within the contaminated zone to document that natural attenuation was occurring. Also, sampling would be performed outside the contaminated area to identify any migration of contaminants that might require initiation of more active remedial measures. The direction and rate of movement of the contaminated groundwater would be tracked as a function of time. Under Alternative 3, groundwater monitoring would continue for a reasonable period of time (i.e., greater than 10 years) or until remedial objectives were met.

Groundwater monitoring would be conducted using the existing well network, as appropriate. Additional monitoring wells might be installed and sampled to evaluate the protectiveness of this alternative and to detect the migration of contaminated groundwater. These wells would

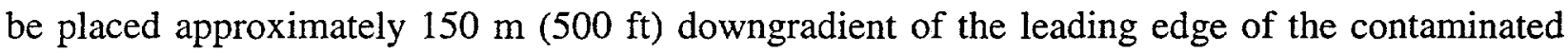
groundwater or at the distance estimated to be traveled by the groundwater in two years, whichever was greater. For the evaluation of this alternative, the construction and operation of 38 additional monitoring wells (approximately $25 \%$ of the number of existing wells) was assumed. All wells would be screened in the same hydrogeologic unit as the contaminated groundwater (i.e., BurlingtonKeokuk Limestone). The exact monitoring network and details regarding frequency of sampling and parameters analyzed would be identified in the ROD or subsequent RD/RA reports.

Because contaminants would remain on-site at concentrations above those that allow for unlimited use and unrestricted exposure, reviews would be conducted at least every five years, consistent with CERCLA requirements. If monitoring showed that the extent and concentrations of contaminants in the groundwater had decreased significantly during the five-year period, the number 
of wells sampled and the sampling frequency might be reduced. Wells that duplicated information (e.g., wells located less than $15 \mathrm{~m}$ [50 ft] apart within the same aquifer, screened over the same interval, and exhibiting similar contaminant concentration profiles), provided unreliable information (e.g., wells that were dry part of the year), or contained contaminant concentrations below the PRGs for all contaminants might be considered for elimination (Air Force Center for Environmental Excellence 1997). The sampling frequency would depend on the location of the monitoring wells and the groundwater flow velocity. The number of monitoring wells and sampling frequency would be determined in collaboration with the regulators.

Active response measures would be considered if data indicated that future migration of contaminants would result in unacceptable exposure concentrations. These contingency measures could include developing an alternate water supply for the public (which would be provided by a wide range of actions, such as well relocation, selective use of wells, or connection to an existing system or surface water source), well head treatment, and use restrictions.

\subsubsection{Alternative 4: Groundwater Removal and On-Site Treatment Using Granular Activated Carbon}

Alternative 4 would involve extraction and ex-situ treatment of the WSCP and the WSOW groundwater to achieve PRGs for groundwater. Groundwater containing concentrations exceeding these limits would be removed by using conventional vertical extraction wells, pumped to and treated in an aboveground treatment system consisting of a sequence of physical and chemical unit operations, and released to a permitted discharge point. If discharged to surface water (e.g., the Missouri River), the treated water might be required to meet federal and state effluent standards. This analysis assumed that compliance with these standards would be required. Reinjection of the treated groundwater back into the aquifer was not considered desirable because of the large number of required injection wells and the low hydraulic conductivity of the shallow aquifer.

Groundwater extraction and treatment (i.e., "pump and treat") is a widely applied remedial technology. Groundwater extraction systems are relatively simple to design, can be readily constructed and operated, and use standard equipment available from many sources. These systems are used to enhance free product recovery, contain a dissolved contaminant plume, and reduce the mass of contamination in an aquifer. Groundwater extraction wells used in aquifer remediation are typically located near the area of highest contaminant concentrations or near the leading edge of the plume. If located near the leading edge of the plume, the groundwater withdrawal system typically intercepts the downgradient extent of the contaminant plume. For a well-defined contaminant plume, conventional extraction is often the first line of defense in preventing further migration and in removing the majority of the contamination. 
The first step during construction would involve installation of the vertical extraction wells, which is generally conducted by drilling into the aquifer. The selection of a drilling method is a function of site-specific geologic conditions, well specifications, and degree of subsurface disturbance. Three drilling methods (i.e., hollow-stem auger, water/mud rotary, and air rotary) are generally considered when installing wells for groundwater extraction. This analysis assumed the use of water/mud rotary drilling because of the size of the extraction well (a 15-cm [6-in.] extraction well was assumed in this design because it contains adequate space for pumps and pipes for most extraction systems). After each well installation, the drilling equipment, risers, and caps, as well as drilling tools, would be decontaminated.

Between approximately 300 and 930 vertical extraction wells at the WSCP and between 27 and 80 wells at the WSOW (Appendix C) were assumed to be required to achieve a reasonable extraction rate and to contain further spread of contaminants. The wells would be between $15 \mathrm{~m}$ $(50 \mathrm{ft})$ and $24 \mathrm{~m}(80 \mathrm{ft})$ deep, have a screened length of $10 \mathrm{~m}(30 \mathrm{ft})$, and be $15 \mathrm{~cm}(6 \mathrm{in}$.$) in$ diameter. Additional investigation of aquifer characteristics would be necessary for detailed evaluation of the placement of the extraction wells and estimation of groundwater extraction rates. The actual location, size, capacity, and depth of the various extraction wells would be determined during the remedial design phase, at which time the hydrogeologic characteristics (i.e., permeability, thickness of the aquifer, depth of the affected groundwater) and the delineation of the contaminated area would be taken into account.

The extracted groundwater would be contained in an aboveground tank prior to pumping for treatment. Contaminated groundwater would be pumped through polyvinyl chloride (PVC) pipes directly to the treatment process. A pipeline would be constructed connecting the outlet of the aboveground tank with the appropriate groundwater treatment facility.

Under Alternative 4, construction of two groundwater treatment facilities with similar treatment capabilities was assumed: one to treat extracted groundwater from the WSCP and another for the WSOW. (Groundwater at the WSOW would not need treatment to remove TCE or nitrate; therefore, the treatment processes associated with these contaminants [e.g., reverse osmosis for nitrate removal] would not be applied for the WSOW.) The general-use treatment facilities would be single-story, metal frame structures that would house the groundwater treatment system, water storage tanks, pumps, and ancillary equipment. These facilities would have treatment capacities from 760 to $2,400 \mathrm{~L} / \mathrm{min}$ ( 200 to $620 \mathrm{gpm}$ ) for the groundwater extracted from the WSCP and from 24 to $72 \mathrm{~L} / \mathrm{min}$ ( 6 to $19 \mathrm{gpm}$ ) for the WSOW groundwater. The facility footprint would range from 360 to $750 \mathrm{~m}^{2}$ (3,900 to $8,000 \mathrm{ft}^{2}$ ) for the WSCP and from 42 to $70 \mathrm{~m}^{2}$ (450 to $740 \mathrm{ft}^{2}$ ) for the WSOW, depending on the number of extraction wells required. (This analysis also considered the use of existing on-site wastewater treatment facilities such as the Quarry Water Treatment Plant [QWTP] and the Site Water Treatment Plant [SWTP]. However, use of the QWTP for treatment was rejected because it is not equipped to treat TCE and nitrate that would be present in the extracted groundwater 
at the GWOU. The SWTP would be considered in the remedial design for treatment of extracted groundwater, if it is available and determined to be cost effective.)

A preconceptual process flow diagram for groundwater treatment is provided in Figure 3.1. This process is similar to that currently applied for treatment of contaminated surface water by the SWTP at the WSCP. In the analysis for this FS, it was assumed that if the effluent from groundwater treatment was discharged to a surface water body, the treated water might be required to meet federal and state effluent standards.

The extracted groundwater would first be sent to a feed tank to dampen variations in flow and groundwater quality among the extraction wells, thereby providing equalization of influent. Uranium and other metals would be removed within the mix tank by precipitation. Several precipitation additives are available. Although lime is the most common precipitant in general use because of its low cost, lime tends to be inefficient because of the volume of sludge produced. This analysis assumed the use of lime; an additive (or combination of additives) would be selected during the $\mathrm{RD} / \mathrm{RA}$ phase on the basis of cost and volume of sludge produced. Following precipitation, the precipitate would be rapidly transferred to the clarifier, where the solids in the precipitate mixture would settle to the bottom. Sludge from the clarifier, containing the solids and precipitated uranium and other metals, would be dewatered using a filter press. The solid sludge would be sent for disposal.

Clarifiers are generally sufficient for the removal of suspended solids. However, because solids from precipitation or filter backwash sometimes coagulate and settle poorly, multimedia filters would be included to remove any fine particles that did not settle out in the clarifier.

Granular activated carbon would be used to remove organic materials, including nitroaromatic compounds (such as 2,4-DNT and TNT) and TCE, by chemically and physically binding them to the carbon. In liquid-phase carbon adsorption, the groundwater would be passed through beds containing the activated carbon, where the contaminants would be adsorbed.

Ionic species such as nitrate would be removed by means of reverse osmosis, which involves forcing the contaminated water across a semipermeable membrane, which reduces the mineral content in the groundwater, thereby removing nitrate. Treatment by reverse osmosis would result in a permeative stream with low concentrations of ions and a low-volume reject stream containing the concentrated dissolved compounds. This reject stream would be sent to an evaporator for further concentration. The evaporator concentrate would be dewatered using a filter press and then mixed with cement additives to produce a solidified residue (grout) for disposal. (Groundwater treatment at the WSOW would not require reverse osmosis for nitrate removal.) 


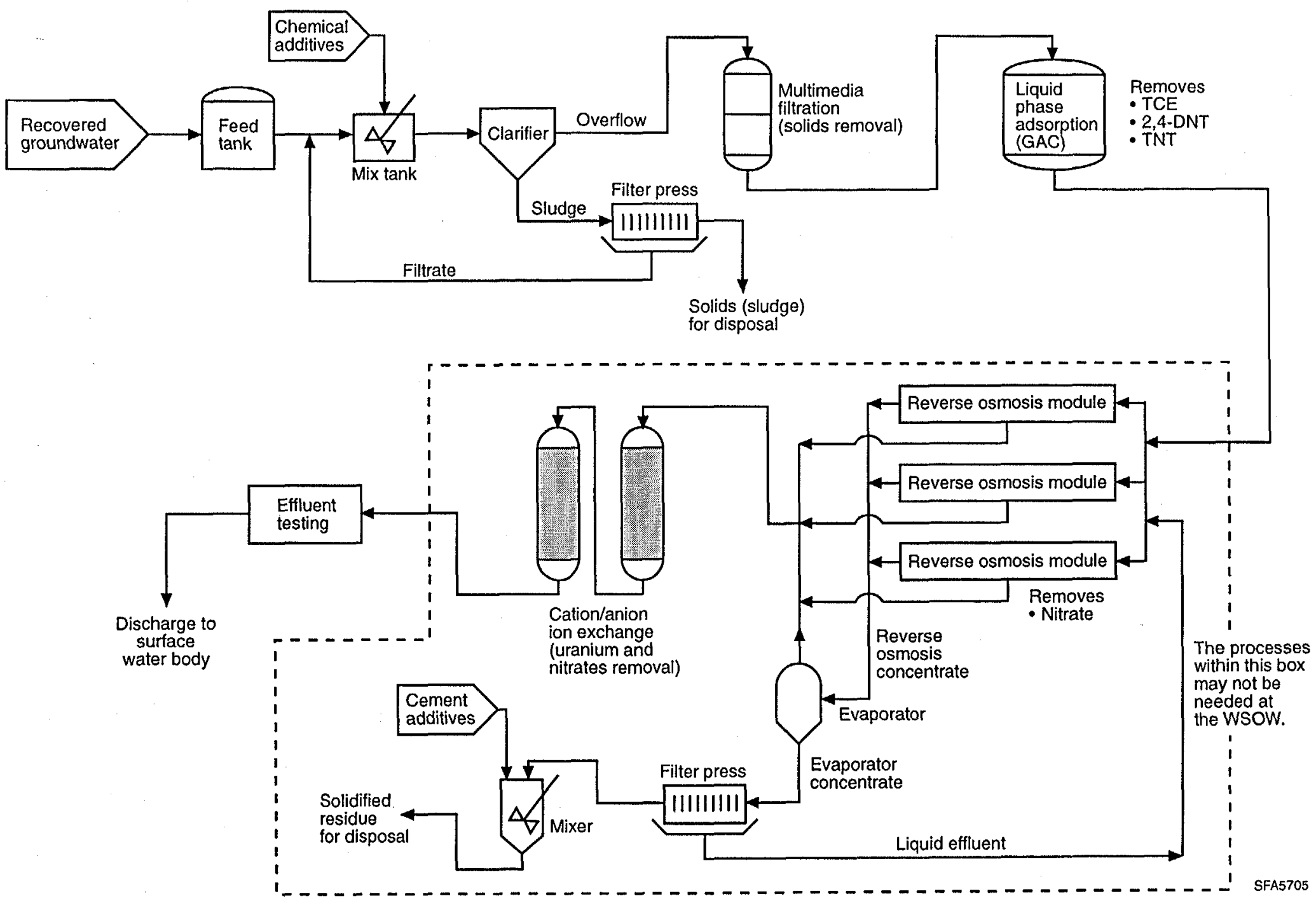

FIGURE 3.1 Process Flow Diagram for Proposed Groundwater Treatment under Alternative 4 
Ion exchange would be used to remove trace amounts of uranium and nitrate from the groundwater; this method has been widely applied for the treatment of high flows of wastewater with dilute concentrations of metals. In ion exchange, the contaminants are exchanged with ions of the resin (e.g., sodium $\left[\mathrm{Na}^{+}\right]$). (Groundwater treatment at the WSOW would not require ion exchange for uranium removal.) The treated water from the ion-exchange units would be chemically analyzed to verify that the water had been treated to acceptable levels for discharge.

Liquid-phase carbon adsorption would be used under Alternative 4 for removal of organic compounds from the groundwater. This technology is well developed and widely used, and it is very effective in removing a wide range of organic contaminants from groundwater, including TCE and explosives. It is a transfer technology only, however, and the carbon adsorption media would require replacement after reaching its capacity. In liquid-phase carbon adsorption, the contaminated groundwater comes in contact with the GAC by flowing through a series of packed bed adsorbers (which are simply columns packed with GAC). The activated carbon selectively adsorbs organic compounds, which are attracted to and held in the internal micropores of the carbon granules. This analysis assumed the use of downflow fixed-bed GAC adsorbers (see Figure 3.2), because they constitute a cost-effective treatment technology that produces the lowest effluent concentrations compared with other carbon adsorber designs.

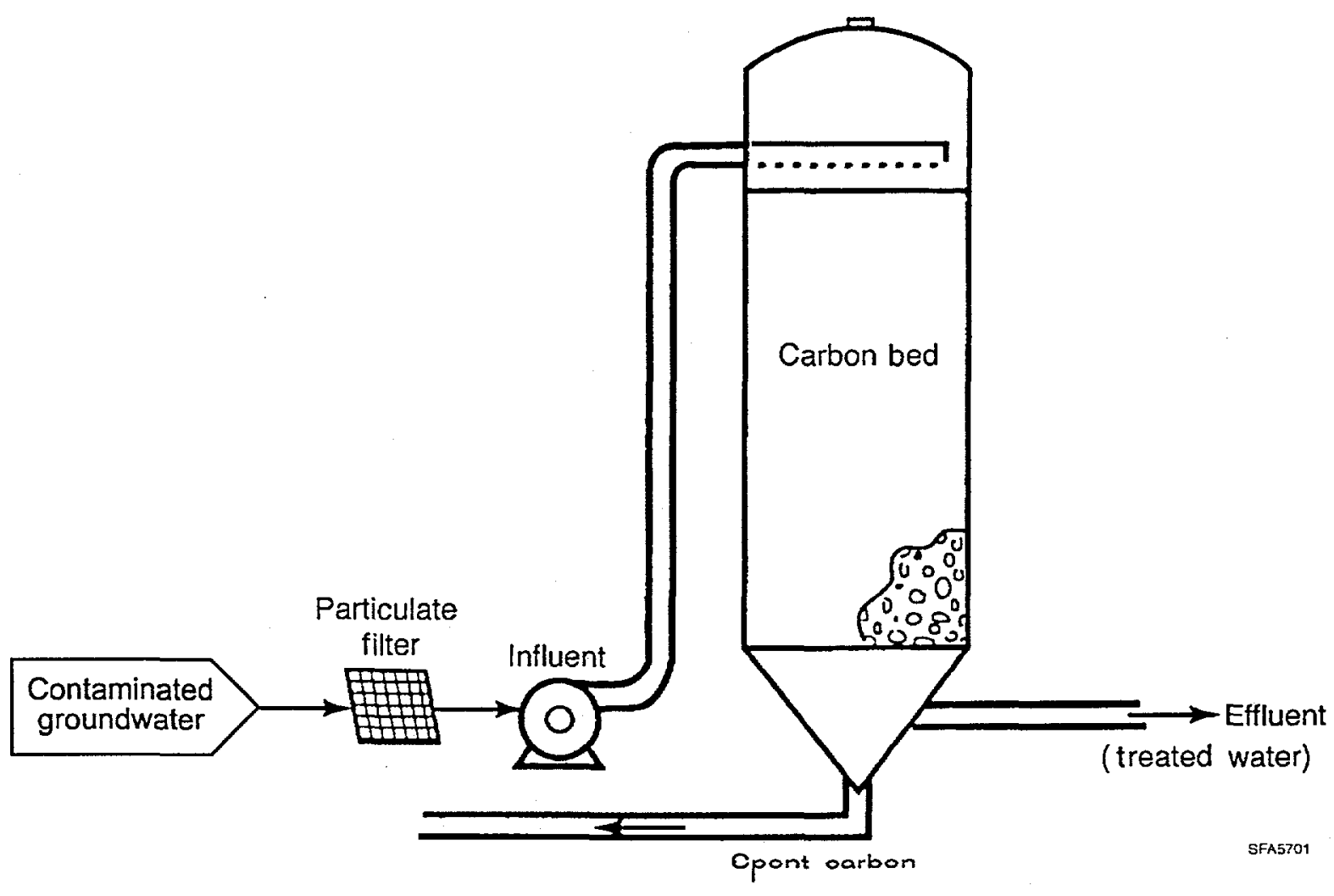

FIGURE 3.2 Typical Fixed-Bed GAC Adsorption System (Source: Marks et al. 1994) 
The system described for Alternative 4 should be effective for removing TCE, nitrate, nitroaromatic compounds, and uranium. (The process flow diagram in Figure 3.1 is provided for purposes of illustration and is not intended as a final or definitive treatment system. Other treatment processes or system configurations could be used, provided they are capable of cost effectively achieving the required effluent concentrations.) In general, however, the removal characteristics of any particular combination of contaminants in a waste stream are not predictable. A pilot test using a sample of the affected groundwater under conditions comparable to those of the GWOU might be required to accurately determine the optimal process and its characteristics. The actual design for treatment of the extracted groundwater would be determined during the remedial design phase, at which time the necessary flow capacity, required contact time to reduce contaminant concentrations, and contaminant concentrations likely to be encountered would be taken into account.

It was assumed that any sludge generated by groundwater treatment at the WSCP and the WSOW would be managed similarly to sludge generated by the water treatment process at the SWTP. This sludge is currently placed into $3-\mathrm{m}^{3}\left(4-\mathrm{yd}^{3}\right)$ boxes and transported to the temporary storage area at the WSCP. The sludge is placed within a bermed area constructed on top of the finegrained soil pile at the temporary storage area and allowed to dewater. Eventually, the sludge is mixed within the fine-grained soil matrix (Valett 1997); this mixture will be disposed of in the on-site engineered disposal facility when it becomes available.

Following closure of the on-site disposal facility at the WSCP, the dewatered sludge from the GWOU would be packaged for off-site shipment and disposal. If the waste-acceptance criteria for off-site disposal are met, the dewatered sludge would be shipped via truck to an off-site licensed disposal facility (transport by rail does not appear to be an option because of the lack of a nearby railhead for shipping). Assuming packaging in a standard 55-gal (208-L) drum and truck transport, only one off-site shipment to a licensed disposal facility would be required annually.

If necessary to meet the waste acceptance criteria for off-site disposal, the sludge would be treated by chemical fixation (stabilization/solidification) prior to disposal. Most of the solids in the sludge would be uncontaminated dissolved solids such as calcium carbonates and hydroxides.

The maximum radioactivity of the dewatered sludge is estimated to be about $60 \mathrm{pCi}$ of uranium per gram of sludge for the WSCP groundwater and less than $1 \mathrm{pCi}$ of uranium per gram of sludge for the WSOW groundwater. These values are based on the maximum detected concentrations of 870 and $10 \mathrm{pCi} / \mathrm{L}$ measured during monitoring at the WSCP and the WSOW, respectively (DOE and DA 1998b), and an assumed $1.5 \mathrm{~g}(0.05 \mathrm{oz})$ of sludge per $100 \mathrm{~g}(3.5 \mathrm{oz})$ of wastewater [Shropshire et al. 1995]). Both values are much lower than the maximum average concentration of $18,000 \mathrm{pCi} / \mathrm{g}$ of uranium allowed in waste sent to the Envirocare facility for off-site commercial disposal. These estimates could actually be much lower because more recent maximum concentrations of uranium at the WSCP and the WSOW are lower (i.e., the maximum concentrations reported were $60 \mathrm{pCi} / \mathrm{L}$ for wells at the WSCP [MW-4024] and $2 \mathrm{pCi} / \mathrm{L}$ for wells at the WSOW). 
In fact, it is suspected that the $60 \mathrm{pCi} / \mathrm{L}$ could have been due to the bentonite grout used for installing well MW-4024 in 1995.

The replacement schedule for spent GAC would depend on its adsorption efficiency under actual operating conditions. It was assumed that the spent carbon would be replaced every three months. The spent carbon would then be regenerated at the supplier facility or sent to a commercial disposal facility. Because a process for off-site thermal regeneration of GAC contaminated with explosives is currently under development (PNNL 1997), this analysis assumed disposal of the spent contaminated carbon. For a carbon fill of $400 \mathrm{~kg}(880 \mathrm{lb})$, the amount of spent carbon to be disposed of annually as hazardous waste would be approximately $1,600 \mathrm{~kg}(3,500 \mathrm{lb})$. Assuming packaging in standard 55-gal (208-L) drums and truck transport, less than one shipment to a licensed disposal facility would be required annually for both the WSCP and the WSOW groundwater treatment facilities. On the basis of literature values of carbon adsorption capacity for various compounds (EPA 1995c), the spent carbon would contain approximately $2 \mathrm{wt} \%$ contaminant (primarily TCE for the WSCP and nitroaromatic compounds for the WSOW).

The air would be monitored to detect airborne contamination generated during remedial activities, so that appropriate mitigative measures could be taken. Long-term air monitoring would be implemented following completion of construction of the GAC treatment system to ensure detection of any potential airborne releases of contaminants associated with duct leaks or maintenance of the system. Environmental monitoring at the sites would continue to the extent necessary to ensure long-term performance of the remedy.

\subsubsection{Alternative 5: Groundwater Removal and On-Site Treatment Using Ultraviolet Oxidation}

The objectives and design of Alternative 5 are similar to those for Alternative 4, except that on-site treatment using UV oxidation was assumed for Alternative 5. UV oxidation technology would replace the GAC process applied in Alternative 4 for the removal of TCE and nitroaromatic compounds from the extracted groundwater. Groundwater containing contaminants exceeding the PRGs would be removed by using conventional vertical extraction wells. Contaminated groundwater would be pumped to and treated at an aboveground treatment system, consisting of a sequence of physical and chemical unit operations, and would then be released to a discharge point.

UV oxidation is a relatively new treatment technology that has been used as a full-scale application to treat groundwater for more than 12 years (GWRTAC 1996). (Technologies such as GAC and ion exchange have been used commercially for a number of decades.) It has not been used extensively for remediating water contaminated with organic compounds because of the widespread use of GAC treatment. UV oxidation can be an effective treatment for water contaminated with TCE and explosives, and, unlike carbon adsorption, actually destroys these compounds rather than just 
transferring them to a more easily disposable medium. UV oxidation uses UV light in conjunction with an oxidant or cavitation to produce free radicals. These free radicals oxidize the contaminant to produce a simpler molecule that is nonhazardous. In this case, the UV light energy (photon) is absorbed by the oxidant, either $\mathrm{H}_{2} \mathrm{O}_{2}$ or ozone $\left(\mathrm{O}_{3}\right)$, to form a hydroxyl radical $(\mathrm{OH} \bullet)$. Some systems use a combination of these two oxidants to improve the stoichiometry of the chemical reaction. This analysis assumed that the oxidizer $\left(\mathrm{H}_{2} \mathrm{O}_{2}\right)$ would be added through a traditional feed system consisting of a tank with secondary containment, one to two feed pumps, and distribution piping (see Figure 3.3).

The UV oxidation system causes the TCE to react to form nontoxic by-products that can be released directly to the environment. The UV oxidation process can treat cyanides, carbonyls, many aromatic compounds, phosphorus and sulfur pesticides, PCBs, and dioxins. UV oxidation is not applicable to heavy metals, fluorides, acids, and many aliphatic compounds.

A preconceptual process flow diagram for groundwater treatment, including UV oxidation, is provided in Figure 3.4. This system would be expected to remove uranium, nitrate, and other compounds to levels that are acceptable for discharge. The system is described primarily for purposes of illustration and is not intended as a final or definitive treatment system. Other treatment processes or system configurations could be used, provided they were capable of cost effectively achieving the required effluent concentrations. The system described here shows a representative process option that was assumed to be effective for removal of contaminants detected in the groundwater at the WSCP and the WSOW.

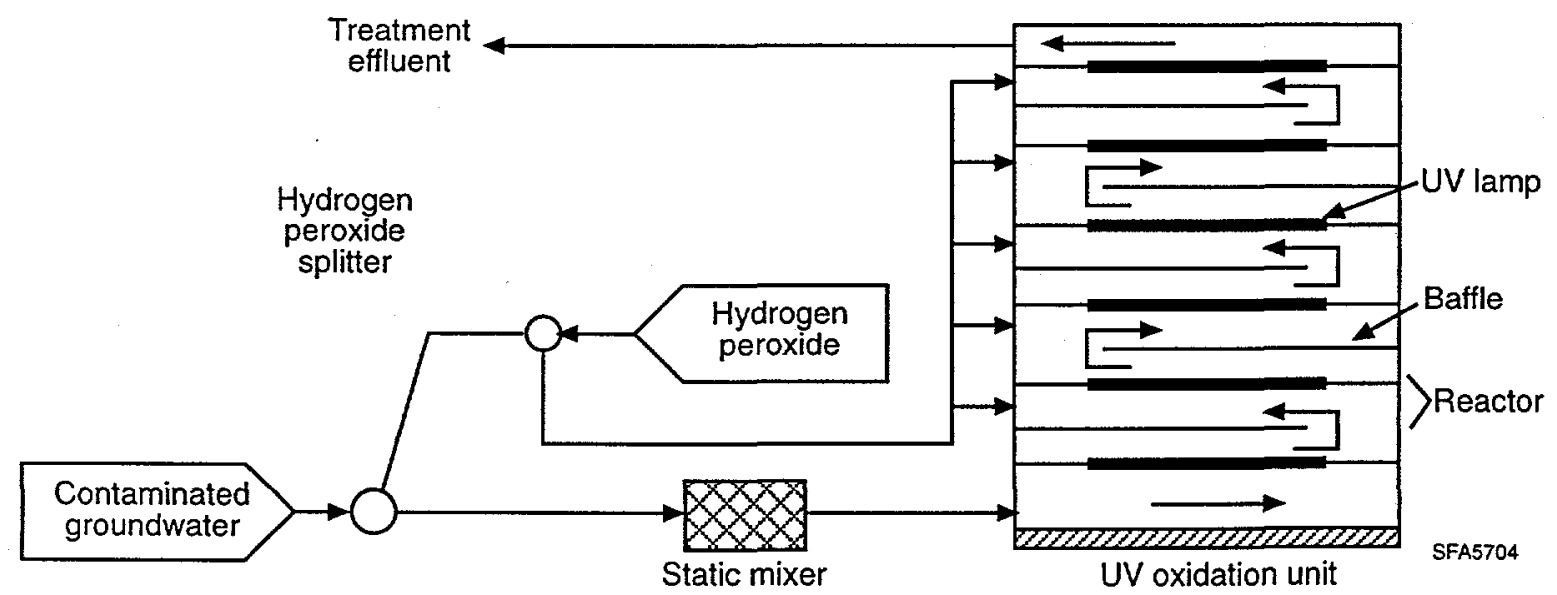

FIGURE 3.3 Ultraviolet Oxidation Treatment System (Source: Adapted from EPA 1995b) 


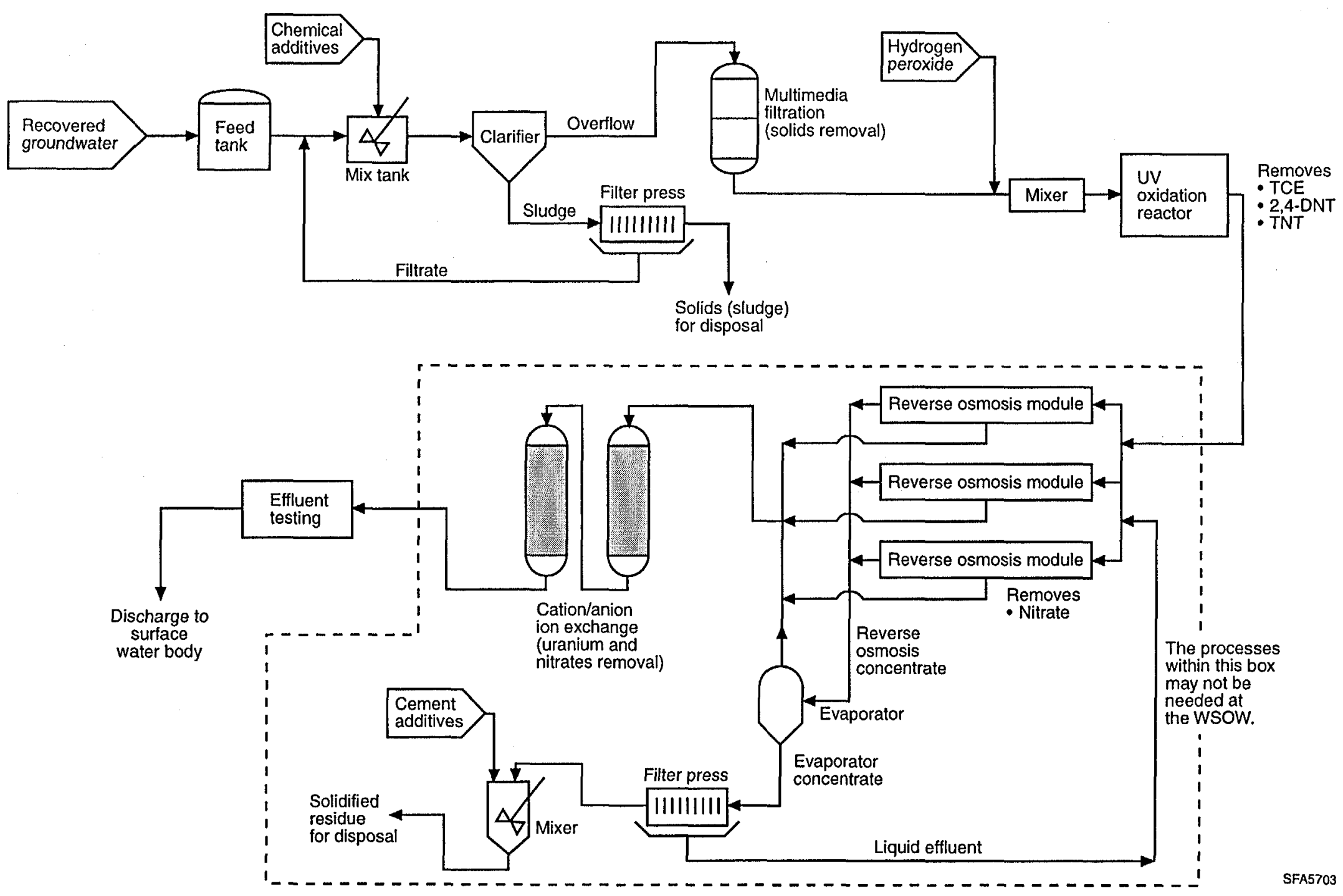

FIGURE 3.4 Process Flow Diagram for Proposed Groundwater Treatment under Alternative 5 
The characteristics of Alternative 5 would be very similar to those of Alternative 4, except that no spent carbon would be generated. Environmental monitoring at the sites would continue as necessary to ensure long-term performance of the remedy.

\subsubsection{Alternative 6: Groundwater Removal and On-Site Treatment Using Phytoremediation}

The objectives and design of Alternative 6 are similar to those of Alternative 4, except that on-site treatment using phytoremediation was assumed for Alternative 6. Groundwater contaminants exceeding the PRGs would be removed by using conventional vertical extraction wells. Contaminated groundwater would be pumped to and treated at aboveground constructed wetlands and released to a discharge point.

Phytoremediation is the use of enzymatic activity occurring in plants at the root level to remediate contaminated groundwater. Phytoremediation has been reported to be most suited for sites containing groundwater with moderately hydrophobic contaminants, which include chlorinated solvents such as TCE, nitrotoluene ammunition wastes such as TNT and DNT, and excess nutrients such as nitrate. Plant species can extract and assimilate or extract and chemically decompose target organic contaminants. Inorganic compounds such as nitrate, which are considered to be environmental contaminants in groundwater, are in fact vital plant nutrients that can be absorbed through the root system for use in growth and development. In general, plants will survive higher concentrations of hazardous wastes than will most microorganisms used for bioremediation.

Phytoremediation has been effective in a number of full-scale and pilot-scale studies. It has already been successfully implemented by the DA to clean TNT and hexahydro-1,3,5-trinitro1,3,5-triazine ( $R D X)$ from contaminated wetlands (Boyajian and Carreira 1997). Levels of TNT were reduced by more than $99 \%$ by using a variety of native aquatic and wetland plants (Boyajian and Devedjian 1997). Studies performed by the EPA involving phytoremediation using the parrot feather plant indicated that dissolved TNT concentrations decreased from $128 \mathrm{ppm}$ (saturation conditions) to $10 \mathrm{ppm}$ in one week (Schnoor et al. 1995).

Constructed wetlands have proven to be effective for treating municipal wastewater and acid mine drainage by using natural geochemical and biological processes inherent in an artificial wetland ecosystem to accumulate and remove nitroaromatic compounds and other contaminants from influent waters (Schnoor 1997). Certain plants native to wetland environments support nitroreductase and lactase enzymes that can degrade complex nitrogen-based compounds into benign substances. The parrot feather and Eurasian water milfoil plants have been applied in aquatic mesocosms. Their enzymes have been shown to break down nitroaromatic compounds and incorporate the broken ring structures into new plant material or organic detritus that becomes part 
of sediment organic matter (Schnoor et al. 1995). Another plant-derived enzyme, dehalogenase, helps reduce chlorinated solvents such as TCE to chloride ion, carbon dioxide, and water.

Under Alternative 6, two constructed wetlands would be built: one to treat extracted groundwater from the WSCP and another for the WSOW. A constructed wetland consists of a lined, man-made lagoon with a variety of plants (including parrot feather) that is located outdoors (see Figure 3.5). Two basic types of constructed wetlands are used in the United States: subsurface flow and free-water surface flow (Reed and Brown 1992). The major difference is that the water level is designed to remain below the surface of the media for the subsurface flow wetland, whereas the water surface is exposed to the atmosphere for the free-water surface flow wetland. For this analysis, the free-water surface flow wetland design was assumed to be applied at the Weldon Spring area to allow photolysis of the nitroaromatic compounds and evaporation of the TCE.

In a free-water surface flow wetland, groundwater is typically introduced across one end of the constructed wetland by either a concrete channel with $V$-notch weirs or by a perforated pipe located within the crushed rock inlet zone. The distribution channel and inlet zone uniformly distribute the groundwater across the constructed wetland. From the inlet zone, groundwater flows through soil or gravel media, where it is treated by phytoremediation. Effluent is collected in the outlet zone, which resembles the inlet zone with the addition of a perforated pipe installed at the bottom to facilitate collection and discharge of the effluent. The water level in the root zone bed where phytoremediation occurs is controlled by a flow-control device, such as the standpipe in a manhole illustrated in Figure 3.5. Automatic sampling devices can be included as part of a monitoring system, and fencing and screens can be provided to limit contact with contaminated groundwater by terrestrial animals and waterfowl. Operations involve primarily fertilization and watering, if necessary, to maintain plant growth. Other activities include monitoring nutrient concentrations, water levels, and plant growth, and removal of any invading species and weeds. Harvesting, disposal of contaminated plant mass, and repeating the plant growth cycle are necessary for plants involved in heavy metal remediation (i.e., uranium removal). Replanting is performed as necessary.

The two constructed wetlands for the WSCP and the WSOW would have the capacity to treat between 760 and 2,400 L/min (200 and $620 \mathrm{gpm})$ and between 24 and $72 \mathrm{~L} / \mathrm{m}(6$ and $19 \mathrm{gpm})$, respectively, of extracted groundwater and would have total footprints of between approximately 18 and 56 ha (44 and 140 acres) at the WSCP and between 0.6 and 2 ha ( 2 and 5 acres) at the WSOW. (For the WSOW, three wetland areas, with a total footprint of $0.3 \mathrm{ha}$ [ 0.7 acre], might be constructed because of the large distances between the areas of contaminated groundwater. This analysis assumed treatment of WSOW-extracted groundwater at one location. The siting and locations of any constructed facilities would be determined during the RD/RA phase.) The footprint required for the two constructed wetlands was estimated assuming an idealized plug flow of the contaminated

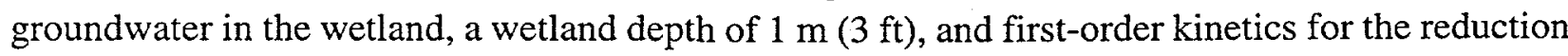
of TNT and DNT concentrations with time (Medina and McCutcheon 1996; Todd and 


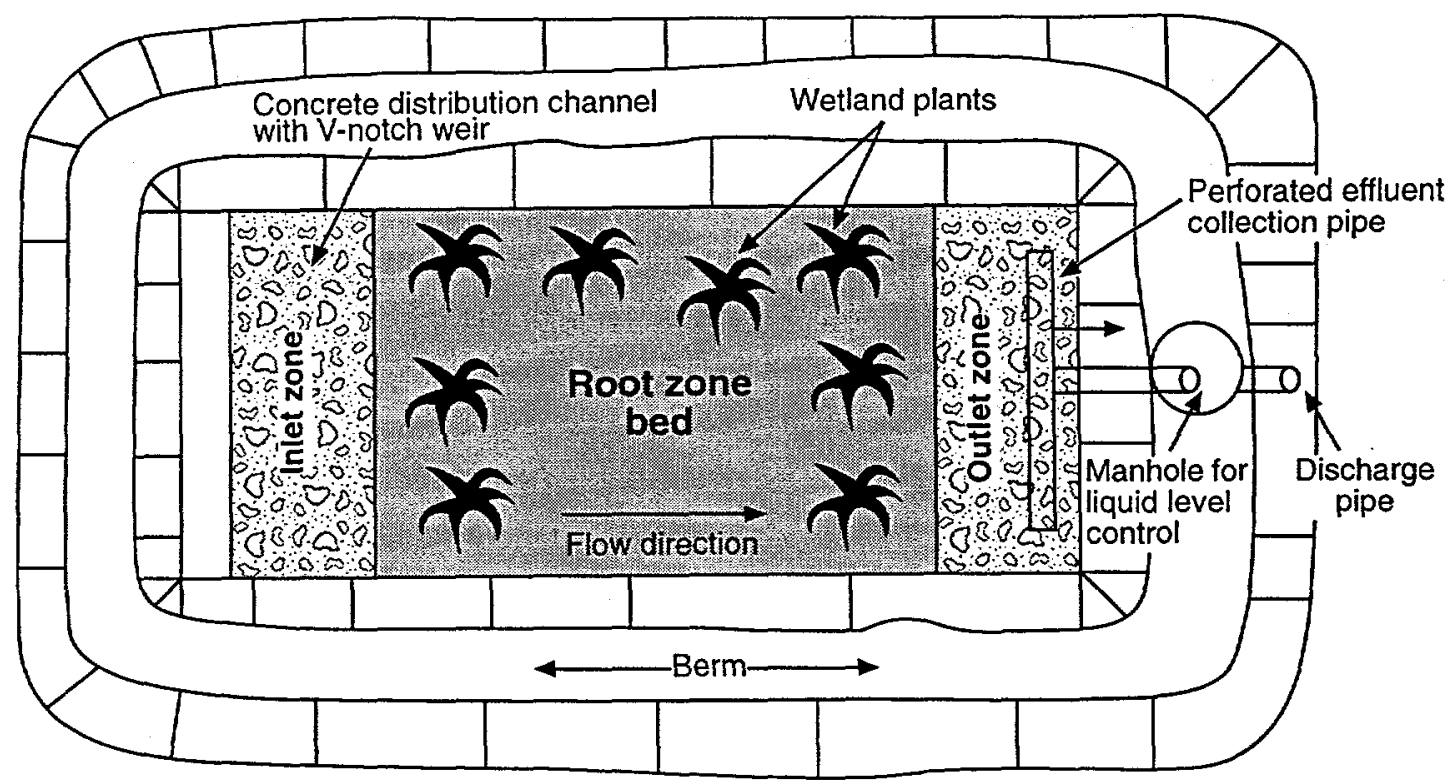

PLAN

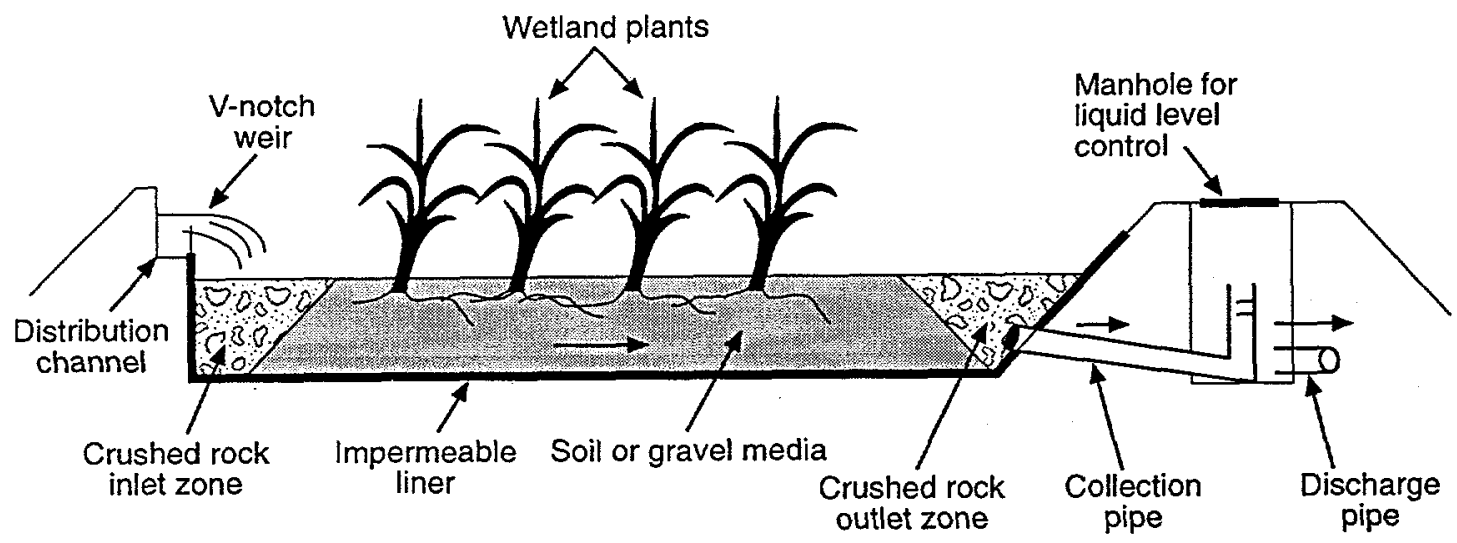

FIGURE 3.5 Typical Root Zone Bed (Source: Conley et al. 1991) 
Lange 1996). This analysis also assumed that the plant-mediated degradation of TNT and DNT would be the rate-limiting steps in the phytoremediation of contaminated groundwater (i.e., the removal of TCE from the groundwater would occur primarily by volatilization, not phytoremediation). The actual design of the phytoremediation system would be determined during the remedial design phase, at which time the necessary flow capacity, required contact time to reduce contaminant concentrations, contaminant concentrations likely to be encountered, and selection of appropriate plant types for the various contaminants would be taken into account.

Environmental monitoring at the sites would continue to the extent necessary to ensure long-term performance of the remedy. Monitoring for toxic effects on indigenous wildlife (because of drinking the wetland influent) and wildlife control would be part of the annual monitoring program.

\subsubsection{Alternative 7: Removal and On-Site Treatment of TCE-Contaminated Groundwater}

Alternative 7 would involve extraction and on-site treatment of the groundwater contaminated with TCE to achieve a groundwater concentration of $5 \mu \mathrm{g} / \mathrm{L}$ or less for TCE. An approach identical to that applied in Alternative 2 would be used for managing groundwater not contaminated with TCE. This alternative would actively remediate primarily TCE; however, other contaminants that are colocated with the TCE would also be extracted and treated.

The objectives and design of Alternative 7 are similar to those for Alternative 4, except that only groundwater within the TCE-contaminated plume would be removed and treated under this alternative. Groundwater containing TCE at concentrations exceeding $5 \mu \mathrm{g} / \mathrm{L}$ would be removed by using conventional extraction wells, pumped to and treated in an aboveground treatment system consisting of a sequence of physical and chemical unit operations, and released to a discharge point.

Remediation of TCE-contaminated groundwater in a triangular area with a height of $120 \mathrm{~m}$ $(380 \mathrm{ft})$ and a base of $420 \mathrm{~m}(1,400 \mathrm{ft})$ was assumed for this method. (The proposed location is

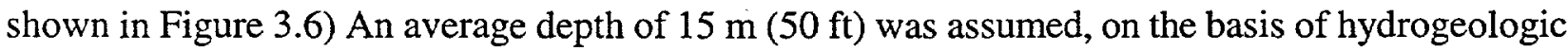
cross-sectional data given in the RI (DOE and DA 1998b), which shows the depth of the shallow (weathered Burlington-Keokuk) aquifer as a function of distance.

Approximately 200 to 650 vertical extraction wells at the WSCP and the WSOW (Appendix $\mathrm{C}$ ) were assumed to be required to achieve a reasonable extraction rate and to contain

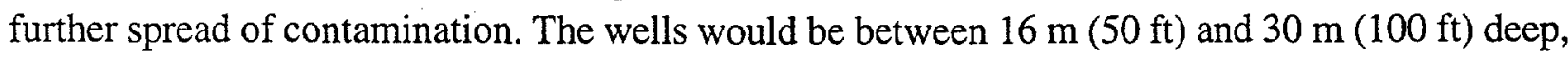
have a screened length of about $10 \mathrm{~m}(30 \mathrm{ft})$, and be $15 \mathrm{~cm}(6 \mathrm{in}$.) in diameter. Additional investigation of the shallow aquifer characteristics would be necessary for detailed evaluation of the placement of the extraction wells and estimation of groundwater extraction rates. The actual location, 


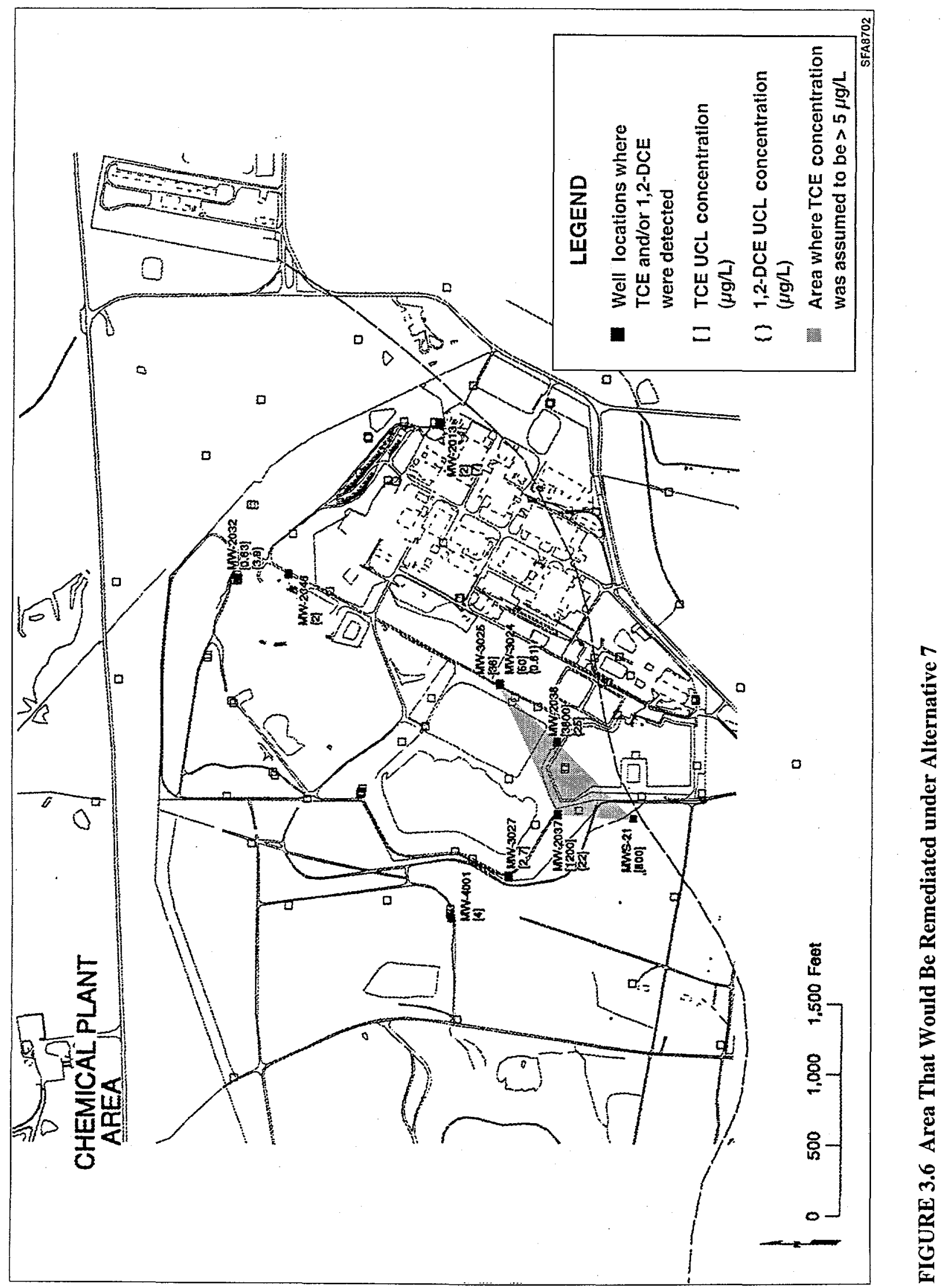


size, capacity, and depth of the various extraction wells would be determined during the remedial design phase, at which time the hydrogeologic characteristics (i.e., permeability, thickness of the aquifer, depth of the affected groundwater) and the delineation of the TCE-contaminated area would be taken into account.

Under Alternative 7, a single groundwater treatment facility was assumed to be constructed, with a treatment capacity ranging from 4 to $12 \mathrm{~L} / \mathrm{s}(60$ to $195 \mathrm{gpm}$ ) and a footprint ranging from 180 to $360 \mathrm{~m}^{2}$ (1,900 to $3,800 \mathrm{ft}^{2}$ ), depending upon the number of extraction wells required. The preconceptual groundwater treatment process would be similar to that proposed for Alternative 4 and would involve clarification and multimedia filtration to remove any solids collected during groundwater extraction, liquid phase adsorption using GAC to remove TCE and other organics, and reverse osmosis and ion exchange for nitrate removal.

The air would be monitored to detect airborne contamination generated during remedial activities, so that appropriate mitigative measures could be taken. Long-term air monitoring would be implemented following construction of the GAC treatment system to ensure detection of any potential airborne releases of contaminants associated with duct leaks or maintenance. Environmental monitoring at the sites would continue to the extent necessary to ensure long-term performance of the remedy.

After construction of the extraction well network and associated groundwater treatment system, the two systems would be carefully monitored on a regular basis and their performance evaluated. The time required for on-site treatment for Alternative 7 is predicted to be 16 years (Appendix C), assuming a maximum TCE concentration of $1,300 \mu \mathrm{g} / \mathrm{L}$. The actual performance in the field may vary from that assumed during design, given uncertainties about subsurface geology prior to construction and operation.

Because contaminants (other than TCE) would remain in site groundwater at concentrations above those that would allow for unlimited use and unrestricted exposure, reviews would be conducted at least every five years, consistent with CERCLA requirements.

\subsubsection{Alternative 8: In-Situ Treatment of TCE Using In-Well Vapor Stripping}

Alternative 8 involves in-situ treatment of the groundwater contaminated with TCE by using in-well vapor stripping to achieve a groundwater concentration of $5 \mu \mathrm{g} / \mathrm{L}$ or less of TCE. An approach identical to that applied in Alternative 2 would be used to manage the other groundwater contaminants such as the nitroaromatic compounds and nitrate. 
In-well vapor stripping technology involves the creation of a groundwater circulation pattern and simultaneous aeration within the vapor stripping well that volatilizes VOCs (in this case, TCE) from the circulating groundwater. (The in-well vapor stripping process in its current stage of development cannot remove nonvolatile or highly soluble compounds from groundwater.) Air-lift pumping is used to lift groundwater and strip it of contaminants. Contaminated vapors are drawn off for aboveground treatment. Partially treated groundwater is then forced out of the well into the vadose zone, where it reinfiltrates to the water table. Untreated groundwater enters the well at its base and replaces the water lifted through pumping. Eventually, the partially treated water is cycled back through the well, this process is repeated until contaminant concentration goals are met (Miller and Roote 1997).

One reported advantage of the in-well vapor stripping technology is that it can continuously remove VOCs from groundwater without pumping the water to the surface. Thus, it eliminates the need to handle contaminated water above the ground and to dispose of or store partially treated water. It also eliminates the need to drill injection wells required by other in-situ treatment processes. Other reported advantages of in-well stripping include its lower capital and operating costs, because of the use of a single well for extracting vapors and remediating groundwater, and its simple design, which limits maintenance requirements (Miller and Roote 1997).

The in-well vapor stripping technology consists primarily of a screened well submerged beneath the water table and an air line within that well that also extends below the water table (see Figure 3.7). A compressor delivers air or an inert gas such as nitrogen to the water column, which aerates the water within the well. The gas bubbles cause the water within the well to be less dense than the nonaerated water outside. As a result, the dense water flows in through the well screen and forces the aerated water upward within the well. The result is a rising column of aerated water within the well, which forms an air lift pumping system.

As the aerated groundwater column rises within the well, the VOCs dissolved in that groundwater volatilize from the aqueous phase into the vapor phase within the air space of each bubble. The air/water mixture rises until it encounters a packer or deflector plate installed within the well that prevents the passage of rising water or bubbles. When the rising water column hits the packer, the bubbles burst and the entrained vapor is stripped off laterally through the upper vacuum casing along with surrounding soil vapor. The outer casing is under a vacuum, and the vapors are drawn upward through the annular space and collected at the surface for treatment. The groundwater from which some VOCs have been removed reenters the contaminated zone. The laterally deflected water percolates downward through the vadose zone back to the groundwater. Reinfiltrating water creates a toroidal circulation pattern around the well so that waters can be treated through multiple cycles to achieve the desired level of removal. The partially treated groundwater reentering the aquifer is eventually cycled back through the process as groundwater enters the base of the well. Because the VOCs are stripped from the groundwater below the surface, contaminated water is never removed from the ground, thus eliminating the need for wastewater discharge permits. 


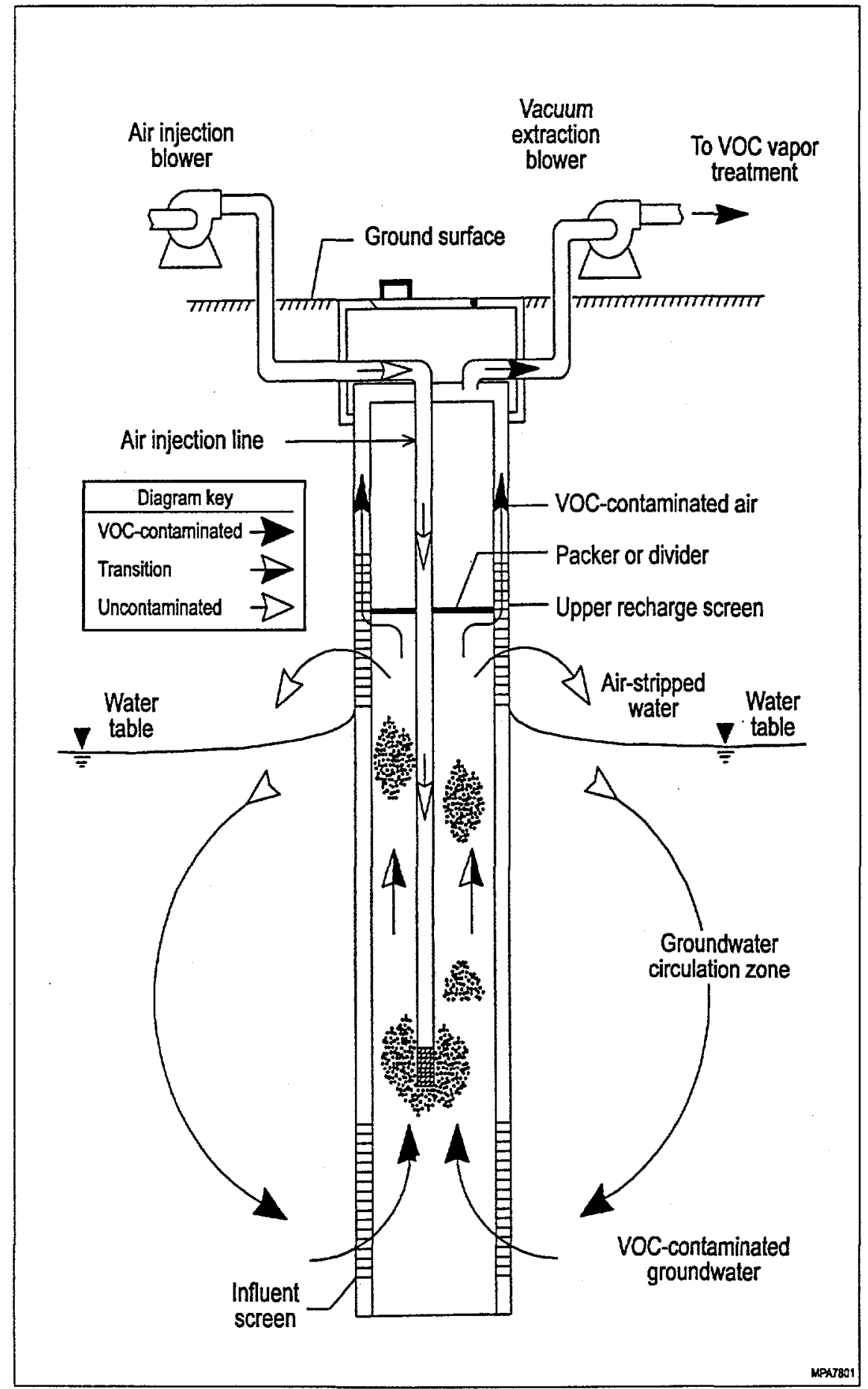

FIGURE 3.7 In-Well Vapor Stripping Process (Source: Miller and Roote 1997) 
The circulation of groundwater surrounding the well has been reported to create strong vertical gradients that effectively dislodge residual pore-space contamination (EPA 1996c). This flushing action enhances and expedites removal beyond results usually obtained by conventional groundwater extraction systems. A large radius of influence for each vapor stripping well also gives the technology significant installation and cost advantages over other in-situ treatment technologies such as air sparging.

The in-well vapor stripping treatment system would be constructed by using a drilling rig to install the stripping wells. This analysis assumes a vapor stripping well design composed of a 25-cm (10-in.)-diameter PVC pipe that is screened at two discrete intervals. Similar to Alternative 7, remediation of a triangular area with a height of $120 \mathrm{~m}(380 \mathrm{ft})$ and a base of $420 \mathrm{~m}(1,400 \mathrm{ft})$ was assumed. Preliminary calculations were performed with using the following methodology (Schrauf and Pennington 1995) to estimate the number of required vapor stripping wells:

$$
N_{\text {wells }}=\left(L_{\text {contam }} W_{\text {contam }} / 2\right) /\left(\pi r_{\text {well }}^{2}\right) \text {, }
$$

where

$$
\begin{aligned}
& N_{\text {wells }}= \text { number of required vapor stripping wells (dimensionless), } \\
& L_{\text {contam }}= \text { length of TCE-contaminated zone }(420 \mathrm{~m}[1,400 \mathrm{ft}]), \\
& W_{\text {contam }}= \text { width of TCE-contaminated zone }(120 \mathrm{~m}[380 \mathrm{ft}]), \text { and } \\
& r_{\text {well }}= \text { radius of influence of a single vapor stripping well }(\mathrm{m}[\mathrm{ft}]), \\
& \text { estimated by the following equation: } \\
& \qquad r_{\text {well }}=\left(L\left(K, / K_{z}\right)^{0.5}\right)(1+C),
\end{aligned}
$$

where

$L=$ aquifer thickness (average value of $8.2 \mathrm{~m}[27 \mathrm{ft}]$ applied in analysis)

$K_{r}=$ horizontal hydraulic conductivity (average value of $3.4 \times 10^{-3} \mathrm{~cm} / \mathrm{s}$

$[9.5 \mathrm{ft} / \mathrm{d}]$ applied in analysis),

$K_{z}=$ vertical hydraulic conductivity (assumed to be $10 \%$ of $K_{r}$, $\left.3.4 \times 10^{-4} \mathrm{~cm} / \mathrm{s}[0.95 \mathrm{ft} / \mathrm{d}]\right)$, and

$C=$ degree of conservatism (dimensionless). 
The above calculation indicates that the successful application of the in-well stripping process would require installation of a minimum of nine vapor stripping wells with possibly seven additional wells to allow for some degree of conservatism in the estimates. The actual design process is proprietary and is based on a series of steps that lead to the development of the geometric and flow parameters governing the system. The actual spacing and design of the remediation system would be determined during the remedial design phase, at which time the following would be taken into consideration: the radius of influence of a single vapor stripping well, the required number of recirculations of contaminated groundwater through the stripping well, contaminant concentrations likely to be encountered, lithology of the shallow bedrock aquifer, and results of any tracer tests and demonstrations performed in the field.

After the screened intervals are developed, a PVC eductor pipe with a slightly smaller diameter than that of the stripping well would be inserted into the well and would extend from the lower screen to above the upper screen. An air injection line $10 \mathrm{~cm}(4 \mathrm{in}$.) in diameter with a diffuser at the lower end would be inserted into the eductor pipe. The upper end of the air line would be attached to an injection blower for pressurized air injection.

An injection blower would force air down the air line and out the diffuser into the groundwater. Groundwater would enter the lower screen, and aerated water would rise in the eductor pipe. The rising water would hit the packer, flow out of the eductor pipe, and exit through the upper well screen. The treated water would recharge to the vadose zone at a maximum recirculation rate estimated to be approximately $0.1 \mathrm{~L} / \mathrm{s}(2 \mathrm{gpm})$, on the basis of the methodology described in Schrauf and Pennington (1995). This methodology appears to result in conservative (lower) estimates of the groundwater recirculation rate, when compared with experimentally determined values in the literature (Gvirtzman and Gonen 1995; SBP Technologies, Inc. 1997). Aquifer pumping tests and modeling studies may be necessary to determine the well recirculation rate that would occur under field conditions.

A vacuum blower would be supplied for stripped VOC vapor removal. Once stripped from the groundwater and brought to the surface, the vapors would be removed from the upper well casing by a vacuum blower and treated by an off-gas system consisting of gas-phase adsorption using GAC.

Gas-phase adsorption is a natural process in which molecules of a gas are physically attracted to and held at the surface of a solid (Cheremisinoff and Cheremisinoff 1993). Treating waste streams by adsorption involves transferring and concentrating contaminants (the adsorbate) from one medium (gas) to another (the adsorbent). The most commonly used adsorbent is GAC. In gas-phase carbon adsorption, the contaminated gas comes in contact with the carbon by passing through one or more adsorbers, usually the fixed-bed type. A fixed-bed adsorber is a stationary canister packed with GAC beds. The activated carbon selectively adsorbs organic molecules that are held in the internal micropores of the carbon granules. This analysis assumed that gas-phase adsorption of the TCE vapor stream would be performed by a dual-bed packaged treatment system 
consisting of two carbon adsorbers, a pump, and associated piping configured in series (EPA 1995c). The replacement schedule for the spent carbon adsorbers and the total quantity of carbon required due to replacements would depend on the duration of the carbon treatment, the carbon adsorber unit chosen, and the number of adsorbers. This analysis assumed replacement of the spent carbon every three months. Tests may be performed during the remedial design phase to better define the design of the carbon adsorption system, including the optimum number of canisters.

Prior to gas-phase carbon adsorption, the relative humidity (RH) of the gas stream may need to be lowered to increase the efficiency of the activated carbon. At high RH values, most of the pores are filled with water, thereby reducing the capacity of the GAC. As the temperature increases, the RH is reduced; more pores are dried, and capacity increases. An air heater can be used to raise the temperature of the gas stream by $11^{\circ}$ to $14^{\circ} \mathrm{C}\left(20^{\circ}\right.$ to $\left.25^{\circ} \mathrm{F}\right)$ above ambient. This analysis assumed the installation of explosion-proof hazardous air location heaters that would generally be able to raise the ambient air temperature by $11^{\circ} \mathrm{C}\left(20^{\circ} \mathrm{F}\right)$. The need for a heater would be based on the results of a pilot test of the in-well stripping technology.

The air would be monitored during remedial activities so that appropriate mitigative measures could be taken if any airborne contamination was detected. Long-term air monitoring would be implemented following completion of construction to ensure the detection of potential airborne releases of contaminants resulting from system failure during operations. Environmental monitoring would continue at the sites to the extent necessary to ensure long-term performance of the remedy.

After construction of the in-well stripping and associated off-gas treatment systems, the two systems would be carefully monitored on a regular basis, and their performance would be evaluated. The time required for in-situ treatment for Alternative 8 is predicted to range from two to three years, if it is assumed that water can be stripped of $90 \%$ of its TCE by one pass through a vapor stripping well (Cichon et al. 1997) and that the maximum TCE concentration is $1,300 \mu \mathrm{g} / \mathrm{L}$. The actual performance in the field may vary from that assumed during design, given uncertainties about subsurface geology prior to construction and operation.

Because contaminants (other than TCE) would remain in site groundwater at concentrations above those that would allow for unlimited use and unrestricted exposure, reviews would be conducted at least every five years, consistent with CERCLA requirements.

\subsubsection{Alternative 9: In-Situ Chemical Oxidation of TCE Using Fenton-Like Reagents}

Alternative 9 would involve in-situ treatment of the groundwater contaminated with TCE using Fenton's reagent to achieve a TCE groundwater concentration of $5 \mu \mathrm{g} / \mathrm{L}$ or less. Because this 
treatment would actively remediate only TCE, long-term monitoring similar to that described for Alternative 2 would be implemented to address other groundwater contaminants.

Treatment of TCE using Fenton's reagent is a relatively new technology that has been developed over the past few years. It has been used in a limited number of full-scale applications for remediating water contaminated with TCE in fractured bedrock (Pucik et al. 1997) and in soil overburden (Vigneri 1996). Lab-scale tests have been performed to determine the potential of the Fenton's reagent method for remediating water contaminated with TNT (Li et al. 1997) and 2,4-DNT (Mohanty and Wei 1993); however, full-scale application of Fenton's reagent for in-situ treatment of nitroaromatic compounds does not appear to have been performed. Because of this lack of fullscale implementation, this analysis did not consider the potential of Fenton's reagent for in-situ remediation of nitroaromatic compounds.

Using Fenton's reagent to remediate contaminated groundwater has recently received increased attention because of the ability of this technique to oxidatively degrade and in some cases completely mineralize a wide range of contaminants. This oxidation process involves the decomposition of $\mathrm{H}_{2} \mathrm{O}_{2}$ catalyzed by ferrous iron $\left(\mathrm{Fe}^{2+}\right.$ ) or other transition elements leading to hydroxyl radical $(\mathrm{OH} \bullet)$ production:

$$
\mathrm{H}_{2} \mathrm{O}_{2}+\mathrm{Fe}^{2+} \rightarrow \mathrm{OH} \cdot+\mathrm{OH}^{-}+\mathrm{Fe}^{3+}
$$

Hydroxyl radicals are nonspecific oxidants that react with most organic contaminants at rates close to their theoretical limit, which is controlled by the rate of diffusion in water (Kakarla and Watts 1997). The basic overall oxidation reduction of a hydrocarbon (HC) contaminant has the following (simplified) form:

$$
\mathrm{H}_{2} \mathrm{O}_{2}+2 \mathrm{HC}+\mathrm{H}_{2} \mathrm{O} \rightarrow 3 \mathrm{H}_{2} \mathrm{O}+\mathrm{CO}_{2}
$$

An advantage of Fenton's reagent $\left(\mathrm{H}_{2} \mathrm{O}_{2}\right.$ and $\left.\mathrm{Fe}^{2+}\right)$ over other oxidizing agents is the faster rate at which the reagent reacts with many organic compounds and the fact that only innocuous materials (oxygen $\left[\mathrm{O}_{2}\right]$ and water $\left[\mathrm{H}_{2} \mathrm{O}\right]$ ) result from the decomposition of the reagent $\mathrm{H}_{2} \mathrm{O}_{2}$. The process is applicable to the remediation of most volatile and semivolatile organic materials. Also, Fenton's reagent, a dense liquid, has the potential to follow similar pathways as TCE.

Alternative 9 would involve the direct sequential injection into the shallow bedrock aquifer of aqueous solutions of $\mathrm{H}_{2} \mathrm{O}_{2}, \mathrm{FeSO}_{4}$, and other chemicals (e.g., acetic acid) through a well (see Figure 3.8). New wells would be installed for injection purposes. This analysis assumed that these new injection wells would be approximately $10 \mathrm{~cm}$ (4 in.) in diameter and constructed of low carbon steel piping with stainless-steel screen. A treating flow of acetic acid would first be provided to establish acidic conditions conducive to production of hydroxyl radicals by Fenton's reagent. During the acidification step, the groundwater region would typically be brought to a $\mathrm{pH}$ of from 3 to 4 . An 


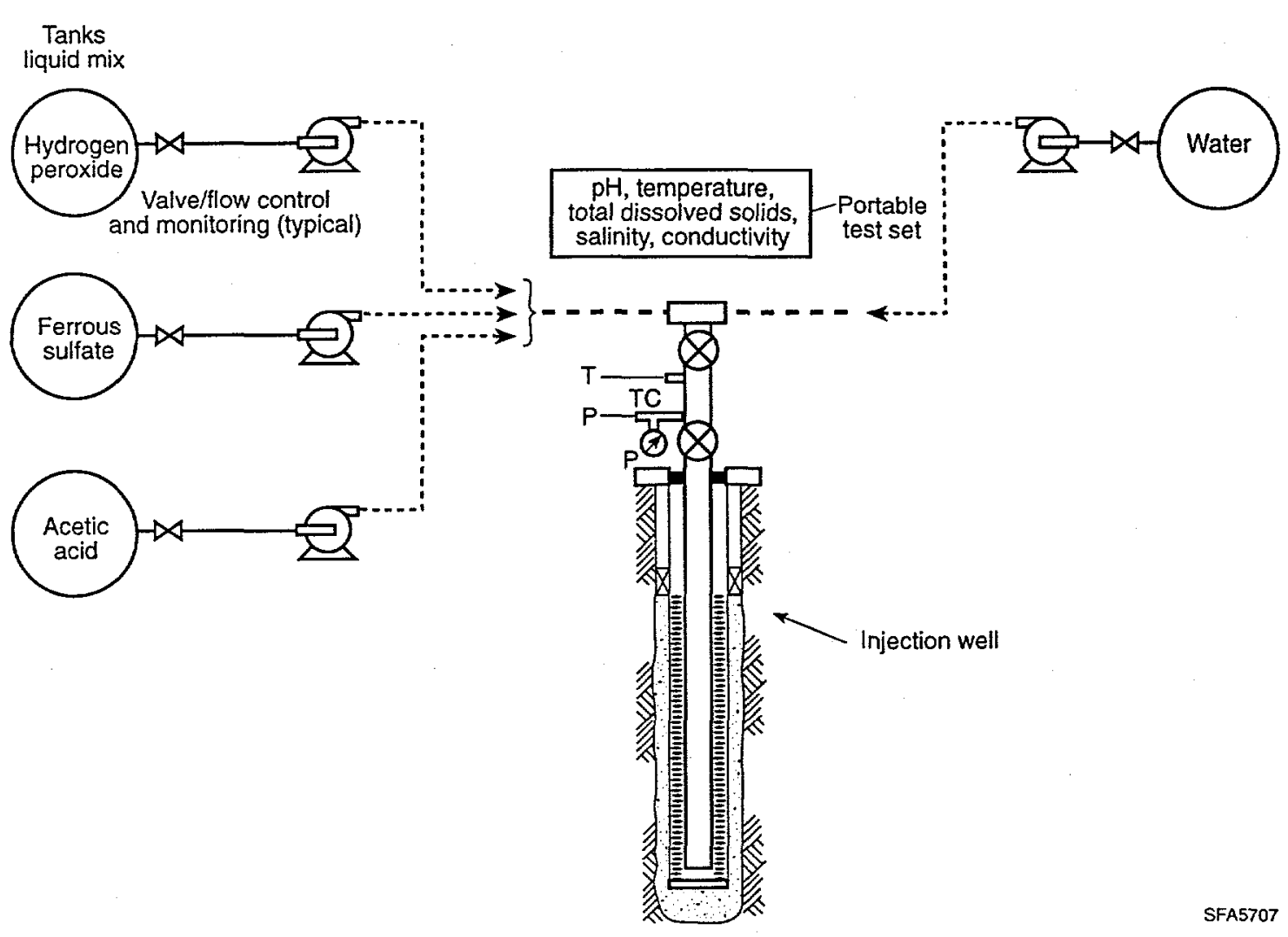

FIGURE 3.8 Application of Fenton-Like Reagents for In-Situ TCE Remediation

aqueous solution of $\mathrm{Fe}^{2+}$ would be introduced into the groundwater to provide a catalyst for disassociation of hydrogen peroxide and to generate hydroxyl-free radicals for oxidizing the TCE contamination. The ultimate reaction products would be expected to be $\mathrm{CO}_{2}$ and $\mathrm{H}_{2} \mathrm{O}$.

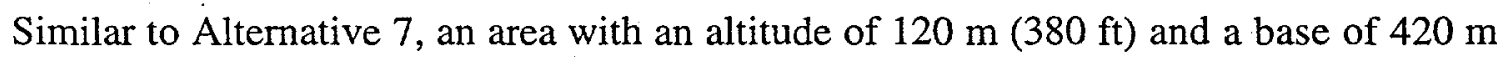
$(1,400 \mathrm{ft})$ was assumed to be remediated by this method for TCE removal under Alternative 9 . The actual design of the remediation system would be determined during the remedial design phase and would take into account the required contact time to achieve reduction of contaminant concentrations, contaminant concentrations likely to be encountered, geochemistry of the shallow bedrock aquifer, and the results of any bench-scale or pilot-scale tests. For this evaluation, two sets of nested wells and multiple rounds (at least two) of chemical reagent injection were assumed.

Bench-scale treatability studies would be performed to evaluate the effectiveness and optimum conditions necessary for successful application of Fenton's reagent. Because the rate of oxidation and the product distribution can be greatly affected by the physical and chemical properties of the subsurface materials, environmental conditions such as $\mathrm{pH}$, and concentrations of the substrate and oxidants, the effects of these parameters would be investigated to ensure the effective application of Fenton's treatment at this location. 


\subsection{CRITERIA FOR SCREENING ALTERNATIVES}

As defined in the NCP (EPA 1990a), the development and screening of the remedial alternatives should be guided by three criteria: effectiveness, implementability, and cost. Effectiveness focuses on (1) the degree to which an alternative reduces toxicity, mobility, or volume through treatment; minimizes residual risks and affords long-term protection; complies with PRGs; and minimizes short-term impacts; and (2) how quickly the alternative achieves protection. Both short-term and long-term effectiveness are evaluated. Short-term effectiveness refers to the active remediation period when construction and implementation activities are performed; long-term effectiveness refers to the period after the remediation activities have been performed.

Implementability focuses on the technical feasibility and availability of the technologies needed for an alternative and the administrative feasibility of implementing that alternative. Timeliness of implementation, potential interference with site operations, and potential future maintenance needs are also assessed as secondary factors.

The cost criterion considers the costs of construction and any long-term costs to operate and maintain the components of an alternative. A general cost analysis should be applied to identify alternatives that are significantly more expensive than other alternatives that achieve the same level of risk reduction (EPA 1988b). Costs considered in this screening process are only approximate, and an alternative is eliminated if it is clearly an order-of-magnitude more expensive than other alternatives that provide the same apparent degree of protection. Alternatives providing effectiveness and implementability similar to the features of another alternative by employing a similar method of treatment or engineering control, but at a greater cost, may also be eliminated.

\subsection{SCREENING OF PRELIMINARY ALTERNATIVES}

\subsubsection{Alternative 1: No Action}

Alternative 1 - which effectively is no further action beyond what has already occurred or is projected to occur - is described in Section 3.3.2.1. The no action alternative provides a baseline for comparison with the other alternatives.

\subsubsection{Effectiveness}

Alternative 1 would provide no additional reduction in risk to human health posed by the contaminated groundwater, other than through natural processes - including reduction of the nitroaromatic compounds and TCE by biodegradation and sorption and attenuation of the uranium 
by decay, sorption, precipitation, and dilution of the contaminated groundwater with rainwater and runoff. Alternative 1 would allow for the possible continued migration of the contaminants and potential further degradation of the groundwater within the WSCP and the WSOW. There would be no reduction in toxicity, mobility, or volume of the contaminated groundwater because no treatment would be involved, and there would be no short-term impacts to members of the public, workers, or the environment during construction or implementation because no remedial action would be conducted.

Alternative 1 would not prevent the use of contaminated groundwater. Under current land use conditions, the contaminated groundwater at the WSCP and the WSOW is not accessed and used and, therefore, poses no imminent risk to human health or the environment. Likely future land use is expected to be similar to current land use. However, concentrations of groundwater contaminants could result in potential unacceptable risk if access and use occurred at levels similar to those under a residential scenario. Therefore, under Alternative 1, protection of human health and the environment in the extended future could not be ensured and verified because all monitoring activities would end.

\subsubsection{Implementability}

No implementability concerns would be posed by Alternative 1 because no action would be taken and no future activities would be considered. No technologies or management strategies would be implemented, nor would any permits, licenses, or approvals associated with undertaking a remedial action be needed.

\subsubsection{Cost}

No net present worth, capital, or annual O\&M costs would be associated with the no action alternative because no activities would be undertaken.

\subsubsection{Alternative 2: Long-Term Monitoring}

Alternative 2 would involve routine sampling and analyses to ensure the protection of human health and the environment. This alternative is described in Section 3.3.2.2. 


\subsubsection{Effectiveness}

Alternative 2 would be protective of human health and the environment over the long term. Monitoring activities would provide data to verify that remediation goals were being met within a reasonable time period and would ensure protection of human health and the environment. Additional response measures would be considered if data indicated potential unacceptable exposure concentrations at receptor locations. (Possible contingency measures are described in Section 3.3.2.2.) Institutional controls could be implemented to prevent access and minimize use of the contaminated groundwater, thereby reducing the potential for exposure and risk to human health.

Alternative 2 would have the least potential short-term environmental impacts among any of the action alternatives. The short-term impacts associated with this alternative would be minimal. Potential physical hazards to workers could result from construction of additional monitoring wells. Appropriate safety and mitigative measures would be taken during construction and operations to protect workers and members of the public.

For Alternative 2 to remain effective over the long term, careful consideration would have to be given to long-term monitoring, maintenance, and control for a reasonable period (e.g., 10 years).

Alternative 2 would not satisfy the statutory preference for treatment as a principal element of remediation, and there would be no reduction in toxicity, mobility, or volume of the contaminated groundwater through treatment. Residual contamination levels would remain as they are in the short term. Concentrations of groundwater contaminants at the WSCP and the WSOW, however, have decreased with time because source control has already been provided through removal, treatment, and storage and disposal of materials that could release contaminants to groundwater (e.g., remediation of contaminated soil, removal of contaminated structures, construction of berms around the raffinate pits at the WSCP to eliminate surface runoff, and dewatering of the raffinate pits). These concentrations are expected to continue to decrease because of infiltration of uncontaminated groundwater from rainwater and runoff and through natural processes such as adsorption to soil particles, biodegradation, and chemical reactions with subsurface materials.

\subsubsection{Implementability}

Few implementability concerns would be posed by Alternative 2 because of the limited actions required. The proposed monitoring would provide data to verify and ensure protection of human health and the environment.

Monitoring could easily be carried out by DOE and the DA. No special equipment or personnel would be required to implement Alternative 2 other than what is commonly associated 
with the construction and operation of groundwater monitoring networks. Procedures are readily available to detect the presence of contaminants in groundwater samples drawn from the monitoring wells. Construction of any proposed monitoring wells would require mobilization of a drilling rig for installation; such equipment is readily available. Resources required for maintenance of the existing and proposed groundwater monitoring systems would also be readily available. Implementation of institutional controls on properties that are not federally owned would require reaching agreement with the appropriate property owners.

\subsubsection{Cost}

The estimated cost of Alternative 2 is relatively low; it would be the least expensive of all the action alternatives. In general, expenses associated with institutional control and monitoring would be low. Capital expenses would include the construction of any monitoring wells and routine replacement of existing equipment for groundwater monitoring. Given the low replacement costs compared with the capital cost for monitoring well installation, the cost of routine equipment replacement was not considered. On the basis of this preconceptual design and the application of cost factors specific to the Weldon Spring site for indirect activities, the capital cost of Alternative 2 is estimated to be approximately $\$ 0.3$ million (Appendix D).

Annual expenses would be incurred for the groundwater monitoring program. The annual cost of operating the proposed monitoring wells was estimated on the basis of the current costs for the existing monitoring well network, assuming that existing wells would be sampled annually. The annual O\&M cost is estimated to be approximately $\$ 0.4$ million. Per EPA guidance, the annual costs were discounted to a current value using a discount rate of $7 \%$ (before taxes and after inflation) (EPA 1993) and a time period of 30 years (EPA 1988a). The 30-year present worth of Alternative 2 is estimated to be approximately $\$ 4.8$ million, which is the lowest of all the action alternatives.

The costs associated with potential future actions (e.g., in the event that migration of residual contamination would result in unacceptable exposure concentrations) were not quantified because the uncertainty associated with these future activities precludes accurate assessment of costs.

\subsubsection{Alternative 3: Natural Attenuation}

Alternative 3 would consist of sampling and analyses to verify and monitor natural processes that would remediate contaminant concentrations to PRGs. This alternative is described in Section 3.3.2.3. 


\subsubsection{Effectiveness}

Alternative 3 would be similar to Alternative 2 in protecting human health and the environment over the long term. Unacceptable impacts to human health and the environment are not expected to occur.

The potential short-term environmental impacts associated with Alternative 3 are minimal and, like those for Alternative 2, would result from the construction and operation of additional monitoring wells (approximately 15 additional monitoring wells were estimated as part of the evaluation for this alternative in this FS). The short-term impacts associated with Alternative 3 would be similar to Alternative 2 .

Institutional controls could be implemented to prevent access and minimize use of the contaminated groundwater. This would further reduce the potential for exposure and risk to human health. For Alternative 3 to remain effective over the long term, careful consideration would have to be given to long-term monitoring for a reasonable period (i.e., greater than 10 years).

Alternative 3 would not satisfy the statutory preference for treatment as a principal element of remediation and would not result in reduction in toxicity, mobility, or volume of the contaminated groundwater through treatment. Contamination levels would remain as they are in the short term. Contaminant concentrations at the WSCP and the WSOW, however, have already decreased with time as a result of the following: source control, in the form of treatment of materials that might release contaminants to groundwater (e.g., remediation of the contaminated soil, removal of contaminated structures, construction of berms around the raffinate pits at the WSCP to eliminate surface runoff, and dewatering of the raffinate pits); infiltration from rainwater and runoff; and natural processes such as biodegradation, adsorption, and chemical reactions with subsurface materials.

\subsubsection{Implementability}

One implementability issue for Alternative 3 would be determining site-specific biodegradation rates. These rates must be determined because biodegradation is considered to be the dominant contaminant degradation process for natural attenuation. A site-specific biodegradation rate would be required for all contaminants; these rates would be compared with the rates of contaminant transport and natural attenuation to assess whether natural attenuation would degrade contaminants to acceptable levels. Evidence exists that DNT will degrade under the groundwater conditions present at the WSOW shallow aquifer (Bradley et al. 1997). Laboratory "microcosm" studies might have to be developed to simulate aquifer conditions and to demonstrate that native bacteria could create the necessary biochemical reactions to destroy contaminants other than DNT. In some cases, these data might be inconclusive or ambiguous because of technical difficulties in 
collecting data in the field (Odermatt 1997). Nearly complete removal of TNT by microbial degradation can be achieved in several months under laboratory conditions (Bradley and Chapelle 1995); however, the rates of degradation of nitroaromatic compounds are expected to be slower in the field (see Section 3.3.2.2). Thus, laboratory studies, which are generally timeconsuming and expensive, might not provide adequate documentation that biodegradation is taking place or quantify the biodegradation rate.

Another implementability issue for Alternative 3 is the development of a three-dimensional representation of the site's hydrogeologic and contaminant transport system. Simulation of natural attenuation requires using analytical or numerical solute fate and transport modeling. These data would be used to determine whether natural attenuation was sufficient to prevent contaminant migration from completing exposure pathways in concentrations above applicable regulatory or riskbased corrective action standards. (Thus, determining the potential decrease in contaminant concentrations currently on-site, assuming no groundwater movement, would not account for potential contaminant transport to off-site receptors or establish whether natural attenuation processes would reduce contaminant concentrations to acceptable risk levels.) Transport modeling of the shallow aquifer on a three-dimensional basis would be difficult because of the high temporal variation in the groundwater flow regime (see Section 3.3.3.2). Two regimes of groundwater flow are postulated to exist in the shallow bedrock aquifer: diffuse flow and high-velocity turbulent flow occurring in conduits and in large, isolated fractures. Diffuse flow follows Darcy's law for a porous medium, but turbulent flow does not. Accurate representation of site conditions would require consideration of both flow regimes. Two models might have to be developed; one model would assume a groundwater flow system dominated by porous media, and the other would assume a system dominated by fracture flow.

Monitoring would provide notice of failure before unacceptable exposure occurred, which would allow contingency measures to be taken. Contaminant migration could easily be monitored; no special equipment or personnel would be required beyond what is already available at the sites. Existing analytical procedures could be used to determine the presence of contaminants (such as nitroaromatic compounds) in groundwater samples drawn from the monitoring wells. However, new procedures might have to be developed for sampling and analysis of parameters used to determine the extent of contaminant degradation (e.g., nutrients and electron acceptors such as dissolved oxygen). Construction of any proposed monitoring wells would require mobilization of a drilling rig for installation; such equipment is readily available. Resources required for maintenance of the existing and proposed groundwater monitoring systems should be readily available. Implementation of institutional controls on properties that are not federally owned would require reaching agreement with the appropriate property owners. 


\subsubsection{Cost}

The cost would be slightly higher for Alternative 3 than for Alternative 2 . On the basis of engineering judgment, it was assumed that the cost for additional subsurface sampling and sample analysis to confirm contaminant degradation rates and cleanup status would be similar to the cost of a remedial investigation for the WSCP and the WSOW. On the basis of this preconceptual design and application of cost factors specific to the DOE Weldon Spring site for indirect activities, the capital cost of Alternative 3 was estimated to be approximately $\$ 0.7$ million (Appendix D). The capital cost would be primarily for construction of the proposed monitoring wells.

Annual expenses would be incurred from the groundwater monitoring program. The annual cost of operating the proposed monitoring wells was estimated on the basis of current costs for the existing monitoring well network, assuming that existing wells would be sampled annually. It was also assumed that the field investigations to verify and monitor natural remediation processes would be performed over a five-year period, and that these costs would be included as an annual O\&M cost. The annual O\&M cost was estimated to be between $\$ 1$ million and $\$ 2$ million (Appendix $D$ ). Assuming a discount rate of $7 \%$ per year, the 30-year present worth of Alternative 3 would be approximately $\$ 10$ million (Appendix D).

The costs associated with potential future actions (e.g., if migration of residual contamination resulted in unacceptable exposure concentrations) were not quantified because the uncertainty associated with these future activities precludes accurate assessment of these costs.

\subsubsection{Alternative 4: Groundwater Removal and On-Site Treatment Using Granular Activated Carbon}

Alternative 4 would involve extraction of contaminated groundwater using vertical wells and on-site treatment using GAC. This alternative is described in Section 3.3.2.4.

\subsubsection{Effectiveness}

Alternative 4 would protect human health and the environment by remediating groundwater in the shallow bedrock aquifer to reduce contaminant concentrations to levels below PRGs. In addition, any potential further contaminant migration would be largely halted upon implementation of this alternative, and any potential future large-scale contamination of the nearby springs would be effectively prevented. Alternative 4 would be expected to attain all PRGs when remediation was complete. The time required for installation of the treatment system has been estimated at two to three years. 
Alternative 4 would reduce the volume of contaminants through treatment and would provide long-term protection. After remediation was complete, no long-term action would be required.

The short-term impacts associated with Alternative 4 would include the following:

- Physical hazards to workers during installation of the extraction wells, construction and operation of the groundwater treatment facilities, and operation of the monitoring systems;

- Criteria pollutant emissions during construction;

- Disturbance of soil during site clearing, excavation, and regrading for construction of the groundwater treatment facilities and the resulting dust emissions; and

- Off-site transport of spent carbon.

Appropriate mitigative measures would be taken during construction and operations to protect workers and members of the public. Special safety precautions would be maintained during removal and handling of the spent carbon contaminated with explosives because spontaneous combustion could potentially occur at certain conditions of temperature and humidity (EPA 1995b). Engineering controls (such as spraying water for dust suppression) would be used to minimize shortterm risks to the public, and the air would be monitored to verify that the controls were working. Protective equipment and dust suppression methods would be used to minimize short-term risks to workers. More short-term impacts would result from Alternative 4 than from Alternative 5 because of the off-site transport of spent carbon for disposal.

\subsubsection{Implementability}

The groundwater extraction and treatment technology associated with Alternative 4 has been widely used and found reliable if properly constructed and maintained. However, there are a number of implementability concerns posed by this alternative for this application.

Although groundwater extraction via vertical wells is a relatively mature technology with a history of operating experience, it is generally not applicable when contaminated groundwater migrates into formations from which the groundwater cannot easily be removed, such as fractured bedrock or karst aquifers. The heterogeneous nature of the shallow bedrock aquifer might preclude extraction rates sufficient to attain PRGs. In addition, conventional groundwater treatment is not effective in areas with low permeability (less than $1 \times 10^{-4} \mathrm{~cm} / \mathrm{s}$ ); formations with a high degree of 
secondary permeability, such as fractured bedrock; and low-solubility contaminants that tend to absorb in the subsurface media (Roote et al. 1997). Drawdown pump test studies might be needed to determine long-term sustainable pumping rates for various points at the WSCP and the WSOW.

Other implementability issues would be associated with conventional extraction. Such issues would include the generation of substantial amounts of wastewater requiring treatment prior to discharge, high energy costs for pumping and moving large volumes of water (which might require additional site infrastructure to supply the necessary electricity), indiscriminate removal of all groundwater components (including those with contaminant concentrations below health-based levels), and general slow progress toward regulatory goals because of technical limitations.

A major implementability issue concerns the extraction of TCE-contaminated groundwater. The proposed groundwater extraction system might not be effective for aquifer restoration to ARARs for TCE. Significant amounts of data have indicated that conventional technologies, such as pump and treat, were ineffective in treating groundwater contaminated with TCE.

This implementability issue is the result of technical limitations of groundwater remediation technologies, which include contaminant-related factors (e.g., slow desorption of contaminants from aquifer materials) and hydrogeologic factors such as aquifers of very low permeability or with a high degree of heterogeneity (i.e., containing fractured media or karst, both of which have been observed at the WSCP and the WSOW).

For example, contaminated groundwater at the Twin Cities Army Ammunition Plant at New Brighton, Minnesota, is currently being remediated with conventional pump-and-treat technology (EPA 1995a). Groundwater extraction followed by air stripping has been used at this site to treat contaminated groundwater. TCE is the most prevalent contaminant in the groundwater. The underlying geology at the site is complex and contains heterogeneities such as fractured bedrock and discontinuous sand layers. The hydraulic conductivity at this site ranges from $3.5 \times 10^{-7}$ to $4.8 \times 10^{-2} \mathrm{~cm} / \mathrm{s}(0.001$ to $137 \mathrm{ft} / \mathrm{d})$, with transmissivities between 34 to $309 \mathrm{~cm}^{2} / \mathrm{s}(3,160$ to $28,724 \mathrm{ft}^{2} / \mathrm{d}$ ). (For comparison, the hydraulic conductivity at the WSCP varies from $5.3 \times 10^{-6}$ to $8.9 \times 10^{-5} \mathrm{~cm} / \mathrm{s}$ [0.015 to $\left.0.25 \mathrm{ft} / \mathrm{d}\right]$.) Although over 5.3 billion liters (1.4 billion gallons) of water was removed from the aquifer at the Twin Cities Army Ammunition Plant from October 1991 to September 1992, TCE plumes have changed little after several years of treatment. An estimate of the time required for complete remediation has been revised from 30 years to 50 to 70 years, on the basis of a review of data collected to date. Although the hydrogeologic conditions at the Twin Cities Army Ammunition Plant do not exactly match those at the WSCP, the operational history at the Twin Cities Army Ammunition Plant would indicate that conventional pump-and-treat of the TCE at the WSCP may not be the optimal remediation approach.

No special equipment would be required to implement Alternative 4. It might, however, become necessary to conduct detailed studies to determine whether the proposed vertical extraction 
well network would achieve acceptably low concentrations in the groundwater, given the underlying lithology at the WSCP and the WSOW. Vendor expertise would be required for carbon selection because the type and pore size of the carbon, as well as operating temperature, would affect process performance. Bench tests using a groundwater sample from the WSCP and the WSOW might be needed to estimate the carbon usage rate and optimal contact time because the presence of multiple contaminants could affect process performance.

Resources required for maintenance and monitoring should be readily available. The replacement of spent carbon would require an engineer to supervise the operation. Depending on the design, replacement of the spent carbon could take from 1 to 12 hours, with an average time of 6 hours. Resources required for maintenance of the groundwater extraction and product pumps and associated controls should be readily available. Pump maintenance and repair would generally be needed every 18 months. The only other requirement would be maintenance of the groundwater monitoring wells, which is currently ongoing and does not require any additional special equipment or personnel.

Another major implementability concern for Alternative 4 is the active life of the groundwater treatment facilities, which is generally about 30 to 35 years. Three to four equivalent plant lifetimes of treatment capacity (or more) might be required to meet the estimated treatment duration of at least 100 years for extraction of 2,4-DNT-contaminated groundwater. The technical feasibility of this aspect of Alternative 4 is uncertain given the potential number of replacement facilities that would be required if conventional extraction of 2,4-DNT was applied.

To allow discharge of the treated water to the Missouri River, the groundwater treatment facilities at the WSCP and the WSOW would have to meet the substantive requirements and standards of Missouri National Pollutant Discharge Elimination System (NPDES) regulations. Monitoring of the treated groundwater prior to its release to the Missouri River would be required to ensure compliance with state discharge regulations.

\subsubsection{Cost}

The estimated cost of Alternative 4 is slightly lower than that of Alternative 5. On the basis of the preconceptual design and application of cost factors for indirect activities, the capital cost of Alternative 4 is estimated to be between $\$ 41$ million and \$120 million (Appendix D). The capital cost would be primarily for installation of the approximately 330 to 1,000 extraction wells.

The annual O\&M cost is estimated to be between $\$ 2$ million and $\$ 4$ million per year (Appendix D). The annual O\&M costs would be primarily for groundwater extraction and treatment. Assuming a discount rate of $7 \%$ per year, the 30-year present worth of Alternative 4 is estimated to 
be approximately $\$ 53$ million to $\$ 140$ million (Appendix $D$ ), much greater than that for Alternatives 2 or 3 .

\subsubsection{Alternative 5: Groundwater Removal and On-Site Treatment Using Ultraviolet Oxidation}

Alternative 5 would consist of extracting contaminated groundwater via vertical wells and treatment on-site of the TCE and nitroaromatic compounds using UV oxidation. This alternative is described in Section 3.3.2.5.

\subsubsection{Effectiveness}

The effectiveness of Alternative 5 would be similar to that of Alternative 4, except that special safety precautions would be maintained during handling and storage of $\mathrm{H}_{2} \mathrm{O}_{2}$, and off-site shipment and disposal of spent carbon would not be necessary.

\subsubsection{Implementability}

UV oxidation is currently being used for wastewater treatment; however, a number of implementability concerns would be posed by Alternative 5 at this location. The potential difficulties associated with groundwater extraction would be similar to those discussed for Alternative 4 .

One implementability issue for Alternative 5 would be the fact that UV oxidation is an innovative groundwater treatment technology that has been used in full-scale groundwater treatment applications for only 12 years. As of 1994, UV oxidation was in operation in 15 full-scale remedial applications; the majority of these applications were for groundwater contaminated with petroleum products or industrial solvent-related organics (such as TCE and vinyl chloride) (Marks et al. 1994). Another concern would be the possible formation of intermediate compounds that would be more hazardous and less reactive to UV oxidation. Pilot-scale and/or treatability studies might be necessary to ensure that UV oxidation could successfully reduce contaminant levels for the groundwater within the shallow bedrock aquifer. One disadvantage of UV oxidation would be its high electrical consumption, which might limit the rate of treatment on the basis of the availability of needed electrical capacity.

UV oxidation is an innovative technology, and special equipment (i.e., the UV oxidation unit) would be needed to implement this alternative. Specialists might be required to establish the proper UV system design parameters - for example, UV radiation source (i.e., high or low intensity) and UV system design (i.e., whether to use ozone generation, $\mathrm{H}_{2} \mathrm{O}_{2}$, and/or cavitation in 
the formation of hydroxyl radicals and in direct photolysis of some contaminants). Detailed studies may be required to determine whether the proposed vertical extraction well network would achieve acceptably low concentrations in the groundwater, given the underlying lithology at the WSCP and the WSOW.

Resources required for maintenance and monitoring should be readily available. A typical UV oxidation unit requires about 2 to 10 hours each week for maintenance, including daily checks. Resources required for maintenance of the groundwater extraction and product pumps and associated controls should be readily available. Pump maintenance and repair would generally be necessary every 18 months. The only other requirement would be maintenance of the groundwater monitoring wells, which is currently ongoing and does not require any additional special equipment or personnel.

Another major implementability concern for Alternative 5 is the active life of the groundwater treatment facilities, which is generally about 30 to 35 years. Three to four equivalent plant lifetimes of treatment capacity or more might be required to meet the estimated treatment duration of at least 100 years for extraction of 2,4-DNT-contaminated groundwater. The technical feasibility of this aspect of Alternative 5 appears uncertain, given the potential number of replacement facilities that would be required if conventional extraction of 2,4-DNT was applied.

To allow discharge of the treated water to the Missouri River, the groundwater treatment facilities at the WSCP and the WSOW would have to meet the substantive requirements of Missouri NPDES regulations. Monitoring of the treated groundwater prior to its release to the Missouri River would be required to verify compliance with state discharge regulations.

\subsubsection{Cost}

The estimated cost of Alternative 5 is slightly higher than that of Alternative 4. Costs for UV oxidation are generally higher than those of competing technologies because of energy requirements (Marks et al. 1994). On the basis of the preconceptual design and application of cost factors specific to the Weldon Spring site for indirect activities, the capital cost of Alternative 5 is estimated to be between $\$ 42$ million and $\$ 120$ million (Appendix D). The capital cost would be primarily for the installation of 330 to 1,000 extraction wells.

The annual O\&M cost is estimated to be between $\$ 2$ million and $\$ 4$ million per year (Appendix D). The O\&M costs for UV oxidation would be affected by the groundwater characteristics, treatment process design (lamp maintenance and oxidant dosage costs), and operations. The annual O\&M costs would be primarily for groundwater extraction and treatment. Assuming a discount rate of $7 \%$ per year, the 30-year present worth of Alternative 5 is estimated to be between $\$ 54$ million and $\$ 140$ million (Appendix D) higher than that for Alternative 4. 


\subsubsection{Alternative 6: Groundwater Removal and On-Site Treatment Using Phytoremediation}

Alternative 6 would consist of extracting contaminated groundwater by means of vertical wells and treatment on-site using phytoremediation. This alternative is described in Section 3.3.2.6.

\subsubsection{Effectiveness}

Alternative 6 would be protective of human health and the environment by reducing contaminant concentrations in groundwater in the shallow bedrock aquifer to below PRGs. In addition, any potential contaminant migration would be largely halted upon implementation of this alternative, and any potential future large-scale contamination of the aboveground springs would be effectively prevented. Alternative 6 might be expected to attain all PRGs when remediation was complete. Wetlands construction has been estimated to take about one to two years.

Alternative 6 would reduce the volume of contaminants through treatment and would afford long-term protection. After remediation was complete, long-term action might not be required. One long-term indirect benefit to be considered would be the development of additional wetlands that could be released for public use after completion of active remediation. These wetlands could potentially be used for green space, wildlife habitat, and recreational and educational areas. The decision regarding removal of the constructed wetlands following completion of the groundwater treatment would be made in collaboration with the regulators.

The short-term impacts associated with Alternative 6 would include the following:

- Physical hazards to workers during installation of the extraction wells, construction and operation of the wetlands, and operation of the monitoring systems;

- Criteria pollutant emissions during construction; and

- Disturbance of soil (during site clearing, excavation, and regrading during construction of the wetlands) and the resulting airborne dust emissions.

Appropriate mitigative measures would be taken during construction and operations to protect workers and members of the public. Engineering controls, such as spraying water for dust suppression, would be used to minimize short-term risks to the public. The air would be monitored to verify that the controls were working. Because of the potential for contaminant release during cultivation and planting, protective equipment and dust suppression methods would be used to minimize short-term risks to workers. Fewer short-term impacts would result from Alternative 6 than from Alternatives 4 and 5 . 
The operational duration for Alternative 6 would be expected to be the longest among all alternatives involving active remediation because of the curtailment of active remediation during the winter.

\subsubsection{Implementability}

Phytoremediation is commonly used to treat wastewater; however, a number of implementability concerns would be posed by Alternative 6 at this location. The potential difficulties associated with groundwater extraction would be similar to those discussed for Alternative 4 .

A major implementability concern for Alternative 6 is the uncertainty about whether phytoremediation could sufficiently reduce the contamination to meet EPA cleanup targets for drinking water. The possibility exists for the binding or complexation of some of the contaminants with the exudates and their subsequent transport by the groundwater through the constructed wetland without further contaminant reduction; therefore, research would be required to find suitable plants for further investigation. Bench-scale and pilot-scale testing would then be conducted of the promising plant species; groundwater samples would be taken from the WSCP and the WSOW.

One implementability concern is the relative newness of phytoremediation compared with the other technologies. Field investigations would be necessary before phytoremediation could be applied at the Weldon Spring site.

This analysis assumed that concurrent phytoremediation of nitroaromatic compounds and chlorinated organics such as TCE would be possible within a single constructed wetland. However, a plant designed to phytoremediate one contaminant might be inhibited by the presence of a different contaminant. Research would have to be conducted prior to the RD/RA phase with samples of extracted groundwater from the WSCP and the WSOW to ensure the successful implementation of Alternative 6.

A key design consideration and potential implementability concern is associated with avoiding recontamination of the groundwater because of failure of the liner. Additional design features such as multiple liner systems and/or subsurface drains might be necessary.

Another implementability concern for Alternative 6 involves the control of animals drinking water from the wetland or feeding on wetland plants. At the influent of the wetland, contaminant removal would be limited. Thus, a potential adverse effect on the food chain could occur if insects and small rodents ate the plants that were collecting the contaminants and these organisms were then eaten by larger mammals. Control of wildlife might be necessary, which could be difficult given the large estimated area of the proposed constructed wetlands. 
Information is lacking with regard to whether contaminants can collect within the plants and be released from the plants after harvesting. Development of proper handling procedures and the potential requirement for disposal have not been resolved from a regulatory point of view.

Phytoremediation is generally applied in warmer climates, which allows continuous remediation throughout the year. The potential application of phytoremediation at the Weldon Spring site might be limited in this respect.

Temperature is among the many variables involved in using constructed wetlands. When the temperature drops below a certain point, wetland plants cease to take up nutrients and die, and microbial activity drops off considerably. For this reason, a constructed wetland would not provide a stable level of treatment year round. Seasonal variation in the performance of Alternative 6 would have to be established through field testing.

Another implementability issue for Alternative 6 concerns how well the plant species identified for contaminant degradation (e.g., parrot feather and Eurasian water milfoil for nitroaromatic degradation) would adapt climatically to the Weldon Spring site.

No special equipment or personnel would be required to implement Alternative 6 after completion of any bench-scale and pilot-scale testing. Phytoremediation typically uses equipment and materials common to agricultural practice. A technician on a part-time basis could operate the wetlands system and perform any cultivation and planting.

Resources for maintenance and monitoring should be readily available. Maintenance would require about one hour per month. Basic chemical and biological laboratory analyses of water and plant samples would be required. Resources required for maintenance of the groundwater extraction and product pumps and associated controls should be readily available. Pump maintenance and repair would generally be needed every 18 months. The only other requirement would be maintenance of the groundwater monitoring wells, which is currently ongoing and does not require any additional or special equipment or personnel.

To allow discharge of the treated water to the Missouri River, the effluent from the constructed wetlands at the WSCP and the WSOW would have to meet substantive requirements of Missouri NPDES discharge regulations. Monitoring of the treated groundwater prior to its release to the Missouri River would be required to verify compliance with state discharge regulations.

\subsubsection{Cost}

The estimated cost of Alternative 6 is relatively high, even though phytoremediation has been shown to be a low-cost technology for treatment of contaminated sites. The high cost would 
result from the required construction of between 330 and 1,000 extraction wells. On the basis of this preconceptual design, which uses preliminary phytoremediation cost data provided in Medina and McCutcheon (1996) and applies cost factors specific to the Weldon Spring site for indirect activities, the capital cost of Alternative 6 is estimated to be between $\$ 36$ million and $\$ 110$ million (Appendix D).

Including the operating cost of the phytoremediation system and continued groundwater monitoring, the annual O\&M cost is estimated to be between $\$ 0.8$ million and $\$ 1.8$ million per year (Appendix D). These costs would be primarily for groundwater monitoring. Assuming a discount rate of $7 \%$ per year, the 30-year present worth of Alternative 6 is estimated to be between $\$ 46$ million and $\$ 130$ million (Appendix D).

\subsubsection{Alternative 7: Removal and On-Site Treatment of TCE-Contaminated Groundwater}

Alternative 7 would involve extraction of TCE-contaminated groundwater and ex-situ treatment on-site using adsorption onto GAC. Long-term monitoring would be implemented to address the other groundwater contaminants. This alternative is described in Section 3.3.2.7.

\subsubsection{Effectiveness}

Alternative 7 would actively remediate only TCE. Alternative 7 would provide further protection to human health and the environment by reducing TCE concentrations in groundwater at the WSCP and the WSOW to below the ARAR of $5 \mu \mathrm{g} / \mathrm{L}$. In addition, TCE migration would be largely halted upon implementation of this alternative, and any potential future contamination by TCE of the aboveground springs would be effectively prevented. Alternative 7 might be expected to attain ARARs for TCE when remediation was completed. Remediation via this alternative has been estimated to take approximately two to three years.

Alternative 7 would reduce the volume of TCE through treatment and would afford longterm protection against further spread in the groundwater system. Alternative 7 would also be protective of human health and the environment over the long term for groundwater contaminants other than TCE. Monitoring data would verify and ensure protection of human health and the environment and would indicate that remediation goals were being met. Response measures, such as land use restriction, would be considered if data indicated that contaminant concentrations would result in unacceptable exposure in the future. Unacceptable impacts to human health and the environment are not expected to occur.

The short-term impacts associated with this alternative are minimal and could include potential physical hazards to workers during installation of the extraction wells, construction and 
operation of the groundwater treatment facilities, and operation of the monitoring systems; criteria pollutant emissions during construction; disturbance of soil and its resulting airborne dust emissions; and off-site transport of spent carbon. Appropriate mitigative measures would be taken during construction and operations to protect the workforce and the public. More short-term impacts would result from this alternative than from Alternative 8 because of the large number of extraction wells that have to be installed (between 200 and 650 wells).

For Alternative 7 to remain effective over the long term for contaminants other than TCE (which would be remediated under this alternative), careful consideration would have to be given to monitoring, maintenance, and control over a relatively long period (i.e., greater than 100 years). Because this alternative would leave contaminants (other than TCE) on-site at concentrations above those that allow for unlimited use and unrestricted exposure, reviews would be conducted at least every five years, consistent with CERCLA requirements.

Alternative 7 would satisfy the statutory preference for treatment as a principal element of remediation for contaminants relative to TCE only; similarly, reduction in toxicity, mobility, or volume of the contaminated groundwater would be achieved relative to TCE treatment only. Contamination levels would remain as they are in the short term. The concentrations of groundwater contaminants at the WSCP and the WSOW, however, are expected to decrease with time because of the removal of the original sources of the contamination and the natural processes that occur, including dilution by infiltration and biodegradation.

\subsubsection{Implementability}

A number of implementability concerns would be posed by Alternative 7 . The potential concerns with groundwater monitoring and groundwater extraction and treatment using GAC would be similar to those discussed for Alternatives 2 and 4, respectively.

A major implementability issue concerns the extraction of TCE-contaminated groundwater. The proposed groundwater extraction system might not be effective for aquifer restoration to ARARs for TCE.

No special equipment would be required to implement Alternative 7. It might, however, become necessary to conduct detailed studies to determine whether the proposed groundwater extraction well network would achieve acceptably low concentrations in the groundwater. Resources required for maintenance and monitoring should be readily available.

A major implementability concern for Alternative 7 is the possibility of dewatering the shallow aquifer. Enhancing the recovery of contaminants from the shallow aquifer if dewatering occurs may require pulsed pumping. In pulsed pumping, some or all extraction pumps are turned off 
and then back on for specified periods of time. Although not widely used in remedies to date, pulsed pumping can recover contaminants located in the portions of an aquifer that have been dewatered, eliminate flow stagnation areas, and allow sorbed contaminants to partition into groundwater. Application of pulsed pumping (or other measures such as adjusting the rate of extraction from some or all wells) may affect the time frame estimated to reduce TCE groundwater concentrations to a maximum of $5 \mu \mathrm{g} / \mathrm{L}$.

To allow discharge of the treated water to the Missouri River, the groundwater treatment facility would have to meet the substantive requirements and standards of Missouri NPDES regulations. Monitoring of the treated groundwater prior to its release to the Missouri River would be required to ensure compliance with state discharge regulations.

\subsubsection{Cost}

The estimated cost of Alternative 7 is much higher than that of Alternative 8. On the basis of the preconceptual design and application of cost factors for indirect activities, the capital cost of Alternative 7 is estimated to range between $\$ 9$ million and $\$ 25$ million, depending on the number of extraction wells required (i.e., 200 to 650 wells). The capital cost would be primarily for installation of the 200 to 650 extraction wells.

The annual O\&M cost is estimated to range between $\$ 1$ million and $\$ 2$ million per year. The annual $O \& M$ costs would be primarily for groundwater extraction and treatment. Assuming a discount rate of $7 \%$ per year, the 30 -year present worth of Alternative 7 is estimated to range from $\$ 23$ million to $\$ 53$ million, much greater than that for Alternative 8 .

\subsubsection{Alternative 8: In-Situ Treatment of TCE Using In-Well Vapor Stripping}

Alternative 8 would consist of in-situ treatment of groundwater contaminated with TCE using in-well vapor stripping. Long-term monitoring would be implemented to address other groundwater contaminants. This alternative is described in Section 3.3.2.8.

\subsubsection{Effectiveness}

Similar to Alternative 7 , Alternative 8 would actively remediate only TCE. Alternative 8 would protect human health and the environment by reducing TCE concentrations in the groundwater primarily at the WSCP to the ARAR of $5.0 \mu \mathrm{g} / \mathrm{L}$. In addition, TCE migration would be largely halted upon implementation of this alternative, and any potential future large-scale contamination of the aboveground springs by TCE would be effectively prevented. Alternative 8 
would be expected to attain ARARs for TCE when remediation was completed. The remediation period has been estimated to take approximately two to three years.

Alternative 8 would reduce the volume of TCE through treatment and afford long-term protection against potential widespread groundwater contamination. Alternative 8 would also be protective of human health and the environment over the long term for groundwater contaminants other than TCE. Monitoring would provide data to verify and ensure continued protection of human health and the environment. Monitoring activities would provide data to indicate that remediation goals were being met. Active response measures would be considered if future migration of residual contaminant concentrations would result in unacceptable exposure at existing or potential receptors. Unacceptable impacts to human health and the environment would not be expected to occur.

The short-term impacts associated with this alternative are associated with the physical hazards to workers during construction of the vapor stripping wells and operation of the in-well vapor stripping remediation system, minor criteria pollutant emissions during construction, and the disturbance of soil and its resulting airborne dust emissions. Appropriate mitigative measures would be taken during construction and operations to protect the workforce and the public. Exposure to TCE from duct leaks or venting from the wells is possible. Air monitoring would be used to make sure that the controls are working. Protective equipment and dust suppression methods would be enacted to minimize short-term risks to workers. Precautions would be taken to prevent spills or releases during transportation of GAC canisters for off-site treatment and disposal. More short-term impacts would result from this alternative than from Alternative 7, because of the off-site transport of spent carbon for disposal.

For Alternative 8 to remain effective over the long term for contaminants other than TCE (which would be remediated under this alternative), careful consideration would have to be given to monitoring, maintenance, and control over a relatively long period (i.e., greater than 100 years).

Alternative 8 would not satisfy the statutory preference for treatment as a principal element of remediation, and there would be no reduction in toxicity, mobility, or volume of the contaminated groundwater through treatment for contaminants other than TCE. Residual levels of contamination would remain high in the short term. Contaminant concentrations at the WSCP and the WSOW, however, have decreased with time because of the removal of the original source of the contamination, dilution from infiltration from rainwater and runoff, and biodegradation.

\subsubsection{Implementability}

A number of implementability concerns would be posed by Alternative 8 . One potential concern for Alternative 8 is the application of the in-well vapor stripping technology at the WSCP and the WSOW. In-well stripping has been used in a variety of soil types from silty clay to gravel. 
Because reinfiltration of stripped water is integral to the process, the soil should be low in clay content and have a hydraulic conductivity exceeding $1 \times 10^{-5} \mathrm{~cm} / \mathrm{s}(0.03 \mathrm{ft} / \mathrm{d})$. Because the in-well vapor stripping system would have to be installed into the shallow (consolidated) bedrock aquifer with hydraulic conductivities two to three orders of magnitude lower than the minimum hydraulic conductivity of $1 \times 10^{-5} \mathrm{~cm} / \mathrm{s}(0.03 \mathrm{ft} / \mathrm{d})$ in some locations, the application of this remediation technology would likely require field testing and treatability studies under site-specific conditions. These additional studies would also be useful in determining correct placement of the in-well vapor stripping remediation system.

Another potential concern is that the circulation pattern of the in-well stripping technology cannot be assured at some sites and could potentially lead to loss of hydraulic control of the reinfiltrating water (Cichon et al. 1997). If the vapor stripping wells are not properly designed or constructed, the TCE-contaminated zone may spread beyond the wells' radius of influence.

On the basis of an assumed stripping efficiency of $90 \%$, between two and three recirculations of TCE-contaminated groundwater through the in-situ vapor stripping process would be necessary to achieve the ARAR of $5 \mu \mathrm{g} / \mathrm{L}$. Because of the heterogeneity of the TCE-contaminated zone in terms of aquifer thickness and hydraulic conductivity (both horizontal and vertical), it is not known whether the required number of recirculations would be achieved.

In-well stripping removes excess $\mathrm{CO}_{2}$ from the groundwater and equilibrates the groundwater with atmospheric $\mathrm{CO}_{2}$ levels. As the $\mathrm{CO}_{2}$ is stripped from the groundwater, the $\mathrm{pH}$ rises. Chemical precipitates may form during air stripping and may clog the well screens, thus limiting groundwater circulation. High levels of dissolved iron and/or manganese and high alkalinity can also cause problems; these conditions appear to exist within the shallow aquifer containing the TCE contamination. Managing the chemical changes in the groundwater, soil, and aquifer (such as chemical precipitation or oxidation) that may accompany use of this system (PNNL 1994) may pose problems.

No special equipment would be required to implement Alternative 8 . The method itself involves no moving parts beneath the ground surface; however, careful packer and well designs would be required to successfully divert the groundwater from the well back into the unsaturated zone and to the water table. Most of the equipment used in this technology is available off-the-shelf and has proven to be reliable. The system is designed to run continuously with only routine maintenance. One to two persons would be required to maintain and monitor the in-well vapor stripping system; the expertise needed to use and monitor in-well vapor stripping technology is limited to three suppliers in the private sector (Miller and Roote 1997).

The application of in-well vapor stripping for the remediation of TCE in bedrock aquifers is in the developmental phase, and numerous aspects of the process, as considered for Alternative 8, have not been proven (e.g., its application in a consolidated aquifer at hydraulic conductivities lower 
than $\left.1 \times 10^{-5} \mathrm{~cm} / \mathrm{s}[0.03 \mathrm{ft} / \mathrm{d}]\right)$. The technical feasibility of this aspect of Alternative 8 appears uncertain.

Groundwater monitoring would be required to track the progress and effectiveness of the groundwater remediation. Monitoring at various depths may be necessary to show that the appropriate recirculation path has been established. Resources required for maintenance of the groundwater monitoring wells should be readily available.

\subsubsection{Cost}

The estimated cost of Alternative 8 is much lower than that of Alternative 7 . On the basis of the preconceptual design and application of cost factors for indirect activities, the capital cost of Alternative 8 is estimated to range between $\$ 1$ million and $\$ 3$ million (Appendix D). The capital cost would be primarily for installation of the vapor stripping and monitoring wells.

The annual O\&M cost is estimated to be approximately $\$ 0.4$ million per year (Appendix D). The annual O\&M costs would be primarily for groundwater monitoring. Assuming a discount rate of $7 \%$ per year, the 30-year present worth of Alternative 8 is estimated to range between $\$ 6$ million and $\$ 7$ million (Appendix D), much lower than that of Alternative 7.

\subsubsection{Alternative 9: In-Situ Chemical Oxidation Using Fenton-Like Reagents}

Alternative 9 would involve in-situ treatment of groundwater contaminated with TCE using Fenton-like reagents. Long-term monitoring would be performed for the other groundwater contaminants. This alternative is described in Section 3.3.2.8.

\subsubsection{Effectiveness}

The overall effectiveness of this alternative would be similar to that of Alternative 8 . Alternative 9 would also actively remediate only TCE. Alternative 9 would protect human health and the environment by remediating the contaminated groundwater so that when the remediation was complete, the TCE concentration in the groundwater within the WSCP would be at or below the ARAR of $5.0 \mu \mathrm{g} / \mathrm{L}$. In addition, any potential further TCE migration would be largely halted upon implementation of this alternative, and any potential future large-scale contamination by TCE of the aboveground springs would be effectively prevented. Alternative 9 would be expected to attain ARARs for TCE when remediation was completed (see Section 3.5.8.1). The remediation period, including installation and operations, would be expected to take approximately 1 year. 


\subsubsection{Implementability}

A number of implementability concerns would be posed by Alternative 9 . The potential concerns with groundwater monitoring would be similar to those discussed for Alternative 2. One potential concern is the projected complete conversion of TCE within the shallow aquifer. An incomplete reaction of TCE with Fenton's reagent could result in by-products such as tetrachloroethane, trichloroethane, dichloropropene, chloroform, and carbon tetrachloride (Stanforth and McCartney 1995). The end-products of a completed reaction, however, are expected to be innocuous (i.e., $\mathrm{CO}_{2}$ and $\mathrm{H}_{2} \mathrm{O}$ ). The treatment effectiveness is directly related to the proper amounts and mix of Fenton's reagent, which would be dictated by site-specific hydrogeological conditions such as those presented by a carbonate-based aquifer such as that at the WSCP. Another potential concern is related to achieving the optimum $\mathrm{pH}$ needed for effective treatment by Fenton's reagent, which is in the acidic range of 2 to 4 (Venkatadri and Peters 1993).

Optimal placement of the Fenton's reagent remediation system would require accurate predictions of the TCE migration. The final detailed design would have to be based on further benchscale and field testing specific to the site.

Additional bench-scale and field testing would be required before implementation of this alternative. Currently, the application of Fenton's reagent for the remediation of TCE is in the developmental phase. Numerous aspects of the process, as considered in Alternative 9, have not been proven for groundwater and aquifer conditions similar to those at the WSCP.

Groundwater monitoring would be required to track the progress and effectiveness of the groundwater remediation. Resources required for maintenance of the groundwater monitoring wells should be readily available.

\subsubsection{Cost}

The estimated cost of Alternative 9 is the lowest of the action alternatives. The capital cost is on the order of $\$ 0.5$ million and would be primarily for the installation of up to two sets of nested wells and multiple rounds (at least two) of chemical injection. Costs for additional monitoring wells were also incorporated into this estimate.

Including the annual operating cost of continued groundwater monitoring, the annual $O \& M$ cost is estimated to be about $\$ 0.4$ million, primarily for long-term monitoring. Assuming a discount rate of $7 \%$ per year, the 30 -year present worth of Alternative 9 is estimated to be approximately $\$ 5$ million. 


\subsection{SCREENING SUMMARY AND IDENTIFICATION OF FINAL ALTERNATIVES}

The results of the screening analysis for the preliminary alternatives are presented in Table 3.2. Each alternative was evaluated against the three criteria defined in Title 40, Part 300 of the Code of Federal Regulations (40 CFR Part 300): effectiveness, implementability, and cost. On the basis of the screening process, the following alternatives were excluded from further consideration:

- Alternative 3: Natural Attenuation;

- Alternative 5: Groundwater Removal and On-Site Treatment Using Ultraviolet Oxidation;

- Alternative 6: Groundwater Removal and On-Site Treatment Using Phytoremediation;

Alternative 1 was retained for further consideration, as required by CERCLA regulations (40 CFR 300.430(e)(6)), to provide a comparative baseline against which other alternatives can be evaluated.

Alternative 2 was retained for further consideration because it is protective of human health and the environment over the long term. Monitoring and investigative activities by the DOE and DA would ensure that remediation goals are met and that contaminant distribution in the water-bearing zone is tracked. Because of the limited actions required, few implementability concerns would be posed by this alternative. Unacceptable impacts to human health and the environment are not expected to occur.

Alternative 3 was not retained for further consideration because of implementability concerns associated with demonstrating natural attenuation, including development and measurement of necessary biodegradation rates for contaminants other than DNT and threedimensional contaminant transport and flow modeling of the shallow aquifer where two regimes of groundwater flow (diffuse flow and high-velocity turbulent flow) are postulated to exist. Alternative 3 does not provide greater protection of human health and the environment compared with Alternative 2.

Alternative 4 was retained for further consideration because it is protective of human health and the environment over the long term. It would reduce contaminant concentrations to levels below PRGs and would largely eliminate any potential further contaminant migration. 
TABLE 3.2 Screening of Preliminary Alternatives

Alternative

Alternative 1:

No Action

Alternative 2:

Long-Term Monitoring

Alternative 3: Natural

Altenuation

\section{Effectiveness}

Implementability

Cost

Would provide protection of human health and the environment only as the result of natural processes. Would allow for the possible continued migration of the contaminated groundwater and further degradation of the groundwater. No reduction in toxicity, mobility, or volume of the contaminated groundwater would occur because no treatment would be carried out

Same as Alternative 1. Monitoring would allow for collecting data to verify the beneficial effects of source removal and to verify expectations that contaminants will decrease over time. Potential for minor short-term impacts to workers (mainly from monitoring)

Same as Alternative 2. Potential for minor shortterm impacts to workers (mainly from monitoring and subsurface data collection).
No implementability concerns because no action would be taken. No technologies or management strategies would be implemented, nor would any permits, licenses, or approvals associated with undertaking a remedial action be needed.

Few implementability concerns because of the limited actions taken. Contaminant migration could be easily monitored.

Proposed monitoring would provide notice before unacceptable conditions occurred. No special equipment or personnel would be needed, and resources required for maintenance of monitoring wells would be readily available.

Implementability concerns associated with development and measurement of necessary biodegradation rates, and the need for threedimensional contaminant transport and flow modeling. Technical protocol for data collection and analysis in support of remediation by natural attenuation to restore contaminated groundwater exists for

chlorinated aliphatic hydrocarbons such as TCE, but not for nitroaromatic compounds. This guidance is not intended to replace state-specific guidance and has not been adopted by EPA Region VII.
No net present worth, capital, or annual O\&M costs because no activitics would be undertaken.

Low capital expenditures, annual costs (associated with monitoring activities), and present-worth costs.

Low capital expenditures and presentworth costs. Moderate annual costs (associated with monitoring activities and investigative activities). 
TABLE 3.2 (Cont.)

\begin{tabular}{lll}
\hline Alternative & Effectiveness & Implementability \\
\hline
\end{tabular}

Alternative 4:

Groundwater Removal and On-Site Treatment

Using Granular

Activated Carbon

\section{Alternative 5:}

Groundwater Removal

and On-Site Treatment

Using Ultraviolet

Oxidation

Altcrnative 6:

Groundwater Removal

and On-Site Treatment

Using Phytoremediation
Would protect human health and the

environment by remediating contaminated

groundwater. Might be expected to attain all

PRGs when remediation was complete. Would

reduce the volume of contaminants through

treatment and would afford long-term protection.

No long-term action would be required after

remediation was complete. Some potential for

short-term impacts associated with transport of

ground water treatment residuals for on-site

storage and disposal (prior to closure of the

on-site disposal cell), potential transport of

ground water treatment residuals for off-site

disposal, physical hazards to workers during

construction and operations, criteria pollutant

emissions during construction, and disturbance

of soil and resulting airborne dust emissions.

Time to achieve remediation goals would be at least 100 years.

Same as Alternative 4.

Same as Alternative 4, except that the time to achieve remediation goals would be at least 130 years.
Implementability concerns associated with potential failure of groundwater extraction to remove contaminants to acceptably low concentrations and the proposed location of extraction wells. No special equipment or personnel would be required for implementation. Resources required for maintenance and monitoring should be readily available. Implementability concerns about continued replacement of groundwater treatment facilitics and disposal of contaminated wastes.

Implementability would be similar to Alternative 4 . Special equipment, the ultraviolet oxidation unit, would be required.

Implementability would be similar to Alternative 4 , except that phytoremediation is in the developmental stage. No special

equipment or personnel would be required.
Moderate-to-high capital expenditures (associated with extraction well installation and construction of groundwater treatment facilities). Moderate annual costs (associated with operation of extraction wells and treatment facilitics). High

30-year present-worth costs.

Moderate to high capital expenditures associated with extraction well installation and construction of groundwater treatment facilities). Moderate annual costs (associated with operation of extraction wells and treatment facilities). High 30-year present-worth costs.

Moderate to high capital expenditures (associated with extraction well installation). Low to moderate annual costs (associated with monitoring). Moderate to high 30-year present-worth costs. 
TABLE 3.2 (Cont.)

Alternative

Effectiveness

Implementability

Cost

Alternative 7:

Removal and On-Site

Treatment of TCE-

Contaminated

Groundwater

\section{Alternative 8:}

In-Situ Treatment of

TCE Using In-Well

Vapor Stripping
Would protect human health and the

environment by remediating TCE-contaminated groundwater. Would reduce the volume of TCE

contamination through treatment and would afford long-term protection.

Monitoring would allow consideration of active response measures to address any potential future migration. Some potential for short-term impacts associated with physical hazards to workers during construction and operations of pump-and-treat system, and minor short-term impacts to workers from monitoring. Time to achieve remediation goals on the order of at least 100 to 500 years for contaminants other than TCE.

Same as Alternative 7.

Same as Alternative 7.

Alternative 9: In-Situ Chemical Oxidation Using Fenton-Like

Reagents
Implementability concerns associated with the developmental stage of in-well vapor stripping process. No special equipment or personnel would be required. Resources required for maintenance of monitoring wells should be readily available. Contaminant migration could be easily monitored. Proposed monitoring would provide notice before unacceptable conditions occurred.

Implementability concerns associated with potential failure of groundwater extraction to remove contaminants to acceptably low concentrations and the proposed location of s. No special equipment or personnel would be required for implementation. Resources required for maintenance replacement of groundwater treatment facilities and disposal of contaminated wastes.

Implementability concerns associated with the developmental scale of the in-situ oxidation process. Additional bench-scale and field testing would be implemented via this alternative. Resources required for maintenance of monitoring wells should be readily available. Any potential contaminant migration could be easily monitored.

Proposed monitoring would provide notice

before unacceptable conditions occurred. Implementability concerns about continued
High capital expenditures. Low-tomoderate annual costs (associated with activities and groundwater extraction and treatment). Moderate 30-year presentworth costs.

Low to moderate capital expenditures. Low annual costs (associated with monitoring)

Low 30-year present-worth costs.

Low capital expenditures. Low annual costs (primarily associated with monitoring). Low 30 -ycar present-worth costs. 
Alternative 5 was not retained for further consideration. Although it provides protection of human health and the environment similar to that of Alternative 4, the UV oxidation technology is not as well established as GAC and could ultimately be rejected for technical reasons during the remedial design phase. Alternative 6 was not retained for further consideration for reasons similar to those for Alternative 5 .

Alternatives 7,8 , and 9 were retained for further consideration. A detailed analysis of these three alternatives is warranted in order to provide the information that would allow for consideration of an active remediation option to address TCE, if any. TCE has been reported at relatively higher concentrations than the other contaminants, and it is also located in a somewhat definable continuous plume. TCE is the primary contributor to estimated potential human health risk as presented in the BRA (DOE and DA 1998a). Therefore, any reduction of TCE contamination could result in a relatively large decrease in the estimated potential (hypothetical) risk results.

On the basis of the screening process, the following alternatives were retained for detailed evaluation:

- Alternative 1: No Action;

- Alternative 2: Long-Term Monitoring;

- Alternative 4: Groundwater Removal and On-Site Treatment Using GAC;

- Alternative 7: Removal and On-Site Treatment of TCE-Contaminated Groundwater;

- Alternative 8: In-Situ Treatment of TCE Using In-Well Vapor Stripping; and

- Alternative 9: In-Situ Chemical Oxidation of TCE Using Fenton-Like Reagents.

These alternatives are discussed further in Chapters 4 and 5 . 


\section{DETAILED ANALYSIS OF FINAL ALTERNATIVES}

Six of the nine remedial action alternatives considered for the GWOUs at the WSCP and the WSOW were retained through the screening process presented in Chapter 3:

- Alternative 1: No Action;

- Alternative 2: Long-Term Monitoring;

- Alternative 4: Groundwater Removal and On-Site Treatment Using GAC;

- Alternative 7: Removal and On-Site Treatment of TCE-Contaminated Groundwater;

- Alternative 8: In-Situ Treatment of TCE Using In-Well Vapor Stripping; and

- Alternative 9: In-Situ Chemical Oxidation of TCE Using Fenton-Like Reagents.

These alternatives are described further in Sections 4.1 through 4.6. Engineering information and identification of any required equipment that would be representative of a final remedial design are provided only for the purpose of comparing the feasibility of the alternatives and assessing potential impacts on human health and the environment. Actual equipment requirements and engineering procedures would be defined in subsequent $\mathrm{RD} / \mathrm{RA}$ reports, as appropriate.

A detailed analysis of these six final alternatives consisted of an assessment of each alternative relative to the following nine evaluation criteria, as specified in the NCP (EPA 1990a):

1. Overall protection of human health and the environment - addresses whether each alternative provides adequate protection of human health and the environment. Evaluation focuses on a specific alternative's ability to achieve adequate protection and describes how site risks posed by each pathway are eliminated, reduced, or controlled through natural processes, treatment, engineering, or institutional controls. This evaluation also allows for consideration of any unacceptable short-term impacts associated with each alternative. Because of its broad scope, this criterion also reflects the focus of criteria 2 through 5 .

2. Compliance with ARARs - addresses whether all applicable or relevant and appropriate state and federal laws and regulations are met. Evaluation focuses 
on whether each alternative will meet federal and state ARARs or whether there is justification for an ARAR waiver. The various ARARs and the waiver conditions are identified in Appendix A, in which the key requirements for each alternative are discussed.

3. Long-term effectiveness and permanence - addresses the risk remaining at the operable units after remediation goals have been met. Evaluation focuses on the ability of an alternative to maintain reliable protection of human health and the environment over time, once these goals have been met.

4. Reduction of toxicity, mobility, or volume - addresses the statutory preference for selecting alternatives that permanently and significantly reduce the toxicity, mobility, or volume of hazardous substances at a site. Evaluation focuses on the extent to which this is achieved by each alternative.

5. Short-term effectiveness - addresses the potential impacts to workers, the general public, and the environment during implementation of each alternative.

6. Implementability - addresses technical and administrative feasibility, including the availability and reliability of resources or materials required during implementation, and the need to coordinate with other agencies.

7. Cost - addresses both capital costs and annual O\&M costs, as well as the combined net present worth of each alternative.

8. State acceptance - addresses the statutory requirements for substantial and meaningful state involvement. This criterion will be addressed in the responsiveness summary and ROD that will be prepared following the public comment period.

9. Community acceptance - assesses the community's apparent preference for, or concerns about, the alternatives being considered. This criterion will be addressed in the responsiveness summary and the ROD that will be prepared following the public comment period.

The effectiveness, implementability, and cost of the six alternatives retained for detailed analysis are summarized in Table 3.2. The six alternatives that were retained through the screening process were evaluated on the basis of criteria 1 through 7 relative to potential health and environmental impacts. The results of this comprehensive analysis are presented in Sections 4.1 through 4.6. 


\subsection{ALTERNATIVE 1: NO ACTION}

The no action alternative provides a baseline against which other alternatives can be evaluated. Under this alternative, the WSCP and the WSOW would remain "as is." No containment, removal, treatment, or other mitigative actions would be implemented. However, it was assumed that the source-control measures listed in Section 3.1 would have been completed. The no action alternative does not include groundwater monitoring by DOE and the DA or any additional active or passive institutional controls that could further reduce the potential for human exposure (e.g., physical barriers, deed restrictions). Under Alternative 1, it was assumed that all current groundwater monitoring activities by DOE and the DA would be discontinued.

\subsubsection{Overall Protection of Human Health and the Environment}

The no action alternative would be adequately protective of human health and the environment over the long term. Under current conditions, the contaminated groundwater at the WSCP and the WSOW poses no imminent risk to human health or the environment. The groundwater is not accessible and is not used at the sites. The likely future land use is expected to be similar to current land use. Groundwater contaminant levels are also expected to decrease with time because of source removals and naturally occurring processes that would further attenuate contaminant concentrations.

\subsubsection{Compliance with Potential ARARs}

Potential regulatory requirements that would be applicable or relevant and appropriate to the final remedial action alternatives are identified and evaluated in Appendix A. Current levels of TCE, nitrate, and 2,4-DNT in groundwater (only 2,4-DNT would be exceeded in WSOW groundwater) exceed the relevant and appropriate standard of $5 \mu \mathrm{g} / \mathrm{L}, 10 \mathrm{mg} / \mathrm{L}$, and $0.11 \mu \mathrm{g} / \mathrm{L}$, respectively. However, contaminant concentrations in groundwater at the WSCP and the WSOW will continue to decrease with time to comply with ARARs because of source removal and naturally occurring processes (e.g., biodegradation of the organic contaminants and dilution through infiltration of rainwater and storm-water runoff).

\subsubsection{Long-Term Effectiveness and Permanence}

Under current conditions and land use, groundwater at the WSCP and the WSOW poses no imminent risk to human health or the environment. Although groundwater contaminant concentrations would not be measured in the future, it is expected that no potential impacts to human health and the environment would occur because the likely foreseeable future land use of the WSCP and 
the WSOW would remain similar to current land use, whereby the contaminated groundwater is not used or accessed.

\subsubsection{Reduction of Toxicity, Mobility, or Volume through Treatment}

No reduction of toxicity, mobility, or volume through treatment would occur because the contaminated groundwater would not be treated under this alternative.

\subsubsection{Short-Term Effectiveness}

No short-term impacts would occur to human health or the environment because no remedial action would be conducted. No construction activities would be conducted; therefore, no negative impacts would occur.

\subsubsection{Implementability}

No concerns regarding implementability are associated with Alternative 1 because no action would be taken nor would any future activities be considered. No technologies or management strategies associated with undertaking a remedial action would need to be implemented.

\subsubsection{Cost}

No net present worth, capital, or annual O\&M costs are associated with the no action alternative because no activities would be undertaken.

\subsection{ALTERNATIVE 2: LONG-TERM MONITORING}

The activities associated with Alternative 2 include the following:

- Long-term monitoring of groundwater to verify and ensure protection of human health and the environment;

- Institutional controls to ensure that access to and use of contaminated groundwater remain consistent with current land use; and 
- Contingency measures in the event that potential unacceptable off-site concentrations and exposure could occur.

The concentrations of contaminants in groundwater at the WSCP and the WSOW are expected to decrease with time. This decrease could be caused by a number of environmental processes affecting contaminant fate and migration, including (1) source removals, (2) transformation (i.e., hydrolysis, photolysis, oxidation/reduction, chemical precipitation, radioactive decay, and biodegradation), (3) transfer(i.e., adsorption/desorption and dissolution), and (4) dilution through infiltration of rainwater and runoff (DOE and DA 1998b). Further evaluation through long-term monitoring and associated activities would determine whether these processes had resulted in decreased contamination, thereby ensuring protection of human health and the environment at these operable units.

Groundwater monitoring would be conducted using the existing well network, as appropriate. This network could be expanded or reduced, depending on the results of future efforts to optimize the network for long-term monitoring. For Alternative 2, it was assumed that additional monitoring wells, equivalent to approximately $10 \%$ of the number of existing wells (i.e., about 15 additional wells), would be installed and operated. The exact monitoring network and details regarding frequency of sampling and parameters analyzed would be identified in subsequent RD/RA reports for these operable units. The evaluation of historical groundwater data was based on the groundwater monitoring programs of DOE and the DA; groundwater data from 73 wells at the WSCP and 79 wells at the WSOW were evaluated. (The current [July 1997] monitoring program conducted by the DA involved sampling of 49 wells and 6 springs.) Of these wells, 10 monitor groundwater in the soil overburden. The remaining wells are screened in the bedrock system (Burlington/Keokuk, Fern Glen/Chouteau, Kimmswick, Joachim/St. Peter).

Monitoring would continue for a reasonable period of time and would be reviewed at least every five years or until remediation goals identified in the ROD were achieved. Standard operating procedures used for current monitoring activities would be adopted for the long-term monitoring efforts. These efforts would include water-level measurements and the collection of quality assurance/quality control samples during each sampling event.

The monitoring frequency for the wells is expected to be location-specific and will depend on the level of contamination encountered. For example, wells with low contaminant concentrations that were constant or decreasing over time would be sampled less frequently than wells containing contaminant concentrations much greater than the PRGs. For this analysis, sampling was assumed to be performed on an annual basis (once per year). Details of the final monitoring scheme will be presented in subsequent reports prepared for these operable units, as appropriate.

Periodic maintenance of the groundwater monitoring wells and purge pumping equipment would be expected to extend the life of the equipment. Monitoring wells would be evaluated with 
regard to performance and condition and integrity of various well components such as concrete pads, posts, and protective casings. Periodic inspections to determine the need for maintenance would be guided by the collection and analysis of representative groundwater samples. After the completion of long-term monitoring activities, the monitoring wells would be managed in accordance with on-site procedures (e.g., plugged and abandoned).

As required by CERCLA, because contaminants would remain on-site at levels above those that allow for unlimited use and unrestricted exposure, reviews would be conducted at least every five years. If monitoring showed that the level of contaminants in the groundwater had decreased significantly during the prior five-year period, the number of wells sampled and the sampling frequency might be reduced. Wells that duplicated information, provided unreliable information (e.g., wells that were dry part of the year), or yielded samples containing groundwater concentrations below the PRGs for all contaminants might be considered for elimination. The number of monitoring wells and sampling frequency would be determined in collaboration with the regulators.

Other limitations or controls on groundwater use at the GWOUs include St. Charles County zoning requirements and land use restrictions by owners. The DOE and DA would have to reach some agreement with the appropriate landowners, such as the Missouri Department of Conservation, on land not currently under federal ownership.

Continued federal ownership of the WSTA at the WSOW and the area containing the on-site disposal cell at the WSCP appears certain and would involve continued control by the federal government with the intent of restricting site development activities through rights of ownership.

\subsubsection{Overall Protection of Human Health and the Environment}

Alternative 2 would be adequately protective of human health and the environment over the long term. Potential migration of the contamination toward the surface springs would be monitored. The data collected would be used to verify and ensure protection of human health and the environment. This monitoring program would be used to measure attainment of remediation goals, that is, to determine whether groundwater contaminant concentrations are equal to or less than the PRGs. Restoration of the water-bearing zone within the operable units would be provided by existing natural processes that would be expected to attenuate contaminant concentrations. Dilution of the contaminated groundwater with uncontaminated groundwater drawn through infiltration of rainwater and runoff could also result in decreased concentrations. 


\subsubsection{Compliance with Potential ARARs}

Compliance with potential ARARs for Alternative 2 would be the same as for Alternative 1 (Section 4.1.2).

\subsubsection{Long-Term Effectiveness and Permanence}

Similar to Alternative 1, under current land use conditions, groundwater is not used and, therefore, poses no imminent risk to human health or the environment. Deed restrictions could be used to ensure that no new wells would be installed in the area of the contaminated groundwater, but these restrictions could be difficult to enforce without the application of additional controls (e.g., access restrictions). Additional protection for off-site residents is currently provided by quarterly sampling of off-site wells by the Missouri Department of Health. Continued federal ownership would eliminate any potential risks associated with on-property groundwater. Monitoring activities carried out by DOE and the DA at these operable units would provide data to ensure protection of human health and the environment in the extended future. Unacceptable impacts to human health and the environment would not be expected to occur.

\subsubsection{Reduction of Toxicity, Mobility, or Volume through Treatment}

Reduction of toxicity, mobility, or volume through treatment is not applicable to Alternative 2 because the contaminated groundwater would not be treated under this alternative.

\subsubsection{Short-Term Effectiveness}

Construction activities associated with the installation of additional monitoring wells are estimated to result in less than one case of occupational injury and no occupational fatalities. (This estimate is based on industry-specific statistics from the U.S. Bureau of Labor Statistics, as reported by the National Safety Council [1995]).

Minimal short-term impacts on recreational use of the surrounding wildlife areas might occur as a result of noise, exhaust fumes, and dust associated with construction of any new monitoring wells. Potential impacts to environmental resources would be avoided by the implementation of mitigative measures. 


\subsubsection{Implementability}

Alternative 2 poses few implementability concerns because of the limited actions taken. Site operations would continue to use readily available resources for monitoring and maintaining institutional controls. Construction of any new monitoring wells would simply require mobilization of a drilling rig for installation. Minimal administrative complexities, including permit applications, would be associated with monitoring well installation.

Groundwater monitoring could be readily implemented. Numerous wells currently exist at these operable units; additional wells could be easily installed and monitored. Monitoring of potential off-site contaminant migration would be relatively easy to implement.

Implementation of institutional controls on land that is not federally owned would require administrative effort and legal enforcement and agreements with respective landowners. No difficulties associated with technical implementation are expected. Continued federal ownership could be readily implemented because it is already in place.

The administrative feasibility of Alternative 2 would be relatively straightforward. Remediation activities at the WSCP and the WSOW are coordinated with the State of Missouri and EPA Region VII. That coordination would continue during implementation of Alternative 2, and no additional coordination would be required with any other agencies beyond that already occurring.

\subsubsection{Cost}

Costs for Alternative 2 would be associated with continuing the existing environmental monitoring program, constructing and operating possible new monitoring wells (up to 15), and conducting a performance review at least every five years. Feasibility-level cost estimates were prepared using standard cost-estimating sources. The proposed monitoring wells were assumed to be constructed of stainless steel for long-term effectiveness. It was assumed in this analysis that the new wells would be purged and sampled with dedicated pumps.

The costs for individual construction activities were taken from the latest version of the Unit Price Book developed by the U.S. Army Corps of Engineers (1989) and other sources (see Appendix E). A cost differential was included to account for differences in material and labor costs in the Weldon Spring area compared with the generic Unit Price Book costs. The workforce estimates for various support activities (e.g., construction and health and safety) were derived by a parametric approach based on similar levels of construction activities for related construction projects. Other costs - such as those for small tools, indirect costs, and bond and insurance costs

- were estimated on the basis of various percentages of other costs. Present worth was calculated 
from procedures identified in EPA guidance and using a 7\% discount rate. Long-term maintenance costs were based on a 30-year period and include annual sampling and analytical costs.

Estimated total and present-worth costs for Alternative 2 are given in Table 4.1. Costs are estimated to be about $\$ 0.34$ million. The present-worth cost would increase from $\$ 4.8$ million for a 30 -year period to $\$ 5.5$ million for a 100 -year period.

The costs associated with potential future actions, in the event that potential migration of residual contamination does result in unacceptable exposure concentrations, were not quantified because the uncertainty associated with these future activities precludes accurate assessment of these costs.

\subsection{ALTERNATIVE 4: GROUNDWATER REMOVAL AND ON-SITE TREATMENT USING GRANULAR ACTIVATED CARBON}

The activities associated with Alternative 4 include the following:

- Extraction and ex-situ treatment of the groundwater at the WSCP and the WSOW to achieve PRGs for groundwater;

- Groundwater monitoring at the WSCP and the WSOW to ensure long-term performance of the remedy.

TABLE 4.1 Cost Estimate for Alternative 2

\begin{tabular}{lc}
\hline \multicolumn{1}{c}{ Activity } & $\begin{array}{c}\text { Estimated Cost } \\
\text { (\$ million) }\end{array}$ \\
\hline Monitoring well construction $^{\mathrm{a}}$ & 0.31 \\
Groundwater monitoring $^{\mathrm{b}}$ & 10.8 \\
Total $^{\mathrm{b}}$ & 11.1 \\
Present worth $^{\mathrm{b}}$ & 4.8 \\
\hline a & \\
Based on construction of 15 new monitoring wells. \\
$\mathrm{b}$ Estimated upper-bound cost for a 30-year period, \\
assuming annual sampling frequency for the \\
existing network of monitoring wells. Any \\
reduction in duration of monitoring, sampling \\
frequency, or number of wells sampled would \\
result in a proportional reduction in cost.
\end{tabular}


Alternative 4 involves extraction and ex-situ treatment of WSCP and WSOW groundwater to achieve PRGs for groundwater. Groundwater exceeding these concentration limits would be removed via conventional vertical extraction wells, pumped to and treated at an aboveground treatment system consisting of a sequence of physical and chemical unit operations, and discharged to a permitted discharge point.

Approximately 330 to 1,000 vertical extraction wells at the WSCP and the WSOW (see Appendix C) were estimated to be required to achieve a reasonable extraction rate and to provide wide enough coverage so as not to allow any bypass of groundwater contaminated above the PRGs. The wells would be between $16 \mathrm{~m}(50 \mathrm{ft})$ and $30 \mathrm{~m}(100 \mathrm{ft})$ deep, have a screened length of about

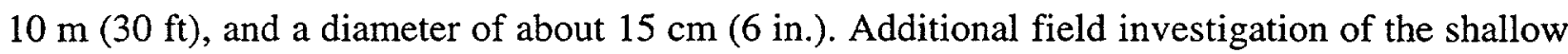
aquifer characteristics at specific contamination zones would provide a more accurate estimation of the number of extraction wells necessary because of the complex hydrogeology and heterogeneous geology of the sites.

Two groundwater treatment facilities were assumed to be constructed, one to treat extracted groundwater from the WSCP and another for the WSOW. These facilities would have treatment capacities from 760 to $2,400 \mathrm{~L} / \mathrm{min}(200$ to $620 \mathrm{gpm})$ for the groundwater extracted from the WSCP and from 24 to $72 \mathrm{~L} / \mathrm{min}$ ( 6 to $19 \mathrm{gpm}$ ) for the WSOW groundwater. The facility footprint would range from 360 to $750 \mathrm{~m}^{2}$ (3,900 to $8,000 \mathrm{ft}^{2}$ ) for the WSCP and from 42 to $70 \mathrm{~m}^{2}$ (450 to $740 \mathrm{ft}^{2}$ ) for the WSOW, depending upon the number of extraction wells required. The preconceptual groundwater treatment process would involve clarification and multimedia filtration to remove any solids collected during groundwater extraction, liquid phase adsorption using granular activated carbon to remove TCE and other organics, and reverse osmosis and ion exchange for nitrate removal. (Groundwater at the WSOW would not need treatment to remove TCE or nitrate; therefore, the treatment processes associated with these contaminants [e.g., reverse osmosis for nitrate removal] would not be applied at the WSOW.)

After construction of the extraction well network and associated groundwater treatment systems, the two systems would be carefully monitored on a regular basis and their performance evaluated. The actual performance in the field may vary from that assumed during design, given uncertainties about subsurface geology prior to construction and operation.

As required by CERCLA, because contaminants would remain in site groundwater at concentrations above levels that allow for unlimited use and unrestricted exposure, reviews would be conducted at least every five years.

Air monitoring would be used to detect airborne contamination generated during remedial activities, so that appropriate mitigation measures could be taken. Long-term air monitoring would be implemented following completion of construction to assure detection of any potential airborne 
releases of contaminants resulting from duct leaks and during maintenance of the GAC treatment system.

\subsubsection{Overall Protection of Human Health and the Environment}

Alternative 4 would be protective of human health and the environment because remediation of the contaminated groundwater in the shallow bedrock aquifer could result in groundwater contaminant concentrations that are similar to or below PRGs. In addition, contaminant migration would be largely halted upon implementation of this alternative, and any potential future large-scale contamination of the nearby ground springs would be effectively eliminated.

\subsubsection{Compliance with Potential ARARs}

Compliance with potential ARARs for Alternative 4 would be similar to that for Alternative 2 (Section 4.2.2), except that under Alternative 4, compliance with the ARARs could occur in a shorter time period, depending on the performance of this alternative.

\subsubsection{Long-Term Effectiveness and Permanence}

Alternative 4 would afford long-term effectiveness and performance because contaminated groundwater would be removed and treated. This alternative would provide for the reduction or elimination of potential risk associated with the COCs within the shallow aquifer at the WSCP and the WSOW.

\subsubsection{Reduction of Toxicity, Mobility, or Volume through Treatment}

Alternative 4 would satisfy the statutory preference for treatment as a principal element of remediation and would reduce the toxicity, mobility, or volume of the contaminated groundwater through treatment. Alternative 4 would reduce mobility by hydraulically controlling migration of contaminated groundwater at the WSCP and the WSOW through extraction of contaminants. Successful implementation of Alternative 4 would reduce the toxicity, mobility, or volume associated with all contaminants in groundwater within the shallow bedrock aquifer. 


\subsubsection{Short-Term Effectiveness}

Risks to workers would result primarily from physical hazards during construction activities primarily associated with the construction of extraction wells and treatment facilities. Those construction activities are estimated to result in up to 50 cases of occupational injury, assuming construction of the maximum number of wells (i.e., 1,000 wells). No occupational fatalities are expected to occur. This estimate is based on industry-specific statistics from the U.S. Bureau of Labor Statistics, as reported by the National Safety Council (1995). Physical hazards would be minimized by adherence to stringent health and safety protocols.

Minimal environmental impacts would result from construction of the extraction wells and associated groundwater treatment facility. The primary impact to the environment would be associated with installation of the 330 to 1,000 extraction wells. These activities may result in physical disturbances of the habitat, but would be of short duration. Some short-term impacts might occur as a result of noise, exhaust fumes, and dust associated with any construction activities.

\subsubsection{Implementability}

Significant uncertainty in the implementability of Alternative 4 is associated with the need for site- (area) specific hydrogeologic data to verify the appropriateness of assumptions used in the evaluations. The evaluation in this FS assumed a flow rate of $1.2 \mathrm{~L} / \mathrm{min}(0.3 \mathrm{gpm})$ [MK-Ferguson and Jacobs Engineering Group, Inc. 1990a] for a single extraction well. If area-specific flow rates vary from this assumption, performance of this alternative would vary accordingly.

Few implementability concerns associated with the groundwater extraction and treatment technologies would be posed by Alternative 4 . Because groundwater extraction and treatment are well-developed technologies, technical problems are not likely to cause significant delays. Site operations would continue to use readily available resources for monitoring. Discharge of treated groundwater would likely require coordination with other agencies such as the EPA and the Missouri Department of Natural Resources.

Groundwater treatment services are commercially available; equipment and specialists are available within DOE and private industry. The groundwater treatment technologies considered for Alternative 4 are well-developed and have proven to be effective in SWTP operations. Further development of these technologies will not be required before they can be applied at the site. Shortterm disposal services would be available within the WSSRAP on-site disposal cell.

Groundwater monitoring is readily implementable. Presently, numerous wells are located at these operable units, and additional wells could be easily installed and monitored. The ability to 
monitor any off-site plume migration is high. The existing network of monitoring wells would provide notice before any unacceptable exposure could occur.

The administrative feasibility of this alternative would be relatively straightforward. WSSRAP and remedial action project activities at the WSOW are coordinated with the State of Missouri and EPA Region VII. That coordination would continue during the duration of implementation. The implementation of this alternative would not require coordination with any other agencies beyond that already occurring, and no permit or license for on-site activities would be required.

\subsubsection{Cost}

Costs for this alternative would be associated with continuing the existing environmental monitoring program, constructing and operating groundwater extraction and treatment systems, and conducting a performance review at least every five years. Feasibility-level cost estimates were prepared using standard cost-estimating sources such as the latest version of the Unit Price Book developed by the U.S. Army Corps of Engineers (1989).

The estimated total and present-worth costs for Alternative 4 are given in Table 4.2; annual costs are estimated to range between $\$ 2$ million to $\$ 4$ million per year. The capital cost of Alternative 4 is estimated to range between $\$ 41$ million to $\$ 120$ million, depending upon the number of extraction wells required (i.e., 330 to 1,000 wells). The capital cost would be primarily for installation of the 330 to 1,000 extraction wells.

Excluding the decontamination and decommissioning (D\&D) costs of the two groundwater treatment facilities (which are highly speculative), the 30-year present worth of Alternative 4 is estimated to range between $\$ 53$ million and $\$ 140$ million, much greater than that of the other alternatives considered in this chapter.

\subsection{ALTERNATIVE 7: REMOVAL AND ON-SITE TREATMENT OF TCE-CONTAMINATED GROUNDWATER}

The activities associated with Alternative 7 include the following:

- Extraction and on-site treatment of TCE-contaminated groundwater (primarily at the WSCP near the raffinate pits area) to achieve a TCE groundwater concentration of $5 \mu \mathrm{g} / \mathrm{L}$ or lower;

- Long-term monitoring of groundwater contaminants other than TCE to verify and ensure protection of human health and the environment; 
accurate estimation of the number of extraction wells necessary, the optimal location for these wells, and a better determination of groundwater extraction rates.

It was assumed that a single groundwater treatment facility would be constructed, with a treatment capacity ranging between 4 to $12 \mathrm{~L} / \mathrm{s}(60$ to $195 \mathrm{gpm})$ and a footprint ranging from 180 to $360 \mathrm{~m}^{2}\left(1,900\right.$ to $\left.3,800 \mathrm{ft}^{2}\right)$, depending on the number of extraction wells required. The preconceptual groundwater treatment process would be similar to that proposed for Alternative 4 and would involve clarification and multimedia filtration to remove any solids collected during groundwater extraction, liquid phase adsorption using GAC to remove TCE and other organics, and reverse osmosis and ion exchange for nitrate removal.

After construction of the extraction well network and associated groundwater treatment systems, the two systems would be carefully monitored on a regular basis and their performance evaluated. The time required for on-site treatment of extracted groundwater for Alternative 7 is predicted to require approximately 16 years, on the basis of a maximum TCE concentration of $9,000 \mu \mathrm{g} / \mathrm{L}$. The actual performance in the field may vary from that assumed during design, given uncertainties about subsurface geology prior to construction and operation.

Long-term groundwater monitoring would be implemented to address contaminants other than TCE as described in Alternative 2 (see Section 4.2).

Because contaminants would remain in site groundwater at concentrations above levels that allow for unlimited use and unrestricted exposure, reviews would be conducted at least every five years consistent with CERCLA requirements.

\subsubsection{Overall Protection of Human Health and the Environment}

Alternative 7 would actively remediate only TCE because TCE concentrations in groundwater have been determined to be the primary contributor to potential human health risk from groundwater exposure. When remediation is completed, the TCE concentration in groundwater at the WSCP and the WSOW is expected to be at or below the PRG of $5 \mu \mathrm{g} / \mathrm{L}$. In addition, any potential for further TCE migration would be eliminated upon implementation of this alternative, and any potential future TCE migration to the aboveground springs would be likewise effectively eliminated.

Alternative 7 would be adequately protective of human health and the environment over the long term. Potential contaminant migration toward the surface springs would be monitored. Data collected from long-term monitoring would be used to verify and ensure protection of human health and the environment. Monitoring would also track progress toward the attainment of remediation goals. Remediation of contaminants other than TCE in the water-bearing zone within the operable 
units would be provided by natural processes that are expected to attenuate contaminant concentrations. Dilution of the contaminated groundwater with uncontaminated groundwater drawn from infiltration of rainwater and runoff could also result in decreased concentrations.

\subsubsection{Compliance with Potential ARARs}

Under Alternative 7, the ARAR for TCE ( $5 \mathrm{ug} / \mathrm{L})$ would be attained in a shorter time period than under Alternatives 1 and 2. Attainment of ARARs for nitrate and nitroaromatic compounds would be similar to that of Alternatives 1 and 2 .

\subsubsection{Long-Term Effectiveness and Permanence}

TCE-contaminated groundwater would be removed and treated under Alternative 7, which would eliminate any potential risk associated with current TCE levels at the WSCP and the WSOW.

However, under current and foreseeable future land use conditions, groundwater is and would not be used and, therefore, poses no imminent risk to human health or the environment. In addition, protection of human health and the environment in the extended future would be ensured by the collection of monitoring data. Unacceptable impacts to human health and the environment are not expected to occur.

\subsubsection{Reduction of Toxicity, Mobility, or Volume through Treatment}

Relative to TCE, implementation of Alternative 7 would satisfy the statutory preference for treatment as a principal element of remediation and would reduce the toxicity, mobility, or volume of the contaminated groundwater through treatment. Alternative 7 would reduce mobility by hydraulically controlling the migration of TCE-contaminated groundwater through contaminant extraction. In addition, extraction and treatment of TCE-contaminated groundwater would also reduce the concentrations of other contaminants (e.g., nitrate and nitroaromatic compounds) that also exist in the TCE-contaminated groundwater at the WSCP near the raffinate pits area.

\subsubsection{Short-Term Effectiveness}

Risks to workers would result primarily from physical hazards during construction activities. Construction activities are estimated to result in between 3 to 9 cases of occupational injury, depending on the number of extraction wells required and no occupational fatalities. (This estimate is based on industry-specific statistics from the U.S. Bureau of Labor Statistics as reported 
by the National Safety Council [1995]). Physical hazards would be minimized by adherence to stringent health and safety protocols.

Minimal environmental impacts would result from construction of the extraction well network and the associated groundwater treatment facility. The primary impact to the environment would be associated with installation of the 200 to 650 extraction wells. These activities may result in physical disturbances of the habitat, but would be of short duration. Short-term impacts such as noise, exhaust fumes, and dust associated with any construction activities are expected to be minimal.

\subsubsection{Implementability}

Uncertainties are associated with the implementation of Alternative 7. There is a need for site- (area) specific hydrogeologic data to verify the appropriateness of assumptions used in the evaluations. The evaluation in this FS assumed a flow rate of $1.2 \mathrm{~L} / \mathrm{min}(0.3 \mathrm{gpm})$ [MK-Ferguson and Jacobs Engineering Group, Inc. 1990a] for a single extraction well. A higher or lower flow rate would accordingly increase or decrease performance of this alternative.

Few implementability concerns associated with the groundwater extraction and treatment technologies would be posed by Alternative 7, because these technologies are well-developed and few problems are expected. Site operations would continue to use readily available resources for monitoring. Discharge of treated groundwater would require coordination with other agencies such as the EPA and the Missouri Department of Natural Resources.

Groundwater treatment services are commercially available; equipment and specialists are readily available within DOE and private industry. The groundwater treatment technologies considered for Alternative 7 are well developed and have proven to be effective in SWTP operations. Further development of these technologies would not be required before they could be applied at the site. Short-term disposal services would be available within the WSSRAP on-site disposal cell.

Groundwater monitoring would be readily implementable because numerous wells exist at these operable units. Additional wells could be easily installed to monitor any off-site plume migration. The existing network of monitoring wells would provide warning of any unacceptable exposure.

The administrative feasibility of this alternative would be relatively straightforward. WSSRAP and remedial action project activities at the WSOW are coordinated with the State of Missouri and EPA Region VII. That coordination would continue during the duration of implementation. Implementation of this alternative would not require coordination with any other 
agencies beyond that already occurring, and no permit or license for on-site activities would be required.

\subsubsection{Cost}

Costs for this alternative would be associated with continuing the existing environmental monitoring program, constructing and operating groundwater extraction and treatment systems, and conducting a performance review at least every five years. Feasibility-level cost estimates were prepared using standard cost-estimating sources such as the latest version of the Unit Price Book developed by the U.S. Army Corps of Engineers (1989).

The estimated total and present-worth costs for Alternative 7 are given in Table 4.3; annual costs are estimated to range between $\$ 1$ million and $\$ 2$ million per year. The capital cost of Alternative 7 is estimated to range between $\$ 9$ million and $\$ 25$ million, depending on the number of extraction wells required (i.e., 200 to 650 wells). The capital cost would be primarily for installation of the 200 to 650 extraction wells.

TABLE 4.3 Cost Estimate for Alternative 7

\begin{tabular}{|c|c|}
\hline Activity & $\begin{array}{l}\text { Estimated Cost } \\
(\$ \text { million })\end{array}$ \\
\hline $\begin{array}{l}\text { Extraction well and groundwater } \\
\text { treatment facility construction }\end{array}$ & $9-25$ \\
\hline $\begin{array}{l}\text { Extraction well and groundwater } \\
\text { treatment facility operations }\end{array}$ & $13-31$ \\
\hline Groundwater monitoring $^{\mathrm{b}}$ & 9 \\
\hline Total $^{\mathrm{b}}$ & $32-65$ \\
\hline Present worth ${ }^{b}$ & $23-53$ \\
\hline \multicolumn{2}{|c|}{$\begin{array}{l}\text { Based on construction of between } 200 \text { to } 650 \\
\text { extraction wells. }\end{array}$} \\
\hline \multicolumn{2}{|c|}{$\begin{array}{l}\text { Estimated upper-bound cost for a 30-year period, } \\
\text { assuming annual sampling frequency for the } \\
\text { existing network of monitoring wells. Any } \\
\text { reduction in duration of monitoring, sampling } \\
\text { frequency, or number of wells sampled would } \\
\text { result in a proportional reduction in cost. }\end{array}$} \\
\hline
\end{tabular}


Excluding the D\&D costs of the groundwater treatment facility (which are highly speculative), the 30 -year present worth of Alternative 7 is estimated to range between $\$ 23$ million and $\$ 53$ million.

The costs associated with potential future actions, in the event that potential migration of residual contamination did result in unacceptable exposure concentrations, were not quantified because the uncertainty associated with these future activities precludes accurate assessment of these costs.

\subsection{ALTERNATIVE 8: IN-SITU TREATMENT OF TCE USING IN-WELL VAPOR STRIPPING}

Activities associated with Alternative 8 include the following:

- In-situ treatment of the TCE-contaminated groundwater (primarily at the WSCP near the raffinate pits area) to achieve a TCE concentration of $5 \mu \mathrm{g} / \mathrm{L}$ or lower;

- Long-term monitoring of groundwater to verify and ensure protection of human health and the environment;

- Institutional controls to ensure that access to and use of contaminated groundwater remain consistent with current land use, and

- Contingency measures in the event that potential unacceptable off-site concentrations and exposure could occur.

In-well vapor stripping technology involves the generation of a groundwater circulation pattern and simultaneous aeration within the vapor stripping well to volatilize the TCE from the circulating groundwater. This alternative would actively remediate the TCE-contaminated groundwater near the raffinate pits area of the WSCP. This alternative, however, would not address the nitrate and nitroaromatic compounds that may also be present. Long-term monitoring as described in Alternative 2 would be implemented to manage other contaminants in the groundwater. This alternative provides for active remediation of TCE only. As in Alternatives 2 and 7, long-term monitoring would be conducted in order to obtain data that would verify decreasing nitrate and nitroaromatic concentrations with time. This decrease is expected to result from source removals and from continued occurrence of natural attenuation processes.

The in-well vapor stripping technology consists primarily of a screened well submerged beneath the water table and an air line within the well extending to below the water table. A 
compressor delivers air or an inert gas such as nitrogen to the water column, thereby aerating the water within the well. The gas bubbles cause the water within the well to be less dense than the nonaerated water outside. As a result, the dense water flows in through the well screen and forces the aerated water upward within the well. The result is a rising column of aerated water within the well, which forms an air lift pumping system.

After construction of the in-well vapor stripping network and associated groundwater treatment systems, the two systems would be carefully monitored on a regular basis and their performance evaluated. The time required for in-situ treatment for Alternative 8 is predicted to require from two to three years, assuming that water can be stripped of $90 \%$ of its VOCs (in this case, TCE) with one pass through a vapor stripping well (Cichon et al. 1997). Actual field performance may vary from that assumed during design, given uncertainties about subsurface geology prior to construction and operation.

Long-term groundwater monitoring would be implemented to address contaminants other than TCE as described in Alternative 2 (see Section 4.2).

Because contaminants would remain in site groundwater at concentrations above levels that allow for unlimited use and unrestricted exposure, reviews would be conducted at least every five years consistent with CERCLA requirements.

\subsubsection{Overall Protection of Human Health and the Environment}

Similar to Alternative 7 , Alternative 8 would actively remediate only TCE because TCE concentrations in groundwater have been determined to be the primary contributor to potential human health risk from groundwater exposure. Potential further migration of TCE would be largely halted upon implementation of this alternative, and any potential future TCE migration to the aboveground springs would be effectively eliminated.

Alternative 8 would be adequately protective of human health and the environment over the long term. Any potential migration of the contamination toward the surface springs would be monitored. Data collected would verify and ensure protection of human health and the environment. Monitoring would also track progress toward the attainment of remediation goals. Remediation of contaminants other than TCE of the water-bearing zone within the operable units would be provided by natural processes that are expected to attenuate these contaminant concentrations. Dilution of the contaminated groundwater with uncontaminated groundwater drawn from infiltration of rainwater and runoff could also result in decreased concentrations. 


\subsubsection{Compliance with Potential ARARs}

Alternative 8 would comply with potential ARARs similar to Alterative 7 (Section 4.4.2).

\subsubsection{Long-Term Effectiveness and Permanence}

Similar to Alternative 7, groundwater contaminated with TCE would be treated under Alternative 8 , which would reduce or eliminate any potential risk associated with TCE levels currently found at the WSCP.

Under current land use conditions, groundwater is not used and, therefore, poses no imminent risk to human health or the environment. Monitoring activities carried out by DOE and the DA at these operable units would ensure protection of human health and the environment.

\subsubsection{Reduction of Toxicity, Mobility, or Volume through Treatment}

Alternative 8 would satisfy the statutory preference for treatment as a principal element of remediation and would reduce the toxicity, mobility, or volume of the contaminated groundwater through treatment relative to TCE only. Mobility would be reduced by hydraulically controlling the migration of TCE-contaminated groundwater through contaminant extraction.

\subsubsection{Short-Term Effectiveness}

Risks to workers would result primarily from physical hazards during construction activities. Minimal or low risks to workers and environmental impacts would result from construction of the vapor stripping well network and associated off-gas treatment facility. Construction activities are estimated to result in less than two cases of occupational injury, depending on the number of vapor stripping wells required, and no occupational fatalities. The primary impact to the environment would be associated with installation of the vapor stripping wells. These activities may result in physical disturbances of the habitat, but would be of short duration. Some short-term impacts might occur as a result of noise, exhaust fumes, and dust associated with the construction activities.

\subsubsection{Implementability}

Uncertainties associated with the implementation of Alternative 8 involve the need for site(area) specific hydrogeologic data to verify the appropriateness of assumptions used in the 
evaluations. The number of recirculations that would be achieved given the heterogeneity of the TCE-contaminated zone would have to be determined. This situation could result in schedule delays and/or unsuccessful implementation of this innovative technology.

Off-gas treatment services are commercially available; equipment and specialists are readily available within DOE and private industry. The off-gas treatment technology considered for Alternative 8 is well developed and has proven to be effective. Further development of this technology would not be required before it could be applied at the site. Disposal services needed in the next few years (i.e., two to three years) would be available within the WSSRAP on-site disposal cell.

Groundwater monitoring would be readily implementable because numerous wells already exist at these operable units. Additional wells could be easily installed to monitor any off-site plume migration. The existing network of monitoring wells would provide notice before any unacceptable exposure could occur.

The administrative feasibility of this alternative would be relatively straightforward. WSSRAP and remedial action project activities at the WSOW are coordinated with the State of Missouri and EPA Region VII. That coordination would continue during the duration of implementation. The implementation of this alternative would not require coordination with any other agencies beyond that already occurring, and no permit or license for on-site activities would be required.

\subsubsection{Cost}

Costs for this alternative would be associated with continuing the existing environmental monitoring program, constructing and operating the in-well vapor stripping and associated off-gas and treatment systems, and conducting a performance review at least every five years. Feasibilitylevel cost estimates were prepared using standard cost-estimating sources such as the latest version of the Unit Price Book developed by the U.S. Army Corps of Engineers (1989).

The estimated total and present-worth costs for Alternative 8 are given in Table 4.4; annual costs are estimated to be approximately $\$ 0.4$ million per year for monitoring. The capital cost of Alternative 8 is estimated to range between $\$ 1$ and $\$ 3$ million, depending on the number of vapor stripping wells. The capital cost would be primarily for installation of the vapor stripping and monitoring wells.

Excluding the D\&D costs of the in-well vapor stripping network (which are highly speculative), the 30-year present worth of Alternative 8 is estimated to range between $\$ 6$ million and $\$ 7$ million. 
TABLE 4.4 Cost Estimate for Alternative 8

\begin{tabular}{lc}
\hline \multicolumn{1}{c}{ Activity } & $\begin{array}{c}\text { Estimated Cost } \\
\text { (\$ million) }\end{array}$ \\
\hline $\begin{array}{l}\text { Vapor stripping well and off-gas } \\
\text { treatment facility construction }\end{array}$ & $1-3$ \\
$\begin{array}{l}\text { Vapor stripping well and off-gas } \\
\text { treatment facility operations }\end{array}$ & 0.5 \\
$\begin{array}{l}\text { Groundwater monitoring } \\
\text { Total }\end{array}$ & 9 \\
Present worth $^{\text {b }}$ & $11-12$ \\
\hline
\end{tabular}

a Based on construction of between 9 to 16 vapor stripping and associated monitoring wells.

b

Estimated upper-bound cost for a 30-year period, assuming annual sampling frequency for the existing network of monitoring wells. Any reduction in duration of monitoring, sampling frequency, or number of wells sampled would result in a proportional reduction in cost.

The costs associated with potential future actions, in the event that potential migration of residual contamination resulted in unacceptable exposure concentrations, were not quantified because the uncertainty associated with these future activities precludes accurate assessment of these costs.

\subsection{ALTERNATIVE 9: IN-SITU CHEMICAL OXIDATION OF TCE USING FENTON-LIKE REAGENTS}

The activities associated with Alternative 9 include the following:

- In-situ treatment of TCE-contaminated groundwater primarily at the WSCP near the raffinate pits area contaminated with TCE to achieve a TCE concentration of $5 \mu \mathrm{g} / \mathrm{L}$ or less;

- Long-term monitoring of groundwater to verify and ensure protection of human health and the environment; 
- Institutional controls to ensure that access and use of contaminated groundwater remain consistent with current land use; and

- Contingency measures in the event that potential unacceptable off-site concentrations and exposure could occur.

The in-situ chemical oxidation technology consists primarily of the installation of injection wells into the shallow bedrock aquifer. For the purposes of this analysis, it was assumed that new injection wells would be installed. Chemical solutions (e.g., $\mathrm{H}_{2} \mathrm{O}_{2}$ and $\mathrm{FeSO}_{4}$ ) are injected into the aquifer to produce a Fenton-like reaction under acidic conditions. Hydroxyl free radicals are generated from this reaction to oxidize the TCE. The time required for in-situ treatment under Alternative 9 is predicted to be less than one year. Actual field performance may vary from that assumed during design, given uncertainties about the subsurface geology prior to construction and operation.

This alternative, however, would not address the nitrate and nitroaromatic compounds that may also be present. Long-term monitoring as described in Alternative 2 would be implemented to manage other contaminants in the groundwater. This alternative provides for active remediation of TCE only. As in Alternatives 2, 7, and 8, long-term monitoring would be conducted to obtain data that would verify decreasing nitrate and nitroaromatic concentrations with time. This decrease is expected to result from source removals and from continued occurrence of natural attenuation processes.

Because contaminants would remain in site groundwater at concentrations above levels that allow for unlimited use and unrestricted exposure, reviews would be conducted at least every five years consistent with CERCLA requirements.

\subsubsection{Overall Protection of Human Health and the Environment}

Similar to Alternative 7 , Alternative 9 would actively remediate only TCE because TCE concentrations in groundwater have been determined to be the primary contributor to potential human health risk from groundwater exposure. Further potential migration of TCE would be largely halted upon implementation of this alternative, and any potential future TCE migration to the aboveground springs would be effectively eliminated.

Alternative 9 would be adequately protective of human health and the environment over the long term. Any potential migration of the contamination toward the surface springs would be monitored. Data collected would verify and ensure protection of human health and the environment. Monitoring would also track progress toward the attainment of remediation goals. Remediation of contaminants other than TCE in the water-bearing zone within the operable units would be provided 
by natural processes that are expected to attenuate these contaminant concentrations. Dilution of the contaminated groundwater with uncontaminated groundwater drawn from infiltration of rainwater and runoff could also result in decreased concentrations.

\subsubsection{Compliance with Potential ARARs}

Alternative 9 would comply with potential ARARs similar to Alternative 7 (see Section 4.4.2).

\subsubsection{Long-Term Effectiveness and Permanence}

Similar to Alternatives 7 and 8 , the contaminated groundwater would be treated under Alternative 9 , which would reduce or eliminate any potential risk associated with TCE levels currently found at the WSCP.

Under current land use conditions, groundwater is not used and, therefore, poses no imminent risk to human health or the environment. Monitoring data obtained by DOE and the DA at these operable units would verify and ensure protection of human health and the environment. Unacceptable impacts to human health and the environment would not be expected to occur.

\subsubsection{Reduction of Toxicity, Mobility, or Volume through Treatment}

Alternative 9 would satisfy the statutory preference for treatment as a principal element of remediation and would reduce the toxicity, mobility, or volume of the contaminated groundwater through treatment, only relative to TCE. However, in-situ treatment of TCE-contaminated groundwater using Fenton-like reagents would have the potential to reduce the concentrations of other organic contaminants (such as nitroaromatic compounds) that also exist in the TCEcontaminated groundwater at the WSCP near the raffinate pits area.

\subsubsection{Short-Term Effectiveness}

Construction activities are estimated to result in less than two cases of occupational injury and no occupational fatalities. Minimal environmental impacts would result from construction of the injection wells. These activities may result in physical disturbances of the habitat, but they would be of short duration. 


\subsubsection{Implementability}

Alternative 9 poses a number of implementability concerns. Optimal placement of the injection wells and a determination of the number of chemical injections needed would depend on a more area-specific determination of hydrogeological conditions.

Special equipment or specialists may be required to implement this alternative. The application of Fenton's reagent for the remediation of TCE is in the developmental phase, and numerous aspects of the process, as considered in Alternative 9, have not been proven effective for groundwater and aquifer conditions similar to those at the WSCP.

Groundwater monitoring of the other contaminants would be readily implementable because of the numerous wells located at these operable units. The monitoring network would provide notice before any unacceptable exposure could occur.

The administrative feasibility of this alternative would be relatively straightforward. WSSRAP and remedial action project activities at the WSOW are coordinated with the State of Missouri and EPA Region VII.

\subsubsection{Cost}

Costs for this alternative would be associated with continuing the existing environmental monitoring program, constructing and operating the in-situ chemical oxidation system, and conducting a performance review at least every five years. Feasibility-level cost estimates were prepared using standard cost-estimating sources such as the latest version of the Unit Price Book developed by the U.S. Army Corps of Engineers (1989).

The estimated total and present-worth costs for Alternative 9 are given in Table 4.5; annual costs are estimated to be about $\$ 0.4$ million per year. The capital cost of Alternative 9 is estimated to be approximately $\$ 0.5$ million. The capital cost would be primarily for installation of two sets of nested injection wells and multiple rounds (at least 2) of chemical injection. Costs for additional monitoring wells were also incorporated into this estimate..

Excluding the D\&D costs of the injection wells (which are highly speculative), the 30 -year present worth of Alternative 9 is estimated to be about $\$ 5$ million. The estimated cost of Alternative 9 is the lowest of the action alternatives. 
TABLE 4.5 Cost Estimate for Alternative 9

\begin{tabular}{lc}
\hline \multicolumn{1}{c}{ Activity } & $\begin{array}{c}\text { Estimated Cost } \\
\text { (\$ million) }\end{array}$ \\
\hline $\begin{array}{l}\text { Injection well construction and } \\
\text { three rounds of chemical injection }\end{array}$ & 0.5 \\
Groundwater monitoring $^{\mathrm{b}}$ & 10.8 \\
Total $^{\mathrm{b}}$ & 11.3 \\
Present worth $^{\mathrm{b}}$ & 5 \\
\hline
\end{tabular}

a Based on construction of between two sets of nested injection wells.

b Estimated upper-bound cost for a 30-year period, assuming annual sampling frequency for the existing network of monitoring wells. Any reduction in duration of monitoring, sampling frequency, or number of wells sampled would result in a proportional reduction in cost. 


\section{COMPARATIVE ANALYSIS OF ALTERNATIVES}

A comparison of the alternatives with regard to the nine evaluation criteria listed in Chapter 4 is presented in Sections 5.1 and 5.2. These criteria are categorized into the following three groups as stipulated in the NCP (EPA 1990a): threshold criteria, primary balancing criteria, and modifying criteria.

The threshold category contains the two criteria that each alternative must meet to be eligible for selection:

- Overall protection of human health and the environment; and

- Compliance with ARARs, unless a waiver condition applies.

These threshold criteria ensure that the remedial action selected will be protective of human health and the environment and that the action will attain the ARARs identified at the time of the ROD or that it provides grounds for obtaining a waiver.

The primary balancing category contains the five criteria that are used to assess the relative advantages and disadvantages of each alternative to determine which is most appropriate:

- Long-term effectiveness and permanence;

- Reduction of toxicity, mobility, or volume through treatment;

- Short-term effectiveness;

- Implementability; and

- Cost.

The first two criteria consider the preference for treatment as a principal element and the bias against off-site land disposal of untreated waste. Cost-effectiveness is determined by evaluating the following three of the five balancing criteria: long-term effectiveness and permanence; reduction of toxicity, mobility, or volume through treatment; and short-term effectiveness. Overall effectiveness is then compared with cost to ensure that the costs are proportional to the overall effectiveness of a remedial action. 
The modifying category consists of two criteria that are considered in remedy selection and that will be addressed in the responsiveness summary and the ROD to be prepared following the public comment period for this FS:

- State acceptance, and

- Community acceptance.

The two modifying criteria are not addressed in this comparative analysis.

The six final alternatives retained after screening are compared in Sections 5.1 and 5.2 for the threshold and primary balancing criteria, respectively. Table 5.1 gives the results of this comparison.

\subsection{THRESHOLD CRITERIA}

\subsubsection{Overall Protection of Human Health and the Environment}

Alternative 1 would be adequately protective of human health and the environment in both the short term and long term. Under current land use conditions, the contaminated groundwater at the WSCP and the WSOW poses no imminent risk to human health or the environment at the surface springs. Future land use conditions are expected to be similar to current conditions.

Alternative 2 would also be protective of human health and the environment over the long term. Monitoring and investigative activities by DOE and the DA would verify and ensure protection of human health and the environment. The results from monitoring activities would be used to assess the attainment of remediation goals. Chemical distribution in the water-bearing zone could also be tracked.

Continued federal ownership of the WSTA at the WSOW and the area containing the on-site disposal cell at the WSCP would restrict site development activities through rights of ownership, so that development activities such as agricultural or residential usage could be prevented in these areas. However, implementation of institutional controls for the remaining site areas would involve agreements by the DOE and the DA with the respective landowners (i.e., Missouri Department of Conservation). As with Alternative 1, unacceptable impacts to human health and the environment would not be expected to occur.

Alternative 4 would remove groundwater contaminants of concern until PRGs are attained. 
TABLE 5.1 Comparative Analysis of Alternatives

\begin{tabular}{cl}
\hline \multicolumn{1}{c}{ Alternative } & $\begin{array}{c}\text { Overall protection of human health } \\
\text { and the environment }\end{array}$ \\
\hline Alternative 1: No Action & $\begin{array}{l}\text { Like all of the alternatives, would be } \\
\text { adequately protective of human } \\
\text { health and the environment, although } \\
\text { monitoring data would not be } \\
\text { available to verify this occurrence. }\end{array}$
\end{tabular}

Alternative 2: Long-Term Monitoring

Alternative 4: Groundwater Removal and On-Site Treatment Using GAC
Like all of the alternatives, would be adequately protective of human health and the environment. Monitoring data would be collected to verify that conditions continue to be protective of human health and the environment.

Like all of the alternatives, would be adequately protective of human health and the environment.
Compliance with ARARs

Complies with ARARs; ARARs for TCE, nitrate, and nitroaromatic compounds would be met after a period of time because of source removals performed under the chemical plant ROD (DOE 1993).

Complies with ARARs; similar to Alternative 1.

Complies with ARARs. Could take a similar amount of time as Alternatives 1 and 2 for all contaminants to meet ARARs. However, ARARs could be met in a shorter period of time because of active remediation of the entire aquifer contaminated above PRGs.

Complies with ARARs; similar to Alternatives 1 and 2 for all contaminants except TCE. The ARAR for TCE could be met in a similar amount of time as Alternative 4 but longer than Alternatives 8 and 9 .

Similar to Alternative 7; could meet ARAR for TCE in a shorter period of time than Alternative 7 and in a slightly longer time than Alternative 9.

Complies with ARARs. Requires the least time to comply with ARARs for TCE as compared with all other alternatives, including Alternatives 7 and 8.
Alternative 9: In-Situ Chemical Oxidation of TCE Using

Fenton-Like Reagents
Like all of the alternatives, would be adequately protective of human health and the environment. Monitoring data would be collected to verify that conditions continue to be protective of human health and the environment. 
TABLE 5.1 (Cont.)

\begin{tabular}{cll}
\hline Alternative & $\begin{array}{c}\text { Long-term effectiveness } \\
\text { and permanence }\end{array}$ & $\begin{array}{l}\text { Reduction of toxicity, mobility, or } \\
\text { volume through treatment }\end{array}$ \\
\hline Alternative 1: No Action & $\begin{array}{l}\text { Is expected to afford long-term } \\
\text { effectiveness and permanence, } \\
\text { although investigative and } \\
\text { monitoring activities would not be } \\
\text { performed. }\end{array}$ & $\begin{array}{l}\text { Not applicable because the } \\
\text { contaminated groundwater would } \\
\text { not be treated. Restoration of the } \\
\text { water-bearing zone within the } \\
\text { operable unit would be provided by } \\
\text { natural processes such as } \\
\text { biodegradation, adsorption, and } \\
\text { chemical reactions with subsurface } \\
\text { materials and by dilution of the } \\
\text { contaminated groundwater with } \\
\text { uncontaminated groundwater drawn } \\
\text { through infiltration of rainwater and } \\
\text { runoff. }\end{array}$ \\
&
\end{tabular}

Alternative 2: Long-Term Monitoring
Provides for long-term effectiveness and performance; unlike Alternative 1, would provide verification monitoring of the groundwater within the operable unit.

Would remove or reduce the contaminant concentrations through extraction and treatment and afford long-term protection.
Not applicable because the contaminated groundwater would not be treated. Restoration of the water-bearing zone within the operable unit would be provided by natural processes such as biodegradation, adsorption, and chemical reactions with subsurface materials and by dilution of the contaminated groundwater with uncontaminated groundwater drawn through infiltration of rainwater and runoff.

Reduction of the toxicity, mobility, or volume associated with all groundwater contamination within the shallow bedrock aquifer would be accomplished upon successful implementation of this alternative. 
TABLE 5.1 (Cont.)

\begin{tabular}{ll}
\hline \multicolumn{1}{c}{ Alternative (Cont.) } & \multicolumn{1}{c}{$\begin{array}{c}\text { Long-term effectiveness } \\
\text { and permanence (Cont.) }\end{array}$} \\
$\begin{array}{l}\text { Alternative 7: Removal and } \\
\text { On-Site Treatment of TCE- } \\
\text { Contaminated Groundwater }\end{array}$ & $\begin{array}{l}\text { Would reduce concentrations of } \\
\text { TCE and other contaminants present } \\
\text { in the plume. Would provide } \\
\text { monitoring data to verify positive } \\
\text { impacts from source removals via } \\
\text { the chemical plant ROD (DOE } \\
\text { 1993). Decreases in contaminant } \\
\text { concentrations other than TCE as a } \\
\text { result of natural processes would } \\
\text { also be verified via monitoring. }\end{array}$ \\
\end{tabular}

Alternative 8: In-Situ Treatment of TCE Using In-Well Vapor Stripping

Alternative 9: In-Situ Chemical Oxidation of TCE Using

Fenton-Like Reagents
TCE in the plume would be reduced or removed by treatment of groundwater. Natural processes and source removals per the chemical plant ROD (DOE 1993) are expected to result in further contaminant decreases.

TCE in the plume would be reduced by treatment of groundwater Natural processes and source removals per the chemical plant ROD (DOE 1993) are expected to result in further contaminant decreases.
Reduction of toxicity, mobility, or volume through treatment (Cont.)
Reduction of the toxicity, mobility, or volume associated with TCE contamination at the WSCP would be accomplished. Further restoration of the water-bearing zone within the operable unit would be provided by natural processes such as biodegradation, adsorption, and chemical reactions with subsurface materials and dilution of the contaminated groundwater with uncontaminated groundwater drawn through infiltration of rainwater and runoff.

Similar to Alternative 7.

Similar to Alternative 7.
Alternative

Alternative 1: No Action

Alternative 2: Long-Term Monitoring
Expected to be low, with less than one case of occupational injury and no occupational fatalities during proposed monitoring well construction. Any potential shortterm environmental impacts would be limited to the immediate vicinity of the operable unit, and mitigative measures would be applied to ensure minimal impacts to off-site areas.
No implementability concerns because no action would be taken nor would any future activities be considered.

Few implementability concerns because of the limited actions taken. Current monitoring operations would continue with the use of readily available resources. 
TABLE 5.1 (Cont.)

\begin{tabular}{|c|c|c|}
\hline Alternative (Cont.) & Short-term effectiveness (Cont.) & Implementability (Cont.) \\
\hline $\begin{array}{l}\text { Alternative 4: Groundwater } \\
\text { Removal and On-Site } \\
\text { Treatment Using GAC }\end{array}$ & $\begin{array}{l}\text { Expected to be relatively high } \\
\text { compared with other alternatives } \\
\text { because of a large number of } \\
\text { extraction wells (between } 330 \text { to } \\
1,000 \text { wells. Construction activities } \\
\text { are estimated to result in up to } \\
50 \text { cases of occupational injury and } \\
\text { less than one occupational fatality. } \\
\text { Any potential short-term } \\
\text { environmental impacts would be } \\
\text { limited to the immediate vicinity of } \\
\text { the operable unit, and mitigative } \\
\text { measures would be applied to ensure } \\
\text { minimal impacts to off-site areas. }\end{array}$ & $\begin{array}{l}\text { Uncertainties with implementation } \\
\text { of this alternative are associated } \\
\text { with the need for location (or area)- } \\
\text { specific hydrogeologic data to } \\
\text { verify the appropriateness of } \\
\text { assumptions applied in the } \\
\text { evaluations. Groundwater treatment } \\
\text { technologies have been } \\
\text { demonstrated at full-scale } \\
\text { implementation for similar } \\
\text { contaminants. }\end{array}$ \\
\hline $\begin{array}{l}\text { Alternative } 7: \text { Removal and } \\
\text { On-Site Treatment of TCE- } \\
\text { Contaminated Groundwater }\end{array}$ & $\begin{array}{l}\text { Expected to be low, with less than } \\
\text { nine cases of occupational injury and } \\
\text { no occupational fatalities during } \\
\text { operations and well construction } \\
\text { activities. Any potential short-term } \\
\text { environmental impacts would be } \\
\text { limited to the immediate vicinity of } \\
\text { the operable unit, and mitigative } \\
\text { measures would be applied to ensure } \\
\text { minimal impacts to off-site areas. }\end{array}$ & $\begin{array}{l}\text { Uncertainties with implementation } \\
\text { of this alternative are associated } \\
\text { with specific hydrogeologic data } \\
\text { that indicate dewatering and very } \\
\text { slow recovery of the aquifer as } \\
\text { indicated by the recent pump test. }\end{array}$ \\
\hline $\begin{array}{l}\text { Alternative 8: In-Situ Treatment } \\
\text { of TCE Using In-Well Vapor } \\
\text { Stripping }\end{array}$ & Similar to Alternative 7. & $\begin{array}{l}\text { Uncertainties with implementation } \\
\text { of this alternative are relative to the } \\
\text { generation of a vertical circulation } \\
\text { pattern. }\end{array}$ \\
\hline $\begin{array}{l}\text { Alternative 9: In-Situ Chemical } \\
\text { Oxidation of TCE Using } \\
\text { Fenton-Like Reagents }\end{array}$ & Similar to Alternative 7. & $\begin{array}{l}\text { Uncertainties related to the ability } \\
\text { to optimally locate injection wells } \\
\text { and the ability to inject the needed } \\
\text { chemicals into the aquifer. }\end{array}$ \\
\hline
\end{tabular}


TABLE 5.1 (Cont.)

Alternative

Alternative 1: No Action

Alternative 2: Long-Term Monitoring

Alternative 4: Groundwater Removal and On-Site

Treatment Using GAC

Alternative 7: Removal and On-Site Treatment of TCEContaminated Groundwater

\section{Cost}

Lowest future cost.

Could be considered cost effective because it would provide overall protection of human health and the environment for a reasonable cost. Costs would be associated with continuing the existing environmental monitoring program, constructing and operating the proposed new monitoring wells, and conducting a performance review at least every five years. Could be implemented with existing resources and maintained at a relatively low cost. Annual monitoring costs are estimated to be $\$ 0.4$ million.

On the basis of an estimate of 330 to 1,000 extraction wells, capital costs are estimated to range from $\$ 41$ million to $\$ 120$ million, with the 30 -year present worth cost estimated to range from $\$ 53$ million to $\$ 140$ million. The least costeffective of the six alternatives because the degree of protectiveness provided is not commensurate with the significantly greater cost.

Capital costs are estimated to range between $\$ 9$ million and $\$ 25$ million; assuming monitoring for 30 years. The 30-year present worth cost is estimated to range between $\$ 23$ million and \$53 million. Provides some increases in protection because of TCE removal or reduction, but at a much higher cost than Alternatives 8 and 9. 
TABLE 5.1 (Cont.)

Alternative (Cont.) Cost (Cont)

Alternative 8: In-Situ Treatment of TCE Using In-Well Vapor Stripping

Alternative 9: In-Situ Chemical Oxidation of TCE Using

Fenton-Like Reagents
Capital cost estimated to range between $\$ 1$ million and $\$ 3$ million. Annual costs are estimated to be \$0.4 million for monitoring. The 30-year present worth cost is estimated to range between $\$ 6$ million and $\$ 7$ million.

Most cost-effective for remediation of TCE contamination as compared with Alternatives 7 and 8; capital cost estimated to be approximately $\$ 0.5$ million and includes the material costs of the chemical reagents. Annual costs are estimated to be $\$ 0.4$ million and are associated with groundwater monitoring. The 30-year present worth cost is on the order of $\$ 5$ million. This alternative provides an increase in protectiveness that is proportionate to the cost.

Under Alternatives 1 and 2, the currently contaminated groundwater would not be removed or treated. Alternatives 7, 8, and 9 would remediate the TCE-contaminated groundwater at the WSCP and the WSOW to or below the PRG of $5 \mu \mathrm{g} / \mathrm{L}$. Naturally occurring processes, including dilution of the contaminated groundwater with uncontaminated groundwater drawn through infiltration of rainwater and runoff, are expected to attenuate contaminant concentrations other than TCE. Therefore, long-term overall protection of the environment would be provided through restoration of the water-bearing zone at the WSCP and the WSOW.

\subsubsection{Compliance with ARARs}

Chemical-Specific ARARs. Potential regulatory requirements that might be applicable or relevant and appropriate to the final remedial action alternatives are identified and evaluated in Appendix A of the FS (DOE and DA 1998b). Chemical-specific ARARs (MCLs) have been identified for nitrate $(10 \mathrm{mg} / \mathrm{L}), \mathrm{TCE}(5 \mu \mathrm{g} / \mathrm{L})$, and three nitroaromatic compounds (nitrobenzene at $17 \mu \mathrm{g} / \mathrm{L}, 2,4-\mathrm{DNT}$ at $0.11 \mu \mathrm{g} / \mathrm{L}$, and 1,3-DNB at $1.0 \mu \mathrm{g} / \mathrm{L}$ ). The current levels of nitrate, TCE, and 2,4-DNT in groundwater at the chemical plant area exceed the respective chemical-specific ARARs. 
All of the alternatives meet chemical-specific ARARs. Under no action, decreases in concentrations for these contaminants are expected as a result of source removals being performed per the chemical plant ROD (DOE 1993). Natural processes that are occurring are likewise expected to continue and lower contaminant concentrations. Alternative 2 would meet chemical-specific ARARs as a result of natural processes that would continue to occur and from source removals per the chemical plant ROD (DOE 1993). Monitoring data would be obtained to verify the expected decreases in contaminant concentrations.

Alternative 4 would meet chemical-specific ARARs because groundwater extraction and treatment would be performed.

Alternative 7 would meet chemical-specific ARARs as a result of groundwater extraction and treatment and from natural processes and source removals at the chemical plant (DOE 1993). Alternatives 8 and 9 would meet chemical-specific ARARs as a result of in-situ treatment and from natural processes and source removals at the chemical plant (DOE 1993).

Location-Specific ARARs. Location-specific ARARs are discussed in Appendix A of the FS (DOE and DA 1998b). Location-specific ARARs would be similar for all alternatives. All alternatives would meet location-specific ARARs.

Action-Specific ARARs. Action-specific ARARs would vary depending on the alternative or technology involved. Action-specific ARARs are discussed in Appendix A of the FS (DOE and DA 1998).

For the no action alternative, there would be no action-specific ARAR associated with this alternative because there would be no action taken. Alternatives 2, 4, 7, 8, and 9 would meet substantive requirements related to any action-specific ARARs (e.g., construction, monitoring, extraction, injection wells, treatment plants, and discharge limits).

\subsection{PRIMARY BALANCING CRITERIA}

\subsubsection{Long-Term Effectiveness and Permanence}

Alternative 1 does not include investigative and monitoring activities to verify long-term effectiveness. Under current land use conditions, the contaminated groundwater at the WSCP and the WSOW poses no imminent risk to human health and the environment. Although contaminant concentrations would not be measured by the DOE and DA in the future, it is expected that unacceptable impacts to human health and the environment would not occur. However, Alternative 1 does not address the potential for implementation of any contingency response measures if 
unacceptable impacts to human health and environment did occur (e.g., prevent or limit access and use of the contaminated groundwater if contaminant concentrations remain at current levels).

Under Alternatives 2, 4, 7,8, and 9, monitoring and maintenance activities would be carried out at the WSCP and the WSOW for a reasonable period. These activities would be evaluated at least every five years, or until remediation goals identified in the ROD were achieved. Thus, these activities would provide adequate and reliable controls to manage the groundwater within these areas. Long-term effectiveness of Alternatives 2, 4, 7, 8, and 9 would be ensured because investigative and monitoring activities would continue, thereby allowing consideration of contingency response measures in the future, if appropriate.

\subsubsection{Reduction of Toxicity, Mobility, or Volume through Treatment}

No reduction of toxicity, mobility, or volume through treatment would be achieved by either Alternative 1 or 2 because the contaminated groundwater would not be treated under either alternative. Restoration of the water-bearing zone within the WSCP and the WSOW would be provided by natural processes such as biodegradation, adsorption, and chemical reactions with subsurface materials, and by dilution of the contaminated groundwater with uncontaminated groundwater drawn through infiltration of rainwater and runoff.

Alternatives $4,7,8$, and 9 would satisfy the statutory preference for treatment as a principal element of remediation and reduce the toxicity, mobility, or volume of the contaminated groundwater through treatment. The latter three alternatives would provide treatment of primarily TCE.

\subsubsection{Short-Term Effectiveness}

For Alternative 1, conditions would essentially remain the same in the short term, and no significant changes in potential exposures would be expected because no activities would be undertaken. No potential impacts would occur to workers or the environment under Alternative 1.

The short-term impacts for Alternative 2 would be expected to be low, with less than one case of occupational injury and no occupational fatalities during proposed monitoring well construction. Potential short-term environmental impacts resulting from implementation of Alternative 2 would be limited to the immediate vicinity of the operable units, and mitigative measures would be applied to ensure minimal impacts to off-site areas.

Short-term impacts from construction activities under Alternatives 7,8, and 9 are estimated to result in less than nine cases of occupational injury, depending on the number of wells required; in addition, no occupational fatalities are predicted. 


\subsubsection{Implementability}

No implementability concerns would be posed by Alternative 1 because no action would be taken nor would any future activities be considered. Alternative 2 would pose few implementability concerns because resources would be readily available for groundwater monitoring and additional wells could be easily installed, if appropriate. Monitoring the effectiveness of Alternative 2 would be relatively easy to implement. The administrative feasibility of Alternative 2 would be relatively straightforward.

Uncertainty is associated with the implementability of Alternatives 4, 7, 8, and 9. Uncertainties are primarily associated with the need for site (area)-specific hydrogeologic data to verify the appropriateness of assumptions used in the evaluations.

\subsubsection{Cost}

Alternative 1 would be the least expensive alternative in the short term. Because no activities would be undertaken, there would be no present-worth, capital, or annual O\&M costs. However, total costs could be highest in the long term if contaminated groundwater from the WSCP and the WSOW traveled to the surface springs in high concentrations. Because all monitoring and investigative activities by DOE and the DA would have ceased, conditions could have worsened considerably over time, necessitating an expensive emergency and/or expanded response in the future. Thus, the cost-effectiveness of the no-action alternative can be considered to be low in the long term.

Preliminary costs were estimated for Alternative 2 for comparative purposes. Final costs would be developed during the detailed design stage following remedy selection. The total cost, long-term monitoring costs, and present-worth costs for Alternative 2 are summarized in Table 4.1.

Compared with Alternative 1, Alternative 2 is more cost effective because it would provide overall protection of human health and the environment for a reasonable cost. Costs for Alternative 2 would be associated with continuing the existing environmental monitoring program, constructing and operating any proposed new monitoring wells, and conducting a performance review at least every five years. Alternative 2 could be implemented with existing resources and maintained at a relatively low cost.

Costs associated with Alternative 4 would be the highest; capital costs are estimated to range between $\$ 41$ million and $\$ 120$ million. For Alternative 7, capital costs are estimated to range between $\$ 9$ million and $\$ 25$ million. For Alternative 8 , capital costs are estimated to range between 
$\$ 1$ million and $\$ 3$ million. For Alternative 9, capital costs are estimated to be approximately $\$ 0.5$ million.

\subsection{SUMMARY}

In summary, Alternative 1 would satisfy the threshold criteria for protecting human health and the environment and complying with PRGs. However, data would not be available for verification. Alternatives $2,4,7,8$, and 9 would satisfy the threshold criteria, with waivers as appropriate. In addition, these alternatives would provide long-term protection of human health and the environment in the extended future because investigative and monitoring activities would continue and would allow consideration of contingency response measures in the future if contaminant concentrations are identified at unacceptable levels and access and use of contaminated groundwater occurred.

Any short-term impacts associated with Alternatives 2, 4, 7, 8, and 9 would be temporary and limited to the immediate vicinity of the operable units; mitigative measures would be applied to ensure minimal impacts to off-site areas. Implementation of monitoring activities associated with Alternatives $2,7,8$, and 9 would be straightforward because the groundwater monitoring system established at the WSCP and the WSOW would be used. Implementation of Alternatives 2, 4, 7, 8 and 9 would not be as certain as implementation of Alternative 2 because of site (area)-specific hydrogeologic data (e.g., hydraulic conductivity and sustainable pump rates) are needed to verify the appropriateness of assumptions used in the evaluations.

Alternative 2 is considered to be more cost effective than Alternative 1 because it would provide overall protection of human health and the environment for a reasonable cost. The costeffectiveness of Alternatives 4,7,8, and 9 would depend on the ability to minimize uncertainties related to their implementation. Implementation of Alternative 4 would hinge on the sustainable yield at the various zones of contamination at the WSCP and the WSOW. Similarly, the uncertainties related to the sustainable yield of groundwater extraction at the TCE contaminated area would dictate implementability of Alternative 7. The ability to generate vertical circulation would determine the success of Alternative 8. Uncertainties related to acceptance of injection activities by the aquifer system and stakeholders would determine the implementation of Alternative 9. 


\section{REFERENCES}

Acar, Y.B., et al., 1993, "Fundamentals of Extracting Species from Soils by Electrokinetics," Waste Management 13:141-151.

Air Force Center for Environmental Excellence, 1997, Long-Term Monitoring Optimization Guide, Draft Final, prepared by The Waste Policy Institute, April.

Andrews, T., et al., 1997, "Oxidizing Agent Can Finish Cleanup Where Other Systems Taper Off: Process Remediates Contaminated Sites to No Further Action Point," Soil and Groundwater Cleanup (7):39-40.

Barton, L.L., et al., 1996, "Bacterial Reduction of Soluble Uranium: The First Step of In Situ Immobilization of Uranium," Radioactive Waste Management and Environmental Restoration 20:141-151.

Boopathy, R., et al., 1993, "Metabolism of 2,4,6-Trinitrotoluene (TNT) by Desulfovibrio Sp. (B Strain)," Applied Microbiology and Biotechnology 39:270-275.

Boopathy, R., et al., 1997, "Optimization of Environmental Factors for the Biological Treatment of Trinitrotoluene-Contaminated Soil," Archives of Environmental Contamination and Toxicology 32: 94-98.

Bottcher, J., et al., 1990, "Using Isotope Fractionation of Nitrate-Nitrogen and Nitrate-Oxygen for Evaluation of Microbial Denitrification in a Sandy Aquifer," Journal of Hydrology 114:413-424.

Boyajian, G.E., and L.H. Carreira, 1997, "Phytoremediation: A Clean Transition from Laboratory to Marketplace?" Nature Biotechnology 15:127-128.

Boyajian, G.E., and D.L. Devedjian, 1997, "Phytoremediation: It Grows on You," Soil \& Groundwater Cleanup, pp. 22-26, Feb./March.

Bradley, P.M., and F.H. Chapelle, 1995, "Factors Affecting Microbial 2,4,6-Trinitrotoluene Mineralization in Contaminated Soil," Environmental Science and Technology 29(3):802-806.

Bradley, P.M., et al., 1994, "Microbial Transformation of Nitroaromatics in Surface Soils and Aquifer Materials," Applied and Environmental Microbiology 60:2170-2175.

Bradley, P.M., et al., 1997, "The Potential for Intrinsic Bioremediation of a DNT-Contaminated Aquifer," Ground Water 35(1):12-17. 
Canter, L.W., 1997, Nitrates in Groundwater, CRC Press, New York, N.Y.

Cheremisinoff, N.P., and P.N. Cheremisinoff, 1993, Carbon Adsorption for Pollution Control, Prentice Hall, Englewood Cliffs, N.J.

Cichon, E.P., et al., 1997, "Rising Bubbles Lower Costs," Soil and Groundwater Cleanup Online Magazine, Group III Communications, Inc., Independence, Mo. [URL: http://www.sgcleanup. com/vocl.html].

Cohen, R.M., et al., 1994, Methods for Monitoring Pump-and-Treat Performance, EPA/600/R-94/123, prepared by R.S. Kerr Environmental Research Laboratory, Ada, Okla., for U.S. Environmental Protection Agency.

Conley, L.M., et al., 1991, "An Assessment of the Root Zone Method of Wastewater Treatment," Research Journal of the Water Pollution Control Federation 63(3):239-247.

Cooney, C.M., 1996, "Sunflowers Remove Radionuclides from Water in Ongoing Phytoremediation Field Tests," Environmental Science and Technology 30(5):194A.

Cornish, J.E., et al., 1995, "Phytoremediation of Soils Contaminated with Toxic Elements and Radionuclides," in Bioremediation of Inorganics (Third International In Situ and On-Site Bioreclamation Symposium), R.E. Hinchee et al. (editors), Battelle Press, Columbus, Ohio.

Cox, E., et al., 1995, "Intrinsic Biodegradation of Trichloroethene and Trichloroethane in a Sequential Anaerobic-Aerobic Aquifer" in Intrinsic Bioremediation (Third International In Situ and On-Site Bioreclamation Symposium), R.E. Hinchee et al. (editors), Battelle Press, Columbus, Ohio.

Crigler, D., 1992, personal communication from Crigler(Wildlife Management Biologist, August A. Busch Memorial Wildlife Area, St. Charles, Mo.) to G. Valett (Project Management Contractor, Weldon Spring Site Remedial Action Project, St. Charles, Mo.), as documented in memorandum from G. Valett to R. Ferguson (Jacobs Engineering Group, Inc., Weldon Spring Site Remedial Action Project, St. Charles, Mo.), May 21.

DA: see U.S. Department of the Army.

DOD: see U.S. Department of Defense.

DOE: see U.S. Department of Energy. 
Ellis, D.E., et al., 1997, "Remediation Technology Development Forum Intrinsic Remediation Project at Dover Air Force Base, Delaware," pp. 95-99 in Proceedings of the Symposium on Natural Attenuation of Chlorinated Organics in Ground Water, EPA/540/R-97/504, U.S. Environmental Protection Agency, Office of Research and Development, Washington, D.C.

Enzien, M.V., et al., 1994, "Radioactive Dechlorination of Trichloroethylene and Tetrachloroethylene under Aerobic Conditions in a Sediment Column," Applied and Environmental Microbiology 60:2200-2204.

EPA: see U.S. Environmental Protection Agency.

Fernando, T., et al., 1990, "Biodegradation of TNT (2,3,6-Trinitrotoluene) by Phanaerochaete Chrysosporium," Applied and Environmental Microbiology 56:1666-1671.

Funk, S.D., et al., 1993, "Initial-Phase Optimization for the Bioremediation of Munition CompoundContaminated Soils," Applied and Environmental Microbiology 59:2171-2177.

Gates, D.G., and R.L. Siegrist, 1995, In-Situ Chemical Oxidation of Trichloroethylene Using Hydrogen Peroxide," Journal of Environmental Engineering 121:639-644.

Goffredi, P.E. (editor), 1997, "Evaluating Whether Natural Attenuation Is Feasible for Ground-Water Cleanup," The Hazardous Waste Consultant, pp. 1.2-1.8, Jan./Feb.

Gordon, M., et al., 1996, "Phytoremediation of Trichlorethylene with Hybrid Poplars," Book of Abstracts, AGRO-100, 212th American Chemical Society National Meeting, Orlando, Fla., Aug. 25-29.

Groundwater Remediation Technology Analysis Center, 1996, "Technical Documents-Technical Overview Reports: Ultraviolet/Oxidation Treatment" [URL http://www.gwrtac.org/html/ tech_over.html].

Guest, P.R., et al., 1995, "Inferring Biodegradation Processes for Trichloroethene from Geochemical Data," in Intrinsic Bioremediation (Third International In Situ and On-Site Bioreclamation Symposium), R.E. Hinchee et al. (editors), Battelle Press, Columbus, Ohio.

Gvirtzman, H., and O. Gonen, 1995, "Feasibility Study of In-Well Vapor Stripping Using Airlift Pumping," Ground Water Monitoring and Remediation, pp. 155-162, fall.

GWRTAC: see Groundwater Remediation Technology Analysis Center. 
Haderlein, S.B., et al., 1996, "Specific Adsorption of Nitroaromatic Explosives and Pesticides to Clay Minerals," Environmental Science and Technology 30(2):612-622.

Hallas, L.E., and M. Alexander, 1983, "Microbial Transformation of Nitroaromatic Compounds in Sewage Effluent," Applied and Environmental Microbiology 45:1234-1241.

Hiscock, K.M., et al., 1991, "Review of Natural and Artificial Denitrification of Groundwater," Water Res. 25(9):1099-1111.

Hopkins, G.D., et al., 1993, "Microcosm and In Situ Field Studies of Enhanced Biotransformation of Trichloroethylene by Phenol-Utilizing Microorganisms," Applied and Environmental Microbiology 59(7):2277-2285.

Hughes, J.B., et al., 1997, "Transformation of TNT by Aquatic Plants and Plant Tissue Cultures," Environmental Science and Technology, pp. 266-271.

International Technology Corporation, 1992a, Final Remedial Investigation Report, Weldon Spring Ordnance Works, Weldon Spring, Missouri, Project No. 312071, prepared by International Technology Corporation, Itasca, Ill., for U.S. Department of the Army, Corps of Engineers, Kansas City District, Kansas City, Mo., Nov.

International Technology Corporation, 1992b, Quarterly Groundwater Monitoring, Third Report, Weldon Spring Ordnance Works, Project No. 312188, prepared by International Technology Corporation, Itasca, Ill., for U.S. Department of the Army, Corps of Engineers, Kansas City District, Kansas City, Mo. (Round 6 analytical data; Aug. 1992).

International Technology Corporation, 1993a, Final Feasibility Study, Former Weldon Spring Ordnance Works, Weldon Spring, Missouri, prepared by International Technology Corporation, Itasca, Ill., for U.S. Department of the Army, Corps of Engineers, Kansas City District, Kansas City, Mo., July.

International Technology Corporation, 1993b, Final Remedial Investigation Report, Weldon Spring Training Area, Weldon Spring, Missouri, Project No. 312188, prepared by International Technology Corporation, Itasca, Ill., for U.S. Department of the Army, Corps of Engineers, Kansas City District, Kansas City, Mo., March (Round 1-3 analytical data; March and Oct. 1989; June 1991).

IT Corporation: see International Technology Corporation.

Ivanovich, M., and R.S. Harmon (editors), 1992, Uranium-Series Disequilibrium: Applications to Earth, Marine, and Environmental Sciences, 2nd ed., Clarendon Press, Oxford, United Kingdom. 
Kakarla, P.K.C., and R.J. Watts, 1997, "Depth of Fenton-Like Oxidation in Remediation of Surface Soil," Journal of Environmental Engineering 123:11-17.

Kaplan, D.L., 1992, "Biological Degradation of Explosives and Chemical Agents," Current Opinion in Biotechnology 3:253-260.

Kaplan, D.L., and A.M. Kaplan, 1982, "Thermophilic Biotransformations of 2,4,6-Trinitrotoluene under Simulated Composting Conditions," Applied and Environmental Microbiology 44:757-760.

Kapoor, A., and T. Viraraghavan, 1997, "Nitrate Removal from Drinking Water - Review," Journal of Environmental Engineering 123(4):371-380.

Kleeschulte, M.J., 1991, "Geohydrology of Bedrock Aquifers and Public Supply and Domestic Water Use, 1962-85, in St. Charles County, Missouri," pp. 41-74 in Proceedings of the Geosciences Workshop, DOE/OR/21548-197, published by MK-Ferguson Company and Jacobs Engineering Group, Inc., St. Charles, Mo., for U.S. Department of Energy, Oak Ridge Operations Office, Weldon Springs Site Remedial Action Project, St. Charles, Mo., Feb.

Kleeschulte, M.J., and L.F. Emmett, 1987, Hydrology and Water Quality at the Weldon Spring Radioactive Waste-Disposal Sites, St. Charles, Missouri, U.S. Geological Survey Water-Resources Investigation Report 87-4169.

Kleeschulte, M.J., and J.L. Imes, 1994, Geohydrology, Water Quality, and Simulation of GroundWater Flow at the Weldon Spring Chemical Plant and Vicinity, St. Charles County, Missouri, 1987-90, U.S. Geological Survey Open-File Report 93-648.

Krumme, M.L., et al., 1993, "Degradation of Trichloroethylene by Pseudomonas cepacia G4 and the Constitutive Mutant Strain G4 5223 PR1 in Aquifer Microcosms," Applied and Environmental Microbiology 59:2746-2749.

Leahy, J.G., et al., 1996, "Comparison of Factors Influencing Trichloroethylene Degradation by Toluene-Oxidizing Bacteria," Applied and Environmental Microbiology 62:825-833.

Lee, M.D., et al., 1995, "Intrinsic In Situ Anaerobic Biodegradation of Chlorinated Solvents at an Industrial Landfill," in Intrinsic Bioremediation (Third International In Situ and On-Site Bioreclamation Symposium), R.E. Hinchee et al. (editors), Battelle Press, Columbus, Ohio.

Li, Z.M., et al., 1997, "Destruction of 2,4,6-Trinitrotoluene by Fenton Oxidation," Journal of Environmental Quality 26(2):480-487. 
Lovely, D.R., et al., 1993, "Reduction of Uranium by Cytochrome $\mathrm{c}_{3}$ of Desulfovibrio vulgaris," Applied Environmental Microbiology 59(11):3572-3576.

Lu, C.-J., et al., 1989, "Aerobic Biodegradation of Trichloroethylene by Microorganisms that Degrade Aromatic Compounds," pp. 1-7 in Bioremediation of Chlorinated Solvents, R.E. Hinshaw and A. Leeson (editors), Battelle Columbus Press, Columbus, Ohio.

Major, D., et al., 1995, "Intrinsic Dechlorination of Trichloroethene to Ethene in a Bedrock Aquifer," in Intrinsic Bioremediation (Third International In Situ and On-Site Bioreclamation Symposium), R.E. Hinchee et al. (editors), Battelle Press, Columbus, Ohio.

Marks, P.J., et al., 1994, Remediation Technologies Screening Matrix and Reference Guide, Second Edition, SFIM-AEC-ET-CR-94065, prepared by Roy F. Weston, Inc., for U.S. Army Environmental Center, Aberdeen Proving Ground, Md., Oct.

Martin, M., and T.E. Imbrogiotta, 1994, "Contamination of Ground Water with Trichloroethylene at the Building 24 Site at Picatinny Arsenal," pp. 109-115 in Proceedings of the Symposium on Natural Attenuation of Ground Water, EPA/600/R-94/162, U.S. Environmental Protection Agency, Office of Research and Development, Washington, D.C., Sept.

McCarty, P.L., 1994, "An Overview of Anaerobic Transformation of Chlorinated Solvents," pp. 104-108 in Proceedings of the Symposium on Natural Attenuation of Ground Water, EPA/600/R-94/162, U.S. Environmental Protection Agency, Office of Research and Development, Washington, D.C., Sept.

Medina, V.F., and S.C. McCutcheon, 1996, "Phytoremediation: Modeling Removal of TNT and Its Breakdown Products," Remediation 7(1):31-45.

Miller, R.R., 1996a, Phytoremediation, Technology Overview Report TO-96-03, Ground-Water Remediation Technologies Analysis Center, Pittsburgh, Penn., Oct.

Miller, R.R., 1996b, Artificially-Induced or Blast-Enhanced Fracturing, Technology Overview Report TO-96-01, Ground-Water Remediation Technologies Analysis Center, Pittsburgh, Penn., June.

Miller, R.R., and D.S. Roote, 1997, In-Well Vapor Stripping, Technology Overview Report TO-97-01, Ground-Water Remediation Technologies Analysis Center, Pittsburgh, Penn., Feb. 
Missouri Department of Natural Resources, 1991, Shallow Groundwater Investigations at Weldon Spring, Missouri: Final Report for Fiscal Years 1988-1990, prepared by Division of Geology and Land Survey, Rolla, Mo., for U.S. Department of Energy, Weldon Spring Site Remedial Action Project, St. Charles, Mo., June.

MK-Ferguson Company and Jacobs Engineering Group, Inc., 1990a, Aquifer Characteristics Data Report for the Weldon Spring Site Chemical Plant/Raffinate Pits and Vicinity Properties, DOE/OR/21548-122, Rev. 0, prepared for U.S. Department of Energy, Oak Ridge Operations Office, Weldon Spring Site Remedial Action Project, Weldon Spring, Mo., Nov.

MK-Ferguson Company and Jacobs Engineering Group, Inc., 1990b, WSSRAP Chemical Plant Geotechnical Investigations, DOE/OR/21548-158, prepared for U.S. Department of Energy, Oak Ridge Operations Office, Weldon Spring Site Remedial Action Project, St. Charles, Mo., Dec.

MK-Ferguson Company and Jacobs Engineering Group, Inc., 1998, Weldon Spring Site Environmental Report for Calendar Year 1997, DOE/OR/21548-730, prepared for U.S. Department of Energy, Oak Ridge Operations Office, Weldon Spring Site Remedial Action Project, St. Charles, Mo., Aug.

Mohanty, N.R., and I.W. Wei, 1993, "Oxidation of 2,4-Dinitrotoluene Using Fenton's Reagent: Reaction Mechanisms and Their Practical Applications," Hazardous Waste \& Hazardous Materials 10(2):171-183.

Mugel, D., 1994, letter from D. Mugel (U.S. Geological Survey, Water Resources Division, Rolla, Mo.) to L. Durham (Environmental Assessment Division, Argonne National Laboratory, Argonne, IIl.), with attachments, Aug. 4.

Mugel, D.N., 1997, Geohydrology of the Weldon Spring Ordnance Works, St. Charles County, Missouri, USGS Water-Resources Investigations Report 96-4171, prepared in cooperation with the U.S. Army Corps of Engineers, Rolla, Mo., in press.

National Safety Council, 1995, Accident Facts, 1995 ed., Itasca, Ill.

Negri, M.C., and R.R. Hinchman, 1996, "Plants that Remove Contaminants from the Environment," Laboratory Medicine 27:36-40.

Odermatt, J.R., 1997, "Setting Rational Limits on Natural Attenuation," Soil \& Groundwater Cleanup, pp. 44-46, Feb./March.

Pacific Northwest National Laboratory, 1994, "Profile - In-Well Air Stripping for Removal of VOCs" [URL: http://www.pnl.gov.2080/WEBTECH/voc/inwell.html]. 
Pacific Northwest National Laboratory, 1997, “Off-Site Thermal Regeneration of GACs, 9/18/94" [URL: http://www.pnl.gov/WEBTECH/voc/gacregen.html], April 24.

PNNL: see Pacific Northwest National Laboratory.

Price, P., 1991, Shallow Groundwater Investigations at the Weldon Spring Training Area, St. Charles County, Missouri, prepared by Missouri Department of Natural Resources, Division of Geology and Land Survey, Rolla, Mo., for U.S. Department of the Army, Corps of Engineers, Kansas City District, Kansas City, Mo., Oct.

Pucik, L.E., et al., 1997, "In-Situ Treatment of VOCs in a Fractured Bedrock Aquifer Using Fenton's Reagent," presented at 213th Americal Chemical Society National Meeting, San Francisco, Calif., April 13-17.

Reed, S.C., and D.S. Brown, 1992, "Constructed Wetland Design- The First Generation," Water Environmental Research 64(6):776-781.

Roote, D.S., et al., 1997, “Groundwater Clean-Up Options,” Chemical Engineering 104(5):104-111.

Rueff, M., 1992, Surficial Materials Investigation at the Weldon Spring Training Area, St. Charles County, Missouri, prepared by Missouri Department of Natural Resources, Division of Geology and Land Survey, Rolla, Mo., for U.S. Department of the Army, Corps of Engineers, Kansas City District, Kansas City, Mo., Sept.

SBP Technologies, Inc., 1997, "Case Studies: Gasoline Service Station," SBP Technologies, Inc., White Plains, N.Y. [URL: http://www.sbptech.com/gasoline.html].

Schnoor, J.L., et al., 1995, "Phytoremediation of Organic and Nutrient Contaminants," Environmental Science and Technology 28(7):318A-322A.

Schnoor, J.L., 1997, “Technology Evaluation Report: Phytoremediation," prepared for Groundwater Remediation Technology Analysis Center, Pittsburgh, Pa. [URL http://www.gwrtac.org/html/ tech_over.html].

Schrauf, T.W., and L.H. Pennington, 1995, "Design and Application of an Alternative Groundwater Sparging Technology, in In Situ Aeration: Air Sparging, Bioventing, and Related Remedial Processes (Third International In Situ and On-Site Bioreclamation Symposium), R.E. Hinchee et al. (editors), Battelle Press, Columbus, Ohio.

Shannon, D., 1995, “Lasagna Process' Field Success Increases DOE's Interest,” Environmental Science and Technology 29(10):452A. 
Shropshire, D., et al., 1995, Waste Management Facilities Cost Information for Mixed Low-Level Waste, INEL-95/0014, Rev. 1, prepared by Lockheed Idaho Technologies Company for the Idaho National Engineering Laboratory, Idaho Falls, Idaho, June.

Smith, R.L., and J.H. Duff, 1988, "Denitrification in a Sand and Gravel Aquifer," Applied and Environmental Microbiology 54:1071-1078.

Smith, R.L., et al., 1991, "Denitrification in Nitrate-Contaminated Groundwater: Occurrence in Steep Vertical Geochemical Gradients," Geochimica et Cosmochimica Acta 55:1815-1825.

Smith, R.L., et al., 1996, "Comparison of Denitrification Activity Measurements in Groundwater Using Cores and Natural-Gradient Tracer Tests," Environmental Science and Technology 30(12): 3448-3456.

Spain, J.C. (editor), 1996, Environmental Science Research, Vol. 49: Biodegradation of Nitroaromatic Compounds, Plenum Press, New York, N.Y.

Spanggora, R.J., et al., 1991, "Biodegradation of 2,4-dinitrotoluene by a Pseudomonas Sp.," Applied and Environmental Microbiology 57:3200-3205.

Stanforth, R., and M.C. McCartney, 1995, "Using a Dense Oxidizing Agent to Remediate a DNAPL," Proceedings of the Eighteenth International Madison Waste Conference - Municipal Industrial Waste, Madison, Wisc., Sept. 20-21, pp. 14-21.

Todd, S.R., and C.R. Lange, 1996, "Phytoremediation of 2,4-Dinitrotoluene Contaminated Soils Using Parrot Feather (Myriophyllum Brasiliense)," Hazardous and Industrial Wastes 28:557-564.

Trombly, J., 1994, "Electrochemical Remediation Takes to the Field," Environmental Science and Technology 28(6):289A-291A.

Tunnicliff, M., 1997, facsimile transmittal from M. Tunnicliff (U.S. Army Corps of Engineers, Kansas City District, Kansas City, Mo.) to M. Picel (Argonne National Laboratory, Argonne, Ill.), with attachments, June 26.

Uhrie, J.L., et al., 1996, "In Situ Immobilization of Heavy Metals Associated with Uranium Leach Mines by Bacterial Sulfate Reduction," Hydrometallurgy 43:231-239.

U.S. Army Corps of Engineers, 1989, Computer Aided Cost Engineering Support System: Description and Overview, Office of the Chief of Engineers, Atlanta, Ga., May 1. 
U.S. Department of Army, 1993, Final Feasibility Study Former Weldon Spring Ordnance Works Weldon Springs, Missouri, prepared by IT Corporation for U.S. Army Corps of Engineers, Kansas City District, Kansas City, Mo., July.

U.S. Department of Army, 1996, Record of Decision: Former Weldon Spring Ordnance Works Weldon Springs, Missouri, Operable Unit 1: Soils and Pipeline, prepared by IT Corporation for U.S. Army Corps of Engineers, Kansas City District, Kansas City, Mo., Sept.

U.S. Department of Defense, 1994, Remediation Technologies Screening Matrix and Reference Guide, EPA/542/B-94/013, 2nd ed., Environmental Technology Committee, National Center for Environmental Publications and Information, Cincinnati, Ohio.

U.S. Department of Energy, 1991, Selection of Water Treatment Processes Special Study, DOE/UMTRA-400675-0000, prepared by Uranium Mill Tailings Remedial Action Project Office, Albuquerque Operations Office, Albuquerque, N.M.

U.S. Department of Energy, 1992, Remedial Investigation for the Chemical Plant Area of the Weldon Spring Site, DOE/EIS-0185D (DOE/OR/21548-074, Vol. D), prepared by MK-Ferguson Company and Jacobs Engineering Group, Inc., Weldon Spring, Mo., for U.S. Department of Energy, Oak Ridge Field Office, Weldon Spring Site Remedial Action Project, Weldon Spring, Mo., Nov.

U.S. Department of Energy, 1993, Record of Decision for Remedial Action at the Chemical Plant Area of the Weldon Spring Site, DOE/OR/21548-376, Oak Ridge Field Office, Weldon Spring Site Remedial Action Project, Weldon Spring, Mo., Sept.

U.S. Department of Energy, 1995, Work Plan for the Remedial Investigation/Feasibility Study for the Groundwater Operable Units at the Chemical Plant Area and the Ordnance Works Area, Weldon Spring, Missouri, DOE/OR/21548-567, prepared by Argonne National Laboratory, Argonne, Ill., for U.S. Department of Energy, Oak Ridge Operations Office, Oak Ridge, Tenn., Aug.

U.S. Department of Energy, 1996, Subsurface Contaminants Focus Area, Technology Summary, Office of Science and Technology, Aug.

U.S. Department of Energy and U.S. Department of the Army, 1998a, Baseline Risk Assessment for the Groundwater Operable Units at the Chemical Plant Area and the Ordnance Works Area, Weldon Spring, Missouri, DOE/OR/21548-568, prepared by Argonne National Laboratory, Argonne, Ill., for U.S. Department of Energy, Weldon Spring Site Remedial Action Project, Weldon Spring, Mo., and U.S. Department of the Army, Corps of Engineers, Kansas City District, Kansas City, Mo., July. 
U.S. Department of Energy and U.S. Department of the Army, 1998b, Remedial Investigation for the Groundwater Operable Units at the Chemical Plant Area and the Ordnance Works Area, Weldon Spring Site, Weldon Spring, Missouri, DOE/OR/21548-571, Final, prepared by MK-Ferguson Company and Jacobs Engineering Group, Inc., Weldon Spring, Mo., and Argonne National Laboratory, Argonne, Ill., for U.S. Department of Energy, Weldon Spring Site Remedial Action Project, Weldon Spring, Mo., and U.S. Department of the Army, Corps of Engineers, Kansas City District, Kansas City, Mo., July.

U.S. Environmental Protection Agency, 1988a, Guidance for Conducting Remedial Investigations and Feasibility Studies under CERCLA, Interim Final, EPA 540-G-89-004 (OSWER Directive 9355.3-01), Office of Emergency and Remedial Response, Washington, D.C., Oct.

U.S. Environmental Protection Agency, 1988b, Guidance on Remedial Actions for Contaminated Groundwater at Superfund Sites, Interim Final, EPA/540/G-88/003, Office of Emergency and Remedial Response, Washington, D.C., Dec.

U.S. Environmental Protection Agency, 1989a, "National Priorities List for Uncontrolled Hazardous Waste Sites, Final Federal Facility Site Update; Final Rule (40 CFR Part 300)," Federal Register 54(47):10512-10517, March 13.

U.S. Environmental Protection Agency, 1989b, Risk Assessment Guidance for Superfund, Volume I: Human Health Evaluation Manual, Part A, Interim Final, EPA/540/1-89/001, Office of Emergency and Remedial Response, Washington, D.C., Dec.

U.S. Environmental Protection Agency, 1990a, "National Oil and Hazardous Substances Pollution Contingency Plan; Final Rule (40 CFR Part 300)," Federal Register 55(46):8666-8865, March 8.

U.S. Environmental Protection Agency, 1990b, "National Priorities List for Uncontrolled Hazardous Waste Sites; Final Rule (40 CFR Part 300)," Federal Register 55(35):6154-6176, Feb. 21.

U.S. Environmental Protection Agency, 1991, "National Primary Drinking Water Regulations: Radionuclides; Notice of Proposed Rulemaking," Federal Register 56:33050-33051, July 18.

U.S. Environmental Protection Agency, 1993, Handbook: Approaches for the Remediation of Federal Facility Sites Contaminated with Explosive or Radioactive Wastes, EPA/625/R-93/013, Office of Research and Development, Washington, D.C., Sept.

U.S. Environmental Protection Agency, 1994, "National Oil and Hazardous Substances Contingency Plan — Revisions," Federal Register 59:47384, Sept. 15. 
U.S. Environmental Protection Agency, 1995a, Abstracts of Remediation Case Studies, EPA 542-K95-001, Federal Remediation Technologies Roundtable, Washington, D.C., March [URL: http://www.clu-in.com/pubitech.html].

U.S. Environmental Protection Agency, 1995b, In-Situ Remediation Technology: Electrokinetics, EPA542-K-94-007, Office of Solid Waste and Emergency Response, Washington, D.C., April.

U.S. Environmental Protection Agency, 1995c, Manual: Ground-Water and Leachate Treatment Systems, EPA/625/R-94/005, Office of Research and Development, Washington, D.C., Jan.

U.S. Environmental Protection Agency, 1996a, Pump-and-Treat Ground-Water Remediation, A Guide for Decision Makers and Practitioners, EPA/625/R-95/005, prepared by Eastern Research Group, Inc., for the U.S. Environmental Protection Agency, Office of Research and Development, National Risk Management Research Laboratory, Center for Environmental Research Information, Cincinnati, Ohio.

U.S. Environmental Protection Agency, 1996b, Vendor Information System for Innovative Treatment Technologies (VISITT), Version 5.0, prepared by Technology Innovation Office, Office of Solid Waste and Emergency Response, Washington, D.C., July.

Valett, G., 1997, personal communication from G. Valett (MK-Ferguson, St. Charles, Mo.) to S. Folga (Argonne National Laboratory, Argonne, Ill.), March 25.

Valli, K., et al., 1992, "Degradation of 2,4-Dinitrotoluene by the Lignin-Degrading Fungus Phanaerochaete Chrysosporium," Applied and Environmental Microbiology 58:221-228.

Van Cauwenberghe, L., 1997, Electrokinetics, Technology Overview Report TO-97-03, GWRTAC Series, Ground-Water Remediation Technologies Analysis Center, Pittsburgh, Penn., July.

Venkatadri, R., and R.W. Peters, 1993, "Chemical Oxidation Technologies: Ultraviolet Light/ Hydrogen Peroxide, Fenton's Reagent, and Titanium Dioxide-Assisted Photocatalysis," Hazardous Waste \& Hazardous Materials 10(2):107-149.

Vidic, R.D., and F.G. Pohland, 1996, Treatment Walls, Technology Evaluation Report TE-96-01, prepared by the University of Pittsburgh, Pittsburgh, Penn., for the Ground-Water Remediation Technologies Analysis Center, Oct.

Vigneri, M., 1996, “Stronger than Dirt - A New Clean Machine for Groundwater," ECON, pp. 6-7, July. 
Weaver, J.W., et al., 1997, "Case Study of Natural Attenuation of Trichloroethene at St. Joseph, Michigan," pp. 71-75 in Proceedings of the Symposium on Natural Attenuation of Chlorinated Organics in Ground Water, EPA/540/R-97/504, by U.S. Environmental Protection Agency, Office of Research and Development, Washington, D.C., May.

Weissmahr, K.W., et al., 1997, "In Situ Spectroscopic Investigations of Adsorption Mechanisms of Nitroaromatic Compounds at Clay Minerals," Environmental Science and Technology 31(1): 240-247.

White, W.B., 1988, Geomorphology and Hydrology of Karst Terrains, Oxford University Press, New York, N.Y.

Whitfield, J.W., et al., 1989, Geologic Map of the Weldon Spring 7.5 Minute Quadrangle, St. Charles County, Mo., OFM-89-252-GI, Missouri Department of Natural Resources, Division of Geology and Land Survey, Rolla, Mo.

Wiedemeier, T.H., et al., 1996, "Overview of the Technical Protocol for Natural Attenuation of Chlorinated Aliphatic Hydrocarbons in Ground Water under Development for the U.S. Air Force Center for Environmental Excellence," presented at the Superfund XVII Conference, Washington, D.C., Oct. 15-17.

Wiedemeier, T.H., et al., 1997, "Natural Attenuation of Chlorinated Aliphatic Hydrocarbons at Plattsburgh Air Force Base, New York," pp. 76-84 in Proceedings of the Symposium on Natural Attenuation of Chlorinated Organics in Ground Water, EPA/540/R-97/504, U.S. Environmental Protection Agency, Office of Research and Development, Washington, D.C., May. 
6-14 
$A-1$

APPENDIX A:

REGULATORY REQUIREMENTS POTENTIALLY APPLICABLE OR RELEVANT AND APPROPRIATE TO THE REMEDIAL ACTION 
A-2 


\section{APPENDIX A:}

\section{REGULATORY REQUIREMENTS POTENTIALLY APPLICABLE OR RELEVANT AND APPROPRIATE TO THE REMEDIAL ACTION}

The U.S. Department of Energy (DOE) and the U.S. Department of Army (DA) are conducting an evaluation of potential alternatives for addressing groundwater contamination at the Weldon Spring Chemical Plant (WSCP) and the Weldon Spring Ordnance Works (WSOW), respectively, in St. Charles County, Missouri. This appendix discusses the regulatory requirements that are potentially applicable or relevant and appropriate to the remedial action.

\section{A.1 INTRODUCTION}

The U.S. Environmental Protection Agency (EPA) has promulgated implementing regulations for the Comprehensive Environmental Response, Compensation, and Liability Act (CERCLA), as amended; these regulations are presented in the National Oil and Hazardous Substances Pollution Contingency Plan (NCP) (Title 40, Part 300, Code of Federal Regulations [40 CFR Part 300]). This feasibility study (FS) follows the feasibility study process for sites on the National Priorities List (NPL). Under this process, remedial alternatives for the groundwater operable units at the WSCP and the WSOW were developed on the basis of remediation goals and potentially suitable technologies. The short-term and long-term aspects of three criteria (effectiveness, implementability, and cost) guided, as appropriate, the development and screening of alternatives. Alternatives that remained after this initial screening underwent a detailed analysis in which the individual alternatives were assessed according to nine evaluation criteria, including compliance with "applicable or relevant and appropriate requirements" (ARARs).

The NCP specifies that the evaluation of alternatives for remedial action at an NPL site must include an assessment of whether the alternatives will attain ARARs under federal environmental laws and state environmental or facility siting laws, or grounds for invoking one of the waivers (40 CFR 300.430(e)(9)(iii)(B)) must be provided. To be eligible for selection as the remedy for an NPL site, an alternative must attain ARARs unless a waiver is appropriate (40 CFR $300.430(f)(1)(D(A))$. Other advisories, criteria, or guidance developed by the EPA, other federal agencies, or states, which might be useful for developing the remedy for an NPL site, can also be considered as part of the evaluation (40 CFR 300.400(g)(3)). These other measures are called "to-beconsidered," or TBC, requirements.

The ARARs are standards properly promulgated under federal or state statutes that might be applicable or relevant and appropriate to all or part of the action. Only those state requirements that are (1) promulgated such that they are of general applicability and legally enforceable, 
(2) identified by the state in a timely manner, and (3) more stringent than federal requirements will be considered ARARs (40 CFR 300.400(g)(4)). TBCs are standards or guidelines that have not been properly promulgated (i.e., a process including publication, comment, and formal adoption under applicable federal or state administrative regulations). TBCs would include DOE Orders or proposed state or federal agency regulations that might be pertinent to the action being considered. In addressing a requirement that might affect a remedial action being considered for a site, a determination is made regarding its relationship to (1) the location of the action; (2) the contaminants involved; and (3) the specific components of the action, such as factors unique to a certain technology.

Any regulation, standard, requirement, criterion, or limitation under any federal or state environmental law or state facility siting law may be either applicable or relevant and appropriate to a remedial action, but not both. Applicable requirements are cleanup standards; standards of control; or other substantive environmental protection requirements, criteria, or limitations promulgated under federal or state laws that specifically address a hazardous substance, pollutant, contaminant, remedial action, location, or other circumstance at a CERCLA site (40 CFR 300.5). Relevant and appropriate requirements are cleanup standards, standards of control, or other substantive environmental protection requirements, criteria, or limitations promulgated under federal or state laws that are not applicable but that address problems or situations sufficiently similar to those encountered at the CERCLA site that their use is well suited to the particular site (40 CFR 300.5). If the requirement is not legally applicable to the remedial action, a determination must be made as to whether the requirement is both relevant and appropriate. For this determination, the requirement must be considered sufficiently similar to the circumstances of the action, and it must also be well suited to the site. Under the NCP, the following comparisons must be made to determine relevance and appropriateness:

- The purpose of the requirement and the purpose of the CERCLA action;

- The medium regulated or affected by the requirement and the medium contaminated or affected at the CERCLA site;

- The substances regulated by the requirement and the substances found at the CERCLA site;

- The actions or activities regulated by the requirement and the remedial action considered for the CERCLA site;

- Any variance, waivers, or exemptions for the requirement and their availability for the circumstances at the CERCLA site; 
- The type of place regulated and the type of place affected by the release or CERCLA action;

- The type and size of structure or facility regulated and the type and size of structure or facility affected by the release or considered by the CERCLA site;

- Any consideration of use or potential use of affected resources in the requirement and the use or potential use of the affected resource at the CERCLA site.

On-site actions must comply with all substantive provisions of an ARAR, but not with related administrative and procedural requirements (e.g., filing reports or obtaining a permit). Off-site actions must comply only with requirements that are legally applicable, but must comply with both substantive and administrative parts of those requirements. On-site actions include actions in the areal extent of contamination and all suitable areas in very close proximity to the contamination that are part of the response action. These actions would include any activities within the WSCP and WSOW areas and other areas contaminated by the migration of a hazardous substance, pollutant, or contaminant from any of the areas under the custody and accountability of DOE (EPA 1995).

Potential TBC requirements are typically considered only if no promulgated requirements exist that are either applicable or relevant and appropriate. TBCs are to be used on an "as appropriate" basis, such as when ARARs do not exist for a contaminant or circumstance (EPA 1990, p. 8745). Because the Weldon Spring site is a DOE facility, applicable DOE Orders, standards, and guidance will be followed, irrespective of their TBC designation under the ARAR process.

For groundwater remedial actions, CERCLA Section 121(d) states that a remedial action will attain a level or standard of control established under the Safe Drinking Water Act (SDWA), where such level or standard of control is applicable or relevant and appropriate to any hazardous substance, pollutant, or contaminant that will remain on-site. The enforceable standards under the SDWA are maximum contaminant levels (MCLs), which represent the maximum permissible level of a contaminant that is delivered to any user of a public water system. Because MCLs are usually only legally applicable under the SDWA to the quality of drinking water at the tap, there will be few instances in which MCLs are applicable to cleanup of groundwater at a site. For this reason, MCLs are generally considered "relevant and appropriate" to groundwater that is or may be used for drinking.

Section 121(d) also states that remedial actions shall attain maximum contaminant level goals (MCLGs), where such goals are relevant and appropriate to the circumstances of the release: It is the EPA's opinion that for cases in which an MCLG establishes a contaminant level above zero, it is appropriate and consistent with CERCLA language to consider the MCLG as a potentially 
relevant and appropriate requirement, and that determinations be made on a site-specific basis as to the relevance and appropriateness of meeting that level under the circumstances of the release (EPA 1990). When an MCLG is determined not to be relevant and appropriate to the circumstances of the release, the corresponding $\mathrm{MCL}$ will be considered a potentially relevant and appropriate requirement and will be evaluated under the circumstances of the release. However, where an MCLG is equal to zero level of contaminants (as is the case for carcinogens such as trichloroethylene [TCE]), the MCLG is not "appropriate" for the cleanup of groundwater at CERCLA sites. In such cases, the corresponding MCL will be considered a potentially relevant and appropriate requirement.

Under the NCP, an alternate concentration limit (ACL) may be established in accordance with CERCLA Section 121(d)(2)(B)(ii). The EPA maintains that ACLs should be used only when active restoration of the groundwater to MCLs or nonzero MCLGs is not practicable. The availability of institutional controls in itself is not sufficient reason to extend the allowance for levels above drinking water standards or nonzero goals; rather, institutional controls are considered the sole remedy only where active remediation is not practicable. It is EPA policy that if relevant and appropriate requirements (i.e., MCLs and MCLGs) exist for groundwater that is or may be used for drinking, a waiver is generally needed for cases in which they cannot be attained. However, if a situation fulfills the criteria for ACLs, including a finding that active restoration of the groundwater to MCLs or nonzero MCLGs is deemed to be impracticable, documentation of these conditions for the ACL is sufficient, and additional documentation of a waiver of the MCL or MCLG is not necessary.

The ACLs may be established where remediation of the groundwater is not practicable. EPA Directive 9283.1-2FS, "A Guide on Remedial Actions for Contaminated Ground Water," sets out factors that may cause active restoration to be impracticable or not cost effective, including:

- Widespread plumes, such as industrial areas, mining sites, and pesticide sites;

- Hydrogeological constraints, such as fractured bedrock or a transmissivity of less than $4.6 \mathrm{~m}^{2} / \mathrm{d}\left(50 \mathrm{ft}^{2} / \mathrm{d}\right)$;

- Contaminant-related factors, such as the presence of dense, nonaqueous-phase liquids (DNAPLs); and

- Physical/chemical factors, such as partitioning to soil or organic matter.

However, CERCLA 121(d)(20)(B)(ii) restricts the use of ACLs to groundwater that discharges to nearby surface water and causes no statistically significant increase in contaminants in the surface water. In addition, provision must be made for enforceable institutional controls that prevent access to the contaminant plume. 
Another provision of the preamble of the NCP states that the EPA agrees that meeting the conditions and requirements associated with a variance or exemption provision can be a means of compliance with an ARAR. Subpart B of 40 CFR Part 192 on "Standards for Cleanup of Land and Buildings Contaminated with Residual Radioactive Materials from Inactive Uranium Processing Sites" provides for ACLs if DOE has determined that the constituent will not pose a substantial present or potential hazard to human health and the environment as long as the ACL is not exceeded and the U.S. Nuclear Regulatory Commission (NRC) has concurred (40 CFR 192.12). In considering the present or potential hazard to human health and the environment of ACLs, the following factors shall be considered:

1. Potential adverse effects on groundwater quality, considering:

(i) The physical and chemical characteristics of constituents in the residual radioactive material at the site, including their potential for migration;

(ii) The hydrogeological characteristics of the site and surrounding land;

(iii) The quantity of groundwater and the direction of groundwater flow;

(iv) The proximity and withdrawal rates of groundwater users;

(v) The current and future uses of groundwater in the region surrounding the site;

(vi) The existing quality of groundwater, including other sources of contamination and their cumulative impact on the groundwater quality;

(vii) The potential for health risks caused by human exposure to constituents;

(viii) The potential damage to wildlife, crops, vegetation, and physical structures caused by exposure to constituents;

(ix) The persistence and permanence of the potential adverse effects;

(x) The presence of underground sources of drinking water and exempted aquifers identified under 40 CFR 144.7; and 
2. Potential adverse effects on hydraulically connected surface water quality, considering:

(i) The volume and physical and chemical characteristics of the residual radioactive material at the site;

(ii) The hydrogeological characteristics of the site and surrounding land;

(iii) The quantity and quality of groundwater and the direction of groundwater flow;

(iv) The patterns of rainfall in the region;

(v) The proximity of the site to surface waters;

(vi) The current and future uses of surface waters in the region surrounding the site and any water quality standards established for those surface waters;

(vii) The existing quality of surface water, including other sources of contamination and their cumulative impact on surface water quality;

(viii) The potential for health risks caused by human exposure to constituents;

(ix) The potential damage to wildlife, crops, vegetation, and physical structures caused by exposure to constituents; and

(x) The persistence and permanence of the potential adverse effects.

Therefore, if after consideration of these factors, it appears that the criteria for establishing an ACL are met, the ACL is established as the ARAR.

In addition, these regulations for addressing contaminated groundwater at inactive uraniumprocessing sites also provide for supplemental standards when one or more of the following criteria apply (40 CFR 192.21):

1. Remedial actions would pose a clear and present risk of injury to workers or to members of the public;

2. Remedial actions would, notwithstanding reasonable measures to limit damage, directly produce health and environmental harm that is clearly 
excessive compared to the health and environmental benefits, now or in the future;

3. The estimated cost at a "vicinity" site is unreasonably high relative to the long-term benefits, and the residual radioactive materials do not pose a clear present or future hazard;

4. There is no known remedial action;

5. The restoration of groundwater quality is technically impracticable from an engineering perspective; or

6. The groundwater is not a current or potential source of drinking water (based on concentrations of total dissolved solids; widespread, ambient contamination; or the quantity of water reasonably available (40 CFR 192.11(e)).

If these criteria are met, a supplemental standard established in accordance with the regulation (40 CFR 192.22) would become the ARAR.

The point of compliance for groundwater cleanup standards is at appropriate locations in the groundwater (40 CFR 300.430(f)(5)(iii)(A)). The EPA believes that remediation levels should generally be attained either throughout the contaminated plume or at and beyond the edge of the waste management area where the waste is left in place. However, the EPA acknowledges that an alternative point of compliance may also be protective of human health and the environment under site-specific circumstances. In determining where to draw the point of compliance in such situations, the lead agency will consider factors such as proximity of the sources, technical practicability of groundwater remediation at that specific site, vulnerability of the groundwater and its possible uses, exposure and likelihood of exposure, and similar considerations.

Under the NCP, ARARs must be met during the course of the remedial action (40 CFR $300.435(b)(2))$. However, in the preamble to the NCP, the EPA clarified that it recognized that ARARs used to determine final remediation levels (e.g., MCLs for groundwater remediation) apply only at the completion of the action (EPA 1990, p. 8755). In addition, CERCLA provides a waiver from ARARs for interim actions, provided the final action will attain the waived standard. If there is doubt about whether an ARAR represents a final remediation goal or an interim standard, and the ARAR cannot be met during the activity, this waiver could be invoked (EPA 1990). Groundwater ARARs for the alternatives analyzed in detail in this FS are final remediation levels and should have to be met only at the completion of the remediation period. 
An alternative that does not meet an ARAR under federal environmental or state environmental or facility siting laws may be selected under five waiver circumstances (40 CFR 300.430(f) (1)(ii)(C)). (A sixth waiver is available to Superfund-financed sites, which would not be applicable to the WSCP and the WSOW.) These five relevant waiver circumstances are as follows:

1. The alternative is an interim measure and will become part of a total remedial action that will attain the ARAR;

2. Compliance with the requirement will result in greater risk to human health and the environment than other alternatives;

3. Compliance with the requirement is technically impracticable from an engineering perspective;

4. The alternative will attain a standard of performance that is equivalent to that required under the otherwise applicable standard, requirement, or limitation through use of another method or approach; or

5. With respect to a state requirement, the state has not consistently applied, or demonstrated the intention to consistently apply, the promulgated requirement in similar circumstances at other remedial actions within the state.

The interim measure waiver requires that (1) the interim measure should be followed within a reasonable time by complete measures that will attain ARARs, and (2) the interim measure should not exacerbate site problems nor interfere with the final remedy. In the preamble to the NCP, the EPA, in response to comments, declined setting a specific time limit as a precondition for invoking this waiver because it is difficult to predict exactly when complete measures can be undertaken, given changes in funding, priorities, and other factors. The EPA believes that careful risk assessments may be used to show that greater risks will result from compliance with ARARs and that a waiver may be appropriate. However, the alternative to which compliance with an ARAR is compared is not limited to a "no action" alternative, but may be a less active measure (e.g., excavation vs. capping).

To obtain a waiver for technical impracticability, the EPA believes that criteria may include engineering feasibility and reliability; cost would generally not be a major factor unless compliance would be inordinately costly. The EPA believes that cost should generally play a subordinate role in determining practicability from an engineering perspective and states that "engineering practice is in reality ultimately limited by costs, hence cost may legitimately be considered in determining what is ultimately practicable" (EPA 1990, p. 8748). The proposed criteria for waiving an ARAR in lieu of an equivalent standard of performance include degree of protection, level of performance, reliability into the future, and time required for results. In the preamble to the final NCP, the EPA 
states that the first three criteria should be at least equal for an alternative to be considered equivalent. In addition, the time required to achieve results using the alternative remedy should not be significantly more than that required under the waived ARAR. The EPA states that the fourth criterion proposed "was not specific precisely in order to allow cases where alternative methods may provide great benefits even though requiring longer time for implementation, as with, for example, the use of bioremediation instead of incineration" (EPA 1990, p. 8749). The last waiver is intended simply to prevent application of state requirements to Superfund sites that have not been consistently applied elsewhere in the state.

\section{A.2 PRELIMINARY EVALUATION OF REQUIREMENTS}

Requirements of federal and state laws that might be considered applicable or relevant and appropriate to the proposed remedial alternatives considered for detailed analysis in this FS are listed in Table A.1. Also included are potential TBC requirements and certain requirements that are part of employee protection laws or other nonenvironmental laws with which the CERCLA actions may have to comply and which are, therefore, not subject to the ARAR evaluation process for attainment or waiver. These requirements have simply been included as TBCs.

The preliminary ARAR and TBC determinations for these requirements are indicated in Table A.1. Because this appendix presents a comprehensive list of requirements, all determinations have been identified as "potentially" applicable, relevant and appropriate, or to-be-considered. These determinations will be finalized in consultation with the State of Missouri and EPA Region VII before the selected remedial action is implemented. During the finalization process, the requirements identified as potentially applicable will be reviewed to confirm direct applicability; only one requirement will be finalized from among those that regulate the same conditions or media. For those requirements identified as potentially relevant and appropriate, the specific portions of the requirement that have bearing on the action and the manner in which compliance would be achieved or waivers sought, will be finalized.

\section{A.3 REFERENCES FOR APPENDIX A}

U.S. Environmental Protection Agency, 1990, "National Oil and Hazardous Substances Pollution Contingency Plan; Final Rule (40 CFR Part 300)," Federal Register 55(46):8666-8865, March 8.

U.S. Environmental Protection Agency, 1995, letter from C.M. Browner (U.S. Environmental Protection Agency, Washington, D.C.) to D.A. Shorr (Director, Missouri Department of Natural Resources, Jefferson City, Mo.), Nov. 1. 
TABLE A.1 Groundwater Operable Unit ARARs

\begin{tabular}{|c|c|c|}
\hline Citation & $\begin{array}{c}\text { Contaminant/ } \\
\text { Activity }\end{array}$ & Requirement \\
\hline $\begin{array}{l}\text { Groundwater Standards for } \\
\text { Remedial Actions at Inactive } \\
\text { Uranium Processing Sites } \\
\text { (40 CFR Part 192) }\end{array}$ & Uranium & $\begin{array}{l}\text { Concentration limits in groundwater must not exceed } \\
\text { the background level of that constituent in the } \\
\text { groundwater or } 30 \mathrm{pCi} / \mathrm{L} \text { for uranium- } 234 \text { and } \\
\text { uranium- } 238 \text { combined (where there is secular } \\
\text { equilibrium, this criterion is satisfied by a concentration } \\
\text { of } 0.044 \mathrm{mg} / \mathrm{L} \text {; for conditions of other than secular } \\
\text { equilibrium, a corresponding value may be derived on } \\
\text { the basis of the measured site-specific ratio of the two } \\
\text { isotopes of uranium); or an alternative concentration } \\
\text { limit set by the U.S. Nuclear Regulatory Commission, } \\
\text { which has determined that the constituent will not pose } \\
\text { a substantial current or potential future hazard to human } \\
\text { health and the environment, on the basis of potential } \\
\text { adverse effects on groundwater quality and potential } \\
\text { adverse effects on hydraulically connected surface water } \\
\text { quality. }\end{array}$ \\
\hline
\end{tabular}

Safe Drinking Water Act;

National Primary Drinking

Water Regulations; Maximum

Contaminant Levels (40 CFR

Parts 141.11 and 141.62);

Missouri Drinking Water

Regulations, Maximum

Inorganic Chemical and Volatile

Organic Contaminant Levels

(10 CSR Parts 60-4.030 and

60-4.100)
Preliminary

Determination

Remarks

Potentially relevant but not

appropriate

Organic and

inorganic

contaminants

The MCL is $0.005 \mathrm{mg} / \mathrm{L}$ for TCE. The MCL is $10 \mathrm{mg} / \mathrm{L}$ for nitrate-N

Potentially relevant and appropriate
This regulation is not applicable because the WSCP and the

WSOW are not inactive uranium processing sites regulated under 40 CFR Part 192. However,

because no MCL or MCLG exists for uranium under the SDWA, this regulation is potentially relevant to the cleanup levels proposed for groundwater. This standard, however, was developed for sites generally located in arid regions of the western United States where water is a scarce resource. As such, this standard is not considered to be well suited to conditions at the WSCP and WSOW.

These regulations are not applicable because MCLs are applicable only to drinking water at the tap, not to groundwater. However, under the NCP, MCLs are relevant and appropriate to groundwater that is a potential drinking water source. 
TABLE A.1 (Cont.)

\begin{tabular}{|c|c|c|c|c|}
\hline Citation & $\begin{array}{c}\text { Contaminant/ } \\
\text { Activity }\end{array}$ & Requirement & $\begin{array}{c}\text { Preliminary } \\
\text { Determination }\end{array}$ & Remarks \\
\hline $\begin{array}{l}\text { Safe Drinking Water Act, } \\
\text { Proposed National Primary } \\
\text { Drinking Water Regulations } \\
\text { (40 CFR Part 141; 56 FR } 33050 \\
\text { [July 18, 1991]) }\end{array}$ & Radionuclides & $\begin{array}{l}\text { The MCL for uranium in drinking water is } 20 \mu \mathrm{g} / \mathrm{L} \\
(20 \mu \mathrm{g} / \mathrm{L} \text { is approximately equal to } 14 \mathrm{pCi} / \mathrm{L} \text {, for } \\
\text { conditions of secular equilibrium between uranium-238 } \\
\text { and uranium- } 234 \text {, which is applicable to groundwater } \\
\text { conditions at the WSCP and the WSOW). }\end{array}$ & Potential TBC & $\begin{array}{l}\text { Because this is a proposed } \\
\text { regulation, it cannot be applicable } \\
\text { or relevant and appropriate; } \\
\text { however, it may be considered in } \\
\text { developing a remediation level for } \\
\text { uranium. }\end{array}$ \\
\hline $\begin{array}{l}\text { Radiation Protection of the } \\
\text { Public and the Environment } \\
\text { (DOE Order 5400.5) }\end{array}$ & Radionuclides & $\begin{array}{l}\text { DOE Order } 5400.5 \text { establishes a maximum limit for the } \\
\text { annual dose to members of the public of } 100 \mathrm{mrem} \\
(1 \mathrm{mSv}) \text { total effective dose equivalent per year. All } \\
\text { radiation exposures should be reduced to levels as low } \\
\text { as reasonably achievable (ALARA). The derived } \\
\text { concentration guide (DCG) values that would result in } \\
100 \mathrm{mrem} / \mathrm{yr} \text { for ingested water contaminated with }\end{array}$ & Potential TBC & $\begin{array}{l}\text { Because DOE Orders are internal } \\
\text { standards and requirements for the } \\
\text { operation of DOE facilities, they } \\
\text { are not ARARs; however, they } \\
\text { may be considered in developing a } \\
\text { remediation level for uranium. }\end{array}$ \\
\hline
\end{tabular}

yr for ingested water contaminated with uranium are as follows:

\begin{tabular}{lc} 
Radionuclide $^{\mathrm{a}}$ & DCG Values \\
\hline Uranium-234 & \\
$\mathrm{f}_{1}$ value $=0.05$ & $5 \times 10^{-7}$ \\
$\mathrm{f}_{1}$ value $=0.002$ & $5 \times 10^{-6}$ \\
& \\
Uranium-238 & \\
$\mathrm{f}_{1}$ value $=0.05$ & $6 \times 10^{-7}$ \\
$\mathrm{f}_{1}$ value $=0.002$ & $6 \times 10^{-6}$ \\
\hline & \\
a & $\mathrm{f}_{1}$ represents the fractional uptake \\
from the small intestine to blood.
\end{tabular}


TABLE A.1 (Cont.)

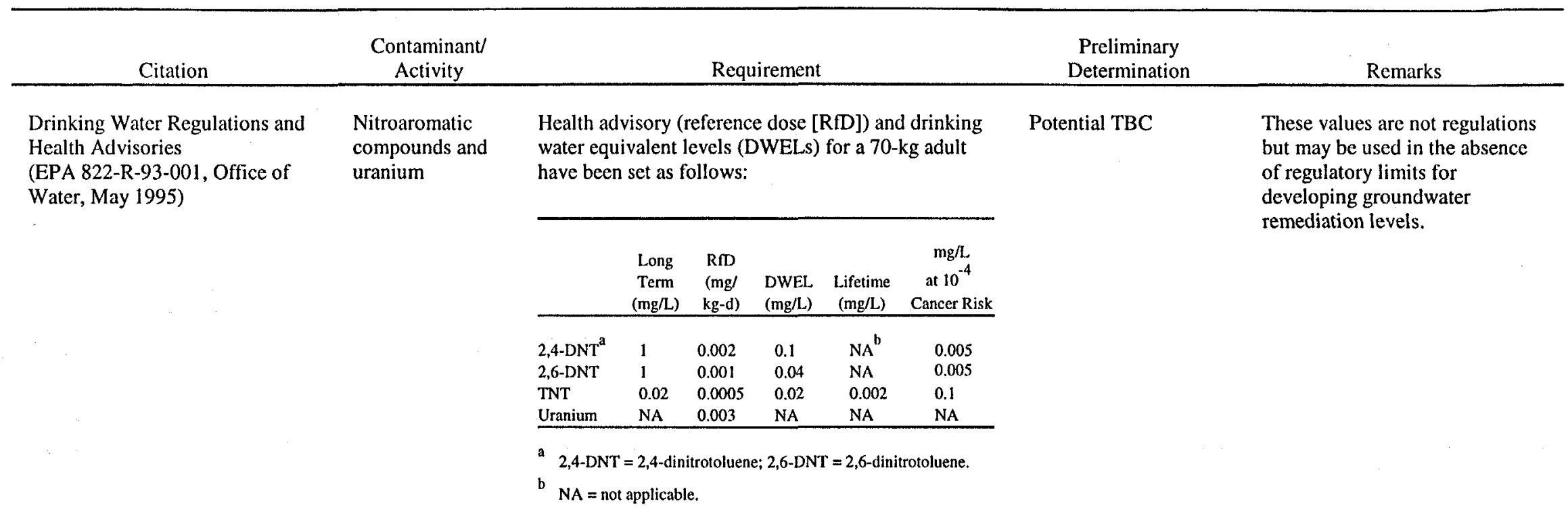


TABLE A.1 (Cont.)

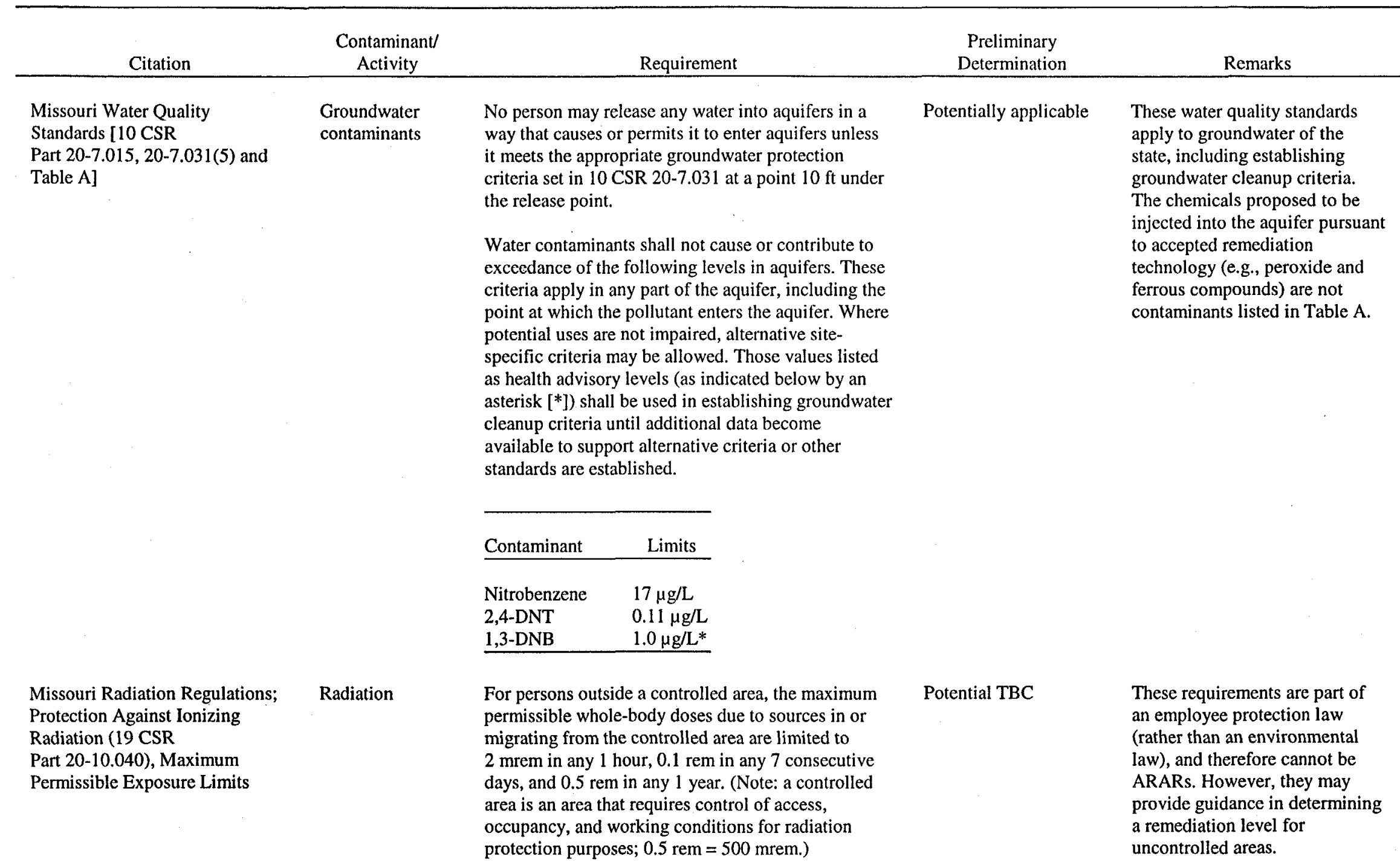


TABLE A.1 (Cont.)

\begin{tabular}{|c|c|c|c|c|}
\hline Citation & $\begin{array}{c}\text { Contaminant/ } \\
\text { Activity }\end{array}$ & Requirement & $\begin{array}{l}\text { Preliminary } \\
\text { Determination }\end{array}$ & Remarks \\
\hline $\begin{array}{l}\text { Health and Environmental } \\
\text { Protection Standards for Uranium } \\
\text { and Thorium Mill Tailings } \\
\text { ( } 40 \text { CFR Part 192), Subpart D, } \\
\text { Standards for Management of } \\
\text { Uranium Byproduct Materials } \\
\text { Pursuant to Section } 84 \text { of the } \\
\text { Atomic Energy Act of } 1954 \text {, as } \\
\text { amended; Subpart E, Standards } \\
\text { for Management of Thorium } \\
\text { Byproduct Materials Pursuant to } \\
\text { Section } 84 \text { of the Atomic Energy } \\
\text { Act of } 1954 \text {, as amended. }\end{array}$ & Radiation & $\begin{array}{l}\text { Processing operations during and prior to the end of } \\
\text { the closure period at a facility managing uranium and } \\
\text { thorium by-product materials should be conducted in } \\
\text { a manner than provides reasonable assurance that the } \\
\text { annual dose equivalent does not exceed } 25 \text { mrem to } \\
\text { the whole body, } 75 \text { mrem to the thyroid, and } 25 \text { mrem } \\
\text { to any other organ of any member of the public as a } \\
\text { result of exposures to the planned discharge of } \\
\text { radioactive material to the general environment } \\
\text { (excluding radon-222, radon-220, and their decay } \\
\text { products). }\end{array}$ & $\begin{array}{l}\text { Potentially relevant } \\
\text { and appropriate }\end{array}$ & $\begin{array}{l}\text { These requirements would not be } \\
\text { applicable because the remedial } \\
\text { action does not constitute a } \\
\text { processing operation, nor does it } \\
\text { include a planned discharge of } \\
\text { radioactive material to the } \\
\text { environment. Nevertheless, the } \\
\text { requirements could be } \\
\text { considered relevant and } \\
\text { appropriate to protection of the } \\
\text { public during implementation of } \\
\text { an action that generates } \\
\text { radioactive waste (i.e., soils) } \\
\text { because the waste type and the } \\
\text { potential release issue could be } \\
\text { considered sufficiently similar. }\end{array}$ \\
\hline $\begin{array}{l}\text { Radiation Protection of the } \\
\text { Public and the Environment } \\
\text { (DOE Order 5400.5) }\end{array}$ & Radiation & $\begin{array}{l}\text { The concentration of radionuclides in liquid wastes } \\
\text { discharged to natural waterways should be reduced to } \\
\text { levels ensuring that the absorbed dose to native } \\
\text { aquatic animal organisms does not exceed } 1 \mathrm{rad} / \mathrm{d} \text {. }\end{array}$ & To be considered & $\begin{array}{l}\text { If water treatment is part of the } \\
\text { selected remedy, this require- } \\
\text { ment, although not a } \\
\text { promulgated standard, provides } \\
\text { protection for aquatic organisms } \\
\text { from liquid discharges with } \\
\text { which the remedial action would } \\
\text { comply. }\end{array}$ \\
\hline
\end{tabular}


TABLE A.1 (Cont.)

\begin{tabular}{|c|c|c|c|c|}
\hline Citation & $\begin{array}{c}\text { Contaminant/ } \\
\text { Activity }\end{array}$ & Requirement & $\begin{array}{l}\text { Preliminary } \\
\text { Determination }\end{array}$ & Remarks \\
\hline $\begin{array}{l}\text { Resourcc Conservation and } \\
\text { Recovery Act (RCRA) ( } 40 \text { CFR } \\
\text { Part 262.11) }\end{array}$ & $\begin{array}{l}\text { Investigative- } \\
\text { derived waste }\end{array}$ & $\begin{array}{l}\text { All waste generated from well construction must be } \\
\text { characterized; if it is hazardous waste under RCRA, it } \\
\text { must be managed and disposed of properly. }\end{array}$ & Potentially applicable & $\begin{array}{l}\text { Investigative-derived waste may } \\
\text { be placed in an on-site disposal } \\
\text { facility or may be transported to } \\
\text { an off-site facility that is in } \\
\text { compliance with RCRA. }\end{array}$ \\
\hline $\begin{array}{l}\text { Missouri Construction and } \\
\text { Operating Permit Regulations } \\
(10 \text { CSR Part 20-6.010) }\end{array}$ & $\begin{array}{l}\text { Wastewater } \\
\text { discharge }\end{array}$ & $\begin{array}{l}\text { A wastewater treatment plant must be constructed and } \\
\text { operated in accordance with a state-approved } \\
\text { engineering report and detailed plans and } \\
\text { specifications so as to meet the state-specified } \\
\text { contaminant release concentrations and/or weights in } \\
\text { compliance with the Missouri Clean Water Law. }\end{array}$ & Potentially applicable & $\begin{array}{l}\text { If water treatment is part of the } \\
\text { selected remedy, pursuant to } \\
\text { CERCLA } \$ 121(\mathrm{e}) \text {, no permit is } \\
\text { required for on-site activities; } \\
\text { however, substantive permit } \\
\text { conditions such as construction, } \\
\text { engineering, and operating } \\
\text { requirements for the treatment } \\
\text { facility would be applicable to } \\
\text { any wastewater treatment facility } \\
\text { constructed on-site, or in very } \\
\text { close proximity to the } \\
\text { contamination, as part of a } \\
\text { remedial action. }\end{array}$ \\
\hline
\end{tabular}


TABLE A.1 (Cont.)

\begin{tabular}{|c|c|c|c|c|}
\hline Citation & $\begin{array}{c}\text { Contaminant/ } \\
\text { Activity }\end{array}$ & Requirement & $\begin{array}{c}\text { Preliminary } \\
\text { Determination }\end{array}$ & Remarks \\
\hline $\begin{array}{l}\text { Missouri General Protection of } \\
\text { Groundwater Quality and } \\
\text { Resources (10 CSR Part 23-3.020 } \\
\text { and 23-4.050) }\end{array}$ & $\begin{array}{l}\text { Well } \\
\text { construction }\end{array}$ & $\begin{array}{l}\text { A well used for injection of any substance is required } \\
\text { to have a permit from the Division of Geology and } \\
\text { Land Survey Underground Injection Control (UIC) } \\
\text { Program rules (10 CSR Division 50) and the Division } \\
\text { of Educational Quality, Water Pollution Control } \\
\text { Program (10 CSR 20-6.010). All wells must be } \\
\text { constructed in accordance with the Well Construction } \\
\text { Code (10 CSR Part 23-3.030). When no longer in } \\
\text { service, wells must be properly plugged. } \\
\text { All monitoring wells and extraction wells } \\
\text { ( } 23 \text { CSR 23-4.010) must be constructed in } \\
\text { accordance with the rules (10 CSR Part } 23-4.060 \text { ). } \\
\text { When no longer in service, monitoring wells must be } \\
\text { properly plugged. New off-site monitoring wells must } \\
\text { be constructed by licensed monitoring well diggers, } \\
\text { pursuant to a well permit, and the construction must } \\
\text { be reported to the Division of Geology and Land } \\
\text { Survey for review by using a certification report form. }\end{array}$ & Potentially applicable & $\begin{array}{l}\text { Pursuant to CERCLA } \$ 121 \text { (e), } \\
\text { no permit is required for on-site } \\
\text { well construction; however, } \\
\text { substantive permit conditions fo } \\
\text { the construction of the wells } \\
\text { would be applicable. }\end{array}$ \\
\hline $\begin{array}{l}\text { Missouri Stormwater Discharge } \\
\text { Regulations [10 CSR } \\
\text { Part 20-6.010(13)] }\end{array}$ & $\begin{array}{l}\text { Stormwater } \\
\text { discharges }\end{array}$ & $\begin{array}{l}\text { Missouri has issued stormwater general permits for } \\
\text { discharges associated with land disturbance activities. } \\
\text { The general permits contain general conditions, } \\
\text { effluent limitations, and a requirement for the } \\
\text { development of Stormwater Pollution Prevention } \\
\text { Plans to prevent construction site runoff from } \\
\text { polluting surface waters of the state. }\end{array}$ & Potentially applicable & $\begin{array}{l}\text { If the remedial action involves } \\
\text { land disturbance activities, the } \\
\text { substantive portions of the } \\
\text { Missouri stormwater general } \\
\text { permit would be applicable, } \\
\text { unless the activities are } \\
\text { exempted under the permit } \\
\text { (i.e., insufficient acreage). }\end{array}$ \\
\hline
\end{tabular}


TABLE A.1 (Cont.)

\begin{tabular}{|c|c|c|c|c|c|c|c|}
\hline Citation & $\begin{array}{c}\text { Contaminant/ } \\
\text { Activity }\end{array}$ & & \multicolumn{3}{|c|}{ Requirement } & $\begin{array}{l}\text { Preliminary } \\
\text { Determination }\end{array}$ & Remarks \\
\hline $\begin{array}{l}\text { National Emission Standards for } \\
\text { Hazardous Air Pollutants } \\
\text { (40 CFR Part 61), Subpart H, } \\
\text { National Emission Standards for } \\
\text { Emissions of Radionuclides } \\
\text { Other Than Radon from } \\
\text { Department of Energy Facilities }\end{array}$ & $\begin{array}{l}\text { Radionuclides } \\
\text { other than } \\
\text { radon-220 and } \\
\text { radon-222 }\end{array}$ & \multicolumn{4}{|c|}{$\begin{array}{l}\text { Emissions of such radionuclides to the ambient air } \\
\text { from DOE facilities should not result in an effective } \\
\text { dose equivalent of }>10 \mathrm{mrem} / \mathrm{yr} \text { to any member of the } \\
\text { public. }\end{array}$} & $\begin{array}{l}\text { Potentially relevant } \\
\text { and appropriate }\end{array}$ & $\begin{array}{l}\text { These requirements would only } \\
\text { be applicable to protection of the } \\
\text { public during implementation of } \\
\text { the remedial action at a DOE } \\
\text { facility that involved disturbance } \\
\text { of radionuclide-contaminated } \\
\text { soil or material. Because the } \\
\text { proposed remedial action is not } \\
\text { on a DOE facility, these } \\
\text { regulations may be relevant and } \\
\text { appropriate. }\end{array}$ \\
\hline \multirow{6}{*}{$\begin{array}{l}\text { Radiation Protection of the } \\
\text { Public and the Environment } \\
\text { (DOE Order 5400.5) }\end{array}$} & \multirow{6}{*}{$\begin{array}{l}\text { Specific } \\
\text { radionuclides } \\
\text { (see table) }\end{array}$} & \multicolumn{4}{|c|}{$\begin{array}{l}\text { Residual concentrations of radionuclides in air in } \\
\text { uncontrolled areas are limited to the following: }\end{array}$} & \multirow[t]{6}{*}{ To be considered } & \multirow{6}{*}{$\begin{array}{l}\text { Although not promulgated } \\
\text { standards, these constitute } \\
\text { requirements for protection of } \\
\text { the public with which the } \\
\text { remedial action that involved } \\
\text { disturbance of radionuclide- } \\
\text { contaminated soil or material } \\
\text { would comply. }\end{array}$} \\
\hline & & & \multicolumn{3}{|c|}{$\begin{array}{l}\text { Derived Concentration Guides }{ }^{\mathrm{a}} \\
(\mu \mathrm{Ci} / \mathrm{mL})\end{array}$} & & \\
\hline & & Isotope & $\mathrm{D}$ & $\mathrm{W}$ & Y & & \\
\hline & & $\begin{array}{l}\text { Uranium-235 } \\
\text { Uranium-238 } \\
\end{array}$ & $\begin{array}{l}5 \times 10^{-12} \\
5 \times 10^{-12}\end{array}$ & $\begin{array}{l}2 \times 10^{-12} \\
2 \times 10^{-12} \\
\end{array}$ & $\begin{array}{l}1 \times 10^{-13} \\
1 \times 10^{-13} \\
\end{array}$ & & \\
\hline & & \multicolumn{4}{|c|}{$\begin{array}{l}\mathrm{D}, \mathrm{W} \text {, and } \mathrm{Y} \text { represent lung retention classes; } \\
\text { removal half-times assigned to the compounds in } \\
\text { classes } \mathrm{D}, \mathrm{W} \text {, and } \mathrm{Y} \text { are } 0.5,50 \text {, and } 500 \text { days, } \\
\text { respectively. Exposure conditions assume an } \\
\text { inhalation rate of } 8,400 \mathrm{~m}^{3} \text { of air per year (based } \\
\text { on an exposure over } 24 \text { hours per day, } 365 \text { days } \\
\text { per year). }\end{array}$} & & \\
\hline & & \multicolumn{4}{|c|}{$\begin{array}{l}\text { For known mixtures of radionuclides, the sum of the } \\
\text { ratios of the observed concentration of each } \\
\text { radionuclide to its corresponding limit should not } \\
\text { exceed 1.0. }\end{array}$} & & \\
\hline
\end{tabular}


TABLE A.1 (Cont.)

\begin{tabular}{|c|c|c|c|c|}
\hline Citation & $\begin{array}{c}\text { Contaminant/ } \\
\text { Activity }\end{array}$ & & \multicolumn{2}{|c|}{ Requirement } \\
\hline \multirow[t]{4}{*}{$\begin{array}{l}\text { Missouri Radiation Regulations; } \\
\text { Protection Against Ionizing } \\
\text { Radiation (19 CSR 20-10.040), } \\
\text { Maximum Permissible Exposure } \\
\text { Limits }\end{array}$} & $\begin{array}{l}\text { Specific } \\
\text { radionuclides } \\
\text { (see table) }\end{array}$ & \multicolumn{3}{|c|}{$\begin{array}{l}\text { The concentrations above natural backgr } \\
\text { radionuclides in air outside a controlled a } \\
\text { averaged over any calendar quarter, shou } \\
\text { exceed the following limits: }\end{array}$} \\
\hline & & & \multicolumn{2}{|c|}{$\begin{array}{c}\text { Concentration Limit } \\
(\mu \mathrm{Ci} / \mathrm{mL})\end{array}$} \\
\hline & & Isotope & Soluble & Insoluble \\
\hline & & $\begin{array}{l}\text { Uranium-235 } \\
\text { Uranium-238 }\end{array}$ & $\begin{array}{l}2 \times 10^{-11} \\
3 \times 10^{-12}\end{array}$ & $\begin{array}{l}4 \times 10^{-12} \\
5 \times 10^{-12}\end{array}$ \\
\hline
\end{tabular}

Missouri Air Pollution Control Regulations; Air Quality

Standards and Air Pollution

Control Regulations for the

St. Louis Metropolitan Area

(10 CSR Part 10-5.180),

Emission of Visible Air

Contaminants from Internal

Combustion Engines
Particulate matter

Visible air contaminants (other than uncombined water) should not be released from an internal combustion engine for more than 10 seconds at any one time.

Preliminary

Determination

Remarks

Potentially applicable

These requirements would be applicable to protection of the public during implementation of

a remedial action that involves disturbance of radionuclidecontaminated soil or material.
Potentially applicable
These requirements would be applicable to particulates released from any internal combustion engines used during the remedial action. 
TABLE A.1 (Cont.)

\begin{tabular}{|c|c|c|c|c|}
\hline Citation & $\begin{array}{c}\text { Contaminant/ } \\
\text { Activity }\end{array}$ & Requirement & $\begin{array}{l}\text { Preliminary } \\
\text { Determination }\end{array}$ & Remarks \\
\hline $\begin{array}{l}\text { Missouri Air Quality Standards } \\
\text { (10 CSR Part 10-6.170), } \\
\text { Restriction of Particulate Matter } \\
\text { to the Ambient Air Beyond the } \\
\text { Premises of Origin }\end{array}$ & Particulate matter & $\begin{array}{l}\text { No person should permit the handling, transport, or } \\
\text { storage of any material without applying reasonable } \\
\text { measures as may be required to prevent fugitive } \\
\text { particulate matter from going beyond the premises of } \\
\text { origin in quantities such that (1) the particulate matter } \\
\text { remains visible in the ambient air beyond the property } \\
\text { line of origin or (2) the particulate matter may be } \\
\text { found on surfaces beyond the property line of origin. } \\
\text { To prevent particulate matter from going beyond the } \\
\text { premises of origin during construction, repair, } \\
\text { cleaning, or demolition of a building or its } \\
\text { appurtenances, construction or use of a road, } \\
\text { driveway, or open area, or operation of a commercial } \\
\text { or industrial installation, the following measures may } \\
\text { be required: revision of procedures involving } \\
\text { construction, repair, cleaning, and demolition of } \\
\text { buildings that produce particulate matter emissions; } \\
\text { paving or frequent cleaning of roads; application of } \\
\text { dust-free surfaces or water; and planting and } \\
\text { maintaining a vegetative ground cover. }\end{array}$ & Potentially applicable & $\begin{array}{l}\text { These requirements would be } \\
\text { applicable to releases of } \\
\text { particulates from the listed } \\
\text { activities during implementation } \\
\text { of the remedial action. }\end{array}$ \\
\hline $\begin{array}{l}\text { Radioactive Waste Management } \\
\text { (DOE Order } 5820.2 \mathrm{~A} \text { ) }\end{array}$ & $\begin{array}{l}\text { Radioactive } \\
\text { waste } \\
\text { management }\end{array}$ & $\begin{array}{l}\text { External exposure to radioactive waste (including } \\
\text { releases) should not result in an effective dose } \\
\text { equivalent of }>25 \mathrm{mrem} / \mathrm{yr} \text { to any member of the } \\
\text { public, and releases to the atmosphere should meet } \\
\text { the requirements of } 40 \mathrm{CFR} \text { Part } 61 \text { (see discussion } \\
\text { above). An environmental monitoring program } \\
\text { should be implemented to address compliance with } \\
\text { performance standards. }\end{array}$ & To be considered & $\begin{array}{l}\text { Although not promulgated } \\
\text { standards, these constitute } \\
\text { requirements for controlling } \\
\text { exposures and releases and for } \\
\text { environmental monitoring with } \\
\text { which the remedial action that } \\
\text { involves the generation of } \\
\text { radionuclide-contaminated } \\
\text { wastes would comply. }\end{array}$ \\
\hline
\end{tabular}


TABLE A.1 (Cont.)

\begin{tabular}{|c|c|c|c|c|}
\hline Citation & $\begin{array}{l}\text { Contaminant/ } \\
\text { Activity }\end{array}$ & Requirement & $\begin{array}{c}\text { Preliminary } \\
\text { Determination }\end{array}$ & Remarks \\
\hline $\begin{array}{l}\text { Missouri Radiation Regulations; } \\
\text { Protection Against Ionizing } \\
\text { Radiation (19 CSR } \\
\text { Part 20-10.070), Storage of } \\
\text { Radioactive Materials }\end{array}$ & $\begin{array}{l}\text { Radioactive } \\
\text { waste storage }\end{array}$ & $\begin{array}{l}\text { Radioactive materials should be stored in a manner } \\
\text { that will not result in the exposure of any person, } \\
\text { during routine access to a controlled area, in excess } \\
\text { of the limits identified in } 19 \text { CSR Part } 20-10.040 \text { (see } \\
\text { related discussion for contaminant-specific } \\
\text { requirements); a facility used to store materials that } \\
\text { may emit radioactive gases or airborne particulate }\end{array}$ & Potentially applicable & $\begin{array}{l}\text { These requirements would be } \\
\text { applicable to the temporary } \\
\text { storage of certain material that } \\
\text { would be generated during the } \\
\text { remedial action, pending the } \\
\text { availability of a disposal facility. }\end{array}$ \\
\hline
\end{tabular}

Missouri Radiation Regulations;

Protection Against Ionizing

Radiation (19 CSR

Part 20-10.080), Control of

Radioactive Contamination
Atomic Energy Act, as amended (42 USC 2112) may emit radioactive gases or airborne particulate

matter should be vented to ensure that the

concentration of such substances in air does not

constitute a radiation hazard; and provisions should

be made to minimize the hazard to emergency

workers in the event of a fire, earthquake, flood, or windstorm.
Radioactive

waste management

Radioactive waste disposal
All work should be carried out under conditions that minimize the potential spread of radioactive material that could result in the exposure of any person above any limit specified in 19 CSR Part 20-10.040 (see related discussion for contaminant-specific requirements). Clothing and other personal contamination should be monitored and removed according to procedures established by a qualified expert; any material contaminated to the degree that a person could be exposed to radiation above any limit specified in 19 CSR Part 20-10.040 should be

retained on-site until it can be decontaminated or disposed of according to procedures established by a

DOE can distribute by-product material only to individuals or organizations who are licensed by the $\mathrm{NRC}$ to receive such material. qualified expert.
Not an ARAR

Potentially applicable
These requirements would be applicable if the disposal of radioactively contaminated (byproduct) material from the Weldon Spring site would take place at a commercial facility (c.g., the Envirocare site near Clive, Utah). 
TABLE A.1 (Cont.)

\begin{tabular}{|c|c|c|c|c|}
\hline Citation & $\begin{array}{c}\text { Contaminant } \\
\text { Activity }\end{array}$ & \multicolumn{3}{|c|}{ Requirement } \\
\hline $\begin{array}{l}\text { Missouri Radiation Regulations; } \\
\text { Protection Against Ionizing } \\
\text { Radiation (19 CSR } \\
\text { Part 20-10.090), Disposal of } \\
\text { Radioactive Wastes }\end{array}$ & $\begin{array}{l}\text { Radioactive } \\
\text { waste disposal }\end{array}$ & \multicolumn{3}{|c|}{$\begin{array}{l}\text { Radioactive waste material should not be disposed of } \\
\text { by dumping or burial in soil, except at sites approved } \\
\text { by and registered with the Missouri Department of } \\
\text { Health; a permit should be obtained for holding and } \\
\text { preparation of such material prior to disposal; and no } \\
\text { releases to air or water should cause exposure to any } \\
\text { person above the limits specified in } 19 \text { CSR } \\
\text { Part } 20 \text {-10.041 (see related discussion for } \\
\text { contaminant-specific requirements). }\end{array}$} \\
\hline \multirow{5}{*}{$\begin{array}{l}\text { Missouri Radiation Regulations; } \\
\text { Protection Against Ionizing } \\
\text { Radiation (19 CSR } \\
\text { Part 20-10.040), Maximum } \\
\text { Permissible Exposure Limits }\end{array}$} & \multirow[t]{5}{*}{ Radiation } & \multicolumn{3}{|c|}{$\begin{array}{l}\text { Limits for occupational doses from ionizing radiation } \\
\text { in a controlled area are as follows: }\end{array}$} \\
\hline & & Part of Body & $\begin{array}{c}\text { Maximum Dose } \\
\text { in Any } \\
\text { Calendar } \\
\text { Quarter (rem) }\end{array}$ & $\begin{array}{c}\text { Maximum Dose } \\
\text { in Any Calendar } \\
\text { Quarter (rem) }\end{array}$ \\
\hline & & $\begin{array}{l}\text { Whole body, } \\
\text { head and trunk, } \\
\text { major portion of } \\
\text { bone marrow, } \\
\text { gonads, or lens of } \\
\text { eye }\end{array}$ & 5 & 3 \\
\hline & & $\begin{array}{l}\text { Hands and fore- } \\
\text { arms, feet and } \\
\text { ankles }\end{array}$ & 75 & 25 \\
\hline & & $\begin{array}{l}\text { Skin of large } \\
\text { body area }\end{array}$ & 30 & 10 \\
\hline
\end{tabular}

Also, the whole-body dose added to the cumulative occupational dose should not exceed $5(\mathrm{~N}-18)$ rem, where $\mathrm{N}$ is the age of the exposed individual.

Preliminary

Determination

Remarks

Potentially applicable

If the remedial action involves radioactive waste from excavation or water treatment activities that would be disposed of at the on-site, approved cell or at a properly licensed off-site commercial disposal facility, these requirements may be applicable.

Not an ARAR

These requirements are part of an employee protection law (rather than an environmental law) with which CERCLA response actions should comply; hence, they are not subject to the ARAR process. They are

indicated in this table to identify requirements for worker

protection with which the remedial action would comply. 
TABLE A.1 (Cont.)

\begin{tabular}{cccc} 
& & & \\
Contaminant/ & Preliminary \\
Citation & Activity & Requirement & Determination \\
\hline
\end{tabular}

Occupational exposure to airborne radioactive material, averaged over any calendar quarter, should not exceed the following limits:

\begin{tabular}{lcc}
\hline & $\begin{array}{c}\text { Concentration Limit } \\
(\mu \mathrm{Ci} / \mathrm{mL})\end{array}$ \\
\cline { 2 - 3 } Isotope & Soluble & Insoluble \\
\hline Uranium-235 & $5 \times 10^{-10}$ & $1 \times 10^{-10}$ \\
Uranium-238 & $7 \times 10^{-11}$ & $1 \times 10^{-10}$ \\
\hline
\end{tabular}

Missouri Radiation Regulations;

Protection Against Ionizing

Radiation (19 CSR

Part 20-10.050), Personnel

Monitoring and Radiation

Surveys
Radiation

Personnel monitoring and radiation surveys are required for each worker for whom there is any reasonable possibility of receiving a weekly dose from all radiation exceeding $50 \mathrm{mrem}$, taking into consideration the use of protective gloves and radiation-limiting devices. An exemption from routine monitoring may be granted under certain conditions.
Not an ARAR

$$
\begin{aligned}
& \text { These requirements are part of } \\
& \text { an employee protection law } \\
& \text { (rather than an environmental } \\
& \text { law) with which CERCLA } \\
& \text { response actions should comply; } \\
& \text { hence, they are not subject to the } \\
& \text { ARAR process. They are } \\
& \text { indicated in this table to identify } \\
& \text { requirements for worker } \\
& \text { protection with which the } \\
& \text { remedial action would comply. }
\end{aligned}
$$


TABLE A.1 (Cont.)

\begin{tabular}{|c|c|c|c|c|c|}
\hline Citation & $\begin{array}{c}\text { Contaminant/ } \\
\text { Activity }\end{array}$ & \multicolumn{2}{|c|}{ Requirement } & $\begin{array}{l}\text { Preliminary } \\
\text { Determination }\end{array}$ & Remarks \\
\hline \multirow{3}{*}{$\begin{array}{l}\text { Occupational Safety and Health } \\
\text { Administration Standards; } \\
\text { Occupational Health and } \\
\text { Environmental Control ( } 29 \text { CFR } \\
\text { Part 1910; 1910.96), Subpart G, } \\
\text { Ionizing Radiation }\end{array}$} & \multirow[t]{3}{*}{ Radiation } & $\begin{array}{l}\text { The dose per calendar quarter } \\
\text { exposure to radiation in a rest } \\
\text { sources in that area is limited }\end{array}$ & $\begin{array}{l}\text { ulting from } \\
\text { the following: }\end{array}$ & \multirow[t]{3}{*}{ Not an ARAR } & \multirow{3}{*}{$\begin{array}{l}\text { These requirements are part of } \\
\text { an employee protection law } \\
\text { (rather than an environmental } \\
\text { law) with which CERCLA } \\
\text { response actions should comply. } \\
\text { Therefore, these requirements } \\
\text { are not subject to the ARAR } \\
\text { evaluation process for attainment } \\
\text { or waiver. They are indicated in } \\
\text { this table to identify } \\
\text { requirements for worker } \\
\text { protection with which the } \\
\text { remedial action would comply. }\end{array}$} \\
\hline & & Part of Body & Dose (rem) & & \\
\hline & & $\begin{array}{l}\text { Whole body, head and trunk, } \\
\text { active blood-forming organs, } \\
\text { lens of eye, or gonads } \\
\text { Hands and forearms, feet and } \\
\text { ankles }\end{array}$ & 18.25 & & \\
\hline
\end{tabular}

Skin of whole body

TThe occupational exposure of an individual younger than 18 is restricted to $10 \%$ of these limits; the

whole-body dose to a worker may not exceed 3 rem

in a calendar quarter and, when added to the

cumulative occupational dose, should not exceed

$5(\mathrm{~N}-8)$ rem, where $\mathrm{N}$ is the age of the exposed

individual. 
TABLE A.1 (Cont.)

Citation

Contaminant

Requirement

Preliminary

Determination

Remarks

Occupational exposure to airborne radioactive material should not exceed the following

concentrations, averaged over a 40 -hour workweek of seven consecutive days:

\begin{tabular}{lcc}
\hline & $\begin{array}{c}\text { Concentration Limit } \\
(\mu \mathrm{Ci} / \mathrm{mL})\end{array}$ \\
\cline { 2 - 3 } Isotope & Soluble & Insoluble \\
\hline Uranium-235 & $5 \times 10^{-10}$ & $1 \times 10^{-10}$ \\
Uranium-238 & $7 \times 10^{-11}$ & $1 \times 10^{-10}$ \\
\hline
\end{tabular}

For mixtures of radionuclides, the sum of the ratios of the quantity present to the specific limit should not exceed 1 . For uranium, chemical toxicity may be the limiting factor for soluble mixtures of uranium in air; if the percent by weight of uranium- 235 is less than 5 , the concentration limit for total uranium is $0.2 \mathrm{mg} / \mathrm{m}^{3}$ of inhaled air. For hours of exposure less than or greater than 40 , the limits are proportionately increased or decreased, respectively. 
TABLE A.1 (Cont.)

\begin{tabular}{|c|c|c|c|c|c|c|}
\hline Citation & $\begin{array}{l}\text { Contaminant/ } \\
\text { Activity }\end{array}$ & \multicolumn{3}{|c|}{ Requirement } & $\begin{array}{c}\text { Preliminary } \\
\text { Determination }\end{array}$ & Remarks \\
\hline \multirow[t]{6}{*}{$\begin{array}{l}\text { Occupational Radiation } \\
\text { Protection (10 CFR Part 835) }\end{array}$} & Radionuclides & \multicolumn{3}{|c|}{$\begin{array}{l}\text { This regulation sets annual limits on intake (ALIs) for } \\
\text { occupational exposure through ingestion during DOE } \\
\text { activities. The oral ingestion ALIs are the annual } \\
\text { intakes of a given radionuclide by "reference man" } \\
\text { that would result in either a committed effective dose } \\
\text { equivalent of } 5 \text { rem/yr (stochastic ALI) or a } \\
\text { committed dose equivalent of } 50 \text { rem/yr to an organ } \\
\text { or tissue (nonstochastic ALI). The ALIs are provided } \\
\text { in Table } 1 \text { of the EPA's Federal Guidance Report } \\
\text { No. } 11 \text {, Limiting Values of Radionuclide Intake and } \\
\text { Dose Conversion Factors for Inhalation, } \\
\text { Submersion, and Ingestion (September 1988). The } \\
\text { ingestion ALIs for uranium-234 and uranium- } 238 \text { are } \\
\text { provided below. The critical organ for the } \\
\text { nonstochastic dose is the bone surface. }\end{array}$} & Not an ARAR & $\begin{array}{l}\text { These requirements are part of } \\
\text { an employee protection law } \\
\text { (rather than an environmental } \\
\text { law) and, therefore, cannot be } \\
\text { ARARs. However, they may be } \\
\text { considered in performing } \\
\text { remediation activities. }\end{array}$ \\
\hline & & \multicolumn{3}{|c|}{$\operatorname{ALI}(\mu \mathrm{Ci})$} & & \\
\hline & & Radionuclide $^{\mathbf{a}}$ & $\begin{array}{l}\text { Stochastic } \\
(5 \mathrm{rem} / \mathrm{yr})\end{array}$ & $\begin{array}{c}\text { Nonstochastic } \\
(50 \mathrm{rem} / \mathrm{yr}) \\
\end{array}$ & & \\
\hline & & \multirow{2}{*}{$\begin{array}{l}\text { Uranium- } 234 \\
f_{1} \text { value }=0.05 \\
f_{1} \text { value }=0.002 \\
\text { Uranium-238 } \\
f_{1} \text { value }=0.05 \\
f_{1} \text { value }=0.002\end{array}$} & $\begin{array}{l}\mathrm{NA}^{\mathrm{b}} \\
200\end{array}$ & $\begin{array}{l}10 \\
\mathrm{NA}\end{array}$ & & \\
\hline & & & $\begin{array}{l}\text { NA } \\
200\end{array}$ & $\begin{array}{l}10 \\
\mathrm{NA}\end{array}$ & & \\
\hline & & \multicolumn{3}{|c|}{$\begin{array}{l}\text { a } \mathrm{f}_{1} \text { represents the fractional uptake from the } \\
\text { small intestine to blood. } \\
\text { b } \mathrm{NA}=\text { not applicable. }\end{array}$} & & \\
\hline
\end{tabular}


TABLE A.1 (Cont.)

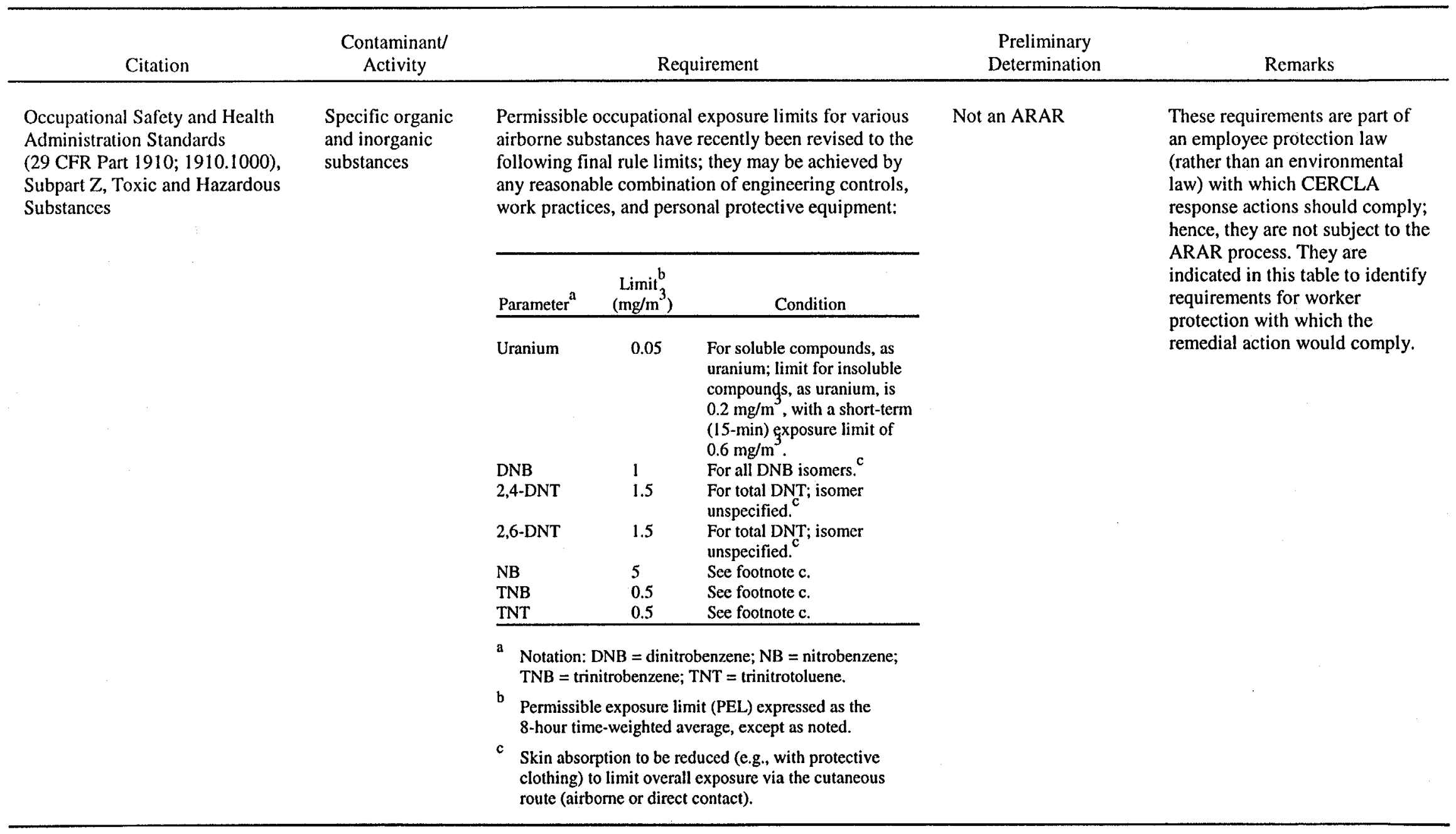


$B-1$

APPENDIX B:

DERIVATION OF RISK-BASED PRELIMINARY REMEDIATION GOALS FOR GROUNDWATER AT THE WSCP AND THE WSOW 
B-2 


\section{APPENDIX B:}

\section{DERIVATION OF RISK-BASED PRELIMINARY REMEDIATION GOALS FOR GROUNDWATER AT THE WSCP AND THE WSOW}

Preliminary remediation goals (PRGs) for trichloroethylene (TCE), nitrate, nitroaromatic compounds (i.e., 2,4,6-trinitrotoluene [2,4,6-TNT], 2,4-dinitrotoluene [2,4-DNT], 2,6-DNT, 2-amino-4,6-DNT, 4-amino-2,6-DNT, 1,3,5-trinitrobenzene [1,3,5-TNB], 1,3-dinitrobenzene [1,3-DNB], nitrotoluenes, and nitrobenzene), and uranium are identified in this feasibility study (FS) as a basis for evaluating the effectiveness of the various technologies and alternatives being considered. Risk-based PRGs were derived for each contaminant of concern (COC) on the basis of the methodology and assumptions used in the baseline risk assessment ([BRA]; U.S. Department of Energy [DOE] and U.S. Department of the Army [DA] 1998). Concentrations of carcinogenic contaminants equivalent to the $1 \times 10^{-4}$ and $1 \times 10^{-6}$ risk range for the recreational and residential scenarios were estimated to provide a range of information for risk management purposes. Calculations were also performed to determine the concentrations of noncarcinogenic contaminants that would be equivalent to a hazard index of 1 for both scenarios.

The primary pathway of exposure for both scenarios is ingestion. The exposure parameters used in the calculations are provided in Table B.1. The range of concentrations calculated for each contaminant and scenario are presented in Table B.2.

Concentrations of uranium in groundwater (in $\mathrm{pCi} / \mathrm{L}$ ) corresponding to a specified risk level were calculated as follows:

$$
R_{w i}=T R / I R \times E F \times E D \times S f_{i n g},
$$

where

$$
\begin{aligned}
& R_{w i}=\text { concentration of radionuclide in water }(\mathrm{pCi} / \mathrm{L}) \\
& T R=\text { target excess individual lifetime cancer risk (unitless), } \\
& I R=\text { water ingestion rate }(\mathrm{L} / \mathrm{d}) \\
& E F=\text { exposure frequency }(\mathrm{d} / \mathrm{yr})
\end{aligned}
$$


TABLE B.1 Exposure Scenario Assumptions and Intake Parameters

\begin{tabular}{lccc}
\hline \multicolumn{1}{c}{ Parameter } & Unit & $\begin{array}{c}\text { Current or Future } \\
\text { Recreational Visitor }\end{array}$ & $\begin{array}{c}\text { Hypothetical } \\
\text { Future Resident }\end{array}$ \\
\hline Exposure frequency & events/yr & 20 & 350 \\
Exposure duration & $\mathrm{yr}$ & 30 & 30 \\
Body weight & $\mathrm{kg}$ & 70 & 70 \\
Springwater ingestion rate & mL/event & 400 & $\mathrm{NA}^{\mathrm{a}}$ \\
Groundwater ingestion rate & L/event & NA & 2 \\
\hline a NA = not applicable. & & &
\end{tabular}

TABLE B.2 Water Concentrations of COCs Associated with the Acceptable Risk Range and Hazard Index

\begin{tabular}{|c|c|c|c|c|}
\hline \multirow[b]{3}{*}{$\begin{array}{l}\text { Contaminant } \\
\text { of Concern }\end{array}$} & \multicolumn{4}{|c|}{ Concentration ( $\mu \mathrm{g} / \mathrm{L}$ unless otherwise indicated) } \\
\hline & \multicolumn{2}{|c|}{ Residential Scenario } & \multicolumn{2}{|c|}{ Recreational Scenario } \\
\hline & $\begin{array}{l}10^{-6} \text { to } 10^{-4} \\
\text { Carcinogenic } \\
\text { Risk Range }\end{array}$ & $\begin{array}{l}\text { Hazard } \\
\text { Index } \\
\text { of } 1\end{array}$ & $\begin{array}{l}10^{-6} \text { to } 10^{-4} \\
\text { Carcinogenic } \\
\text { Risk Range }\end{array}$ & $\begin{array}{l}\text { Hazard } \\
\text { Index } \\
\text { of } 1\end{array}$ \\
\hline TCE & $7.7-770$ & $\mathrm{NA}^{\mathrm{a}}$ & $680-68,000$ & $\mathrm{NA}$ \\
\hline Nitrate-N & NA & $58 \mathrm{mg} / \mathrm{L}$ & NA & $5,100 \mathrm{mg} / \mathrm{L}$ \\
\hline $2,4,6-\mathrm{TNT}$ & $2.8-280$ & 18 & $250-25,000$ & 1,600 \\
\hline 2,4-DNT & $0.13-13$ & 73 & $11-1,100$ & 6,400 \\
\hline 2,6-DNT & $0.13-13$ & 37 & $11-1,100$ & 3,200 \\
\hline 2-Amino-4,6-DNT & NA & 2.2 & NA & 190 \\
\hline 4-Amino-2,6-DNT & NA & 2.2 & NA & 190 \\
\hline $1,3,5-\mathrm{TNB}$ & NA & 1.8 & NA & 160 \\
\hline 1,3-DNB & NA & 3.7 & NA & 320 \\
\hline m-Nitrotoluene & NA & 37 & NA & 3,200 \\
\hline o-Nitrotoluene & NA & 37 & NA & 3,200 \\
\hline p-Nitrotoluene & NA & 37 & NA & 3,200 \\
\hline Nitrobenzene & NA & 18 & NA & 1,600 \\
\hline Uranium & $0.90-90 \mathrm{pCi} / \mathrm{L}^{\mathrm{b}}$ & $110^{c}$ & $78-7,800 \mathrm{pCi} / \mathrm{L}^{\mathrm{b}}$ & $9,600^{\mathrm{c}}$ \\
\hline
\end{tabular}


$E D=$ exposure duration (yr), and

$S f_{i n g}=$ ingestion slope factor for uranium $\left(5.3 \times 10^{-11} / \mathrm{pCi}\right)$.

For the chemical contaminants, the concentration corresponding to specified risk levels was calculated as follows:

$$
C_{w i}=T R \times B W \times A T \times C F / S f_{o i} \times I R \times E F \times E D,
$$

where

$$
\begin{aligned}
C_{w i}= & \text { concentration of contaminant in water }(\mu \mathrm{g} / \mathrm{L}), \\
B W= & \text { average body weight over the exposure period }(\mathrm{kg}), \\
A T= & \text { averaging time }(\mathrm{d}), \\
C F= & \text { conversion factor }\left(10^{3} \mu \mathrm{g} / \mathrm{mg}\right), \text { and } \\
S f_{o i}= & \text { oral slope factor for contaminant } i\left([\mathrm{mg} / \mathrm{kg}-\mathrm{d}]^{-1}, \text { see Table } 4.2\right. \text { of the BRA } \\
& {[\text { DOE and DA } 1998]) . }
\end{aligned}
$$

The concentrations corresponding to specified hazard quotients were calculated as follows:

$$
C_{w i}=T H I \times B W \times A T \times C F \times R f D_{o i} / I R \times E F \times E D,
$$

where

$$
\begin{aligned}
T H I= & \text { target hazard index (unitless), and } \\
R f D_{o i}= & \text { oral reference dose for contaminant } I(\mathrm{mg} / \mathrm{kg}-\mathrm{d}, \text { see Table } 4.1 \text { of the BRA } \\
& {[\text { DOE and DA 1998]). }}
\end{aligned}
$$

\section{REFERENCE FOR APPENDIX B}

U.S. Department of Energy and U.S. Department of the Army, 1998, Baseline Risk Assessment for the Groundwater Operable Units at the Chemical Plant Area and the Ordnance Works Area, Weldon Spring, Missouri, DOE/OR/21548-568, prepared by Argonne National Laboratory, Argonne, Ill., for U.S. Department of Energy, Weldon Spring Site Remedial Action Project, Weldon Spring, Mo., and U.S. Department of the Army, Corps of Engineers, Kansas City District, Kansas City, Mo., July. 


$$
\text { B- } 6
$$




\section{$C-1$}

APPENDIX C:

METHODOLOGY AND ASSUMPTIONS USED TO CALCULATE THE POTENTIAL NUMBER OF EXTRACTION WELLS

FOR THE WSCP AND THE WSOW 
C-2 


\section{APPENDIX C:}

\section{METHODOLOGY AND ASSUMPTIONS USED TO CALCULATE THE POTENTIAL NUMBER OF EXTRACTION WELLS FOR THE WSCP AND THE WSOW}

The U.S. Department of Energy (DOE) and the U.S. Department of Army (DA) are conducting an evaluation of potential alternatives for addressing groundwater contamination at the Weldon Spring Chemical Plant (WSCP) and the Weldon Spring Ordnance Works (WSOW), respectively, in St. Charles County, Missouri. This appendix discusses the methodology and assumptions used to calculate the number of extraction wells required to support Alternatives 3,4 , and 5. The number of wells required will serve as input in selecting the best strategy for site remediation.

\section{C.1 METHODOLOGY}

As a rule, more extraction wells promote faster site cleanup. Because of costs, however, large numbers of extraction wells are not feasible. The minimum number of wells that can be used to effect site remediation for a confined groundwater aquifer (assuming that further site contamination is undesirable) can be estimated by using the method presented by Javandel and Tsang (1986). (The Javandel/Tsang method is the basis of the two-dimensional model RESSQ, a computer code used to evaluate cleanup schemes that use extraction wells for plume capture [Javandel et al. 1984].) In this method, a number of colinear extraction wells, $n$, are installed perpendicular to the direction of groundwater flow near the leading edge of a contaminant plume or in a direction downstream of a local "hot spot." These wells will form a capture zone that can be defined by complex potential theory (Milne-Thomson 1968) as the dividing stream line given by the expression

$$
y= \pm \frac{n Q}{2 B U}- \pm \frac{Q}{2 \pi B U} \sum_{1}^{n} \tan ^{-1} \frac{y-y_{i}}{x}
$$

where $B$ is the thickness of the aquifer, $Q$ is the volumetric rate of extraction, $U$ is the Darcy velocity, and $x$ and $y$ are the coordinates of the stream line. The Darcy velocity, $U$, is simply given as

$$
U=-K \nabla h,
$$

where $K$ is the hydraulic conductivity of the porous medium and $\nabla h$ is the hydraulic gradient (Freeze and Cherry 1979). 
By orienting the coordinate system of the wells such that the wells lie symmetrically along the $y$ axis $(x=0)$, Equation C.1 can be simplified to the following result if each well is pumped at the same rate:

$$
y= \pm \frac{n Q}{4 B U}
$$

For a large $n$, the approximate spacing between adjacent wells, $s$, is given by the expression

$$
s=\frac{1.2 Q}{\pi B U}
$$

For a contaminant plume having a full width, $W$, capture can be conservatively achieved by setting $y$ to $W / 2$. For this condition, the number of wells required is given by the expression

$$
n=\frac{2 B \nabla h K W}{Q}
$$

Equations C.4 and C.5 are usually solved iteratively (Javandel and Tsang 1986) to determine the number of wells that, for given pump rates and aquifer properties, produce a drawdown that will capture the contaminant plume laterally and vertically. As expressed here, Equations C. 4 and C.5 indicate that the aquifer is treated as being homogeneous and isotropic. In addition, the hydraulic gradient was assumed to be constant across the width of the plume. Because these conditions are unlikely to be met at the WSOW or the WSCP, use of the Javandel/Tsang method will produce approximate results. By judiciously selecting the system parameters, a conservative estimate of the number of extractions wells required can be calculated.

If the groundwater aquifer is unconfined, Equation C.5 can be replaced with the expression

$$
n=\frac{W K\left(\frac{h_{1}{ }^{2}-h_{2}{ }^{2}}{L}\right)}{Q},
$$

where $h_{1}$ and $h_{2}$ are the potentiometric heads of the aquifer at locations 1 and 2 that are separated by a distance $L$ in a direction parallel to the natural flow direction (Grubb 1993). As shown by Grubb (1993), stagnation points and dividing stream lines for the unconfined case are slightly less than their corresponding values for confined conditions (less than approximately $10 \%$ for the example problem shown), and the number of extraction wells required to capture a plume with a width $W$ is slightly greater. Because the present set of calculations requires information on the minimum number of extraction wells, and because it is difficult to define the required potentiometric heads and separation 
distances in Equation C.6, the calculations were performed on the basis of the assumption that the aquifer behaves as if it were under confined conditions. The degree of error introduced by this assumption was small and within the uncertainties of the other associated parameters.

\section{C.2 CALCULATIONS FOR THE NUMBER OF EXTRACTION WELLS}

Two methods were used to estimate the minimum number of extraction wells needed to remediate contaminated groundwater at the WSCP and the WSOW. In the first method, sitewide values for hydraulic conductivity and other relevant parameters were used to provide rough estimates of the total number of extraction wells needed. No attempt was made to evaluate the uncertainty associated with these estimates. In the second method, the number of extraction wells required and their uncertainties were estimated on the basis of conditions most applicable to the regions of contamination. These calculations were performed for areas in which the maximum concentrations for post-1995 data exceeded the applicable or relevant and appropriate requirements (ARARs) for the contaminants of concern (COCs) (Table 1.3 in this feasibility study [FS]). Values predicted with this second method provided more realistic estimates of the number of wells required. Both methods for calculating the number of extraction wells required are discussed below.

\section{C.2.1 Estimating the Number of Extraction Wells on the Basis of Sitewide Hydraulic Conductivity Values}

To apply Equation C.5, the following site parameters are required:

- Volumetric extraction rate for the wells,

- Hydraulic gradient,

- Hydraulic conductivity,

- Aquifer thickness, and

- Width of the plume.

The following sections discuss each of the above parameters for the WSCP and the WSOW. 


\section{C.2.1.1 Volumetric Extraction Rate}

Little site-specific information is available on the sustainable pumping rates for either the WSCP or the WSOW. Aquifer tests (i.e., three pumping tests) conducted by the program management contractor indicate that the maximum sustainable pumping rate is approximately 1.2 L/min (0.3 gpm) at the WSCP (MK-Ferguson Company and Jacobson Engineering Group, Inc. 1990). Two of the three pump tests were conducted near areas identified as having discrete flow. In other locations, the sustainable pumping rates might be lower, especially if the well intercepts a more unweathered portion of the limestone aquifer. Use of the known value $(1.2 \mathrm{~L} / \mathrm{min}$ [0.3 gpm]) in Equations C. 4 and C.5 will produce a conservative estimate of the number of extraction wells required (i.e., the estimated number will be greater than the actual number required). Sustainable pumping rates for the WSOW are not known; however, because of the similarity in hydrogeology, the rates are probably similar to those for the WSCP.

The Javandel/Tsang method (Javandel and Tsang 1986) is usually performed iteratively (see Section C.1). Because aquifer properties, sustainable pumping rates, local hydraulic gradients, and the vertical and lateral extent of contaminant plumes at the WSOW and the WSCP are not accurately known, a single pumping rate $(1.2 \mathrm{~L} / \mathrm{min}[0.3 \mathrm{gpm}])$ was assigned for all of the calculations, and no iteration was performed. This pumping rate was then assumed to produce sufficient drawdown to contain the plume of interest. Although such a simplification introduced some uncertainty into the calculations, the results were conservative (i.e., the number of wells calculated were smaller than the actual number required) and useful for the scoping analyses of this FS.

\section{C.2.1.2 Hydraulic Gradient}

The hydraulic gradient north of the groundwater divide at the WSCP and WSOW is about $0.01 \mathrm{ft} / \mathrm{ft}$; south of the divide, the gradient is higher, about $0.04 \mathrm{ft} / \mathrm{ft}$, consistent with the steeper topography in this region (DOE and DA 1998). Although the value of the gradient changes on a local scale, these two values were used in Equations C. 4 and C. 6 to provide approximate results for the number of extraction wells required.

\section{C.2.1.3 Width of Contaminated Groundwater}

By definition, the width of a contaminant groundwater plume is a function of the concentration used to define its boundary. This concentration, in turn, also depends on the scenario being evaluated and the methods being used to establish concentration limits (e.g., risk-based analyses). For the current calculations, the boundaries of the contaminant plumes were defined by concentration limits calculated for the recreational scenario. 
No defined plumes occur within the WSOW. Rather, there are a total of four "hot spots" at well locations MWV-9, MWS-12, MWS-17, and MWS-21. For these calculations, a capture-zone width of $488 \mathrm{~m}(1,600 \mathrm{ft})$ was used. The lines of wells were oriented perpendicular to the assumed direction of groundwater flow.

Similar to the situation at the WSOW, no well-defined plumes occur at the WSCP, but 10 hot spots are present, again, on the basis of the recreational scenario. Like those at the WSOW, some of the hot spots at the WSCP were defined by one contaminated well; others were defined by several contaminated wells in a cluster. For each hot spot, a capture line was assumed. The lengths of these lines were variable (Table C.1) and based on the lateral extent of contamination and the type of contaminant present (the full width of the capture zone is based on the widest contaminated zone present). As they were for the WSOW, the capture lines of wells at the WSCP were oriented in a direction perpendicular to the assumed direction of groundwater flow.

\section{C.2.1.4 Hydraulic Conductivity}

Two values of hydraulic conductivity were used in the calculations (Table C.1). A value of $0.28 \mathrm{ft} / \mathrm{d}(0.0001 \mathrm{~cm} / \mathrm{s})$ was used for the WSOW, consistent with reported values within the Burlington-Keokuk Formation. For the WSCP, a value of $0.28 \mathrm{ft} / \mathrm{d}(0.0001 \mathrm{~cm} / \mathrm{s})$ was used in regions south of the groundwater divide; a value 10 times larger $(2.8 \mathrm{ft} / \mathrm{d}[0.001 \mathrm{~cm} / \mathrm{s}])$ was used for regions north of the divide on the basis of the results of slug test data. These values are consistent with measured values within the WSCP (DOE and DA 1998).

\section{C.2.1.5 Aquifer Thickness}

The approximate thickness of the contaminated aquifer in the vicinity of the capture lines was assigned on the basis of published data (Mugel 1997); these values are listed in Table C.1. The thickness of the contaminated aquifer was assumed to be equal to the difference between the water table and the depth of the bottom of the screened interval that was showing contamination, except for well MW-3024. It is a deep, unweathered well clustered with well MW-3025. For MW-3024, the thickness of the contaminated aquifer was assumed to be equal to the difference between the bottom of MW-3025 (a clean well) and the bottom of the screened interval of MW-3024. If a particular hot spot was defined by more than one well, the well with the larger value (i.e., largest thickness) was used in the calculation. In this way, conservative estimates for the number of wells would be obtained. 
TABLE C.1 Input Parameters and Calculated Number of Extraction Wells for Each of the Contaminated Areas at the WSCP and the WSOW

\begin{tabular}{|c|c|c|c|c|c|c|}
\hline \multirow[b]{3}{*}{ Well/Area } & \multicolumn{4}{|c|}{ Input Parameters } & & \\
\hline & \multirow[b]{2}{*}{$\begin{array}{c}\text { Groundwater } \\
\text { (ft) }\end{array}$} & \multirow[b]{2}{*}{$\begin{array}{l}\text { Gradient } \\
(\mathrm{ft} / \mathrm{ft})\end{array}$} & \multirow{2}{*}{$\begin{array}{l}\text { Hydraulic } \\
\text { Conductivity } \\
\text { (ft/d) }\end{array}$} & \multirow{2}{*}{$\begin{array}{c}\text { Thickness of } \\
\text { Contaminated } \\
\text { Aquifer } \\
\text { (ft) }\end{array}$} & \multicolumn{2}{|c|}{$\begin{array}{l}\text { Calculated Number } \\
\text { of Extraction Wells }\end{array}$} \\
\hline & & & & & Number & Total \\
\hline \multicolumn{7}{|l|}{ wsow } \\
\hline \multicolumn{7}{|l|}{ Individual wells } \\
\hline MWS-9 & 1,600 & 0.01 & 0.28 & 22 & 3 & \\
\hline MWS-12 & 1,600 & 0.01 & 0.28 & 26 & 4 & \\
\hline MWV-17 & 1,600 & 0.01 & 0.28 & 33 & 5 & WSOW $=12$ \\
\hline \multicolumn{7}{|l|}{$W S C P$} \\
\hline \multicolumn{7}{|l|}{ Individual wells } \\
\hline MW-2030 & 500 & 0.01 & 2.8 & 30 & 14 & \\
\hline MW-2032 & 500 & 0.01 & 2.8 & 10 & 5 & \\
\hline MW-3024 & 250 & 0.01 & 2.8 & 48 & 12 & \\
\hline MW-4013 & 500 & 0.01 & 2.8 & 25 & 12 & \\
\hline MW-4024 & 500 & 0.04 & 0.28 & 35 & 7 & \\
\hline \multirow[t]{2}{*}{ MWS- $21^{a, b}$} & 1,600 & 0.01 & 0.28 & 15 & 2 & \\
\hline & 1,600 & 0.04 & 0.28 & 15 & 9 & \\
\hline \multicolumn{7}{|l|}{ Well clusters } \\
\hline $\begin{array}{l}\text { MW-2037 } \\
\text { MW-3012 } \\
\text { MW-3026 } \\
\text { MW-3027 } \\
\text { MW-4001 }\end{array}$ & 1,000 & 0.01 & 2.8 & 64 & 62 & \\
\hline $\begin{array}{l}\text { MW-2001 } \\
\text { MW-2002 } \\
\text { MW-2003 } \\
\text { MW-2005 } \\
\text { MW-3003 } \\
\text { MW-3023 } \\
\text { MW-4011 }\end{array}$ & 1,850 & 0.01 & 2.8 & 62 & 111 & \\
\hline $\begin{array}{l}\text { MW-2038 } \\
\text { MW-2040 }\end{array}$ & 1,900 & 0.01 & 0.28 & 30 & 6 & \\
\hline $\begin{array}{l}\text { MW-2039 } \\
\text { MW-2040 } \\
M W-2041\end{array}$ & 1,200 & 0.04 & 0.28 & 39 & 18 & \\
\hline MW-2041 & & & & & & $\mathrm{WSCP}=258$ \\
\hline
\end{tabular}

a The contaminants detected in WSOW well MWS-21 are associated with the WSCP; this well is included with the contaminated wells at the WSCP.

b WSOW well MWS-21 and WSCP well MW-2040 are located near the groundwater divide. The number of extraction wells was calculated by assuming that contaminants could potentially migrate north and south of the divide. 


\section{C.2.1.6 Results}

Information on the number of wells required for each line at the WSOW and the WSCP is summarized in Table C.1. At the WSOW, approximately 12 wells would be required to contain and capture contaminated material in the vicinity of the hot spots; at the WSCP, about 258 wells would be required.

\section{C.2.2 Estimating the Number of Extraction Wells and Associated Uncertainties on the Basis of Local Conditions}

As discussed above, Equation C.5 was used to estimate the minimum number of extraction wells, $n$, required to prevent further downstream contamination and to clean up contaminated zones associated with the wells that have maximum post-1995 contaminant concentrations that exceed their respective preliminary remediation goals (PRGs) (Table 1.3 in this FS). In some cases, contamination appears to localized in an individual well in which one or more COCs exceed their PRGs. In other cases, a number of wells appear to share a common contaminated area that contains one or more contaminants. Tables C. 2 and C. 3 list the individual wells that have concentrations that exceed their respective PRGs and wells that span the same contaminated zone. As indicated in these tables, the WSCP has four zones of contamination and four individual wells. The WSOW, on the other hand, has one contaminated zone near well MWV-24 and five individual wells. For remediation, the extraction wells are assumed to be located in a line orthogonal to the natural groundwater flow direction downstream of the contaminated zone or hot spot. The lengths of the line of wells, W, were estimated from maps of the WSCP and the WSOW and are consistent with estimated maximum widths for the contaminated zones identified.

The minimum number of wells required to contain and clean up a contaminated zone is a function of five parameters: $K, B, \nabla h, W$, and $Q$. To produce a best-estimate calculation, values for the hydraulic conductivity, $K$, and vertical extent of contamination, $B$, were statistically derived from data on wells completed in the weathered and weathered/unweathered zone that are most closely associated with any contaminated zones. That is, $K$ and $B$ were assumed to be equal to the average values for the wells associated with the zone of contamination. Because of the small numbers of wells for each contamination zone, a log normal distribution was not assumed in evaluating the statistical characteristics for the $K$ distribution because of very large standard deviations in the log normal distribution. For individual wells that have contaminant concentrations exceeding their PRG values, $K$ and $B$ were obtained directly from the remedial investigation (DOE and DA 1998) for the given well.

The thickness parameter or vertical extent of contamination, $B$, was assumed to be equal to the distance between the water table and the depth of an inferred contact between the weathered and unweathered limestone in the Burlington-Keokuk Formation (DOE and DA 1998). This 
TABLE C.2 Wells Associated with

Contaminated Zones at the WSCP

\begin{tabular}{|c|c|c|}
\hline $\begin{array}{c}\text { Contaminated } \\
\text { Zone }\end{array}$ & Well & Contaminant $^{\mathrm{a}}$ \\
\hline \multirow[t]{7}{*}{1} & MW-2037 & TCE \\
\hline & MW-2038 & TCE \\
\hline & MW-3025 & TCE \\
\hline & MWS-21 & TCE \\
\hline & MW-2036 & - \\
\hline & MW-2039 & Nitrate, $2,4-\mathrm{DNT}$ \\
\hline & MW-4004 & - \\
\hline \multirow[t]{2}{*}{2} & MW-4001 & Nitrate, 2,4-DNT \\
\hline & MW-3027 & Nitrate \\
\hline \multirow[t]{5}{*}{3} & MW-2001 & Nitrate, 2,4-DNT \\
\hline & MW-2002 & Nitrate \\
\hline & MW-2003 & Nitrate, 2,4-DNT \\
\hline & MW-2005 & Nitrate \\
\hline & MW-3023 & Nitrate, 2,4-DNT \\
\hline \multirow[t]{4}{*}{4} & MW-2006 & 2,4-DNT \\
\hline & MW-2011 & 2,4-DNT \\
\hline & MW-2013 & 2,4-DNT \\
\hline & MW-2014 & 2,4-DNT \\
\hline 5 & MW-4013 & Nitrate \\
\hline 6 & MW-2032 & Nitrate, 2,4-DNT \\
\hline 7 & MW-4015 & 2,4-DNT \\
\hline 8 & MW-4002 & 2,4-DNT \\
\hline
\end{tabular}

a $\mathrm{TCE}=$ trichloroethylene, $\mathrm{DNT}=$ dinitrotoluene, and a hyphen indicates that contaminant concentrations are below their respective PRGs. 
TABLE C.3 Wells Associated with Contaminated Zones at the WSOW

\begin{tabular}{cll}
\hline $\begin{array}{c}\text { Contaminated } \\
\text { Zone }\end{array}$ & \multicolumn{1}{c}{ Well } & \multicolumn{1}{c}{ Contaminant $^{\mathrm{a}}$} \\
\hline & MWS-12 & 2,4-DNT, 2,6-DNT \\
2 & MWS-17 & 2,4-DNT, 2,6-DNT \\
3 & MWS-21 & TCE, nitrate, 2,4-DNT \\
& & (also in WSCP zone 1) \\
4 & MWV-9 & 2,4-DNT \\
& MWV-24 & 2,4-DNT \\
5 & MW-4002 & 2,4-DNT \\
6 & USGS-4 & 2,4-DNT \\
\hline
\end{tabular}

${ }^{\mathrm{a}} \mathrm{DNT}=$ dinitrotoluene and $\mathrm{TCE}=$ trichloroethylene.

assumption is somewhat more conservative than that used in Section C.3.2.1, in which the thickness of the contaminated zone was assumed to be equal to the difference between the water table and the depth of the screened interval showing contamination. The approach was selected to allow contamination to extend beyond the bottom of the screened interval but not beyond the top of the unweathered zone.

Values for the other parameters were obtained as follows. Hydraulic gradient was obtained from a potentiometric surface of the shallow groundwater system $(0.01 \mathrm{ft} / \mathrm{ft})$. The width of the contaminated zone was estimated from the locations of the wells showing contamination and an inferred interpretation of the groundwater flow direction obtained from the potentiometric surface for the shallow groundwater aquifer (a value of $1,000 \mathrm{ft}$ was used for all single wells). The maximum, sustainable pumping rate was estimated by using engineering judgment. Generally, a maximum pumping rate of $0.3 \mathrm{gpm}$ was assumed for wells in the WSCP, and a rate of $0.03 \mathrm{gpm}$ was used for wells in the WSOW.

In addition to a more detailed calculation for the contaminated zones and individual wells, uncertainty calculations for the number of wells required for each single well or zone were also performed. The transmitted uncertainty (square root of variance) of a dependent variable, $n$, that is 
a nonlinear function of $j$ independent variables, $\zeta$, that have a zero covariance can be expressed by the following relationship (Box et al. 1978):

$$
\Delta n=\sqrt{\sum_{i=1}^{j}\left(\frac{\partial n}{\partial \zeta_{i}}\right)^{2}\left(\Delta \zeta_{i}\right)^{2}}
$$

where $\Delta \zeta_{\mathrm{i}}$ is the uncertainty in parameter $\zeta_{\mathrm{i}}$, and the summation is carried out over all independent variables. Performing the indicated differentiation on Equation C.7 produces the result

$$
\Delta n=\sqrt{T 1+T 2+T 3+T 4+T 5},
$$

where

$$
\begin{gathered}
T 1=\left(\frac{2 \nabla h K W}{Q}\right)^{2}(\Delta B)^{2}, \\
T 2=\left(\frac{2 B K W}{Q}\right)^{2}(\Delta \nabla h)^{2}, \\
T 3=\left(\frac{2 B \nabla h K}{Q}\right)^{2}(\Delta W)^{2}, \\
T 4=\left(\frac{2 B \nabla h W}{Q}\right)^{2}(\Delta K)^{2}, \text { and } \\
T 5=\left(\frac{2 B \nabla h K W}{Q^{2}}\right)^{2}(\Delta Q)^{2} .
\end{gathered}
$$

In carrying out the differentiation, the maximum sustainable pumping rate, $Q$, was assumed to be independent of the hydraulic conductivity of the formation. In actual practice, a relationship exists between $Q$ and $K$, but this relationship is further complicated by factors such as well completion and skin effects within the well bore. Because these other processes can significantly affect the relationship between $K$ and $Q$ and because they are, in general, very well-specific, $Q$ was simplistically assumed to be independent of $K$. Before implementing a pump-and-treat design, additional field work should be conducted to determine the field values for maximum sustainable pumping rates at both the WSCP and the WSOW.

Uncertainties for the hydraulic conductivity and thickness were assumed to be equal to the standard deviation of the values of the wells associated with the zone of contamination (Tables C.2 and C.3). For this statistical method, all wells in the immediate vicinity of a contaminated zone were 
included in the analysis in order to incorporate as much site-specific data as possible, even though not all wells had concentrations that exceeded their PRGs. For a single well in which the contaminant concentration exceeds its PRG, the uncertainty in the hydraulic conductivity was assumed to be twice the value of the hydraulic conductivity of the associated well. The uncertainty in the vertical extent of contamination, $B$, was assumed to be $50 \%$ of the well value. In some cases, the vertical extent of contamination was estimated from nearby wells because information on the depth to the contact between the weathered and unweathered zones was not known. The uncertainty in the hydraulic gradient $(0.001 \mathrm{ft} / \mathrm{ft})$ was assumed to be $10 \%$ of the base-case value, 0.001 . The uncertainty in the width of the capture line was $30 \mathrm{~m}$ (100 ft) for single wells, and somewhat larger for zones of contamination (Table C.4). The uncertainty in the maximum volumetric rate of pumping was assumed to be equal to $50 \%$ of the nominal value. Table C. 4 summarizes the relevant parameters and uncertainties for the WSCP and the WSOW.

TABLE C.4 Summary of Parameters and Their Uncertainties Used to Calculate the Number of Extraction Wells under Local Conditions

\begin{tabular}{|c|c|c|c|c|c|c|c|c|}
\hline $\begin{array}{c}\text { Contaminated } \\
\text { Area }^{2}\end{array}$ & $\begin{array}{l}\text { Average } \mathrm{K} \\
(\mathrm{cm} / \mathrm{s})\end{array}$ & $\begin{array}{c}\Delta \mathrm{K} \\
(\mathrm{cm} / \mathrm{s})\end{array}$ & $\begin{array}{c}\text { Average } B \\
(\mathrm{ft})\end{array}$ & $\begin{array}{l}\Delta \mathrm{B} \\
(\mathrm{ft})\end{array}$ & $\begin{array}{l}\text { Width } \\
\text { of Zone } \\
(\mathrm{ft})^{\mathrm{c}}\end{array}$ & $\begin{array}{l}\Delta \mathrm{W} \\
(\mathrm{ft})\end{array}$ & $\begin{array}{l}\text { Maximum } \\
\text { Pump Rate } \\
\text { (gpm) }\end{array}$ & $\begin{array}{c}\Delta \mathrm{Q} \\
(\mathrm{gpm})\end{array}$ \\
\hline \multicolumn{9}{|l|}{$W S C P$} \\
\hline 1 & $3.3 \times 10^{-3}$ & $7.4 \times 10^{-3}$ & 33.1 & 3.1 & 1,800 & 100 & 0.30 & 0.15 \\
\hline 2 & $4.8 \times 10^{-4}$ & $6.0 \times 10^{-4}$ & 20.6 & 5.9 & 1,000 & 100 & 0.30 & 0.15 \\
\hline 3 & $3.5 \times 10^{-5}$ & $2.3 \times 10^{-5}$ & 28.4 & 7.0 & 1,700 & 100 & 0.30 & 0.15 \\
\hline 4 & $1.3 \times 10^{-3}$ & $1.9 \times 10^{-3}$ & 18.6 & 7.3 & 1,200 & 100 & 0.30 & 0.15 \\
\hline 5 & $5.7 \times 10^{-5}$ & $1.1 \times 10^{-4}$ & 5.5 & 2.8 & 1,000 & 100 & 0.30 & 0.15 \\
\hline 6 & $4.0 \times 10^{-2}$ & $8.0 \times 10^{-2}$ & 10.3 & 5.2 & 1,000 & 100 & 3.0 & 1.5 \\
\hline 7 & $2.9 \times 10^{-5}$ & $5.8 \times 10^{-5}$ & 20.5 & 10.3 & 1,000 & 100 & 0.30 & 0.15 \\
\hline 8 & $1.0 \times 10^{-3}$ & $2.0 \times 10^{-3}$ & 15.6 & 7.8 & 1,000 & 100 & 0.30 & 0.15 \\
\hline \multicolumn{9}{|l|}{ WSOW } \\
\hline 1 & $1.4 \times 10^{-6}$ & $2.8 \times 10^{-6}$ & 30.7 & 15.4 & 1,000 & 100 & 0.03 & 0.015 \\
\hline 2 & $1.5 \times 10^{-7}$ & $3.0 \times 10^{-7}$ & 16.1 & 8.1 & 1,000 & 100 & 0.03 & 0.015 \\
\hline 3 & $3.6 \times 10^{-6}$ & $7.2 \times 10^{-6}$ & 23.1 & 11.5 & 1,000 & 100 & 0.03 & 0.015 \\
\hline 4 & $1.3 \times 10^{-5}$ & $2.6 \times 10^{-5}$ & 33.4 & 16.7 & 1,000 & 100 & 0.03 & 0.015 \\
\hline 5 & $1.0 \times 10^{-3}$ & $2.0 \times 10^{-3}$ & 6.6 & 3.3 & 1,000 & 100 & 0.30 & 0.15 \\
\hline 6 & $2.2 \times 10^{-7}$ & $4.4 \times 10^{-7}$ & 55.2 & 27.6 & 1,000 & 100 & 0.03 & 0.015 \\
\hline
\end{tabular}

a Contaminated zones are defined in Tables C.2 and C.3.

b Derived or obtained directly from data in the remedial investigation (DOE and DA 1998).

c Estimated from the potentiometric surface for the shallow groundwater aquifer and the locations of wells that exceed their respective PRGs.

d Estimated from pump tests at the WSCP. 
The number of extraction wells required for each contaminated area and their associated uncertainties are shown in Table C.5. As indicated in this table, a large number of wells would be required to remediate the trichloroethylene (TCE)-contaminated area at the WSCP. The number of wells required for this contaminated area is also very uncertain, and this uncertainty is primarily the result of the uncertainty in the hydraulic conductivity (i.e., more than $90 \%$ of this uncertainty comes from uncertainty in hydraulic conductivity).

At the WSOW, many fewer extraction wells would be required (Table C.5). However, because of the low hydraulic conductivity values, the time required to establish a capture zone and remove the contaminants would be very long.

If the velocity of a contaminant moving toward an extraction well is given by the expression

$$
V_{r}=\frac{Q}{2 \pi B r \phi}+V_{0}
$$

where $Q$ is the volumetric extraction rate, $\phi$ is the effective porosity of the porous medium, and $V_{0}$ is the average linear velocity produced by the natural gradient (Freeze and Cherry 1979)

$$
V_{0}=-\frac{K \nabla h}{\phi}
$$

then an ordinary, first-order, nonhomogeneous differential can be set up and solved to find the time needed for water to travel from the edge of the contaminated zone to the extraction well. That is,

$$
\frac{d r}{d t}-\frac{Q}{2 \pi B \phi r}=V_{0}
$$

Equation C.11 can be solved to yield the result

$$
L=V_{0} t+\sqrt{\frac{Q t}{\pi B \phi}},
$$

where $L$ is the distance from the edge of the contaminated zone to the extraction well. This equation was then solved iteratively to find the travel time for water. 
TABLE C.5 Number of Extraction Wells Required for Implementing a Pump-andTreat Design at the WSCP and the WSOW

\begin{tabular}{|c|c|c|c|c|}
\hline $\begin{array}{c}\text { Contaminated } \\
\text { Zone }^{\mathrm{a}}\end{array}$ & $\begin{array}{c}\text { No. of } \\
\text { Extraction } \\
\text { Wells Needed }\end{array}$ & $\begin{array}{l}\text { Uncertainty } \\
\text { in the Number } \\
\text { of Extraction } \\
\text { Wells Needed }\end{array}$ & $\begin{array}{c}\text { Cleanup Time } \\
\text { Based on } \\
\text { Travel Path } \\
\text { (yr) }\end{array}$ & $\begin{array}{c}\text { No. of } \\
\text { Extraction Wells } \\
\text { Needed for Cleanup } \\
\text { in } 10 \text { Years }\end{array}$ \\
\hline \multicolumn{5}{|l|}{$W S C P$} \\
\hline 1 & 200 & 450 & 16 & 180 \\
\hline 2 & 10 & 14 & 22 & 120 \\
\hline 3 & 2 & 2 & 195 & 340 \\
\hline 4 & 28 & 45 & 28 & 300 \\
\hline 5 & 1 & 1 & 43 & 20 \\
\hline 6 & 41 & 86 & 0.2 & 10 \\
\hline 7 & 1 & 2 & 121 & 60 \\
\hline 8 & 16 & 33 & 5 & 50 \\
\hline Total & 299 & 633 & & 1,080 \\
\hline \multicolumn{5}{|l|}{ WSOW } \\
\hline 1 & 1 & 1 & 16,100 & 1,650 \\
\hline 2 & 1 & 1 & 10,500 & 900 \\
\hline $3^{f}$ & 1 & 2 & 575 & 340 \\
\hline 4 & 4 & 8 & 2,600 & 920 \\
\hline 5 & 20 & 42 & 15 & 20 \\
\hline 6 & 1 & 1 & 9,500 & 1,550 \\
\hline Total & 28 & 55 & & 5,380 \\
\hline
\end{tabular}

a Contaminated zones are defined in Tables C. 2 and C.3

${ }^{b}$ Calculated in Equation C.5.

c Calculated in Equation C.8.

${ }^{d}$ Calculated in Equation C. 12.

e Calculated in Equation C.14.

f Also included in WSCP contaminated zone 1. 
Although Equation C.12 can be used to estimate the travel time for water, sorption will retard the COCs and increase the travel time. Multiplying the travel time derived from Equation C. 12 by the contaminant's retardation factor, $R$,

$$
R=1+\frac{\rho K_{d}}{\phi} \text {, }
$$

where $K_{d}$ is the contaminant's distribution coefficient and $\rho$ is the bulk density of the porous medium, provides an estimate of the contaminant's travel time and an approximate cleanup time for the contaminant.

Equation C.12 was solved for the contaminated areas associated with COCs by using a bulk density of $1.7 \mathrm{~g} / \mathrm{cm}^{3}$ and distribution coefficients of $0.3,0.5,0.63$, and $1.29 \mathrm{~mL} / \mathrm{g}$ for TCE, nitrate, 2,4-dinitrotoluene (2,4-DNT), and 2,6-DNT, respectively (DOE 1992; DOE and DA 1998). For contaminated areas that have multiple COCs, the one with the largest $K_{d}$ was used to bound the calculation. The results of these calculations are given in Table C.5. As expected, the cleanup times for WSOW areas of contamination are exceedingly long because of the low hydraulic conductivity and the small maximum sustainable pumping rates assumed. (Because of very low conductivities, the assumed value of $0.03 \mathrm{gpm}$ may still cause dewatering of the formation, and additional fieldwork will be required before design implementation).

Because of the very long cleanup times estimated for the WSOW, an additional method was used to estimate the number of extraction wells required for a predefined cleanup time of 100 years. In this method, the number of wells was estimated from the volume of water in one pore volume for the contaminated area and the number of pore volumes that must be removed to accomplish cleanup; that is,

$$
n=\frac{W L B \phi N}{Q \Delta t}
$$

where $N$ is the number of pore volumes that must be removed to attain cleanup goals and $\Delta t$ is the predefined pumping time.

In the absence of dispersion, the number of pore volumes is approximately equal to the retardation coefficient for the COC (Cohen et al. 1997). If dispersion is included in the analyses, the following equation from Cohen et al. (1997) can be used:

$$
N=-R \ln \left(\frac{C_{w}}{C_{0}}\right),
$$


where $C_{0}$ is the initial concentration of the contaminant, and $C_{w}$ is the cleanup goal. Equation C.15 was not used for this analysis because of the large uncertainty introduced by estimating the value for $C_{0}$ for the contaminated areas.

Table C.5 summarizes the number of wells needed in 100 years to clean up the various contaminated areas identified at the WSCP and the WSOW. Many more wells would be required at the WSOW because of its lower hydraulic conductivity and lower assumed maximum sustainable pumping rates.

\section{C.3 PRACTICALITY}

As discussed above, a large number of extraction wells would be needed at both the WSCP and the WSOW to capture and clean up contaminated areas. At the WSCP, a large number of wells would be needed to remediate the TCE-contaminated area. Because of uncertainties in hydraulic conductivities and extraction rates, the uncertainty in the number of wells would also be large. In addition, the presence of potentially high-permeability preferred paths could limit the success of a pump-and-treat technology.

In the WSOW, fewer wells would be needed than in the WSCP, but cleanup times would be exceedingly long if the aquifer was not dewatered by the assumed pumping. More efficient cleanup strategies could be developed that incorporate additional wells being placed upstream of the capture line.

The design of a practical pump-and-treat system for either the WSCP or the WSOW should proceed in stages. First, a small number of wells should be installed and tested to determine more accurate values for the hydraulic conductivity and maximum sustainable pumping rates in the areas of contamination. Next, a combination of analytical and numerical modeling could be used to determine the locations for additional wells. As more information on the actual groundwater system is obtained from the field, the system design could be modified to produce optimal results.

\section{C.4 REFERENCES FOR APPENDIX C}

Box, G.E.P., et al., 1978, Statistics for Experiments: An Introduction to Design, Data Analysis, and Model Building, John Wiley and Sons, Inc., New York, N.Y.

Cohen, R.M., et al., 1997, Design Guidelines for Conventional Pump-and-Treat Systems, EPA/540/S-97/504, U.S. Environmental Protection Agency, Washington, D.C., Sept.

DOE and DA: see U.S. Department of Energy and U.S. Department of the Army. 
Freeze, R.A., and J.A. Cherry, 1979, Groundwater, Prentice-Hall, Inc., Englewood Cliffs, N.J.

Grubb, S., 1993, "Analytical Model for Estimation of Steady-State Capture Zones of Pumping Wells in Confined and Unconfined Aquifers," Ground Water 31(1):27-32, Jan./Feb.

Javandel, I, and C.-F. Tsang, 1986, "Capture-Zone Type Curves: A Tool for Aquifer Cleanup," Ground Water 24(5):616-625.

Javandel, I., et al., 1984, Groundwater Transport: Handbook of Mathematical Models, American Geophysical Union, Washington, D.C.

Milne-Thomson, L.M., 1968, Theoretical Hydrodynamics, MacMillan Company, New York, N.Y.

MK-Ferguson Company and Jacobs Engineering Group, Inc., 1990, Aquifer Characteristics Data Report for the Weldon Spring Site Chemical Plant/Raffinate Pits and Vicinity Properties, DOE/OR/21548-122; Rev. 0, prepared for U.S. Department of Energy, Oak Ridge Operations Office, Weldon Spring Site Remedial Action Project, Weldon Spring, Mo., Nov.

U.S. Department of Energy, 1992, Baseline Assessment for the Chemical Plant Area of the Weldon Spring Site, DOE/OR/21548-091, Oak Ridge Field Office, Weldon Spring Site Remedial Action Project, Nov.

U.S. Department of Energy and U.S. Department of the Army, 1998, Remedial Investigation for the Groundwater Operable Units at the Chemical Plant Area and the Ordnance Works Area, Weldon Spring Site, Weldon Spring, Missouri, DOE/OR/21548-571, Final, prepared by MK-Ferguson Company and Jacobs Engineering Group, Inc., Weldon Spring, Mo., and Argonne National Laboratory, Argonne, Ill., for U.S. Department of Energy, Weldon Spring Site Remedial Action Project, Weldon Spring, Mo., and U.S. Department of the Army, Corps of Engineers, Kansas City District, Mo., July. 


\section{APPENDIX D:}

METHODOLOGY AND ASSUMPTIONS USED TO DETERMINE THE COSTS OF THE VARIOUS ALTERNATIVES IN THIS FEASIBILITY STUDY 
D-2 


\section{APPENDIX D: \\ METHODOLOGY AND ASSUMPTIONS USED TO DETERMINE THE COSTS OF THE VARIOUS ALTERNATIVES IN THIS FEASIBILITY STUDY}

The U.S. Department of Energy (DOE) and the U.S. Department of Army (DA) are conducting an evaluation of potential alternatives for addressing groundwater contamination at the Weldon Spring Chemical Plant (WSCP) and the Weldon Spring Ordnance Works (WSOW), respectively, in St. Charles County, Missouri. This appendix discusses the methodology and assumptions used to determine the costs of the various alternatives considered in this feasibility study (FS). Unless noted otherwise, the direct costs for both construction and operational phases were developed using Version 3.20 of the Remedial Action Cost Estimating and Requirements System (RACER) computer model (Delta Research Corporation 1995).

\section{D.1 REMEDIAL ACTION COST ESTIMATING AND REQUIREMENTS SYSTEM (RACER) SYSTEM}

The RACER system was developed by the U.S. Air Force to estimate the total cost (both direct and indirect) of remedial actions. RACER is a PC-based environmental cost-estimating system that can be used to provide programming, budgeting, and cost engineering support during various phases of remediation: Preliminary Assessment/Site Investigation (PA/SI) Studies, Petroleum Underground Storage Tank Site Assessment, Remedial Investigation (RI)/FS, Remedial Facility Investigation/Corrective Measures Study (RFI/CMS), Remedial Design, Remedial Action (including operations and maintenance [O\&M]), and Site Work and Utilities.

The RACER estimating process involves a series of basic steps, including calculation of site (direct) costs and project costs. A project may consist of a single site or it may contain several sites. For each site included in the project, the user can select and run the technologies and/or processes (cost models) that will be used to remediate the site. The costs calculated for these models are direct costs only (i.e., the cost does not include contractor overhead and profit, cost for contingencies, project management, or escalation). Once direct costs have been calculated for all cost models included in each site of the project, the user completes the estimate by calculating the project costs. Project costs include costs for contractor overhead and profit, contingencies, project management, and escalation. RACER was used in this analysis to determine only the direct costs (costs that can be directly attributed to a particular item of work or activity). Specific indirect cost relationships for the WSCP and the WSOW were applied in this analysis rather than the generic indirect cost relationships provided by the RACER model. 
RACER uses a parametric modeling technique similar to the U.S. Air Force's Construction Cost Management Analysis System (CCMAS). The basic concept of RACER is that predefined engineering relationships link primary parameters to detailed quantities. These quantities are then priced using established cost databases. The RACER cost models are based on generic engineering solutions for environmental projects, technologies, and processes. The engineering solutions were derived from research, government laboratories, construction management agencies, vendors, contractors, engineering analyses, and historic project information. Design parameters within the cost models were tailored by the cost estimator to reflect specific project conditions and requirements. The design was then tailored by RACER into specific quantities of work, which were priced using current price data. The assembly cost database within RACER was developed from the Unit Price Book of the U.S. Army Corps of Engineers (1989) and supplemented by vendor and contractor quotes. A cost differential was included in this analysis to account for the differences in material and labor costs in the Weldon Spring area compared with the generic Unit Price Book costs.

Professional labor includes activities that provide interpretation of the performance of the remedial action during both the construction/startup and O\&M phases of the environmental restoration process. Typical professional labor activities associated with remedial action construction include oversight of construction activities, permit acquisition, and "as built" drawings. Professional labor activities associated with O\&M include evaluation of sampling and analysis data, comparison of results with project goals, coordination of field activities, and documentation and reporting of all efforts. Estimates of professional labor were derived by RACER using a parametric approach based on similar levels of activities for related projects.

\section{D.2 ESTIMATION OF INDIRECT COSTS}

Indirect costs are defined as those costs that cannot be identified specifically with a particular activity, cannot be charged to a specific element of work, or do not become a permanent part of any facility constructed. Indirect costs - small tools and supplies, fringes, insurance, and contingency - were estimated on the basis of various percentages of other costs specific to the WSCP (Hood 1997) and the WSOW (Patton et al. 1996). The various indirect cost relationships applied in this analysis are provided in Tables D.1 and D.2 and were implemented using a Microsoft Excel $^{\mathrm{TM}}$ spreadsheet for each alternative.

Contingency costs are added to a project to cover costs that may result from incomplete design, unforeseen and unpredictable conditions, or uncertainties within the defined scope. In general, the contingency cost is derived from the difference between the $5 \%$ and $50 \%$ chance of overrun of the base estimate. A contingency percentage of $25 \%$ was applied for the WSCP in this analysis, on the basis of Hood (1997), which is within the range recommended by the DOE Office of Environmental Management for projects in the preliminary stage of the remediation process (DOE 1990). 
TABLE D.1 WSCP-Specific Indirect Cost Relationships Applied in This FS

\begin{tabular}{lll}
\hline \multicolumn{1}{c}{ Indirect Cost Component } & \multicolumn{1}{c}{ Relationship } & \multicolumn{1}{c}{ Applied Under } \\
\hline Small tools and supplies & $5 \%$ of total direct labor cost & Cost of supplies \\
Level D personnel protection & $0.179 \times$ direct workforce & Cost of supplies \\
State sales and use tax & $\begin{array}{l}7.23 \% \text { of cost of permanent } \\
\text { materials and supplies }\end{array}$ & $\begin{array}{l}\text { Cost of permanent materials } \\
\text { and supplies }\end{array}$ \\
Indirect labor & $25 \%$ of total direct labor cost & Cost of OH/Fee/Con ${ }^{\mathrm{a}}$ \\
Plant operations & $8.8 \%$ of total direct labor cost & Cost of OH/Fee/Con \\
Fringes & $29 \%$ of indirect labor & Cost of OH/Fee/Con \\
Margin & $\begin{array}{l}10 \% \text { of sum of direct cost and all } \\
\text { preceding indirect cost components }\end{array}$ & Cost of OH/Fee/Con \\
\hline Bond & $\begin{array}{l}2 \% \text { of sum of direct cost and all } \\
\text { preceding indirect cost components }\end{array}$ & Cost of OH/Fee/Con \\
\hline Insurance & $\begin{array}{l}10 \% \text { of sum of direct cost and all } \\
\text { preceding indirect cost components }\end{array}$ & Cost of OH/Fee/Con \\
\hline & $\begin{array}{l}25 \% \text { of sum of direct cost and all } \\
\text { preceding indirect cost components }\end{array}$ & Cost of OH/Fee/Con \\
\hline
\end{tabular}

a $\mathrm{OH} / \mathrm{Fee} / \mathrm{Con}=$ overhead/performance fee/contingency.

Source: Data from Hood (1997).

\section{D.3 PRESENT-WORTH ANALYSIS}

Present worth is defined as the investment-evaluation procedure that involves discounting the sums of capital investment, O\&M, and repairs at a specified interest rate (representing cost of capital or minimum acceptable rate of return). The following analysis complies with the requirements described by the Office of Management and Budget (OBM) Circular No. A-94, the National Bureau of Standards Handbook 135 prepared for DOE, and the U.S. Environmental Protection Agency (EPA) Office of Solid Waste and Emergency Response (OSWER) Directive 9355.3-01 (EPA 1988) for adjusting for converting cash flows at different times to correspond at a common time during preparation of a cost estimate. 
TABLE D.2 WSOW-Specific Indirect Cost Relationships Applied in This FS

\begin{tabular}{lll}
\hline \multicolumn{1}{c}{$\begin{array}{c}\text { Indirect Cost } \\
\text { Component }\end{array}$} & \multicolumn{1}{c}{ Relationship } & Applied Under \\
\hline Contractor overhead & $5 \%$ of total direct labor cost & Cost of OH/Fee/Con ${ }^{\text {a }}$ \\
Contractor profit & $\begin{array}{l}8 \% \text { of sum of direct cost and all } \\
\text { preceding indirect cost components }\end{array}$ & Cost of OH/Fee/Con \\
Contingency & $\begin{array}{l}10 \% \text { of sum of direct cost and all } \\
\text { preceding indirect cost components }\end{array}$ & Cost of OH/Fee/Con \\
Project management & $\begin{array}{l}8 \% \text { of sum of direct cost and all } \\
\text { preceding indirect cost components, } \\
\text { excluding contingency }\end{array}$ & \\
\hline
\end{tabular}

a $\mathrm{OH} / \mathrm{Fee} / \mathrm{Con}=$ overhead/performance fee/contingency.

Source: Data from Patton et al. (1996).

The costs calculated in this analysis are given in 1995 constant dollars. The constant dollar cash flows occurring at different times were converted by the present-worth analysis into a timeequivalent lump sum amount evaluated at the beginning of the base year. This conversion was performed by using an interest rate or "real discount rate" that reflects the opportunity cost apart from any change in the purchasing power of the dollar. A Uniform Series Present Worth Factor (P/A) was calculated by using the real discount rate $I$ :

$$
P / A=\left[(1+I)^{n}-1\right] / I /(1+I)^{n},
$$

where $n$ is the project duration.

A discount rate of $7 \%$ (before taxes and after inflation) was applied in this analysis (EPA 1993). Although remedial activities would continue for a reasonable amount of time (i.e., greater than 10 years) or until remedial objectives were met, long-term operation costs were based on a 30-year period, per instructions in EPA (1988), and include annual sampling and analysis costs.

\section{D.4 SAMPLE CONSTRUCTION COST CALCULATION FOR ALTERNATIVE 2}

The construction of approximately $10 \%$ of the number of existing wells (i.e., 15 additional wells) was conservatively assumed in Alternative 2 (Long-Term Monitoring) to evaluate the 
protectiveness of this alternative. The following assumptions were made during development of the construction costs for Alternative 2:

- Well installation would be in a consolidated formation;

- Safety Level D conditions would be maintained during construction (Level D provides minimal protection against respiratory hazards. Coveralls, hard hat, leather or chemical-resistant boots/shoes, and safety glasses or chemical splash goggles are required. Personal dosimeters are included for Level D radioactive sites.);

- Construction materials would be stainless steel (for long-term effectiveness);

- Fifteen wells would be developed with the following characteristics:

- Well diameter, $5 \mathrm{~cm}(2 \mathrm{in}$.$) ;$

- Depth to top of screen, $20 \mathrm{~m}(65 \mathrm{ft})$;

- Screen length, $3 \mathrm{~m}(10 \mathrm{ft}) ;$ and

- Dedicated pumps would be provided for each well for purge and sampling purposes.

This information was used with the RACER model to determine the direct construction costs. The indirect cost relationships provided in Tables D.1 and D.2 were then applied to determine the total construction cost (direct and indirect). Estimates of the direct costs are given in Table D.3.

\section{D.5 EXAMPLE OF A PRESENT-WORTH COST CALCULATION FOR ALTERNATIVE 2}

Costs for Alternative 2 would be associated with continuing the existing environmental monitoring program, constructing and operating the proposed additional monitoring wells, and conducting a performance review every five years. The methodology outlined in Section D. 3 was implemented within a Microsoft Excel ${ }^{\mathrm{TM}}$ spreadsheet, as shown in Table D.4. The spreadsheet methodology was developed to allow a variable discount rate and operations duration, so as to allow for consideration of different "what-if" scenarios. 
TABLE D.3 Estimated Direct Costs for Alternative 2 (Long-Term Monitoring) ${ }^{\text {a }}$

\begin{tabular}{|c|c|c|c|c|c|c|c|c|c|c|}
\hline \multirow[b]{2}{*}{ Description (WBS Element) } & \multirow[b]{2}{*}{ Quantity } & \multirow[b]{2}{*}{ Unit } & \multirow{2}{*}{$\begin{array}{l}\text { Work Force } \\
\text { (person-hours) }\end{array}$} & \multicolumn{7}{|c|}{ Cost (\$) } \\
\hline & & & & Labor & Equipment & Materials & Supplies & Subcontracts & $\mathrm{OH} / \mathrm{Fee} / \mathrm{Con}$ & Total \\
\hline \multicolumn{11}{|c|}{15 Groundwater Monitoring Wells in Burlington/Keokuk Limestone (33.02.04.01) } \\
\hline $\begin{array}{l}\text { 55-gal drums for drilling cuttings } \\
\text { and developing water }\end{array}$ & 32 & Each & 0 & 0 & 0 & 1,357 & 0 & 0 & 0 & 1,357 \\
\hline Well development equipment rental & 2 & Week & 6 & 77 & 1 & 754 & 0 & $\mathbf{0}$ & 0 & 832 \\
\hline Split-spoon sample, 2 in. $\times 24$ in., during drilling & 228 & Each & 0 & 0 & 0 & 5,643 & 0 & 0 & 0 & 5,643 \\
\hline Organic vapor analyzer, rental, per day & 0 & Day & 0 & 0 & 0 & 0 & 0 & 0 & 0 & 0 \\
\hline Mud drilling, 6-in.-diameter borehole & 1,140 & LNFT & 749 & 10,342 & 13,276 & 0 & 0 & 0 & 0 & 23,618 \\
\hline Surface pad, concrete, $2 \mathrm{ft} \times 2 \mathrm{ft} \times 4 \mathrm{in}$. & 15 & Each & 2 & 15 & 1 & 40 & 0 & 0 & 0 & 55 \\
\hline 5-ft guard posts, cast iron, concrete fill & 60 & Each & 123 & 1,700 & 22 & 1,461 & 0 & 0 & 0 & 3,184 \\
\hline H stem, 8 in. outside diameter borehole for 2 -in. well & 0 & LNFT & 0 & 0 & 0 & 0 & 0 & 0 & 0 & 0 \\
\hline 2-in. well, bentonite seal & 15 & Each & 7 & 94 & 120 & 215 & 0 & 0 & 0 & 429 \\
\hline 2-in. well, portland cement grout & 915 & LNFT & 0 & 0 & 0 & 815 & 0 & 0 & 0 & 815 \\
\hline 2-in. screen, filter pack & 195 & LNFT & 23 & 306 & 393 & 1,132 & 0 & 0 & 0 & 1,831 \\
\hline 2-in. stainless steel, well casing & 1,013 & LNFT & 160 & 2,209 & 2,834 & 15,723 & 0 & 0 & 0 & 20,766 \\
\hline 2-in. stainless steel, well screen & 150 & LNFT & 21 & 277 & 356 & 6,027 & 0 & 0 & 0 & 6,660 \\
\hline 2-in. stainless steel, well plug & 15 & Each & 7 & 83 & 107 & 377 & 0 & 0 & 0 & 567 \\
\hline Groundwater pump, $3 / 4 \mathrm{HP}$, controls & 15 & Each & 251 & 3,465 & 38 & 66,023 & 0 & 0 & 0 & 69,526 \\
\hline Mobilization/demobilization drilling rig and crew & 1 & LS & 41 & 554 & 711 & 0 & 0 & 0 & 0 & 1,266 \\
\hline Moving rig/equipment around site & 14 & Each & 18 & 243 & 311 & 0 & 0 & 0 & 0 & 554 \\
\hline
\end{tabular}

Drilling \& Installation (33.23.11.01)

Monitoring well slug testing equipment rental 15 Week

0

0

0

10,692

0

0

$0 \quad 10,692$ 
TABLE D.3 (Cont.)

\begin{tabular}{|c|c|c|c|c|c|c|c|c|c|c|}
\hline \multirow[b]{2}{*}{ Description (WBS Element) } & \multirow[b]{2}{*}{ Quantity } & \multirow[b]{2}{*}{ Unit } & \multirow[b]{2}{*}{$\begin{array}{c}\text { Work Force } \\
\text { (person-hours) }\end{array}$} & \multicolumn{7}{|c|}{$\operatorname{Cost}(\$)$} \\
\hline & & & & Labor & Equipment & $\begin{array}{l}\text { Permanent } \\
\text { Materials }\end{array}$ & Supplies & Subcontracts & $\mathrm{OH} / \mathrm{Fee} / \mathrm{Con}$ & Total \\
\hline \multicolumn{11}{|l|}{ Construction Support (33.80.01.01) } \\
\hline Project engineer & 12 & hour & 12 & 410 & 0 & 0 & 0 & 0 & 0 & 411 \\
\hline Staff engineer & 120 & hour & 120 & 3,124 & 0 & 0 & 0 & 0 & 0 & 3,124 \\
\hline Staff hydrogeologist & 0 & hour & 0 & 0 & 0 & 0 & 0 & 0 & 0 & 0 \\
\hline Field technician & 120 & hour & 120 & 1,973 & 0 & 0 & 0 & 0 & 0 & 1,973 \\
\hline Certified industrial hygienist & 6 & hour & 6 & 206 & 0 & 0 & 0 & 0 & 0 & 206 \\
\hline Junior geologist & 60 & hour & 60 & 904 & 0 & 0 & 0 & 0 & 0 & 904 \\
\hline Other direct costs & 1 & LS & 0 & 0 & 0 & 95 & 0 & 0 & 0 & 95 \\
\hline \multicolumn{11}{|l|}{ "As Built" Drawings (33.80.01.04) } \\
\hline Staff engineer & 2 & hour & 2 & 52 & 0 & 0 & 0 & 0 & 0 & 52 \\
\hline Surveyor & 3 & hour & 3 & 62 & 0 & 0 & 0 & 0 & 0 & 62 \\
\hline Field technician & 4 & hour & 4 & 66 & 0 & 0 & 0 & 0 & 0 & 66 \\
\hline Draftsman/CADD operator & 12 & hour & 12 & 197 & 0 & 0 & 0 & 0 & 0 & 197 \\
\hline Word processing/clerical & 4 & hour & 4 & 55 & 0 & 0 & 0 & 0 & 0 & 55 \\
\hline Other direct costs & 1 & LS & 0 & 0 & 0 & 6 & 0 & 0 & 0 & 6 \\
\hline \multicolumn{11}{|l|}{ Monitoring Reports (33.80.01.06) } \\
\hline Project engineer & 8 & hour & 8 & 274 & 0 & 0 & 0 & 0 & 0 & 274 \\
\hline Staff engineer & 12 & hour & 12 & 312 & 0 & 0 & 0 & 0 & 0 & 312 \\
\hline Staff hydrogeologist & 16 & hour & 16 & 416 & 0 & 0 & 0 & 0 & 0 & 416 \\
\hline Field technician & 24 & hour & 24 & 395 & 0 & 0 & 0 & 0 & 0 & 395 \\
\hline Draftsman/CADD operator & 56 & hour & 56 & 921 & 0 & 0 & 0 & 0 & 0 & 921 \\
\hline Word processing/clerical & 24 & hour & 24 & 329 & 0 & 0 & 0 & 0 & 0 & 329 \\
\hline Other direct costs & 1 & LS & 0 & 0 & 0 & 38 & 0 & 0 & 0 & 38 \\
\hline
\end{tabular}


TABLE D.3 (Cont.)

\begin{tabular}{|c|c|c|c|c|c|c|c|c|c|c|}
\hline \multirow[b]{2}{*}{ Description (WBS Element) } & \multirow[b]{2}{*}{ Quantity } & \multirow[b]{2}{*}{ Unit } & \multirow[b]{2}{*}{$\begin{array}{c}\text { Work Force } \\
\text { (person-hours) }\end{array}$} & \multicolumn{7}{|c|}{$\operatorname{Cost}(\$)$} \\
\hline & & & & Labor & Equipment & $\begin{array}{c}\text { Permanent } \\
\text { Materials }\end{array}$ & Supplies & Subcontracts & $\mathrm{OH} / \mathrm{Fee} / \mathrm{Con}$ & Total \\
\hline \multicolumn{11}{|l|}{ Sampling and Analysis Plan (33.80.01.24) } \\
\hline Project engineer & 2 & hour & 2 & 69 & 0 & 0 & 0 & 0 & 0 & 69 \\
\hline Staff engineer & 8 & hour & 8 & 208 & 0 & 0 & 0 & 0 & 0 & 208 \\
\hline Word processing/clerical & 8 & hour & 8 & 110 & 0 & 0 & 0 & 0 & 0 & 110 \\
\hline Certified industrial hygienist & 2 & hour & 2 & 69 & 0 & 0 & 0 & 0 & 0 & 69 \\
\hline Other direct costs & 1 & LS & 0 & 0 & 0 & 6 & 0 & 0 & 0 & 6 \\
\hline \multicolumn{11}{|l|}{ Health and Safety Plan (33.80.01.32) } \\
\hline Project engineer & 6 & hour & 6 & 206 & 0 & 0 & 0 & 0 & 0 & 206 \\
\hline Certified industrial hygienist & 60 & hour & 60 & 2,055 & 0 & 0 & 0 & 0 & 0 & 2,055 \\
\hline Other direct costs & 1 & LS & 0 & 0 & 0 & 33 & 0 & 0 & 0 & 33 \\
\hline \multicolumn{11}{|l|}{ Work Plan Amendments (33.80.01.46) } \\
\hline Project engineer & 15 & hour & 15 & 514 & 0 & 0 & 0 & 0 & 0 & 514 \\
\hline Staff engineer & 36 & hour & 36 & 937 & 0 & 0 & 0 & 0 & 0 & 937 \\
\hline Word processing/clerical & 48 & hour & 48 & 658 & 0 & 0 & 0 & 0 & 0 & 658 \\
\hline Certified industrial hygienist & 15 & hour & 15 & 514 & 0 & 0 & 0 & 0 & 0 & 514 \\
\hline Other direct costs & 1 & LS & 0 & 0 & 0 & 38 & 0 & 0 & 0 & 38 \\
\hline Total Direct Cost & & & 2,091 & 34,398 & 18,170 & 110,474 & $\mathbf{0}$ & $\mathbf{0}$ & $\mathbf{0}$ & 163,042 \\
\hline
\end{tabular}

a Abbreviations: $\mathrm{CADD}=$ computer-aided design and drafting; $\mathrm{LNFT}=$ linear foot; $\mathrm{LS}=$ lump sum; OH/Fee/Con = overhead/performance fee/contingency; and WBS = work breakdown structure. 
TABLE D.4 Present-Worth Cost Calculation for Alternative 2 (Long-Term Monitoring)

\begin{tabular}{|c|c|c|c|c|c|c|c|}
\hline Item Description & Quantity & Unit & $\begin{array}{c}\text { Duration } \\
\text { (yr) }\end{array}$ & $\begin{array}{l}\text { Unit Cost } \\
\text { (\$/unit) }\end{array}$ & $\begin{array}{c}\text { Cost } \\
\text { (current } \$ \text { ) }\end{array}$ & $\begin{array}{l}\text { Present-Worth } \\
\text { Cost }(\$)\end{array}$ & \\
\hline Discount rate $(\%)$ : & $7 \%$ & & & & & & \\
\hline Operations duration (yr): & 30 & & & & & & \\
\hline \multicolumn{7}{|l|}{ Capital Costs } & \\
\hline Direct cost, proposed groundwater monitoring wells & 15 & Wells & - & 10,867 & 163,000 & 163,000 & \\
\hline Indirect cost, proposed groundwater monitoring wells & & & & & 127,000 & 127,000 & \\
\hline Well restrictions & 1 & LS & - & 20,000 & 20,000 & 20,000 & \\
\hline Total Capital Costs & & & & & $\mathbf{3 1 0 , 0 0 0}$ & 310,000 & \\
\hline \multicolumn{7}{|l|}{ Annual Costs } & \\
\hline Groundwater monitoring, sampling labor, DOE & 73 & Wells & 30 & 3,195 & $6,998,000$ & $2,895,000$ & \\
\hline $\begin{array}{l}\text { Groundwater monitoring, analytical costs, DOE } \\
\text { (based upon } 81 \text { samples per round, annual sampling; } \\
\$ 210 \text { analysis cost per sample) }\end{array}$ & 73 & Wells & 30 & 233 & 510,000 & 211,000 & \\
\hline Groundwater monitoring, 15 proposed wells & 15 & Wells & 30 & 3,600 & $1,620,000$ & 670,000 & \\
\hline $\begin{array}{l}\text { Groundwater monitoring, WSOW wells } \\
\text { (assumed to be sampled annually rather than quarterly, } \\
\text { as applied in the FS for the WSOW [DA 1993]) }\end{array}$ & 79 & Wells & 30 & 457 & $1,082,000$ & 448,000 & \\
\hline Performance revicw (every 5 years) & 1 & Per $5 \mathrm{yr}$ & 30 & 100,000 & 600,000 & 239,000 & \\
\hline Total Postclosure Costs & & & & & $10,810,000$ & $4,463,000$ & \\
\hline \multicolumn{7}{|l|}{ Present-Worth Costs } & \\
\hline Capital costs & & & & & 310,000 & 310,000 & \\
\hline Annual costs & & & & & $10,810,000$ & $4,463,000$ & \\
\hline \multirow[t]{3}{*}{ Total Cost } & & & & & $11,120,000$ & $4,773,000$ & \\
\hline & & & Time Fran & & 30 years & 100 years & 500 years \\
\hline & & & $\overline{\text { Present } W}$ & & $\$ 4,773,000$ & $\$ 5,453,000$ & $\$ 5,457,000$ \\
\hline
\end{tabular}

Sources: FS for WSOW (DA 1993) and Hood (1997). 


\section{D.6 REFERENCES FOR APPENDIX D}

Delta Research Corporation, 1995, Remedial Action Cost Estimating and Requirements System (RACER) User Manual, Niceville, Fla.

Hood, F., 1997, personal communication from F. Hood (MK-Ferguson Company, Boise, Idaho) to S. Folga (Argonne National Laboratory, Argonne, Ill.), March 13.

Patton, T., et al., 1996, Focused Feasibility Study for Surface Soil at the Main Pits and Pushout Area, J-Field Toxic Burning Pits Area, Aberdeen Proving Ground, Maryland, ANL/EAD/TM-61, prepared for U.S. Army Aberdeen Proving Ground, Aberdeen, Md., June.

U.S. Army Corps of Engineers, 1989, Computer Aided Cost Engineering Support System: Description and Overview, Office of the Chief of Engineers, Atlanta, Ga., May 1.

U.S. Department of the Army, 1993, Final Feasibility Study Former Weldon Spring Ordnance Works Weldon Springs, Missouri, prepared by IT Corporation for the U.S. Army Corps of Engineers, Kansas City District, July.

U.S. Department of Energy, 1990, Cost Estimating Handbook for Environmental Restoration, Environmental Restoration and Waste Management Cost Assessment Team, Rev. 0, Sept.

U.S. Environmental Protection Agency, 1988, Guidance for Conducting Remedial Investigations and Feasibility Studies under CERCLA, Interim Final, EPA 540/G-89/004 (OSWER Directive 9355.3-01), Office of Emergency and Remedial Response, Washington, D.C., Oct.

U.S. Environmental Protection Agency, 1993, Revision to OMB A-94, Average Discount Rate for Beneficial Cost Analysis, OSWER Directive 9355.3-20, Washington, D.C., June. 